Industry Structure and Monetary Policy Effectiveness 
(C) Katharina Raabe, Maastricht 2006

All rights reserved. No part of this publication may be reproduced, stored in a retrieval system, or transmitted in any form, or by any means, electronic, mechanical, photocopying, recording or otherwise, without the prior permission in writing from the author.

ISBN 10: 90-5278-577-5

ISBN 13: 978-90-5278-577-6

Published by Universitaire Pers Maastricht

Printed in the Netherlands by Datawyse Maastricht

This book was typeset by the author using ATEX. 


\section{Industry Structure and Monetary Policy Effectiveness}

\section{Dissertation}

to obtain the degree of Doctor at the Maastricht University, on the authority of the Rector Magnificus Prof. dr. G.P.M.F. Mols in accordance with the decision of the Board of Deans, to be defended in public on Thursday 07 December 2006, at 12.00 hours

by

Katharina Raabe

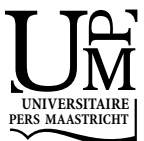




\section{Supervisors:}

Prof. dr. C.J.M. Kool, Utrecht School of Economics

Prof. dr. I.J.M. Arnold, Nyenrode Business University

\section{Assessment Committee:}

Prof. dr. J. Muysken (chairman)

Prof. dr. J. de Haan, University of Groningen

Prof. dr. F. Palm

This research has been financed by the Maastricht Research School of Economics of Technology and Organizations (Meteor). 
"At the present day, with all our differences, there is no part of economic theory which we feel to be more efficient to lend practical aid to the statesman and to the man of affairs, than the theory of money and credit."

Lionel Robbins, 1934, cited in Ludwig von Mises, 1981 (p. 19) 



\section{Acknowledgements}

Writing a thesis is like sailing: the frequency and strength of high- and low-pressure areas and pitfalls like flews and sandbanks determine the duration and hardship of the voyage. Although not free of disturbances, it is enjoyable to see the voyage proceed and the thesis develop because the challenges involved improve one's abilities to deal with unexpected occurrences and new situations.

Writing a thesis has been a solitary experience, but I did not do it alone. Similar to a sailing trip, the successful completion of the thesis reflects the contribution of many people. For their support and encouragement, I would like to thank them all. I am particularly grateful to Clemens Kool and Ivo Arnold for proposing this project to me and for guiding me through its different stages. Having Clemens and Ivo as 'pilots' has been challenging and rewarding in many ways. They made me see the flews and sandbanks when I really needed to and thus fostered my continuous progress. I am most thankful for their very constructive and insightful comments, critics, and suggestions on my numerous revisions. I would also like to thank Clemens for his inspiring lectures during my graduate study. They explain my interest in macroeconomics, monetary economics, and applied economic research and are the foundations of the present work.

For their careful reading of the thesis and their instructive comments, I would like to express my sincere gratitude to the reading committee composed of Joan Muysken, Franz Palm, and Jakob de Haan. Special thanks go to Joan Muysken for helping me to meet the formal requirements of completing the $\mathrm{PhD}$ degree at Maastricht University. I would also like to thank Thilo Liebig and Heinz Herrmann for granting me access to the unique bank balance sheet statistics and borrower statistics of the Deutsche Bundesbank, which are key to the analysis in chapter 5. I greatly appreciate their interest in the topic and thank them for their hospitality during my visit to the Deutsche Bundesbank.

Working at Maastricht University was a very nice experience and I am grateful to my colleagues for making my stay a very pleasurable one. In particular, I would like to thank Alexandra Ayala, Jeroen van den Berg, Kasper Leufkens, Geranda Notten, Martin Rehm, 
Kirsten Rohde, Pia Steffens, and Riccardo Welters for providing a friendly environment conducive to research and writing; Bertrand Candelon for sharing his econometric expertise and for the joint work included in chapter 6 of this thesis; Sylvia Beenen for administrative support in general and handling of travel declarations in particular and Silvana de Sanctis for secretarial assistance. Special thanks go to Jan Piplack. Sharing an office with him was a great pleasure, not only for the 'Apfelberliner', but also for many insightful, pleasant, and entertaining discussions on more than work-related subjects. I truly hope that we will find the time to go for a sail one day.

Furthermore, I would like to thank Jean-Pierre Urbain and Michel Beine for critical comments on parts of this research, Michael Kötter for interesting discussions on the bank lending effects of monetary policy, and Lotte van Poppel for her generous efforts in preparing the Dutch summary of this thesis. Finally, I am also grateful to Esther Lammens for secretarial assistance at the Utrecht School of Economics.

Although my supervisors, the reading committee, and my colleagues had an important impact on this thesis, its completion would not have been possible without my family. They are the sail-maker and constructing engineer without whom sailing would be impossible. I am most grateful to my parents for their relentless support, patience, and constant care. They stimulated my interest in learning and extended my horizon by encouraging me to cast my anchor in more than one harbor. Much gratitude also goes to my sisters Alexandra and Franziska for keeping my spirits up at all times. They sharpen my focus on work-unrelated issues and thus help me to see beyond the boundaries of economics. Very special credit goes to Björn for his absolute reliability and commitment. I want to thank him deeply for making me laugh when it seems less propitious and for showing me that problems usually have solutions and that the challenge is to find them.

Katharina Raabe

Maastricht in December 2006 




\section{Contents}

Contents $\quad$ v

List of Tables $\quad$ ix

List of Figures $\quad$ xi

1 Introduction 1

1.1 Motivation . . . . . . . . . . . . . . . . . . . . . . . . . . 1

1.2 Aim of this Study . . . . . . . . . . . . . . . . . . . . . 4

1.3 Place in the Literature . . . . . . . . . . . . . . . . . . . . . . 5

1.4 The Interest Rate and Credit Channel: A Narrow Focus? . . . . . . . . . . . 6

1.5 Structure . . . . . . . . . . . . . . . . . . . . . 8

2 Transmission Channels of Monetary Policy: Theory and Evidence 11

2.1 Introduction . . . . . . . . . . . . . . . . . . . . . . . . 11

2.2 Theories of Monetary Policy Transmission . . . . . . . . . . . . . . . . . . . 12

2.2.1 Money View . . . . . . . . . . . . . . . . . . . . . . . . . . . . 13

2.2 .2 Credit View . . . . . . . . . . . . . . . . . . . . . . . . . . . 15

2.2.3 Asymmetries in Monetary Policy Effectiveness . . . . . . . . . . . . . 20

2.2.4 Regional and Industry Effects of Monetary Policy . . . . . . . . . . . 21

2.3 Methodological and Empirical Issues . . . . . . . . . . . . . . . . . . . 23

2.3.1 Measuring Monetary Policy Shocks . . . . . . . . . . . . . . . . . 23

2.3.2 Measuring Monetary Transmission Channels . . . . . . . . . . . . 26

2.3.3 Solutions to the Identification Problems . . . . . . . . . . . . . . . 27

2.4 Evidence on Monetary Transmission Channels . . . . . . . . . . . . . . . . . 29

2.4.1 Interest Rate Channel . . . . . . . . . . . . . . . . . . . . . . . . 29

2.4.2 Broad Credit Channel . . . . . . . . . . . . . . . . . . 30

2.4 .3 Narrow Credit Channel . . . . . . . . . . . . . . . . . . . . . . 33

2.4.4 Asymmetries in Monetary Policy Effectiveness . . . . . . . . . . . . . 36

2.4.5 The Relative Strength of the Interest Rate and Credit Channel . . . . 37 
2.5 Conclusion . . . . . . . . . . . . . . . . . . . . . . . . . . 38

Annex 2A Overview of Empirical Studies . . . . . . . . . . . . . . . . 40

3 Firm Size and Monetary Policy Transmission: A Theoretical Model on the Role of Capital Investment Expenditures

3.1 Introduction . . . . . . . . . . . . . . . . . 55

3.2 Existing Literature . . . . . . . . . . . . . . . . . . . . . . . . . 57

3.2.1 The Process of Market Dualization . . . . . . . . . . . . . . . . 57

3.2.2 Investment Behavior and Firm Size . . . . . . . . . . . . . . . 58

3.3 A Model of Firm Investment . . . . . . . . . . . . . . . . . . . . . . 61

3.3.1 Production Function . . . . . . . . . . . . . . . . . 62

3.3.2 Investment Cost Function . . . . . . . . . . . . . . . . . . . . 64

3.3.3 Short-Run Profit Optimization . . . . . . . . . . . . . . . . 67

3.3.4 Fundamental Firm Value . . . . . . . . . . . . . . . . . . . . . . 69

3.3.5 Intertemporal Value Maximization . . . . . . . . . . . . . . . 71

3.4 Firm Size and Interest Rate Sensitivity . . . . . . . . . . . . . . . . . . . . . 77

3.5 Conclusion . . . . . . . . . . . . . . . . . . . . . . . . 81

4 New Evidence on the Firm Size Effects in US Monetary Policy Transmission 83

4.1 Introduction . . . . . . . . . . . . . . . . . . . . 83

4.2 Transmission Mechanisms of Monetary Policy . . . . . . . . . . . . . . . . . 85

4.3 The Industry Effects of Monetary Policy . . . . . . . . . . . . . . . . . . . . 88

4.3.1 Empirical Model . . . . . . . . . . . . . . . . . . . . . . . 88

4.3.2 Time-Series Data . . . . . . . . . . . . . . . . . . . . . . . . . . . . . . 91

4.3.3 Empirical Results of the Time-Series Analysis . . . . . . . . . . . . . 92

4.4 Factors Behind the Industry Effects of Monetary Policy . . . . . . . . . . . . 95

4.4.1 Cross-Section Framework . . . . . . . . . . . . . . . . . . . 95

4.4.2 Independence Tests . . . . . . . . . . . . . . . . . . . . . . . . 9 98

4.4 .3 Cross-Section Evidence . . . . . . . . . . . . . . . . . . . . . 101

4.5 Conclusion . . . . . . . . . . . . . . . . . . . . . . 106

Annex 4A Data Sources and Descriptions . . . . . . . . . . . . . . . . . . 108

Annex 4B Firm Size Effects in Europe . . . . . . . . . . . . . . . . . . . . . 110

5 Industries and the Bank Lending Effects of Bank Credit Demand and Monetary Policy in Germany 121

5.1 Introduction . . . . . . . . . . . . . . . . . . . . 121

5.2 The Credit Channel Effects of Monetary Policy in Germany . . . . . . . . . . 124

5.3 Banks and Industries in Germany: An Overview . . . . . . . . . . . . . . . 128

5.3.1 The Structure of the German Banking Sector . . . . . . . . . . . . . 129

5.3.2 The Industry Structure of Bank Loan Portfolios . . . . . . . . . . . . 134

5.3.3 Industry Determinants of Bank Lending . . . . . . . . . . . . . . . 140

5.4 Empirical Model . . . . . . . . . . . . . . . . . . . . . . . . . . . . . . . 144 
5.4.1 Empirical Estimation Framework . . . . . . . . . . . . . . . . . . 144

5.4 .2 Methodology . . . . . . . . . . . . . . . . . . . . 147

5.5 Data . . . . . . . . . . . . . . . . . . . . . . . . . 148

5.6 Empirical Results . . . . . . . . . . . . . . . . . . . . . . . . . 151

5.6 .1 Sample Overview . . . . . . . . . . . . . . . . . . . . . . . 151

5.6 .2 Analysis of Variance Tests . . . . . . . . . . . . . . . . . . . 152

5.6.3 Evidence from Industry-Specific Bank Lending Functions . . . . . . . 155

5.6 .4 Robustness Tests . . . . . . . . . . . . . . . . . . . . . . . . 171

5.7 Conclusion . . . . . . . . . . . . . . . . . . . . . . . . . . . . . . 174

Annex 5A Data Sources and Descriptions . . . . . . . . . . . . . . . . 176

Annex 5B Variable Description . . . . . . . . . . . . . . . . . . 178

Annex 5C Alternative Model Specifications . . . . . . . . . . . . . . . . . 179

6 The Asymmetric Effects of Monetary Policy on Industry Performance 181

6.1 Introduction . . . . . . . . . . . . . . . . . . . . . . . . . 181

6.2 Literature Review . . . . . . . . . . . . . . . . . . . . . . . . . . . 184

6.3 Empirical Framework . . . . . . . . . . . . . . . . . . . . . . . . . . . . . . 188

6.3.1 Empirical Model Specifications . . . . . . . . . . . . . . . . . . . 189

6.3 .2 Methodology . . . . . . . . . . . . . . . . . . . . 195

6.3 .3 Data . . . . . . . . . . . . . . . . . . . . . . . 197

6.4 Empirical Results . . . . . . . . . . . . . . . . . . . . . . . . . . . . . . . . 198

6.4.1 Empirical Results Assuming Symmetry in Interest Rate Effects . . . . 199

6.4.2 Empirical Results Assuming Asymmetric Sign Effects . . . . . . . . . 199

6.4.3 Empirical Results Assuming Asymmetric State Effects . . . . . . . . 206

6.4.4 Empirical Results Assuming Asymmetric Size Effects . . . . . . . . . 206

6.5 Conclusion . . . . . . . . . . . . . . . . . . . . . 211

Annex 6A List of Industries . . . . . . . . . . . . . . . . 213

7 The Importance of Industry Effects - Concluding Thoughts 215

7.1 Synthesis . . . . . . . . . . . . . . . . . . . . . . . . . 215

7.2 Caveats and Avenues for Future Research . . . . . . . . . . . . . . . . . 219

7.3 Policy Implications . . . . . . . . . . . . . . . . . . . . . . . . . . . . . . . . 222

Bibliography $\quad 225$

Nederlandse Samenvatting (Summary in Dutch) 245

Curriculum Vitae 253 



\section{List of Tables}

2A.1 Evidence on the Interest Rate Channel . . . . . . . . . . . . . . . . . . . . 42

2A.2 Evidence on the Broad Credit Channel . . . . . . . . . . . . . . . 45

2A.3 Evidence on the Narrow Credit Channel . . . . . . . . . . . . . . . . . 50

3.1 Classification of Market Structures . . . . . . . . . . . . . . . . . 56

3.2 Dual Market Structure . . . . . . . . . . . . . . . . . . . . . . 63

4.1 Two-Way Analysis of Variance of the Cumulative Impulse Responses . . . . . 93

4.2 Two-Year Cumulative Responses, US Regions, 1958-2001 . . . . . . . . . . . 94

4.3 Two-Way Analysis of Variance of Industry Characteristics . . . . . . . . . . . 100

4.4 Correlation between Business Size and the Volatility of Industry Earnings . . 101

4.5 Cross-Section Estimations without an Industry Dummy . . . . . . . . . . . 103

4.6 Cross-Section Estimations with a Dummy for the Mining Industry . . . . . . 105

4A.1 Missing Values . . . . . . . . . . . . . . . . . . . . . . . . . . . . . . . . 108

4A.2 Overview of Industries by Classification Scheme . . . . . . . . . . . . . . . 109

4B.1 Two-Year Cumulative Responses, European Countries, 1980-1999 . . . . . . 113

4B.2 Two-Way Analysis of Variance of Impulse Responses . . . . . . . . . . . . . . 114

4B.3 Two-Way Analysis of Variance of Industry Characteristics . . . . . . . . . . . 115

4B.4 Cross-Section Estimations without an Industry Dummy Variable . . . . . . . 117

4B.5 Cross-Section Estimations with an Industry Dummy Variable . . . . . . . . . 118

5.1 Summary Statistics of Bank Balance Sheet Variables, 1992:1-2002:4 . . . . . 131

5.2 One-Way ANOVA of Bank Balance Sheet Variables, 1992:1-2002:4 . . . . . . 135

5.3 Summary Statistics of Bank Lending to Industries, 1992:1-2002:4 . . . . . . 137

5.4 Correlation between Industry Bank Lending and Industry Characteristics . . . 143

5.5 Sample Overview . . . . . . . . . . . . . . . . . . . . . . . . . . 152

5.6 One-Way ANOVA Test Statistics, Aggregate Banking Group . . . . . . . . 154

5.7 Two-Way ANOVA Test Statistics, Short-Term Lending . . . . . . . . . . . 155

5.8 Fixed Effects Long-Run Estimates for Short-Term Lending by the Aggregate Banking Group . . . . . . . . . . . . . . . . . . . . . 157 
5C.1 Summary of Model Specifications . . . . . . . . . . . . . . . . . . . . 179

6.1 Overview of Expected Signs . . . . . . . . . . . . . . . . . . . . . . . . . . 196

6.2 FGLS Long-Run Estimates, Benchmark Model . . . . . . . . . . . . . . . . . 200

6.3 FGLS Long-Run Estimates, Sign and State Effects Model Germany . . . . . . 202

6.4 FGLS Long-Run Estimates, Sign and State Effects Model Spain . . . . . . . 203

6.5 FGLS Long-Run Estimates, Sign and State Effects Model Italy . . . . . . . . 204

6.6 FGLS Long-Run Estimates, Zero and Non-Zero Threshold Model Germany . . 208

6.7 FGLS Long-Run Estimates, Zero and Non-Zero Threshold Model Spain . . . 209

6.8 FGLS Long-Run Estimates, Zero and Non-Zero Threshold Model Italy . . . . 210 


\section{List of Figures}

1.1 Industry and Monetary Policy Transmission . . . . . . . . . . . . . 7

3.1 Small- and Large-Firm Investment Behavior with Size-Dependent Capital . . 75

3.2 Small- and Large-Firm Investment Behavior with Size-Independent Capital . . 76

3.3 The Investment Effects of a Small and Large Interest Rate Shock . . . . . . 80

6.1 The Size Effects of Monetary Policy . . . . . . . . . . . . . . . . . . . . . . 191 



\section{1 \\ Introduction}

\subsection{Motivation}

Since the early 20th century, monetary policy announcements and monetary policy actions have attracted much attention for their internal and external macroeconomic implications. Two important tenets of macroeconomic theory - the Keynesian and the monetarist view do not doubt that monetary policy actions have real short-run economic effects, although for different reasons. Keynes (1936) emphasizes price rigidities, whereas Friedman (1968) stresses worker misperceptions of the price level in a world of flexible prices. Even though the existence of real short-run monetary policy effects is not refuted, there is no dominant view on the channels through which monetary policy operates and on the factors which determine monetary policy effectiveness in a single region or country. However, policy makers need to identify and understand "[ $\mathrm{t}$ ] he process through which monetary policy decisions are transmitted into changes in real GDP and inflation" (Taylor, 1995, p. 11) in order to correctly anticipate the macroeconomic effects of monetary policy, given the state of the economy.

Knowledge of monetary policy transmission is of particular importance for the European Central Bank (ECB) which sets a common (uniform) monetary policy for 12 heterogeneous European countries and their regions. ${ }^{1}$ An investigation of monetary policy transmission is relevant from a policy perspective since a common monetary policy shock will have asymmetric effects on the real economic performance of the individual Euro zone member countries if it is transmitted through country- or region-specific channels. Surely, pronounced asymmetries in the real effects will cast doubt on the ability of the ECB to address the economic conditions of all Euro zone countries. In fact, persistent and pronounced differences in the real effects may even undermine the political and public support for and hence the stability of the European economic and monetary union (EMU) in the long run by raising the net costs of a common currency. ${ }^{2}$ A good example of decreasing political and public commitment to EMU

\footnotetext{
${ }^{1}$ We emphasize the case of the European economic and monetary union (EMU) as a well-known example which has attracted much research. Of course, any individual country that combines a number of (heterogeneous) regions effectively constitutes a monetary union. The subsequent arguments are therefore also applicable in a wider context.

${ }^{2}$ Prior to the onset of the European economic and monetary union, research was largely concerned with the feasibility of a common currency in terms of shock asymmetries. The underlying cost-benefit analyses have emphasized Mundell's (1961) seminal work on optimal currency areas.
} 
is Italy. In July 2005, the then prime minister Berlusconi attributed the poor performance of the Italian economy to the presumed failure or unwillingness of the European Central Bank to avoid the persistent appreciation of the Euro. He openly suggested the return to the Lira as the one and only approach to restore international competitiveness in the absence of monetary policy sovereignty.

In view of these considerations, knowledge of the amplification and propagation mechanisms of monetary policy is required. Although there is a considerable amount of research on monetary policy transmission, the European Central Bank still notes that

"despite the best efforts of economists working in academia, in research institutes and in central banks, it [the monetary policy transmission mechanism] remains imperfectly understood. ... Moreover, institutional and behavioral changes ... may have changed the relationships between different economic variables." (European Central Bank, 2001, p. 44) ${ }^{3}$

Many past studies emphasize structural differences between the financial systems of the Euro zone member countries as source of cross-country differences in the efficacy of monetary policy. A key role is hereby assigned to cross-country disparities in (i) the importance of direct and indirect finance, (ii) the importance of bank and non-bank financial intermediaries, (iii) the amount and composition of corporate and household financial wealth, bank and non-bank indebtedness, and (iv) the degree of credit market imperfections and liquidity constraints. ${ }^{4}$ These factors combined attribute the real effects of monetary policy to the operation of an interest rate channel and/or to the availability and the price of external finance. ${ }^{5}$

Besides between-country differences in financial structures, cross-country asymmetries in the real effects of monetary policy are also associated with between-country and within-country differences in economic structures. Most corresponding research defines economic structures in terms of (i) industry composition and (ii) labor and goods market rigidities. Research on industry composition argues that the macroeconomic effects of monetary policy reflect the (weighed) differential monetary policy response of individual industries. Cross-industry differences in the real effects of monetary policy result from cross-industry heterogeneities in the structure of production functions and in the monetary policy sensitivity of industry demand. For these relationships, cross-country asymmetries in the real effects of monetary policy then reflect cross-country differences in the relative importance of industries. Finally, labor and goods market rigidities influence monetary policy effectiveness through their impact on the aggregate and industry-specific supply curve. One can argue that cross-country differences in real rigidities reflect differences in the contestability of markets and in the degree of centralized wage bargaining.

\footnotetext{
${ }^{3}$ Words in brackets are added.

${ }^{4}$ See Cecchetti (1999) and Putkuri (2003) for an overview of financial structures in European economies.

${ }^{5}$ For example, the importance of variable and fixed rate debt in total debt influences monetary policy transmission through interest rate pass through, but not through the availability of external finance.
} 
In the future, the potential role of differences in financial structures as source of cross-country asymmetries in monetary policy transmission and in the real effects of monetary policy is likely to diminish. One reason is the continuous harmonization of (EU) banking and non-banking regulation which creates a level-playing field for financial intermediaries. Furthermore, rising consolidation of the banking market in all European economies may ameliorate cross-country differences in the speed and the extent at which bank lending rates and bank lending volume respond to changes in the money market interest rate. In fact, market consolidation through mergers and acquisitions will probably mitigate the monetary policy response of bank lending and ultimately economic activity if this process fosters the financial soundness of banks and/or improves the access of banks to non-deposit, uninsured finance. Besides mergers and acquisitions, Fase and De Bondt (2000) stress information and technology advances as additional factors behind the convergence of financial structures. These facilitate the access of (i) firms, households, and non-bank financial institutions to external funds of finance and (ii) banks to non-deposit funds since they reduce the costs of direct and indirect finance by lowering informational frictions.

While cross-country heterogeneities in financial structures will be mitigated by the European integration process, cross-country differences in economic structures are likely to persist or even deepen. Krugman $(1991,1993)$ argues that the European integration process adds to the regional specialization in production ${ }^{6}$ and Midelfart-Knarvik, Overman, Redding, and Venables (2000) lend descriptive and empirical support to this view. In a study for the European Commission, they find that the European integration process is accompanied by the divergence of countries' economic structures. ${ }^{7}$ Beginning in the early $1980 \mathrm{~s}$, this process is characterized by the spatial concentration of manufacturing industries, but the spatial divergence of the service industry. The choice of industry location is hereby predominantly determined by the need for and access to physical capital, labor, and technological resources. Surely, the observed divergence of industry structures in Europe will aggravate betweencountry and between-region differences in the real effects of monetary policy if industries respond differently to a common monetary policy shock. The real effects of monetary policy on the economic performance of countries and regions then depend on the distribution of industries.

In our view, it is of crucial importance for the ECB to understand and quantify the channels through which industry composition influences the real effects of monetary policy because they

\footnotetext{
${ }^{6}$ See the European Commission (1990) for the opposite view according to which a common monetary policy causes the regional convergence of industry structures. Also, the Krugman $(1991,1993)$ view is subject to two interrelated caveats. Firstly, regional specialization should predominantly prevail for the manufacturing industry but not for the service industry. This is because of sectoral differences in the nature of goods: the manufacturing sector produces tradable goods, whereas the service sector produces non-tradables. Secondly, there might be less scope for regional specialization in manufacturing given the observed continuous decline in the importance of the manufacturing industry in total production.

${ }^{7}$ In contrast to countries in Europe, Midelfart-Knarvik et al. (2000) find industry structures of US states to converge.
} 
determine the macroeconomic implications of a common monetary policy. If countries and regions indeed specialize in terms of production and industry structure, possible asymmetries in the economic response of industries to a common monetary policy shock will have important consequences for the degree of income variability and income distribution. This is even more stringent in view of the fact that governments cannot prevent the regional specialization in production patterns. In the absence of compensating income redistribution schemes or adjustment mechanisms like factor mobility or wage-price flexibility, countries and regions with monetary-policy-sensitive industries will then be disproportionately more affected by monetary policy shocks. ${ }^{8}$ This, however, has important repercussions for the costs and benefits of the European economic and monetary union for each country/region. In fact, asymmetries in the transmission of a uniform monetary policy shock ask for compensating fiscal insurance schemes and for factor-mobility-promoting structural reforms so as to smooth the differential income effects of monetary policy across industries and ultimately regions.

\subsection{Aim of this Study}

Although there has been significant progress in research on the role of industry effects in the last years, we believe that existing studies have not exhaustively addressed the role of industry composition as determinant of monetary policy effectiveness at the country and regional level. The objective of this thesis is to add to the ongoing debate. In particular, it aims to qualify and quantify the role of industries as determinant of the monetary policy effects associated with two prominent channels of monetary policy transmission, i.e., the interest rate and credit channel.

We address two interrelated questions. The first question concerns the real effects of monetary policy and asks whether and to what extent industries differ in their economic response to monetary policy disturbances. A discussion of this question is relevant since it shows (i) whether the monetary policy effects at the macroeconomic level are conditioned by industry composition and (ii) whether cross-country (cross-region) differences in the relative importance of industries contribute to cross-country (cross-region) asymmetries in monetary policy effects. To anticipate the answer, estimations for the United States and countries in Europe will show that monetary policy shocks have a heterogeneous effect on industry output.

This finding motivates the second question which asks: are cross-industry differences in the monetary policy response associated with cross-industry differences in the relative strength of the interest rate and credit channel of monetary policy transmission? Stated differently, do the real effects of monetary policy reflect the differential response of industry output (i) to a

\footnotetext{
${ }^{8}$ See the optimum currency area theory for a discussion of the role of factor mobility as necessary adjustment mechanism (e.g., Mundell, 1961). Factor mobility refers to labor and capital mobility. Because capital is free to move between Euro zone member countries, economic and political discussions predominantly emphasize the need for higher labor mobility.
} 
change in the real cost of capital (interest rate channel) or (ii) to a change in the severity of credit market imperfections and information asymmetries (credit channel)? We hypothesize that differences in the structural properties of industries influence the interest rate and credit channel effects of monetary policy at the industry level. Closely related, we argue that the industry composition of a country or region drives the macroeconomic evidence on monetary policy efficacy through the interest rate and credit channel.

\subsection{Place in the Literature}

In order to answer these questions, this thesis encompasses two broad and interrelated strands of research. The first strand of literature refers to studies that identify the real effects of monetary policy shocks. In the past, many empirical and theoretical discussions have been concerned with the real effects of monetary policy on the macroeconomic performance of countries. The results from aggregate data are, however, subject to criticism since the underlying evidence only reflects the smoothed response of the average industry/firm, average banking sector/bank, and average consumer in an economy (e.g., Ganley and Salmon, 1997). In eliminating the differential monetary policy response of each group of agents and thus the effects associated with economic structures, the evidence from aggregate studies does not help to improve the imperfect understanding of monetary policy transmission.

With the increased availability of data for longer sample periods, recent studies adopt an industry focus and investigate the response of industry-specific output to a monetary policy shock. The presumption is that industries differ in their response to monetary policy shocks and that these differences cause monetary policy efficacy to depend on the relative importance of industries in an economy. This claim receives strong empirical support. Unfortunately, the evidence is predominantly derived from single country analyses and usually does not involve cross-country estimations. The absence of evidence from multi-country or multi-region studies complicates the comparability of industry effects across countries because of cross-study differences in the nature of the data and/or estimation techniques. Furthermore, it precludes sensible assessments as to the relative importance of industry and country effects as source of variation in the real effects of monetary policy. It is, however, important to identify and understand the country effects because they reflect the impact of country-specific institutional and/or organizational structures on monetary policy effectiveness.

The second strand of literature links the real effects of monetary policy to the operation of monetary transmission channels. Again, a large part of the corresponding research identifies the interest rate and credit channel effects of monetary policy for the macroeconomic aggregate or for an aggregate of industries. Only a newer strand of research tests for and lends support to the prevalence of interest rate and credit channel effects of monetary policy transmission for industries. Because the corresponding evidence is again predominantly derived for single countries, stylized facts as to the role of industries as source of interest rate and 
credit channel effects cannot easily be established or maintained.

\subsection{The Interest Rate and Credit Channel: A Narrow Focus?}

Before concluding this chapter with an overview of the thesis structure, we motivate our restricted focus on the role of industries as determinant of the interest rate and credit channel effects of monetary policy. In principle, there are many transmission channels which offer scope for industry effects, such as the exchange rate or consumption-wealth channel. Unfortunately, assessments of these channels at the industry level are inherently difficult for their data requirements. Research on the exchange rate channel, for example, requires information on industry-specific import and export prices to control for the exposure of industries to demand fluctuations in the domestic as well as foreign market. Investigations of the consumption-wealth channel ask for estimates of the share of household net wealth spent on industry-specific goods.

In our view, the emphasis on the interest rate and credit channel is highly desirable since these channels provide the clearest illustration of the role of industries in the transmission of monetary policy shocks. Figure 1.1 schematically illustrates the factors through which industries may influence the strength of the interest rate and credit channel effects. The relationships which involve industries in monetary policy transmission through the goods and credit market and which receive attention in this thesis are printed in bold. ${ }^{9}$ The industry effect encompasses the interaction of (i) the production and consumption side of the economy through the traditional interest rate channel and (ii) the production and credit side of the economy through the credit channel of monetary policy transmission.

The left-hand side of Figure 1.1 illustrates the interest rate channel, which emphasizes the monetary policy response of industry investment and industry output supply in order to explain the real effects of monetary policy changes. Here, the monetary policy response of investment reflects the effect of a monetary-policy-induced change in financing costs on capital accumulation and therefore production capacity. The monetary policy response of output supply illustrates the impact of the monetary-policy-induced change in the demand for industry-specific goods. ${ }^{10}$ As will be explained in chapter 2 , both the investment as well as output demand effects of monetary policy are likely to differ between industries producing

\footnotetext{
${ }^{9}$ Figure 1.1 is schematic and reduced to those components that are relevant for the present analysis. Besides ignoring the exchange rate and consumption-wealth channel, we also disregard asset prices and the role of market expectations as determinant of wage and price setting and hence industry supply. Furthermore, we keep the discussion general and stress industries and banking groups rather than firms and banks. This simplistic approach can be motivated by the interdependence of firms and industries and banks and banking groups. Chapter 2 contains detailed explanations of these relationships and presents economic interpretations. Chapter 4, 5, and 6 report new empirical evidence.

${ }^{10}$ Of course, the monetary policy response of industry output and industry investment is not mutually exclusive, but interdependent.
} 
Figure 1.1: Industry and Monetary Policy Transmission

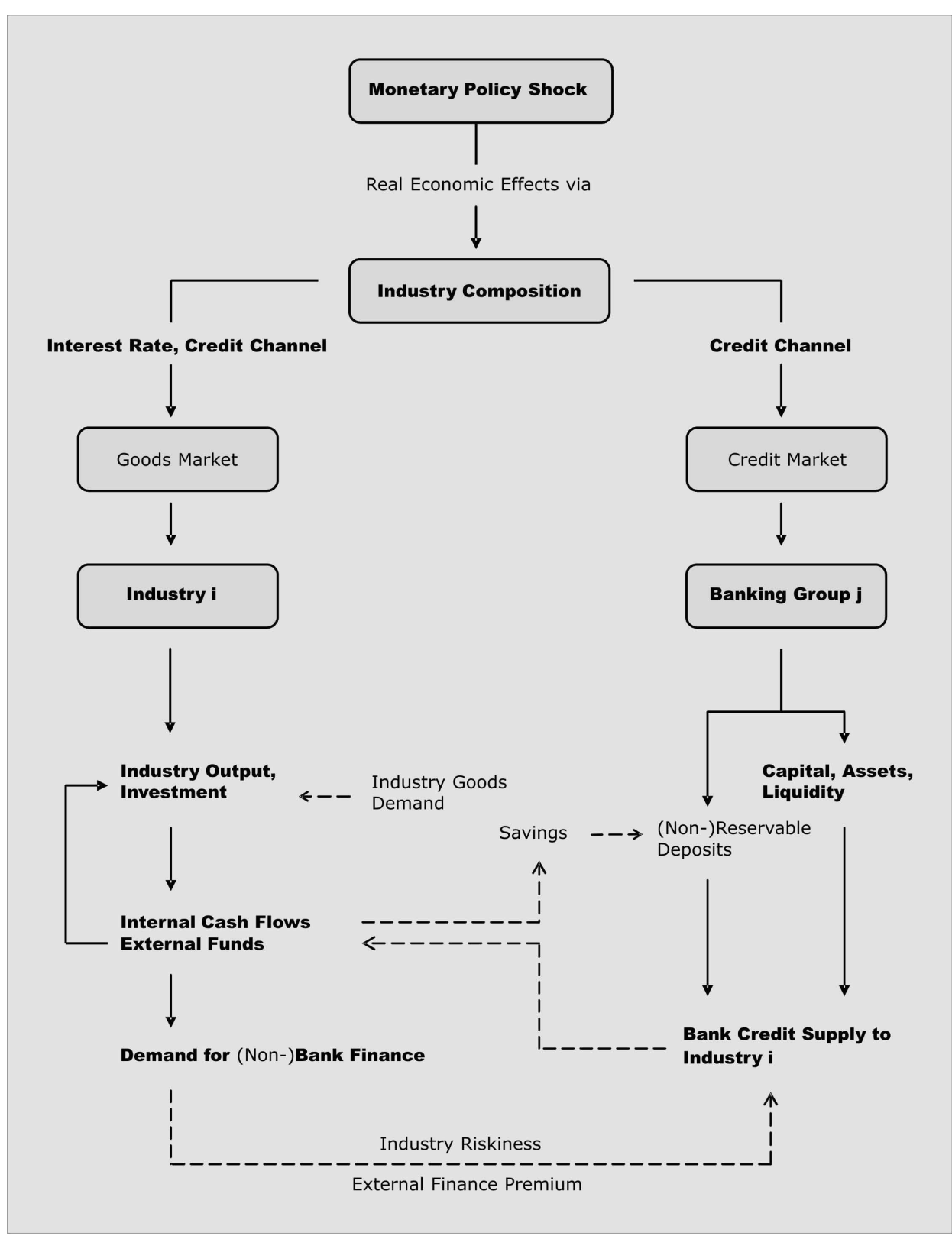


goods that differ in terms of, for example, durability, capital intensity, or tradability.

The monetary-policy-induced change in investment and output also affects industry-specific internal cash flows and ultimately industry demand for external finance. The broad credit view argues that the availability of internal cash affects the access of industries to external bank and non-bank finance through its effect on the balance sheet position of industries. Given credit market imperfections, the balance sheet position in turn defines the external finance premium through its effect on the perceived riskiness of industries.

Besides industry riskiness, the access to external finance also depends on the ability of bank and non-bank institutions to supply credit. The right-hand side of Figure 1.1 emphasizes the role of banking groups as source of external credit. Banking groups grant loans conditional on the amount of deposits, bank equity, and bank liquidity, with bank deposits being determined by private savings. The narrow credit channel theory argues that the monetary policy response of bank lending depends on the ability of banking groups to cope with monetary-policyinduced changes in (non-reservable) bank deposits. The magnitude of the bank lending response hereby depends on banking group efficiency and profitability in the presence of credit market imperfections.

For individual banking groups, the monetary policy response of aggregate credit supply can be defined as the response of lending to individual industries. Cross-industry differences in the monetary policy response of industry-specific bank lending may reflect cross-industry asymmetries in the monetary policy sensitivity of internal cash flows and hence bank credit demand. This, however, points to the potential role of the industry composition of bank credit portfolios as determinant of monetary policy effectiveness.

\subsection{Structure}

This section concludes the introductory chapter by outlining the structure of this thesis. The thesis is composed of seven chapters. Chapter 2 is dedicated to a description of the relationships in Figure 1.1. It presents the theories and empirical evidence on the interest rate and credit channel of monetary policy transmission from a macroeconomic and industry perspective. Within this framework, we emphasize methodological problems on the theoretical and empirical side which complicate and may even bias empirical analyses. We argue that the focus on industry structure may ameliorate some of the methodological difficulties. The review of the existing literature constitutes the background for the subsequent empirical analyses of the industry effects of monetary policy transmission.

Chapter 3 attempts to theoretically explain the observation that empirical credit channel studies lend ambiguous support to the existence of firm size effects in monetary policy transmission. To this end, a dynamic non-linear investment model is presented that explains 
differences in the sensitivity of small- and large-sized firms to changes in the money market interest rate. In contrast to existing studies on the firm size effects of monetary policy, the importance of firms as monetary transmission channel does not originate from credit market imperfections, but from size-related differences in the degree of investment irreversibility. These cause large firms to change investment regimes less frequently than small firms. However, when large firms move, the investment response is more accentuated than that of small firms. The size-related differences in investment irreversibility cause the monetary policy response of small- and large-firm investment to crucially depend on the magnitude of the monetary policy shock. For small interest rate shocks, the model's predictions are in line with the credit view in that small-firm investment is suggested to respond more to monetary policy changes. In contrast to the credit view, however, large-firm investment is more responsive to large monetary policy changes. The model hence illustrates that empirical tests for firm size effects of monetary policy should allow for small and large firm size effects.

Chapter 4 discusses the relationships on the left-hand side of Figure 1.1, with an exclusive focus on the production side of the economy. It analyzes the industry effects of monetary policy in the United States and determines the extent to which industry effects affect conclusions as to the existence of a credit and interest rate channel of monetary policy. The evidence from vector autoregressive models and cross-section estimations shows that conclusions strongly depend on the assumptions as to the independence of industry and either firm size (a commonly used proxy variable of the credit channel) or capital intensity (a proxy variable of the interest rate channel). We stress the United States as an established example for a large economy with a centralized monetary policy and argue that monetary policy transmission in the United States may provide useful insights for monetary policy transmission in the European economic and monetary union. Because the results of a similar analysis for Europe are at most indicative rather than conclusive, we only report the EMU evidence in the annex to chapter 4 .

Chapter 5 emphasizes the relationships on the right-hand side of Figure 1.1 for the banking sector. The analysis is motivated by the observation that existing credit channel studies on the bank lending effects of monetary policy do not take into account possible industry effects. In our view, however, cross-industry differences in cyclical and structural properties and in bank credit demand render industry sectors a potential determinant of the credit channel effects through bank lending. In order to determine the significance of this presumption, we use the industry dimension of microeconomic bank lending data to identify the bank lending effects of changes in bank credit demand and monetary policy in Germany. We hypothesize that changes in bank lending are industry specific and that the industry composition of a bank's loan portfolio determines the effectiveness of monetary policy through credit channel effects. Our evidence from dynamic panel data models supports this hypothesis.

Both chapter 4 and 5 assume that expansionary and contractionary monetary policy changes have symmetric output growth effects on industries. Chapter 6 departs from the symmetry 
assumption. It investigates whether the industry output growth effects of monetary expansions and contractions differ and whether the degree of asymmetry depends on the size of monetary policy changes and on the industry business cycle position. These issues are addressed in country-specific dynamic panel estimations of 24 industries for Germany, Italy, and Spain over the period 1995:1-2002:4. Within this framework, the importance of industries as determinant of monetary policy effectiveness through interest rate and credit channel effects is indirectly examined by stressing cross-industry differences in structural characteristics. The analysis will show that conclusions as to asymmetries in the industry output growth effects of monetary expansions and contractions depend on the choice of country. Furthermore, there is at best weak evidence that monetary policy asymmetries are attributable to industry effects.

Chapter 7 summarizes and concludes the analysis on the industry effects of monetary policy. We discuss limitations of the studies in the previous chapters and offer avenues for future research. 


\section{Transmission Channels of Monetary Policy: Theory and Evidence}

\subsection{Introduction}

There is a wide consensus that monetary policy shocks have real effects on output and relative prices - at least in the short run. ${ }^{1}$ While empirical studies confirm the short-run nonneutrality of monetary policy for European economies as well as for the United States, they also point to cross-country asymmetries in the magnitude of the output and price response and in the time it takes for the dynamics of a monetary policy shock to fully work through the system. These differences are of particular importance for the member countries of the European economic and monetary union (EMU) since they cast doubt on the appropriateness of a common monetary policy. Furthermore, cross-country heterogeneities in the real effects of monetary policy raise questions as to the relative strength of channels through which monetary policy shocks transmit to the economy.

The literature discusses numerous demand- and supply-side factors such as relative asset prices, wealth, exchange rates, financial structure, and the interest rate sensitivity of industries, firms, and banks as mechanisms that propagate and amplify the effects of monetary policy shocks on economic activity. ${ }^{2}$ Surely, the real effects of monetary policy are not exclusively attributable to the operation of any single transmission mechanism, but reflect the relative importance of multiple transmission channels. Stated differently, the various demandand supply-side channels are not mutually exclusive but complement and reinforce each other.

Among the various transmission mechanisms of monetary policy, the interest rate and credit channel have attracted most attention. Discussions ask whether price rigidities and/or credit market imperfections influence the effects of monetary policy and whether one of these factors is a potentially more important monetary transmission mechanism. The answers to these

\footnotetext{
${ }^{1}$ See, for example, Kieler and Saarenheimo (1998), Guiso, Kashyap, Panetta, and Terlizzese (1999), Christiano, Eichenbaum, and Evans (1999), Angeloni et al. (2003), Bean, Larsen, and Nikolov (2003) for reviews of the economic effects of monetary policy in the United States and Europe.

${ }^{2}$ See, among others, Mishkin (1995), Trautwein (2000), and Putkuri (2003) for details and surveys of the different transmission channels.
} 
questions show whether and to what degree monetary policy effectiveness depends on economic structures (goods and labor markets, industry composition) and/or financial structures (bank and non-bank financial markets). These issues are of particular interest for the EMU member countries since they indicate whether regional economic and financial structures have converged to an extent so as to ensure the sustainability of monetary policy centralization under the auspices of the European Central Bank. The conclusions certainly have important economic, welfare, and political implications.

In view of their economic and political relevance, the last decade has produced a considerable number of theoretical and empirical studies on the interest rate and credit channel effects of monetary policy transmission. This chapter provides a comprehensive overview of the corresponding literature. We explore the theoretical and empirical studies by discussing the importance of economic and financial structures as determinants of the real effects of monetary policy effectiveness. It will become evident that theoretical and empirical analyses are complicated by methodological issues regarding the identification of monetary policy shocks and the identification of individual transmission channels. Solutions to the identification problems influence the conclusions regarding the relative importance of the interest rate and credit channel in single- and multi-country studies. The review of the existing theories and empirical evidence provides the background for the subsequent empirical analyses of the industry effects of monetary policy transmission presented in this thesis.

The remainder of this chapter has the following structure. Section 2.2.1 and 2.2.2 describe the transmission of monetary policy changes as stipulated by the traditional interest rate channel and the credit channel, respectively. The discussion assumes that the interest rate and credit channel effects of monetary policy do not depend on the business cycle position of an economy at the time of the monetary policy change. We will depart from this assumption in section 2.2.3. Section 2.2.4 links monetary policy effectiveness to economic structures (e.g., industry composition) and financial structures (e.g., bank and firm size distribution). Section 2.3 critically emphasizes methodological and empirical issues that complicate the analysis of monetary policy transmission mechanisms. We will stress problems related to the identification of monetary policy shocks and to the identification of monetary transmission channels and review possible solutions. Section 2.4 documents the findings of existing empirical research on the interest rate and credit channel. The discussion is particularly attentive to the data and industry dimension of the studies. Section 2.5 summarizes and illustrates how the following chapters in this thesis are related to the existing literature.

\subsection{Theories of Monetary Policy Transmission}

The interest rate channel and credit channel are much debated monetary transmission mechanisms. The channels' main difference concerns the question whether financial structures determine the effectiveness of monetary policy. While the interest rate channel stipulates 
the irrelevance of financial structures and the existence of perfect capital markets, the credit channel argues the opposite. The following sections explain the contrasting views and present the theoretical foundations of the interest rate and credit channel for an unexpected tightening in monetary policy. Unless stated differently, the monetary contraction is approximated with an increase in the money market interest rate. Given the focus of this thesis, we particularly emphasize the predictions of the interest rate and credit channel with respect to the regional effects and industry effects of monetary policy.

\subsubsection{Money View}

The discussion about the role of interest rates in the monetary transmission process is also referred to as the debate on the relevance of the money view. ${ }^{3}$ According to this approach, money is the key financial variable and market interest rates constitute the main avenue through which monetary policy operates. In fact, the short-term interest rate fully accommodates changes in money supply given the contemplated unavailability of money substitutes which could mitigate the response. There are numerous formulations of the money view. We summarize the model's implications in terms of the Keynesian IS-LM model and the sluggish savings and inflexible production model of Christiano and Eichenbaum (1995).

The traditional money view assumes the existence of two perfectly substitutable assets: money and bonds. Money is held as a medium of exchange, while bonds do not serve a transaction purpose. Money is issued by central banks and created by banks via demand deposits. Besides creating money through the liability side of bank balance sheets, banks assume no special role. At the core of the money view is the assumption that prices are slow to adjust. Price stickiness in turn causes changes in the nominal money supply to have real short-run effects. ${ }^{4}$ The real effects of monetary policy shocks are explained with the interest rate sensitivity of demand components. Considering a tightening in monetary policy, the associated increase in nominal interest rates in an environment of sluggish prices raises the short-term real interest rate. $^{5}$ This development depresses real economic activity through its effect on fixed capital investment and consumption. The interest rate response of investment operates through the cost-of-capital channel. The prediction is that higher real interest rates increase the user cost of physical capital investment. This reduces the rate of fixed investment as the higher cost of finance reduces the number of profitable investment projects and raises the required return on investment projects.

\footnotetext{
${ }^{3}$ Also see Gertler and Gilchrist (1993), Hubbard (1995), Kashyap and Stein (1994, 1995), Kakes, Sturm, and Maier (2001), Mojon (2001), Kuttner and Mosser (2002), and Putkuri (2003) for additional details and graphical explorations.

${ }^{4}$ The real effects build on the assumption that output supply is demand determined and perfectly elastic in the short run.

${ }^{5}$ Price stickiness causes changes in nominal money supply to be associated with changes in real money balances. In the wake of a monetary contraction, real money balances decline and money market equilibrium requires a higher real interest rate so as to equilibrate money demand and money supply.
} 
In contrast to the Keynesian framework, the Christiano and Eichenbaum (1995) model explains the real effects of money supply shocks with aggregate supply rather than aggregate demand. ${ }^{6}$ The non-neutrality of money reflects the differential monetary policy response of firms and households that results from (i) frictions in household saving decisions and (ii) ex-post inflexibility in production processes. The frictions arise because households decide on the amount of savings and firms fix production plans prior to the occurrence of a monetary policy shock. Because production only generates returns at the end of the production period, the pre-commitment of firms is such that they have to borrow working capital from the financial sector at the prevailing nominal interest rate to finance running production. The input factors to production are labor and physical capital. ${ }^{7}$ Whether firms can meet their demand for liquidity (i.e., money demand) depends on the availability of (i) predetermined household savings and (ii) lump sum injections of cash by the monetary authority, which define the volume of funds available from financial intermediaries. Firms are thus heavily dependent on external finance and this fact causes them to be most affected by a money supply shock.

In the Christiano and Eichenbaum (1995) model, a money supply shock induces a change in the nominal interest rate. The magnitude of the nominal interest rate response is determined by the ease at which firm production and accordingly firm liquidity demand adjusts. When production is fast to adjust ${ }^{8}$, firm money demand is flexible and only small changes in the nominal interest rate are required to equilibrate the money market. The consequent response of output and consumption is then also small. ${ }^{9}$ The response of output and consumption is attributable to the practice of firms to equate the marginal product of labor and the real cost of hiring labor. For this relationship, a monetary-policy-induced increase in the nominal interest rate reduces labor demand by raising the real cost of hiring labor. In due course, firm production and ultimately aggregate output contracts.

The traditional interest rate channel is criticized for providing an incomplete and restrictive view of the monetary transmission process. ${ }^{10} \mathrm{It}$ is argued to be of limited use since neither the IS-LM framework nor the Christiano and Eichenbaum (1995) model distinguishes (i) different types of financial assets ${ }^{11}$, (ii) different types of interest rates to explain money demand, bond demand, and investment, and (iii) temporary and permanent changes in nominal and real interest rates. Interest rate effects therefore do not fully account for the response of economic aggregates to unexpected monetary policy changes.

Besides, Bernanke and Gertler (1995) point to the existence of at least two puzzles associated

\footnotetext{
${ }^{6}$ Christiano and Eichenbaum (1995) define the monetary policy shock as innovation to money supply. The interest rate response results from adjustments in money demand.

${ }^{7}$ Note, the model treats capital as credit good that cannot respond to a monetary policy shock.

${ }^{8}$ The speed of adjustment is exogenous to the model.

${ }^{9}$ The ultimate results depend on the parameterization of the model, including the assumed ex-post flexibility of production.

${ }^{10}$ See, among others, Hubbard (1995) and Meltzer (1995).

${ }^{11}$ That is, capital structures are irrelevant.
} 
with the traditional interest rate view. The first puzzle concerns the magnitude of the monetary policy response of real aggregate output and individual spending components. Even though there is strong support for the monetary policy response of real economic output, the evidence does not find strong cost-of-capital effects on individual spending components. This inconsistency is particularly striking in view of the fact that investment is considerably more time-variant than output, which should leave investment more interest sensitive (cf. Bean, Larsen, and Nikolov, 2003). The second puzzle exists with respect to the monetary policy response of individual spending components. Empirical research shows that residential investment and durable goods and capital goods consumption generally display a strong response to a change in monetary policy even when the monetary policy response of long-term real interest rates is insignificant. In contrast to expectations, this suggests that spending on durable/capital goods does not depend on the long-term, but on the short-term (i.e., money market) interest rate. ${ }^{12}$ However, not all long-lived assets respond to monetary policy shocks. Empirical research frequently does not find quantitatively important effects of monetary policy on other long-lived spending components like business structures investment. The two puzzles have their origin in the assumption of perfect capital markets. Given this assumption, the money view neglects the role of interest-bearing assets and financial intermediation and assumes the perfect substitutability of bank and non-bank finance. The following section discusses the credit view which allows for credit market imperfections.

\subsubsection{Credit View}

In allowing for only one type of market friction, i.e., price stickiness, the money view fails to account for the observed effects of monetary policy shocks on macroeconomic aggregates. The credit view goes beyond the concept of sticky prices in that it also contemplates frictions in financial markets and the interaction between financial intermediaries and borrowers as mechanisms which amplify and propagate the direct effects of monetary policy. Dependent on whether capital market imperfections are modeled to be more important at the level of nonfinancial firms or banking institutions, the credit view distinguishes the balance sheet channel (broad credit channel) and bank lending channel (narrow credit channel), respectively. ${ }^{13}$ Both types of credit channel consider financial markets to trade three types of imperfectly substitutable assets: money, bonds, and bank loans. As will become evident, the broad and narrow credit view discuss the real effects of monetary policy changes by directly and indirectly emphasizing the monetary policy sensitivity of bank lending. The response of real spending to monetary-policy-induced fluctuations in bank lending is driven by the absence of

\footnotetext{
${ }^{12}$ See Goodfriend (1998) for explanations regarding the absence of a significant short-term interest rate response of real long-term rates.

${ }^{13}$ The balance sheet channel is also known as the broad credit channel since the underlying principles apply to a broad range of financing options. The bank lending channel is also designated as the narrow credit channel because the underlying principles apply to bank financing options only. Also see Gertler and Gilchrist (1993b), Hubbard (1995), Kashyap and Stein (1995), Bernanke and Gertler (1995), and Trautwein (2000) for formal and graphical illustrations of the credit channel view.
} 
perfect substitutes for bank loans.

The broad and narrow credit view do not only consider bank loans and non-bank assets as imperfect substitutes. Instead, both channels also stress the imperfect substitutability of internal and external funds of finance, with internal finance being relatively less expensive than external finance. At the core of this relationship are information asymmetries between borrowers and lenders in financial markets. Associated with the costs for selection, verification, monitoring, and enforcement, financial intermediaries account for asymmetric information problems by imposing a risk premium on external funds that renders external finance more expensive than internal finance. The size of the risk premium is negatively related to the monetary policy stance and positively linked to the level of the interest rate. We present the narrow and broad credit view in more detail in the remainder of this section.

\section{(i) Narrow Credit View}

The narrow credit view stipulates that monetary policy changes have real effects through their impact on bank lending. Credit channel effects via bank lending exist because credit market imperfections cause a bank's lending decisions to depend on its financial structure. The bank lending channel thus stems from a failure of the Modigliani-Miller theorem for banks (cf. Modigliani and Miller, 1958). ${ }^{14}$ Discussions of the bank lending channel distinguish the bank reserve and bank capital channel. Common to both channels is that monetary policy actions in the presence of financial imperfections affect the level of bank credit supply through their effect on the quantity of bank liabilities. ${ }^{15}$ While the bank reserve channel relies on information asymmetries in the market for reservable bank liabilities, the bank capital channel stresses frictions in the market for bank equity.

Bernanke and Blinder (1988) illustrate the bank reserve channel with an extended version of the traditional IS-LM model. The extended IS-LM model not only includes a market for bonds, money, and goods, but also a market for bank credit. ${ }^{16}$ At the core of the bank reserve channel is the practice of banking institutions to finance loans in part with liabilities that are subject to reserve requirements. In order to be operative, the bank reserve channel requires (i) monetary policy shocks to have real effects ${ }^{17}$, (ii) bank credit supply schedules to shift in response to monetary policy actions, (iii) non-bank lending (bonds) and bank lending to

\footnotetext{
${ }^{14}$ Stein (1998) develops a theoretical model on the failure of the Modigliani-Miller theorem for banks.

${ }^{15}$ In general, the interest rate response of bank credit supply is reflected in either price-quantity adjustments or pure quantity rationing.

${ }^{16}$ Also see Kashyap, Stein, and Wilcox (1993), Ramey (1993), Bernanke and Gertler (1995), Kashyap and Stein (1995, 2000), Stein (1998), Trautwein (2000), Farinha and Robalo Marques (2003) for presentations of the bank reserve channel.

${ }^{17}$ The interest rate response of money demand also constitutes a real effect. Only when money demand is interest elastic will bank deposits and, in due course, bank lending fluctuate in response to a monetary policy change (cf. Bean, Larsen, and Nikolov, 2003). The more interest sensitive is money demand, the larger is the interest rate response of bank deposits and thus bank lending.
} 
be imperfect substitutes, and (iv) household and firm expenditures to depend on bank credit supply, with bank credit demand being sensitive to changes in the bank lending rate.

For these conditions, the interest rate response of bank credit supply depends on the ability of banks (i) to offset a monetary-policy-induced decline in bank reserves and the consequent reduction in reservable deposits with alternative non-reservable, uninsured funds and/or (ii) to liquidate bank assets other than bank loans. Ideally, banks are able to fully offset the decline in reservable, insured funds. A monetary contraction then does not affect bank credit supply and any change in bank lending is clearly attributable to an interest-rate induced change in bank credit demand. ${ }^{18}$ However, financial credit market imperfections and the underlying information asymmetries between banks and the issuers of non-reservable, uninsured finance generally render banks unable to completely offset the fall in reserves with alternative forms of non-reservable finance. The ability of banks to supply loans then deteriorates. Cross-bank differences in the degree of information asymmetry concerning the value of a bank's liquid assets and equity cause the interest rate response of bank lending to differ between banks, being more pronounced for small, less liquid, and less capitalized banks. Because banks cut lending, firms and households have to address alternative non-bank sources of external finance. However, if household and firm expenditures depend on bank credit supply and alternative funds are not available, the cutback in bank credit supply will spur competition for bank finance among debtors and worsens the terms under which it can be obtained. This development ultimately curtails corporate investment activity and aggregate spending and thus has real economic effects.

Romer and Romer (1990) question the role of bank reserves in determining the strength of the bank lending channel. ${ }^{19}$ In their view, open market operations do not have a large impact on bank credit supply through reservable deposits since banks can raise funds at the margin by issuing managed (i.e., non-reservable and uninsured) liabilities. The underlying assumption is that there are no information asymmetries about the value of a bank's assets and that uninsured bank liabilities are therefore riskless. ${ }^{20}$ This in turn suggests that the bank lending effects of monetary policy are at best weak. Romer and Romer (1990) argue that - if at all - monetary policy actions affect bank lending through bank capital and regulatory capital requirements. They reason that in the absence of binding reserve requirements on managed liabilities, the ability of banks to access non-reservable liabilities is only determined by the level of bank capital. Similar to the bank reserve channel, the efficacy of monetary policy

\footnotetext{
${ }^{18}$ Note, following a monetary contraction, bank credit demand may expand or contract. Credit demand will expand if borrowers experience an unexpected shortage of liquidity or an increase in inventories due to lower sales (cf. Bean, Larsen, and Nikolov, 2003), but will decrease if borrowers consume or invest less in anticipation of the monetary-policy-induced economic downturn.

${ }^{19}$ Also see Van den Heuvel (2002a, 2002b), Gambacorta and Mistrulli (2004), Gambacorta (2005), and the references therein for explanations.

${ }^{20}$ See Kashyap and Stein $(1995,2000)$ for a counter-argument and counter-evidence according to which asymmetries about the real value of a bank's assets preclude banks from accessing non-reservable funds of finance.
} 
depends on the interest rate sensitivity of bank capital and on the corresponding impact on bank credit supply. To illustrate, a restrictive monetary policy shock reduces bank profits and thus the value of bank equity capital. The squeeze in profits and hence equity results from loan defaults and from a maturity mismatch between bank loans and deposits. ${ }^{21}$ Because banks can renegotiate a smaller fraction of loans in comparison with deposits, a monetary contraction imposes a maturity transformation cost on banks that reflects the increase in interest costs compared with interest revenue.

Bank credit supply contracts for two reasons. Firstly, the decline in the level of bank equity capital raises the risk premium in the market for uninsured funds and constrains banks from readily issuing new equity. This balance sheet effect of monetary policy causes banks to contract bank credit supply. Secondly, banks reduce bank lending to meet regulatory capital requirements and to lower the risk of capital inadequacy. Kashyap and Stein (1994) and Van den Heuvel (2002a) argue that minimum capital requirements affect the strength of credit channel effects through bank lending. Bank lending effects of monetary policy are only at work when bank capital is above the risk-based minimum regulatory capital requirement. The bank lending effects are then stronger for less capitalized banks: less capitalized banks reduce lending in order to reduce the risk of future capital inadequacy. When bank capital is at or below the risk-based minimum regulatory capital requirement, monetary policy shocks have a potentially small or even no effect on bank lending. This is particularly striking in case of a monetary policy expansion. Even when a monetary policy expansion causes an increase in reservable deposits and a decline in the degree of information asymmetries, bank lending may only expand at the margin. The reason is that banks have to accumulate bank equity first so as to meet bank capital requirements. The speed at which bank capital expands then depends on the effect of monetary policy on bank profits. In view of these relationships, Van den Heuvel (2002a) concludes that the bank lending effects of monetary policy are stronger, the larger the share of less, but adequately capitalized banks and the smaller the share of undercapitalized banks.

\section{(ii) Broad Credit View}

Similar to the narrow credit view, the broad credit view accounts for the role of banks in monetary policy transmission. However, the channel emphasizes the asset rather than liability side of bank balance sheets. Furthermore, the broad credit channel does not only describe the effect of monetary policy changes on the supply of bank finance, but examines the role of all financial intermediaries as source of external finance. ${ }^{22}$ At the core of the broad credit channel are the pro-cyclicality of net worth, the counter-cyclicality of the external

\footnotetext{
${ }^{21}$ Note, loans tend to be long-term, while deposits are predominantly short-term.

${ }^{22}$ See Bernanke and Gertler (1989), Bernanke, Gertler, and Gilchrist (1996, 1999), Kiyotaki and Moore (1997), Gilchrist, Hairault, and Kempf (2002) for formalizations of the balance sheet channel. Also see Trautwein (2000) for a literature review on the balance sheet effects of monetary policy and on the relationship between firms' net worth and the access to bank and non-bank finance.
} 
finance premium, and the consequent negative relationship between the external finance premium and the balance sheet position (net wealth) of potential borrowers (e.g., firms). The net effect of these relationships is captured by the financial accelerator principle. In order to be operative, the financial accelerator principle requires monetary policy to affect the balance sheet position of firms. The balance sheet effect generally presents itself as a change in the level of internal cash flows and in the value of collateral assets. It is propagated through endogenous developments in credit markets related to information asymmetries, cost of lending, and credit availability.

The propagation and amplification mechanism operates as follows. A monetary-policyinduced increase in interest rates raises interest payments and worsens the level of cash flows and the discounted value of firms' future income streams by suppressing aggregate demand. In addition, higher money market interest rates trigger a decline in the price of marketable balance-sheet assets which serve as collateral. Both developments - the decline in internal cash flows and the reduction in the value of collateral - worsen the financial status and hence the creditworthiness of borrowers, but also increase the need for external finance. ${ }^{23}$ In order to compensate for the higher agency costs as caused by information asymmetries and a higher probability of borrowers' default, bank and non-bank institutions raise the premium for external finance and engage in credit rationing. The monetary-policy-induced decline in the balance sheet position of borrowers thus causes a contraction of bank and non-bank credit supply to those borrowers and reduces their ability to finance investment projects. ${ }^{24}$ Because these relationships cause some profitable investment projects to be foregone, the decline in investment spending ultimately comes at the expense of lower economic activity and lower cash flows in subsequent periods.

Bernanke, Gertler, and Gilchrist (1996) argue that the deterioration in net worth also induces a 'flight to quality' on the part of bank and non-bank financial institutions. These reshuffle their credit portfolio from low net worth (high-risk) to high net worth (low-risk) borrowers in order to reduce credit risk. Financial accelerator effects are anticipated to be stronger, the weaker the balance sheet position of potential debtors and the higher the consequent information asymmetries and agency costs. Information asymmetries are viewed to be more pronounced for small-sized firms. The broad credit view argues that the creditworthiness of small firms is more sensitive to interest rate and output fluctuations than that of large firms. The larger interest and output sensitivity in turn cause small-firm bank and non-bank credit demand to be more sensitive to monetary policy changes.

\footnotetext{
${ }^{23}$ Mishkin (2001) follows an alternative line of reasoning. Building on Tobin's q-theory (Tobin, 1969), an increase in interest rates raises the replacement cost of capital, while depressing the market value of firms. Since the relative decline in Tobin's q renders investment expensive relative to the value of the firm, investment spending declines. This development may come at the expense of lower credit demand. Ashcraft and Campello (2002) also stress an inverse relationship between credit demand and monetary policy. They presume that credit demand declines in the wake of a monetary tightening because of higher debt service burdens.
}

${ }^{24}$ Note, the broad credit channel may operate even when bank loans and bonds are perfect substitutes. 


\subsubsection{Asymmetries in Monetary Policy Effectiveness}

Monetary policy shocks may have different effects dependent on whether the economy experiences a boom or downturn. They are deemed to be more effective during a downturn than during a boom. The interest rate view attributes cyclical asymmetries in monetary policy effectiveness to cyclical differences in the degree of nominal price and wage rigidities, which affect the shape of the aggregate supply curve. For example, Caballero and Engel (1993) and Ball and Mankiw (1994) advocate a convex aggregate supply curve that is flat up to full employment and steep at and above full employment. The shape is conditioned by upward flexibility and downward rigidity of nominal prices and the assumption of decreasing marginal productivity of productive factors. ${ }^{25}$ Nominal price rigidities result from (i) costs associated with nominal price adjustment (small menu costs), (ii) state-dependent (i.e., cyclical) pricing, and (iii) an upward trend in inflation. ${ }^{26}$ Given these relationships, monetary policy changes are more effective during downturns when the aggregate supply curve is relatively flat and output is below its full employment level than during economic booms when the aggregate supply curve is steep (or even vertical) and output is high. ${ }^{27}$

As regards the credit channel effects through net worth, the cyclical asymmetry of the balance sheet effects and thus of the financial propagation mechanism of monetary policy is attributable to two factors. The first factor refers to cyclical fluctuations in the dependence of debtors on external funds. In general, firms and households are less dependent on external funds in periods of economic booms because their balance sheet position is strong in comparison to episodes of economic downturns. Because the risk of debt default and nonperforming loans is comparatively low, the external finance premium does not respond much to an unexpected monetary tightening and credit conditions do not significantly change. In contrast, episodes of recessions are associated with low cash flows and a higher probability of loan losses. A monetary tightening during a recession worsens information asymmetries. The consequent increase in the external risk premium worsens credit conditions, imposes credit constraints on firms and households, and causes a reallocation of external funds from debtors with weak balance sheets to those with high net wealth. In due course, investment activity declines, which further depresses economic activity.

The second factor concerns differences in the economic relationship between small- and largesized firms in periods of economic booms and recessions. Gertler and Gilchrist (1994) attribute these to heterogeneities in the interest rate sensitivity of small- and large-firm production, with large-firm production being less interest sensitive than small-firm production. The mechanism is as follows. Firms strive to shelter the level of output production from cyclical fluctuations in output demand. Production smoothing is generally more feasible for large than for small

\footnotetext{
${ }^{25}$ See Florio (2004) for an overview of additional reasons. These are related to private sector's expectations and the term structure of interest rates.

${ }^{26}$ In order to allow for price stickiness, models usually allow for monopolistic competition. See, for example, Bernanke, Gertler, and Gilchrist (1999).

${ }^{27}$ Chapter 6 tests for possible 'state' effects of monetary policy.
} 
firms. Indeed, large firms can contract out production to their smaller counterparts during economic booms, while they meet demand internally in episodes of economic recessions. In using small firms as a buffer, production smoothing on the part of large firms stabilizes their cash flows at all stages of the business cycle. This helps to cushion the probability of binding credit constraints during recessions. Opposite relationships prevail for small firms. Given the cyclical fluctuations in cash flows, their credit constraints are likely to be binding.

Overall, cyclical asymmetries in monetary policy effectiveness are such that monetary policy changes are more effective during economic downturns than during booms. The cyclical differences are attributable to real rigidities and credit market frictions. Information asymmetries cause financing constraints of firms and banks to be binding, with the constraints being more stringent in periods of economic downturns when net worth of firms and capitalization of banks are low. As will be evident from the following section, credit market imperfections do not only account for cyclical asymmetries in monetary policy effectiveness, but also explain cross-region and cross-industry differences.

\subsubsection{Regional and Industry Effects of Monetary Policy}

In a study for countries in Europe, Berben et al. (2004) forcefully argue that cross-country differences in the timing and magnitude of monetary policy effects are attributable to crosscountry heterogeneities in the structure of financial, goods, and labor markets as well as fiscal policy frameworks. Fiscal policy frameworks are important since they reflect social preferences regarding the degree of intertemporal income smoothing and hence economic stabilization via, for example, automatic stabilizers. Goods and labor market characteristics determine monetary policy effectiveness through nominal wage inertia and real price-wage rigidity. Nominal inertia and real rigidities depend on the degree of (i) market contestability as determined by government regulation and by barriers to market entry and trade, (ii) trade union power and employment protection, and (iii) centralization of the wage bargaining process. Price and wage rigidities are less pronounced in countries with contestable markets, flexible wages, and deregulated labor markets subject to low bargaining power of labor unions and decentralized wage bargaining.

The structure and operation of goods markets cannot only be described in terms of price rigidities, but also and more directly in terms of industry composition. Industries certainly differ with respect to the nature of goods they produce ${ }^{28}$ and in terms of production structures and therefore input requirements. These factors, however, influence the monetary policy response of industry output through its effect on industry-specific output supply and output demand. Both the money view and credit view of monetary policy transmission help to explain the cross-industry differences in the monetary policy response. Common to both

\footnotetext{
${ }^{28}$ As an example, industries may produce consumption or investment goods, durable or non-durable goods, intermediate or final goods, tradable or non-tradable goods.
} 
transmission channels is the conclusion that monetary policy effectiveness depends on industry composition. ${ }^{29}$

Adherents of the money view argue that the monetary policy response of industry output depends on the interest rate elasticity and cyclicality of demand for industry-specific output. The interest rate response of output is hereby higher for cyclical industries producing investment goods and durable consumption goods. These industries tend to rely on capitalintensive technology and host firms subject to high operating costs and high financial leverage. Cross-industry heterogeneities in the degree of capital intensity in turn point to the role of industry composition as determinant of monetary policy effectiveness at the regional level, with monetary policy being more effective in regions with a comparatively large share of capital-intensive industries. Given these relationships, regional asymmetries in the efficacy of monetary policy are due to cross-region differences in industry mix.

The credit channel theory also allows for industry effects of monetary policy. As concerns the narrow credit view, industry effects will exist if monetary policy has differential effects on bank lending to individual industries. Cross-industry differences in the bank lending effects of monetary policy suggest that the industry composition of bank credit portfolios is a crucial determinant of monetary policy effectiveness. ${ }^{30}$ The broad credit view attributes the existence of industry effects to the possible interdependence of firm size and industry. Eichenbaum (1994), for instance, argues that industry effects are caused by the interrelationship between the size distribution of firms and industry-specific determinants thereof. In his view, one such determinant is the cyclical sensitivity of industry production, with small firms predominantly operating in cyclically sensitive industries. Given that the balance sheet effects of monetary policy are deemed to be stronger for small firms, this relationship suggests that the real effects of monetary policy are more pronounced for countries or regions with a large share of cyclically sensitive industries.

Regional differences in financial market structure, on the other hand, refer to asymmetries in the degree of banking sector concentration and in the size distribution of banks and firms. These factors are related to regional heterogeneities in the degree of information asymmetries and in the relative availability of bank and non-bank finance. ${ }^{31}$ The underlying mechanisms are inherent to the narrow and broad credit view. The narrow credit view argues that credit market imperfections are more pronounced for small, poorly capitalized, and illiquid banks. These banks are not only constrained from accessing non-reservable funds of finance, but have also less information on capital markets (Fase and De Bondt, 2000). Because of this relationship, regions with a relatively large share of small, poorly capitalized, or illiquid banks

\footnotetext{
${ }^{29}$ See chapter 4,5 , and 6 for empirical assessments of these relationships.

${ }^{30}$ We report corresponding evidence in chapter 5 .

${ }^{31}$ See Arnold and De Vries (2000) and Gilchrist, Hairault, and Kempf (2002) for factors that explain crosscountry differences in financial structures. Note, financial market structures are not only approximated with the distribution of banks by asset size, but also by capitalization and liquidity.
} 
are likely to respond more strongly to changes in the monetary policy stance than regions with a large proportion of large, well-capitalized, and liquid banks. The broad credit view attributes regional differences in the efficacy of monetary policy to regional asymmetries in the size distribution of firms. ${ }^{32}$ Countries with a high share of small firms are deemed to be more responsive to monetary policy changes than countries with a comparatively high share of large firms. This reflects the perception that large rather than small firms face a lower degree of credit market imperfections and a comparatively unconstrained access to financial markets.

\subsection{Methodological and Empirical Issues}

This section reviews methodological problems that complicate empirical assessments of monetary policy transmission mechanisms. We keep the discussion general and stress methodological problems which concern the identification of (i) monetary policy shocks and (ii) individual transmission channels. ${ }^{33}$ We consecutively present each set of problems in the two subsequent sections. Section 2.3.3 presents possible solutions to the identification problems as suggested by the use of macro-, microeconomic, and industry data.

\subsubsection{Measuring Monetary Policy Shocks}

In order to determine the real effects of monetary policy, monetary policy shocks need to be identified. Because of disagreement on an appropriate monetary policy measure, the empirical literature extracts monetary policy shocks from a considerable range of variables associated with the monetary policy stance. For example, monetary policy shocks are approximated as shocks to total central bank reserves, non-borrowed reserves, narrow and broad monetary aggregates, and the money market interest rate. ${ }^{34}$ Among these indicator variables, broad monetary aggregates are considered to be very poor proxy variables of monetary policy shocks. The reason is that the individual components of broad monetary aggregates often evolve along different paths, which complicates the interpretation of fluctuations in the total. The money market interest rate is considered to be a more stable indicator of the monetary policy stance than monetary aggregates. ${ }^{35}$

Regardless of the variable, its usefulness as indicator of the monetary policy stance is ques-

\footnotetext{
${ }^{32}$ See, among others, Gertler and Gilchrist (1993) and Oliner and Rudebusch (1996).

${ }^{33}$ We provide more details on channel-specific problems in section 2.4 , which reviews the existing empirical evidence on monetary transmission mechanisms.

${ }^{34}$ See, for example, Christiano and Eichenbaum (1992), Bernanke and Blinder (1992), Gordon and Leeper (1994), Christiano, Eichenbaum, and Evans (1996), Bernanke and Mihov (1998), and McMillin (2001) for overviews and examples of studies which employ one or more of these monetary policy variables. These studies also criticize existing research.

${ }^{35}$ Also see Bernanke and Blinder (1992) and Christiano and Eichenbaum (1992).
} 
tioned because shocks to it are not purely exogenous. Policy indicators consist of an endogenous component which reflects (i) the effect of non-policy factors such as the actions of bank and non-bank institutions and (ii) the accommodating response of monetary authorities to changes in money demand. Because monetary policy is determined by supply and demand conditions and thus consists of an endogenous and exogenous component, empirical estimates on the real effects of monetary policy shocks are generally fraught with a simultaneity bias. ${ }^{36}$

In order to solve the identification problem inherent in macroeconomic data, many macroeconometric studies estimate structural vector autoregressive (VAR) models. VARs have attracted much criticism since the identification of the real effects of monetary policy shocks rests on ad hoc modeling assumptions about the causal relationship between monetary policy and the performance of financial markets and goods markets. ${ }^{37}$ For example, in order to identify monetary policy shocks, studies usually assume that actions taken by agents in financial and goods markets do not influence the real effects of monetary policy. To this end, research imposes extreme assumptions about the interest rate elasticity of money demand and money supply. ${ }^{38}$ The arguments used to identify the exogenous component of monetary policy not only contrast the predictions of theoretical monetary models, but also yield empirical estimates which do not endorse theoretical expectations.

Given the weaknesses associated with traditional measures of monetary policy shocks, some studies employ the narrative approach of Romer and Romer (1989). In a study for the United States, they use information from the minutes of the Federal Open Market Committee (FOMC) to identify dates at which monetary policy adopted a much sharper anti-inflationary stance. The Romer dates have attracted considerable criticism. The dates are still subject to the identification bias due to simultaneity since they do not distinguish the endogenous and exogenous component of a monetary policy shock. Furthermore, they do not represent monetary expansions, but only refer to monetary contractions. Here, Bernanke and Mihov (1998) show that Romer dates do not describe points at which monetary policy switched from an expansionary to a contractionary stance, but points of maximum tightness in monetary policy. These drawbacks are amplified by the observation that the dates do not indicate the degree to which monetary policy changes are contractionary. Motivated by the shortcomings of the Romer dates, Boschen and Mills (1991) expand the narrative approach of Romer and Romer (1989) and assemble a larger set of dates that qualify changes in monetary policy according to five categories, ranging from 'very contractionary' to 'very expansionary'. Unfortunately, the Boschen and Mills (1991) index still fails to control for the endogenous and exogenous component of monetary policy shocks.

\footnotetext{
${ }^{36}$ Also see Bernanke and Mihov (1998), Angeloni et al. (2003), Kuttner and Mosser (2002), Ehrmann and Fratzscher (2004), and Bernanke and Kuttner (2005) for a description of the simultaneity bias at the macroeconomic level.

${ }^{37}$ See Gordon and Leeper (1994), Bernanke and Mihov (1998), and Kieler and Saarenheimo (1998) for criticisms.

${ }^{38}$ See Gordon and Leeper (1994) for an overview of the identifying assumptions.
} 
A new branch of studies measures monetary policy shocks within the framework of event studies. These are predominantly implemented for US data and discuss the response of equity prices to changes in US monetary policy on days of FOMC meetings. ${ }^{39}$ While some event studies simply define monetary policy shocks as the change in the Federal funds rate (e.g., Lobo, 2000), more recent event studies (e.g., Kuttner, 2001; Ehrmann and Fratzscher, 2004; Bernanke and Kuttner, 2005) identify monetary policy shocks as the unexpected change in the monetary policy stance. The unexpected change is usually defined as the directly observable difference between observed market expectations regarding the future monetary policy stance and the Federal funds rate target at the day of its announcement by the FOMC. ${ }^{40}$ Unfortunately, event studies are very information intensive, which confines their radius of applicability. As stated, monetary policy shocks are identified by using information on single meetings of monetary policy authorities (e.g., the FOMC). In order to derive estimates of the interest rate and credit channel effects of monetary policy for single point estimates of monetary policy shocks, high frequency firm-level data on economic performance are required. Corresponding data of sufficient quality are hard to come by, which restricts the applicability of event studies to single rather than multiple countries.

The discussion so far shows that it is intrinsically difficult to distinguish the endogenous and exogenous component of monetary policy shocks. A different strand of literature refutes the need to be exclusively concerned with the real effects of exogenous monetary policy shocks. Bernanke, Gertler, and Watson (1997), Bernanke and Mihov (1998), and McCallum (1999), among others, argue that tests for monetary policy transmission should not exclusively be concerned with the effects of random exogenous shocks. The reason is that these only explain a small part of the variability in monetary policy and that central banks do not conduct monetary policy on purely random terms. Instead, attention should be directed towards the aggregate effect of the endogenous and exogenous component of monetary policy shocks in order to obtain a monetary policy indicator that describes the overall behavior of monetary policy authorities and the overall effect of monetary policy. To this end, Bernanke and Mihov (1998), for example, devise a monetary conditions index that combines information on the money market interest rate and on non-borrowed reserves. In combining these two variables, the measure also accommodates changes in the monetary policy stance which originate from shifts in the target variable of monetary policy. However, this measure like previous variables does not qualify the extent to which monetary policy is contractionary or expansionary.

Overall, the discussion suggests that empirical investigations should exercise great care in selecting indicator variables of monetary policy shocks. This is because indicators differ in their ability to solve the endogeneity bias inherent to monetary policy shocks. Event studies offer the most promising solution for the adequate identification of monetary policy shocks.

\footnotetext{
${ }^{39}$ See, for example, Lobo (2000), Kuttner (2001), Ehrmann and Fratzscher (2004), and Bernanke and Kuttner (2005).

${ }^{40}$ Measures of market expectations are obtained from Federal funds future contracts (Kuttner, 2001; Bernanke and Kuttner, 2005) or from market surveys (Ehrmann and Fratzscher, 2004).
} 
As an (imperfect) alternative to event studies, monetary policy shocks can be approximated with changes in the money market interest rate or in money supply. Money supply should hereby be narrowly defined since the individual components are more likely to capture effects associated with non-policy (endogenous) factors. The discussion suggests that the ultimate choice of the monetary policy variable certainly depends on the aim of the study.

\subsubsection{Measuring Monetary Transmission Channels}

Even if the exogenous component of monetary policy shocks is adequately measured, empirical results may still be biased because of empirical problems regarding the unique identification of monetary transmission channels. One identification problem arises from the mutual dependence of the traditional money view and credit view. Although the money and credit view use different theoretical frameworks to explain monetary policy transmission, the discussion in section 2.2 suggests that both types of transmission channels are not mutually exclusive. Instead, they complement and reinforce each other. Bernanke (1993) argues that the interdependence results from the role of (i) bank liabilities (i.e., bank deposits) as determinant of the interest rate channel and (ii) bank assets (i.e., bank credit) as determinant of the credit channel. ${ }^{41}$ Because bank assets and bank liabilities are related by the accounting identity of the bank balance sheet constraint, the interdependence of the interest rate and credit channel gives rise to an identification problem in empirical estimations. The problem concerns the distinction of shifts in bank lending that are due to either bank credit supply or bank credit demand. ${ }^{42}$

Next to this identification problem, it is hard to distinguish the broad and narrow credit view in empirical research although both views represent distinct monetary transmission channels. The complication is attributable to two factors. The first factor refers to the observation that a monetary-policy-induced contraction in bank credit supply can be associated with (i) the failure of banks to obtain non-reservable funds of finance (bank lending channel) and (ii) the response of banks to higher credit risk due to lower net worth of potential borrowers (balance sheet channel). The second factor refers to the practice of empirical research to approximate credit market imperfections and financial constraints at the level of firms (balance sheet channel) and banks (bank lending channel) with, respectively, firm and bank asset size. At the core of the identification problem is the observation that large (small) banks tend to concentrate their lending and deposit business with large (small) firms. For this relationship, a monetary-policy-induced decline in bank lending can reflect the response of banks to a

\footnotetext{
${ }^{41}$ Recall, the money view stresses the impact of monetary policy on bank lending through the effect on bank deposits, with changes in bank deposits reflecting interest-rate-induced movements in liquidity demand. The credit view links the monetary policy response of bank lending to the ability of banks to offset a decline in reservable with non-reservable funds of finance (i.e., deposits).

${ }^{42}$ See, among others, Romer and Romer (1990), Bernanke and Blinder (1992), Kashyap and Stein (1995, 2000) for details. Chapter 5 discusses the identification problem in greater detail in a microeconomic study for Germany.
} 
deterioration in the creditworthiness of firms and/or the response of banks to a change in the level of bank reserves and bank deposits. It is thus intrinsically difficult to uniquely identify the differential response of bank credit demand across firm size from the differential response of bank credit supply across bank size (Ashcraft, 2003; Ashcraft and Campello, 2002).

\subsubsection{Solutions to the Identification Problems}

Empirical research on monetary transmission mechanisms has addressed the identification biases by distinguishing macroeconomic (aggregate), disaggregated (industry), or microeconomic data. In the remainder of this section, we stress the (dis-)advantages of each type of data in solving the methodological problems. As will become evident, no data type constitutes the ultimate cure for all problems. Considering macroeconomic data, they are usually available for relatively long periods of time for a comprehensive set of countries. Ganley and Salmon (1997) argue that the ease of availability renders macroeconomic data useful instruments to discover stylized facts of monetary policy transmission. However, macroeconomic research cannot appropriately address identification and simultaneity problems. One reason is that data aggregation eliminates differences between agents and markets in terms of behavior. However, especially these differences are crucial determinants of monetary policy effectiveness given their role as propagation and amplification mechanism of monetary policy changes.

In contrast to macroeconomic data, disaggregated and microeconomic data help to capture cross-section heterogeneity, which is required for the identification of significant relationships between the determinants of monetary policy effectiveness. Disaggregated data assist in explaining monetary policy effects at the aggregate level by stressing structural and institutional characteristics (e.g., industry composition, banking groups, types of debtors). The distinction of different borrower groups, banking groups, or industries provides evidence on the distributional effects of monetary policy. These result from asymmetries in group-specific behavioral patterns and can be captured by exploiting between-group heterogeneity.

Microeconomic data do not only stress between-group dissimilarities of agents and markets, but also within-group heterogeneities. The corresponding panel studies exploit the information contained in the variability of the time-series and cross-section dimension of the data so as to emphasize differences between cross-sectional units. By taking advantage of crosssectional variability over time, microeconomic data are natural instruments to identify effects that are unobserved in time-series or cross-section data (Baltagi, 2005). Furthermore, they are well-suited to discover behavioral asymmetries between different groups of agents in the same country and between similar groups of agents across different countries (cf. Guiso et al., 1999; Chatelain et al., 2003). Cross-country comparisons of the effects associated with similar groups of agents help to identify country-specific factors of monetary policy effectiveness. 
Because microeconomic data exploit the information contained in the cross-sectional dimension, they overcome some of the simultaneity problems mentioned above. For example, they appropriately address the simultaneity problem at the macroeconomic level that exists because monetary policy is endogenous to economic activity. Identification rests on the assumption that single cross-section units do not influence the monetary policy stance. ${ }^{43}$ Microeconomic data are also advantageous because they tend to be less distorted by structural or institutional changes at the macroeconomic level.

Microeconomic data and disaggregated data also have their shortcomings. Both tend to be available for comparatively short periods of time at low frequencies only. Low frequency data are problematic in that they do not capture much of the variability inherent in monetary policy and macroeconomic performance. ${ }^{44}$ A short sample period may cause the variation in the monetary policy stance to be too small in order to yield significant fluctuations in aggregate demand, bank lending, or net worth. ${ }^{45}$ Empirical estimates will then be distorted even for a large number of cross sections (Chatelain et al., 2003). Time invariance due to short sample periods is likely to be a particular problem for studies on the bank lending effects of monetary policy. Evidently, the monetary policy response of bank lending is confined to new loan issues and to the amount of bank loans outstanding. The magnitude of the response is dependent on the maturity of bank loans outstanding. The larger the share of long-term lending is, the fewer loans need to be rolled over and the lower is the speed at which the amount of credit outstanding responds to monetary policy changes (De Haan, 2003). In order to capture the interest rate response of bank lending, longer sample periods are therefore required.

Another disadvantage of microeconomic data concerns data quality. Microeconomic studies are typically confined to a single country and do not involve cross-country studies. Crosscountry comparisons of monetary transmission mechanisms are hence complicated if not impossible. The restricted focus is due to the unavailability of (qualitatively) comparable sets of data on industry, firm, or bank characteristics for a comprehensive set of countries. In addition, microeconomic data are frequently biased towards a specific set of banks or firms, banking group, or industry. For instance, firm-level data are generally fraught with a large firm size bias. In the presence of sample biases, the results of microeconomic studies may provide an imperfect view on the macroeconomic effects of monetary policy.

Besides these problems, the evidence from credit channel studies is influenced by the use of sample splitting variables (e.g., firm and bank size). Schiantarelli (1996) emphasizes problems associated with the choice between time-variant and time-invariant sample stratification criteria. Time-invariant measures of financial constraints are criticized since they consider

\footnotetext{
${ }^{43}$ See, for example, Angeloni et al. (2003), Kuttner and Mosser (2002), Chatelain et al. (2003).

${ }^{44} \mathrm{High}$ frequency data are at the other extreme. They might be too noisy for the identification of unambiguous relationships.

${ }^{45} \mathrm{On}$ the other hand, a short sample period is advantageous since it avoids the complications associated with regime shifts.
} 
agents to be either financially constrained or unconstrained throughout the whole sample period regardless of the business cycle position, the monetary policy stance and irrespective of the effects associated with structural changes in financial markets. ${ }^{46}$ Agents are most often precluded from switching between the financial state of being constrained and unconstrained. However, the evidence lends support to cyclical asymmetries in the severity of credit market frictions and financial constraints: the credit channel effects of monetary policy are stronger for monetary policy shocks in economic downturns. ${ }^{47}$ In view of these results, studies on the credit channel effects of monetary policy should employ time-variant measures of financial constraints and credit market frictions to control for cross-period differences in the intensity of financial constraints and in the degree to which financial constraints are binding. Unfortunately, such data tend to be unavailable at relatively high frequencies for time periods of sufficient length.

\subsection{Evidence on Monetary Transmission Channels}

This section asks whether the existing empirical evidence confirms the theoretical predictions of the interest rate and credit channel view. The review is confined to studies for the United States as benchmark country of monetary integration as well as for countries in Western Europe. It will become evident that the empirical results for each transmission channel are frequently sensitive to the choice of country and empirical modeling strategy. Furthermore, they also tend to be very sensitive to the frequency and type of data (i.e., macroeconomic, disaggregated, or microeconomic). The subsequent discussion presents the existing empirical findings in general terms. Table 2A.1 to Table 2A.3 in the annex summarize the empirical findings by study.

\subsubsection{Interest Rate Channel}

The existing empirical studies lend strong support to the operation of an interest rate channel of monetary policy. Aggregate or industry-specific output contracts in response to a monetary tightening ${ }^{48}$ regardless of (i) the time-series and cross-section dimension of the data, (ii) the empirical methodology, and (iii) the frequency of the data. Only few studies report weak or no interest rate effects. Particular to these studies is the use of firm-level data. Chatelain and Teurlai (2004) in a study for France suggest that the insignificance of the interest rate (cost-of-capital) channel in estimations with firm-level data is due to an aggregation bias between firms who invest and disinvest. They find that the user cost of capital only affects

\footnotetext{
${ }^{46}$ Note, Schiantarelli (1996) develops arguments for financial constraints of firms. Because we consider his arguments to be equally valid for banks, we adopt a general view and refer to banks and firms as agents.

${ }^{47}$ See, for example, Atanasova (2003) for the United Kingdom, Balke (2000) for the United States, Ehrmann (2005) for Germany, Kaufmann (2003) for Austria.

${ }^{48}$ Note, empirical studies are predominantly realized for a monetary policy contraction.
} 
capital accumulation of firms that invest. Firms that disinvest do not adjust the amount of disinvestment in response to a change in the user cost of capital.

Studies which allow for industry effects are predominantly implemented for the construction, service, and manufacturing sector and for sub-sectors of the manufacturing industry. The evidence from aggregate and disaggregated data draws a homogenous picture for the United States and for countries in Europe. In line with expectations, the interest rate response is most pronounced for capital-intensive and durable goods producing industries. Industries, accordingly, appear to be important propagation and amplification mechanisms of monetary policy changes for all sampled countries. The evidence from microeconomic industry studies is less robust to the choice of country. Industry effects of monetary policy are documented for Belgium (Butzen, Fuss, and Vermeulen, 2003) and the United States (Ehrmann and Fratzscher, 2004), but not for France (Chatelain and Tiomo, 2003) and Luxembourg (Lünnemann and Mathä, 2003). A possible source of cross-country differences in the existence of industry effects is the choice and number of industries. Evidence against industry effects is particular to studies that only distinguish a small number of homogenous industry sectors. This, however, may cause the cross-industry variation to be too small in order to generate significant industry effects of monetary policy in microeconomic estimations.

\subsubsection{Broad Credit Channel}

Most credit channel studies assess the balance sheet effects of monetary policy by using firms as the unit of analysis, while households are usually not considered. The evidence for firms lends comparatively strong support to the transmission of monetary policy through balance sheet effects. Credit market imperfections - at least at the firm level - thus appear to be an important source of monetary policy effectiveness. To this point, only few studies ask whether the strength of credit channel effects differs between industries. ${ }^{49}$

Although the empirical literature points to the operation of a credit channel, the results are sensitive to the choice of credit channel variable, country, data quality, and data dimension. Conclusions for any single country are, for instance, influenced by the country dimension of the study. That is, the results of single- and multi-country estimations tend to differ from each other. One possible source of heterogeneity is data quality. Multi-country studies predominantly rely on easily accessible measures of credit market imperfections in order to construct a comparable database for a comprehensive set of countries. For example, a credit channel variable commonly used is firm size. Measured in terms of sales, assets, or the number of employees, the evidence for the United States and Europe lends different support to the transmission of monetary policy shocks through firm size effects. In studies for the United

\footnotetext{
${ }^{49}$ See the evidence in Butzen, Fuss, and Vermeulen (2003), Chatelain and Tiomo (2003), Dedola and Lippi (2005), and Peersman and Smets (2005). The corresponding results confirm the evidence for the interest rate channel in that credit channel effects are particular to cyclical industries. Also see the evidence in chapter 4.
} 
States, the evidence endorses the theoretical predictions of the credit view and documents the larger monetary policy response of small firms. ${ }^{50}$ In contrast to the US results, the empirical evidence for European countries lends weak or no support to the existence of small firm size effects of monetary policy. ${ }^{51}$ The contrasting results for the United States and Europe can be explained along two different lines.

Firstly, Eichenbaum (1994) argues that the significance of firm size effects might be driven by the potential interdependence of firm size and the cyclical sensitivity of industries. This, however, complicates the identification of effects associated with the interest rate and broad credit channel. If firm size correlates with the cyclical behavior of industries, significant firm size effects may reflect industry effects, even in perfect credit markets. Chapter 4 addresses this problem. We test whether assumptions regarding the interdependence of firm size and industry indeed affect conclusions about the interest rate and credit channel effects of monetary policy.

Secondly, the absence of significant small firm size effects in Europe can be explained with institutional structures such as the nature of bank-customer relationships. Close relationships between banks and firms attenuate information asymmetries and thus the severity of financing constraints and the link between cash flow and investment activity. For Europe, bank-customer relationships tend to be particularly strong for small firms. ${ }^{52}$ This, however, suggests that small-firm investment might not be more sensitive to monetary policy changes than large-firm investment. In addition, insignificant firm size effects may also result from the use of firm size data that are subject to a sample bias towards large firms (e.g., Chatelain et al., 2003; Peersman and Smets, 2005). This property reduces the importance of information asymmetries in the sample and hence the strength of the firm size effect. Chapter 3 suggests an alternative explanation for the absence of significant small firm size effects. The argument builds on a theoretical non-linear investment model which links the interest rate response of small and large firms to the degree of investment irreversibility and to the size of monetary policy shocks.

In order to overcome the problems associated with firm size, single-country studies frequently employ more detailed data such as firm credit rating, firm age, the firm coverage ratio, or the number of bank lending relationships as proxy variables of creditworthiness and information asymmetries. Firm age, for instance, approximates the extent to which firms have (i) established relationships with bank and non-bank institutions, (ii) gained continuity in operation and creditworthiness, and (iii) accumulated collateral (Lünnemann and Mathä, 2003;

\footnotetext{
${ }^{50}$ See Gertler and Gilchrist (1993b, 1994), Bernanke, Gertler, and Gilchrist (1996), Ehrmann and Fratzscher (2004) for evidence in favor of firm size effects, Carlino and DeFina (1998) for evidence against firm size effects, and Thorbecke and Coppock (1996) for ambiguous findings.

${ }^{51}$ See Mojon, Smets, and Vermeulen (2002), Chatelain et al. (2003), Kalckreuth (2003), and Ehrmann (2005).

${ }^{52}$ See Berger and Udell $(1998,2002)$ and Harhoff and Körting (1998) for evidence.
} 
Valderrama, 2003). Credit rating measures firm riskiness and illustrates the extent to which creditworthiness determines a firm's access to external credit. Closely related, the coverage ratio is a proxy variable of creditworthiness since it assesses the extent to which cash flow covers financial costs. It is evident from their definition that these variables contain more information on information asymmetries and credit market frictions than common measures of firm size. Unfortunately, these proxy variables tend to be available for single countries only rather than for comprehensive sets of economies.

Credit channel effects of monetary policy prevail in estimations that use credit rating (e.g., Chatelain and Tiomo, 2003; Breitung, Chirinko, and Kalckreuth, 2003; Kalckreuth, 2003; Ehrmann and Fratzscher, 2004), firm age (Valderrama, 2003; Lünnemann and Mathä, 2003), or dividend payments (Siegfried, 2000) to discriminate the balance sheet condition of firms. The corresponding evidence confirms the belief that credit channel effects are stronger for young firms and for firms with low or no credit rating. In addition, Chatelain and Tiomo (2003) and Valderrama (2003) demonstrate that a firm's access to trade credit mitigates the credit channel effects through net worth. Nilsen (2002) and Mateut, Bougheas, and Mizen (2003) show that especially small firms consider trade credit an important source of external capital. The availability of trade credit weakens the credit channel effects of monetary policy by lowering the financing constraints imposed by the dependence on external funds from bank and non-bank institutions.

Although credit channel variables other than firm size tend to be more detailed, they are still less than perfect indicators of information asymmetries. Schiantarelli (1996) and Kaplan and Zingales (1997) argue that this particularly holds for indicator variables including cash flow (e.g., coverage ratio). ${ }^{53}$ The criticism builds on the strong correlation between cash flow and firm investment and the observation that cash flow contains information on (unobserved) future expected profitability. This, however, precludes the unique identification of effects associated with the financial accelerator principle or with information asymmetries. In fact, a significant response of investment to cash flow may reflect effects unrelated to financial constraints. ${ }^{54}$

Overall, conclusions regarding the credit channel effects of monetary policy are sensitive to the choice of credit channel variable. Despite potential shortcomings regarding the definition of credit channel variables, the existing empirical evidence lends support to the transmission of monetary policy shocks through credit channel effects. A monetary policy contraction hence seems to be associated with a tightening of external financing constraints as caused by a deterioration in information asymmetries.

\footnotetext{
${ }^{53}$ The coverage ratio is measured as the ratio of cash flow to interest payments (cf. Gertler and Gilchrist, 1994).

${ }^{54}$ See Fazzari, Hubbard, and Petersen (1988) for the role of cash flow as a measure of liquidity constraints. They argue that internal cash flow is an important determinant of investment demand for financially constrained firms.
} 


\subsubsection{Narrow Credit Channel}

Given the central role of banks as source of finance, considerable empirical research is also concerned with the role of banks and bank lending in monetary policy transmission. ${ }^{55}$ Many studies take Germany as unit of analysis. The comparatively large number of German-oriented empirical research is attributable to the availability of comprehensive sets of bank-level data on bank balance sheet items and bank lending for a comparatively long period of time. These facilitate detailed assessments regarding the determinants of the credit channel effects through bank lending. Besides data availability, Germany is an interesting case study since the private sector heavily relies on banks as source of external finance. Known as the housebank principle, the private sector hereby maintains close relationships with very few selected banks. Because both factors - the degree of bank dependence and the housebank principle - have opposite implications for the strength of the credit channel, conclusions as to the importance of credit channel effects in a bank-based system such as Germany cannot be drawn a priori, but require empirical analyses. ${ }^{56}$

Regardless of the country, the amount of detail in each study depends on the level of data aggregation. Studies using aggregate data typically provide imperfect views as to the role of credit market imperfections as determinant of bank lending effects. The reason is that aggregate data do not contain much information on the differential behavior of agents and on the degree of credit market imperfections. Disaggregated analyses are more informative because they distinguish banks by market orientation in order to control for differences in the behavior of banks and in the degree of credit market imperfections. This involves the categorization of banks by banking group (i.e., market segment) and/or group of bank borrower (e.g., firms and households).

Microeconomic studies provide most details on the credit channel effects through bank lending. They do not stop at identifying the credit channel effects, but also test for cross-bank differences in the reaction of bank lending to monetary policy changes. The distributional bank lending effects of monetary policy are explained with bank characteristics related to bank financial health, i.e., bank asset size, bank liquidity, and/or bank capitalization. Bank size approximates the degree of information asymmetries, which is deemed to be more pronounced for small than for large banks (see Kashyap and Stein, 1995, 2000). Bank liquidity determines the ability of banks to cushion the bank lending effects of restrictive monetary policy shocks (see Kashyap and Stein, 2000). Liquid banks are argued to be better able to insulate their loan portfolio since they can draw on their buffer stock of assets. Bank capi-

\footnotetext{
${ }^{55}$ In order to be operative, the credit channel through bank lending requires monetary policy to affect the availability of insured bank deposits. Motivated by this relationship, some credit channel studies investigate the monetary policy response of insured bank deposits (cf. Gambacorta, 2003; Hernando and Martinez-Pagés, 2003). In order to focus the present analysis, we only discuss the empirical literature with respect to the monetary policy response of bank lending rather than bank deposits.

${ }^{56}$ Chapter 5 also takes Germany as unit of analysis and discusses the role of banks in monetary policy transmission.
} 
talization reflects the ability of banks to obtain non-reservable funds of finance in the wake of monetary policy contractions (see Kishan and Opiela, 2000) so as to maintain bank credit supply. Lending by well-capitalized banks is contemplated to be less responsive to monetary policy shocks since these banks are better able to cushion the monetary policy effect on the lending portfolio.

The differences in the amount of detail contained in aggregate, disaggregated, and microeconomic data affect the conclusions regarding the bank lending effects of monetary policy. Considering macroeconomic studies, they document bank lending effects of monetary policy for France, Germany, and Italy, but not for the Netherlands, Belgium, and the United Kingdom. The evidence for a particular country compares well across macroeconomic studies and is therefore robust to cross-study differences in sample periods and data frequency. Empirical research with disaggregated data suggests that the evidence from aggregate studies is influenced by the structure of banking sectors and by the distribution of bank credit among types of bank borrowers. This is particularly evident for Germany and the United Kingdom.

For Germany, disaggregated studies illustrate that credit channel effects through bank lending crucially depend on the distinction of banking groups and borrower groups. Kakes and Sturm (2002) report bank lending effects for the cooperative banking group and Küppers (2001) documents bank lending effects for the banking group with big commercial banks and for aggregate bank lending to the corporate sector. The differential response of lending between banking groups or borrower types suggests that the effects associated with the group of cooperative and big commercial banks and the corporate sector drive the evidence from aggregate data. For the United Kingdom, Dale and Haldane (1995) compile evidence according to which empirical results from aggregate data appear to be influenced by the relative importance of households and firms as bank borrowers: credit channel effects exist for lending to the household sector, but not for lending to the corporate sector. In fact, lending to the corporate sector rises in the immediate periods following a monetary contraction. In view of this finding, the absence of bank lending effects in aggregate studies may reflect the greater importance of the corporate to the household sector in bank lending over the sampled period. ${ }^{57}$

The empirical results of microeconomic studies lend strong support to monetary policy transmission through bank lending in estimations with quarterly and monthly data and weaker support in studies with annual data. One possible reason for the sensitivity of the results to the choice of data frequency is the failure of annual data to capture monetary policy changes and changes in bank lending. The failure manifests itself in the smooth time-series

\footnotetext{
${ }^{57}$ The sample period was 1974-1992. Lending to the corporate sector accounted for a larger share of GDP than lending to the household sector during the period 1975-1983. The opposite relationship emerged as of 1983. While the differential between corporate and household lending was very pronounced in the period before 1983, it was quite small thereafter (cf. Arestis and Biefang-Frisancho Mariscal, 1995). These patterns suggest that the empirical results in Dale and Haldane (1995) are driven by the bank lending behavior before 1983.
} 
behavior of low frequency data, which is caused by limited sample variability. Furthermore, the microeconomic evidence points to the role of bank asset size, liquidity, and capitalization as determinants of the distributional effects of monetary policy. Endorsing the predictions of the credit channel theory, the monetary policy response of bank lending is generally more pronounced for small, less liquid, and less capitalized banks. ${ }^{58}$ Compared with bank asset size and bank capitalization, bank liquidity appears to be the more important determinant of cross-bank differences in the monetary policy response of bank lending in panel investigations.

Microeconomic studies do not only emphasize cross-bank heterogeneities in asset size, liquidity, or capitalization as explanatory variables of monetary policy effectiveness. Instead, they also show that evidence from single bank characteristics could be misleading if any bank characteristic is dominated by or interdependent with alternative bank characteristics. For example, empirical research attributes insignificant bank asset size effects in monetary policy transmission to the interdependence of bank asset size with either bank liquidity (e.g., Kashyap and Stein, 2000, for the US; Loupias, Savignac, and Sevestre, 2003, for France) or bank capitalization (e.g., Kishan and Opiela, 2000, for the US; Loupias, Savignac, and Sevestre, 2003, for France): small banks are on average more liquid and better capitalized than large banks. Bank liquidity and capitalization are presumed to offset the effects associated with bank size.

Besides the correlation of bank liquidity and capitalization with bank asset size, there are alternative factors that contribute to the statistical insignificance of bank asset size as indicator of the distributional effects of monetary policy and the degree of information asymmetry. Angeloni et al. (2003) and Ehrmann et al. (2003) stress institutional and structural properties of banking markets as explanatory factors. For instance, deposit insurance guarantees and government regulation of bank credit supply reduce the risk of holding deposits at small banks since these measures support banks and reduce the probability of bank failure. The role of bank asset size as indicator variable is also diminished by interbank markets and bank networks. These structural characteristics facilitate the internal liquidity management of banks in need of liquidity by providing easy access to funds of banks with excess liquidity. In this function, bank networks reduce the importance of bank asset size as indicator variable of information asymmetries and enable small banks to avoid discontinuous and accelerated shifts in bank lending. Worms (2003) and Ehrmann and Worms (2004) report empirical evidence which supports the importance of interbank relationships as determinant of small bank lending in Germany. Motivated by these findings, the discussion of the determinants of industry bank lending in chapter 5 also controls for the potential importance of interbank lending as factor that may mitigate the bank asset size effects of monetary policy.

The extent to which small banks are committed to maintaining lending relationships with firms

\footnotetext{
${ }^{58}$ As to bank asset size, Altunbaș, Fazylov, and Molyneux (2002) and Ehrmann et al. (2003) find different relationships. The corresponding results emphasize the greater sensitivity of lending by medium-sized banks for EMU member countries and large-sized banks for Spain.
} 
and households also affects the bank size effects of monetary policy. Relationship banking is an important determinant of monetary policy effectiveness because it lowers financing constraints by reducing informational problems in credit markets. That is, close bank-customer ties induce banks not to constrain the access to bank finance in the wake of a monetary contraction. Because relationship banking tends to be particular to small banks, lending by small banks may not be more responsive to monetary policy shocks than lending by large banks. ${ }^{59}$

Summarizing, the bank lending effects of monetary policy are influenced by the structure of the banking system, the distribution of banks, and the distribution of bank credit among types of bank borrowers. Cross-country differences in the relative importance of these factors account for cross-country asymmetries in the strength of the credit channel and in the distributional effects of monetary policy. Unfortunately, cross-country comparisons are hardly feasible because of cross-study differences in the results for any individual country. A good case in point is the evidence for France, Germany, and Spain. For these countries, conclusions regarding the distributional effects of monetary policy through bank lending are sensitive to the level of data aggregation, data frequency, empirical methodology, and the choice of bank characteristic. In order to resolve some of the ambiguity in the empirical results, future research is required to provide additional insights as to the factors which determine bank lending. To this end, chapter 5 explicitly addresses the industry composition of bank credit portfolios as possible determinant of the distributional bank lending effects of monetary policy.

\subsubsection{Asymmetries in Monetary Policy Effectiveness}

Empirical research on cyclical asymmetries in monetary policy effectiveness is rather scarce. Although the number of studies is comparatively small, the empirical evidence lends strong support to cyclical asymmetries in monetary policy transmission through interest rate and credit channel effects. In line with theoretical predictions, interest rate and credit channel effects are particularly strong or only arise in periods of economic downturns. ${ }^{60}$ This, however, suggests that decisions regarding the direction and magnitude of monetary policy changes should control for the business cycle position.

Common to most studies on cyclical asymmetries in monetary policy effectiveness is that

\footnotetext{
${ }^{59}$ See, among others, the references in Gambacorta (2003) on the importance of bank-customer relationships for bank lending.

${ }^{60}$ Evidence on the cyclical asymmetries of monetary policy through (i) the interest rate channel is provided by Atanasova (2003) and Peersman and Smets (2005), (ii) the broad credit channel is documented by Gertler and Gilchrist (1994), Bernanke, Gertler, and Gilchrist (1996), Balke (2000), and Atanasova (2003), and (iii) the narrow credit channel is reported by Kaufmann (2003). Kakes (1998, 2000b), Dolado and Dolores (2001), and Garcia and Schaller (2002) also lend support to cyclical asymmetries of monetary policy effectiveness, with the output effects of monetary policy shocks being stronger in economic downturns. Because these studies do not distinguish effects that are due to the interest rate or credit channel, they are not further considered.
} 
they do not allow for industry effects of monetary policy. ${ }^{61}$ Chapter 6 is motivated by the lack of evidence on the role of industries as determinant of asymmetries in monetary policy effectiveness. The analysis does not only focus on business cycle asymmetries, but also distinguishes the industry effects of monetary policy expansions and contractions.

\subsubsection{The Relative Strength of the Interest Rate and Credit Channel}

The survey of the existing literature points to the significance of credit channel effects and hence to the importance of credit market imperfections as determinant of monetary policy effectiveness. In view of this finding, the assumption of perfect capital markets as imposed by the interest rate channel appears to be overly restrictive. This also suggests that the interest rate channel is unlikely to fully explain the real effects of monetary policy. Assuming that this is true, the question is: are interest rate or credit channel effects the stronger source of monetary policy effectiveness? Unfortunately, there are only few studies which address this question.

Macroeconomic studies indirectly test for the possible dominance of the interest rate channel relative to the credit channel. They ask whether the interest rate response of aggregate output is explained by the interest rate response of interest sensitive spending components of aggregate output (e.g., aggregate investment, durable consumption, inventory investment). Angeloni et al. (2003) summarize the evidence for countries in Europe. Although the conclusions vary with the choice of country, it appears that the interest rate (or cost-of-capital) channel frequently cannot fully explain the empirical response of economic activity to monetary policy shocks. This finding builds on the observation that the monetary policy response of output exceeds that of the interest sensitive spending components.

Disaggregated industry analyses cannot compare the monetary policy response of industry output with that of industry spending components to determine the relative strength of the interest rate channel. This is because of data availability constraints that preclude the decomposition of industry output into its spending components for a sufficient period of time. If at all, industry spending components are only used to explain the monetary policy response of industry output, mainly within the framework of cross-section estimations. Although an imperfect measure, the evidence finds variables associated with the interest rate channel to be as important in explaining the monetary policy response of industry output as variables associated with the credit channel. ${ }^{62}$

Most detail is contained in microeconomic studies. Because many of them simultaneously identify the interest rate and credit channel effects of monetary policy, they are natural means to assess the relative importance of the interest rate and credit channel in monetary policy

\footnotetext{
${ }^{61}$ The exception is the industry study by Peersman and Smets (2005). Chapter 6 summarizes the corresponding methodology and empirical findings.

${ }^{62}$ See the evidence in Dedola and Lippi (2005) and Peersman and Smets (2005).
} 
transmission. The empirical results are mixed. Butzen, Fuss, and Vermeulen (2003) for Belgium, Valderrama (2003) for Austria, and Siegfried (2000) for Germany report evidence according to which the interest rate effects of monetary policy are weaker than the credit channel effects. ${ }^{63}$ Opposite conclusions are drawn by Kalckreuth (2003) for Germany and Gaiotti and Generale (2003) for Italy. The results regarding the role of the interest rate and credit channel as amplification and propagation mechanism hence appear to be sensitive to the choice of country. In view of this finding, country effects related to financial and institutional structures are thus potentially important determinants of monetary policy effectiveness.

\subsection{Conclusion}

There is a considerable number of studies which stress the transmission of monetary policy shocks through an interest rate and/or credit channel. This chapter has provided an overview of the theoretical and empirical literature on each monetary transmission channel. Even though the review is not exhaustive despite its wide coverage, some general conclusions can be drawn. Existing research lends support to the propagation and amplification of monetary policy shocks through an interest rate channel, but ambiguous support to the operation of a credit channel. The conclusions regarding the credit channel effects of monetary policy tend to be sensitive to the choice of estimation methodology, the choice of credit channel variable, and the level of data aggregation. When significant, the existing empirical studies emphasize cross-country heterogeneities (i) in economic structures related to industry composition and (ii) in financial structures related to the distribution of bank and non-bank financial institutions as source of cross-country heterogeneities in the strength of the interest rate and credit channel, respectively. Here, financial structures approximate the extent to which credit market imperfections and information asymmetries introduce uncertainty as to the timing and the magnitude of the real effects of monetary policy.

The remainder of this section summarizes how the subsequent chapters in this thesis are related to the existing empirical and theoretical literature on monetary policy transmission. Chapter 3 is motivated by the ambiguous results regarding the existence of significant firm size effects of monetary policy for the United States and Europe (cf. section 2.4.2). The aim is to identify conditions for which small firms do not respond more to monetary policy shocks than large firms. To this end, a non-linear investment model is specified that links the interest rate response of small and large firms to the degree of investment irreversibility and to the size of monetary policy shocks.

Section 2.3.2 has argued that a number of methodological problems influence the evidence on the interest rate and credit channel. These primarily relate to problems with respect to

\footnotetext{
${ }^{63}$ Tests of the relative strength of transmission channels tend to determine the response of the cash flowcapital ratio and the user cost of capital to changes in the official interest rate. The corresponding evidence is then linked to the response of firm sales to changes in the user cost and cash flow-capital ratio.
} 
the unique identification of the individual transmission channels. The review of empirical studies in section 2.4.1 and 2.4.2 has shown that some studies on the interest rate and credit channel address the identification problem by emphasizing the industry composition of countries/regions as an important determinant of the strength of monetary transmission channels and monetary policy effectiveness. The corresponding studies stress cross-industry differences in economic performance and in structural characteristics such as firm size distribution as possible source of differences in the real effects of monetary policy. Unfortunately, most studies fail to control for the potential interdependence between industry and firm size. Chapter 4 is motivated by this observation and asks whether the assumed independence of firm size and industry affects conclusions regarding the interest rate and credit channel effects of monetary policy.

It became evident from section 2.4.3 that there are comparatively few studies which allow for differences in bank credit demand between borrower groups. In particular, there does not appear to be a single study that (i) controls for cross-industry differences in bank credit demand and (ii) assesses the sensitivity of industry bank lending to changes in industry bank credit demand. Chapter 5 broadens the scope for industry effects of bank lending. Using microeconomic data on German bank lending, the study asks whether cross-industry heterogeneities in cyclical and structural characteristics affect the industry-specific demand for bank credit. Furthermore, the analysis investigates whether industry-specific bank lending growth is predominantly determined by changes in industry bank credit demand or in monetary policy. The answer to this question is relevant from an economic and policy perspective since it indicates whether the effectiveness of monetary policy depends on the industry structure of bank credit portfolios.

Finally, section 2.4.4 illustrates that the interest rate and credit channel effects of monetary policy are particularly pronounced or only arise in periods of economic downturns. Most studies on the cyclical asymmetries in the effects of monetary policy do not ask whether the degree of asymmetry (i) depends on industry structure and (ii) differs between monetary policy expansions and contractions. The analysis in chapter 6 extends the existing literature on cyclical effects along two lines. Firstly, it uses industry data and emphasizes the role of industries as propagation mechanism of monetary policy changes. Secondly, the study determines whether monetary expansions and contractions have asymmetric industry output growth effects and whether the degree of asymmetry varies over the business cycle or depends on the size of monetary policy changes. 


\section{Annex 2A Overview of Empirical Studies}

Table 2A.1 to Table 2A.3 summarize the main findings of the literature on the interest rate, broad, and narrow credit channel, respectively. ${ }^{64}$ Each table is divided into three panels that control for differences in the level of data aggregation. For all tables, panel A reports studies which use performance indicators of the aggregate economy (e.g., aggregate output and price). For Table 2A.1 and 2A.2, Panel B summarizes those studies that adopt an industry focus and employ industry-level data on economic activity in order to assess the importance of industry mix as determinant of monetary policy effectiveness. Panel $\mathrm{C}$ discusses the microeconomic evidence from firm-level data. For Table 2A.3, panel B reports disaggregated studies which distinguish bank credit by banking group, borrower group, and/or the maturity of loans. Panel C presents the evidence from microeconomic bank-level data. In Table 2A.3, credit type refers to aggregate, short-, and/or long-term bank credit and borrower group denotes lending to the household, (non-financial) corporate, or mortgage sector.

Considering the structure of Table 2A.1, column 2 identifies the country and/or region for which the analysis is carried out. Column 3 provides information on the sample period and frequency of the data and column 4 describes the industry dimension of the data. Column 5 reports the empirical method used to identify the interest rate effects of monetary policy. The last two columns summarize the studies' conclusions regarding monetary policy transmission through interest rate effects (column 6) and industry effects (column 7). Although a distinction is made between the interest rate and industry effects, we do not assume that these effects are independent or mutually exclusive: both effects are inherent to the money view. We only separate the effects for illustrative purposes in order to identify those industries for which the interest rate effects are particularly strong.

Columns 1 to 5 in Table 2A.2 are defined as in Table 2A.1. Column 6 reports the sample splitting criterion used to identify the credit channel effects of monetary policy and column 7 documents the studies' conclusions regarding the operation of a credit channel through balance sheet effects. In contrast to Table 2A.1, we do not define a column that contains conclusions as to the industry effects of monetary policy. This is because only few industry studies explore the extent to which cross-industry differences in the interest rate response of industry output can be explained with credit channel relationships. ${ }^{65}$

Columns 1 to 3 in Table 2A.3 are defined as in the previous tables. Column 4 describes the empirical estimation methodology and column 5 documents whether empirical research supports the existence of a credit channel through bank lending. The remaining columns

\footnotetext{
${ }^{64}$ Many studies on the interest rate channel also investigate the broad credit view. Because empirical estimations of the interest rate and credit channel occasionally rely on different empirical models and different sample periods, we summarize the evidence for both transmission channels in separate tables.

${ }^{65}$ See the evidence in Butzen, Fuss, and Vermeulen (2003), Chatelain and Tiomo (2003), Dedola and Lippi (2005), and Peersman and Smets (2005). The corresponding results confirm the evidence for the interest rate channel in that credit channel effects are particular to cyclical industries.
} 
illustrate whether bank characteristics related to profitability and the degree of information asymmetries (i.e., bank financial health) help to explain the bank lending effects of monetary policy. We distinguish the effects associated with bank asset size (column 6), bank liquidity (column 7), and/or bank capitalization (column 8).

The summary of the evidence on monetary transmission channels in Table $2 \mathrm{~A} .1$ to Table $2 \mathrm{~A} .3$ relies on the abbreviations listed below.

\section{Industry Mnemonics}

Ind: Industry/industries; Mfg: Manufacturing; Ser: Services; Con: Construction; Agr: Agriculture; Mng: Mining or extractive industry; Equip: Equipment; Dtb: Distribution; Utl: Utilities; Comm: (Tele-)communication; Cl: Capital-intensive industry; DGP: Durable goods producing industry.

\section{Abbreviations of Empirical Methods}

SEM: Single equation model; MSR: Markov-switching regime; SVAR: Structural vector autoregressive model; OLS: Ordinary least squares estimator; FE: Fixed effects estimator; RE: Random effects estimator; GMM: Generalized methods of moments estimator; IV: Instrumental variable estimator; FPOLS: Fixed effects pooled ordinary least squares estimator; ML: Maximum-likelihood estimator; WLS: Weighted least squares estimator; AB91: Arellano and Bond (1991); AB95: Arellano and Bover (1995); AH82: Anderson and Hsiao (1982); HNR88: Holtz-Eakin, Newey, and Rosen (1988); RC: Rank correlation.

\section{Abbreviations of Bank Variables}

Size: Bank asset size; Liq: Bank liquidity; Cap: Bank capitalization; Cap'd: Capitalized; BG: Banking group; Bks: Banks.

4. Other Abbreviations

Ctr, Ctr's: Country, countries; A, Q, M, D: Annual, quarterly, monthly, daily data; MP: Monetary policy; Downt's: Downturns; w/: with; w/o: without. 


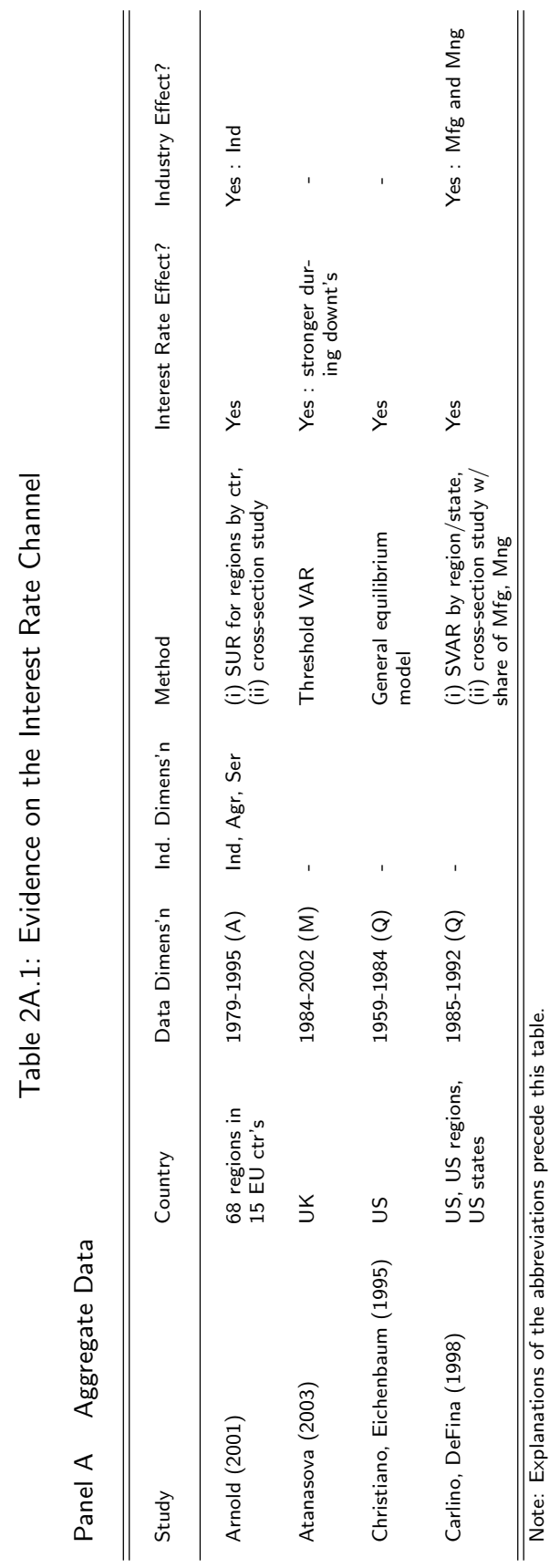




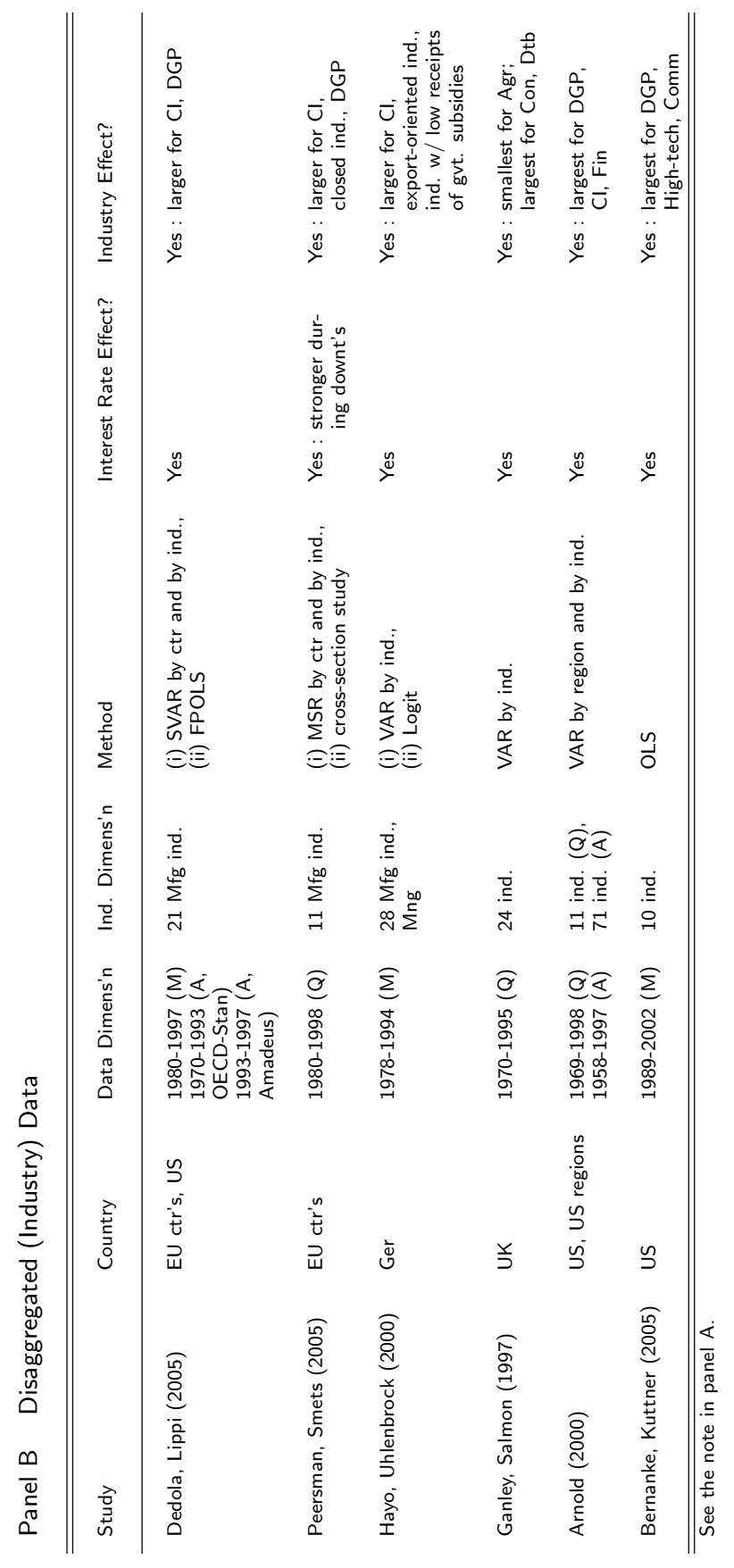




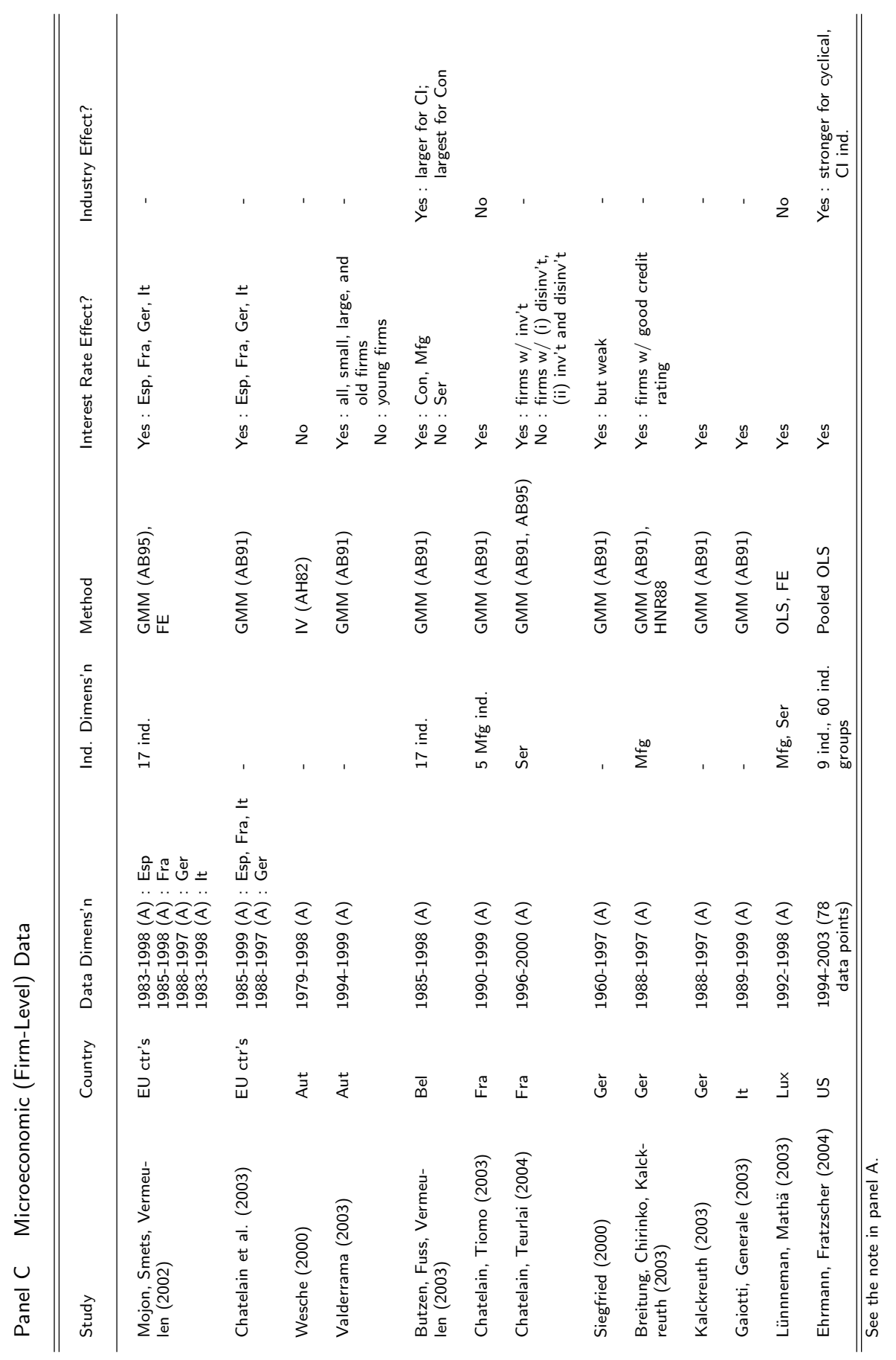




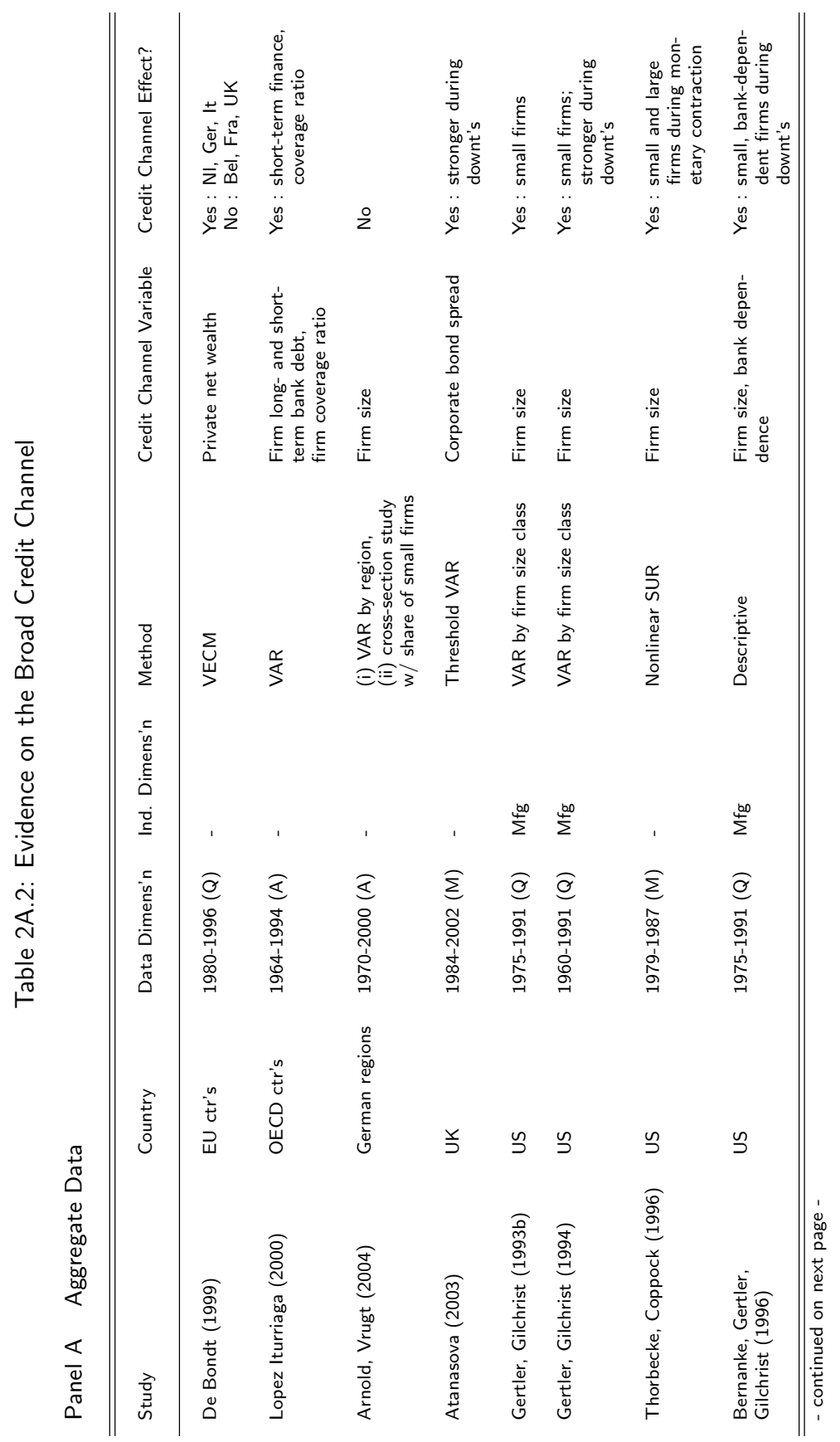




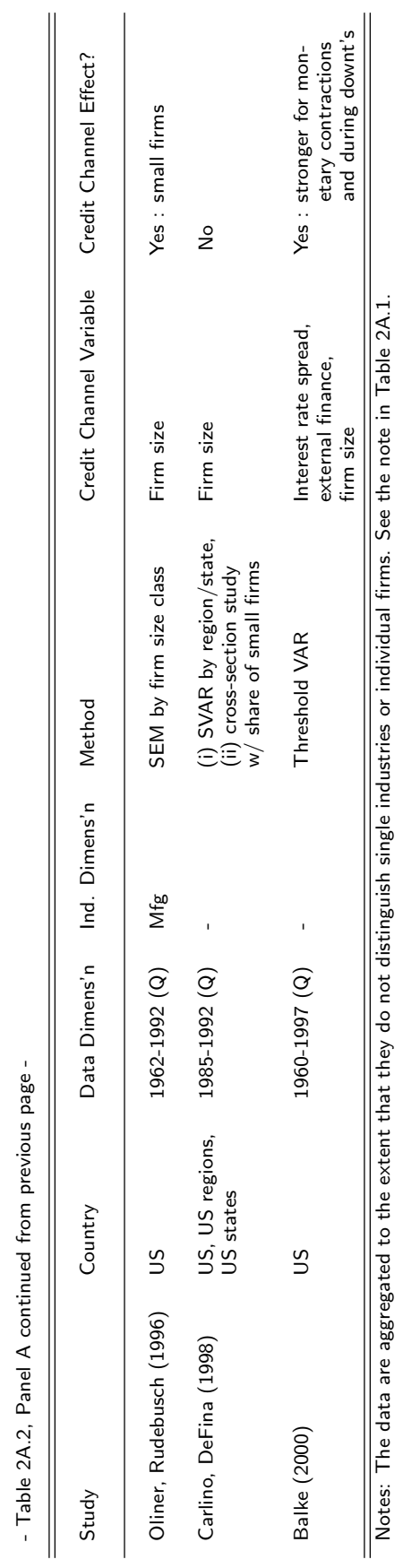




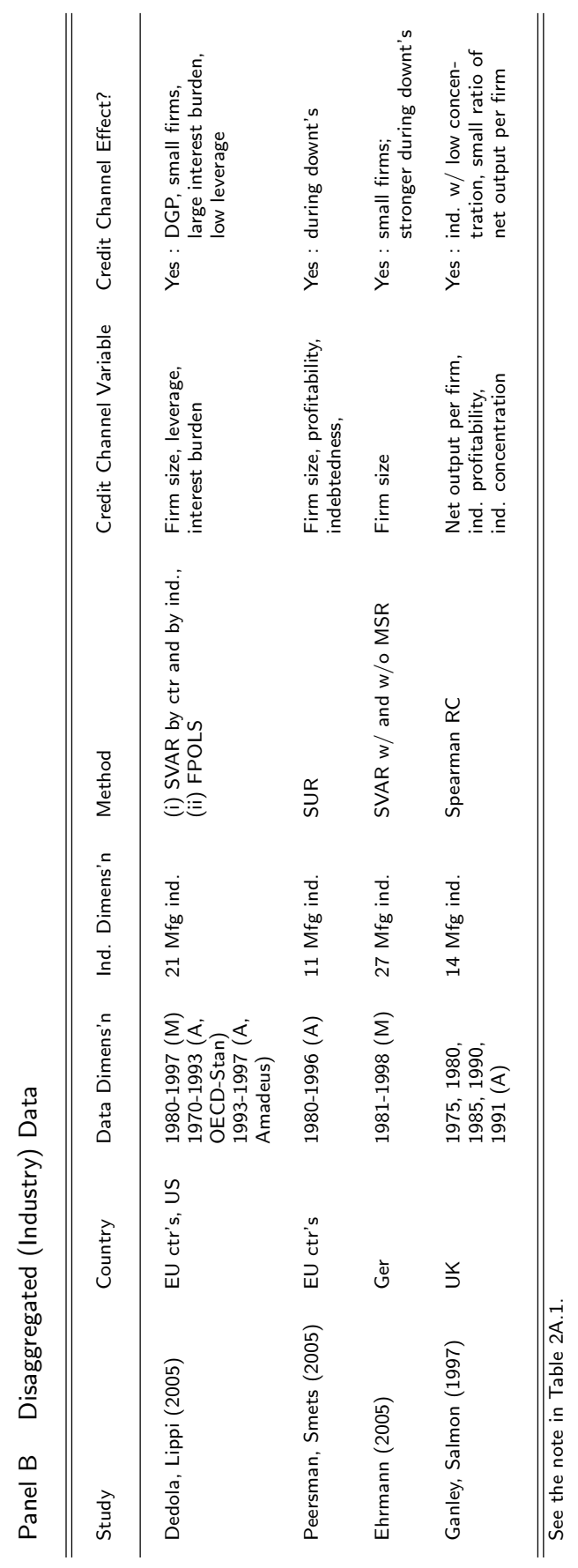




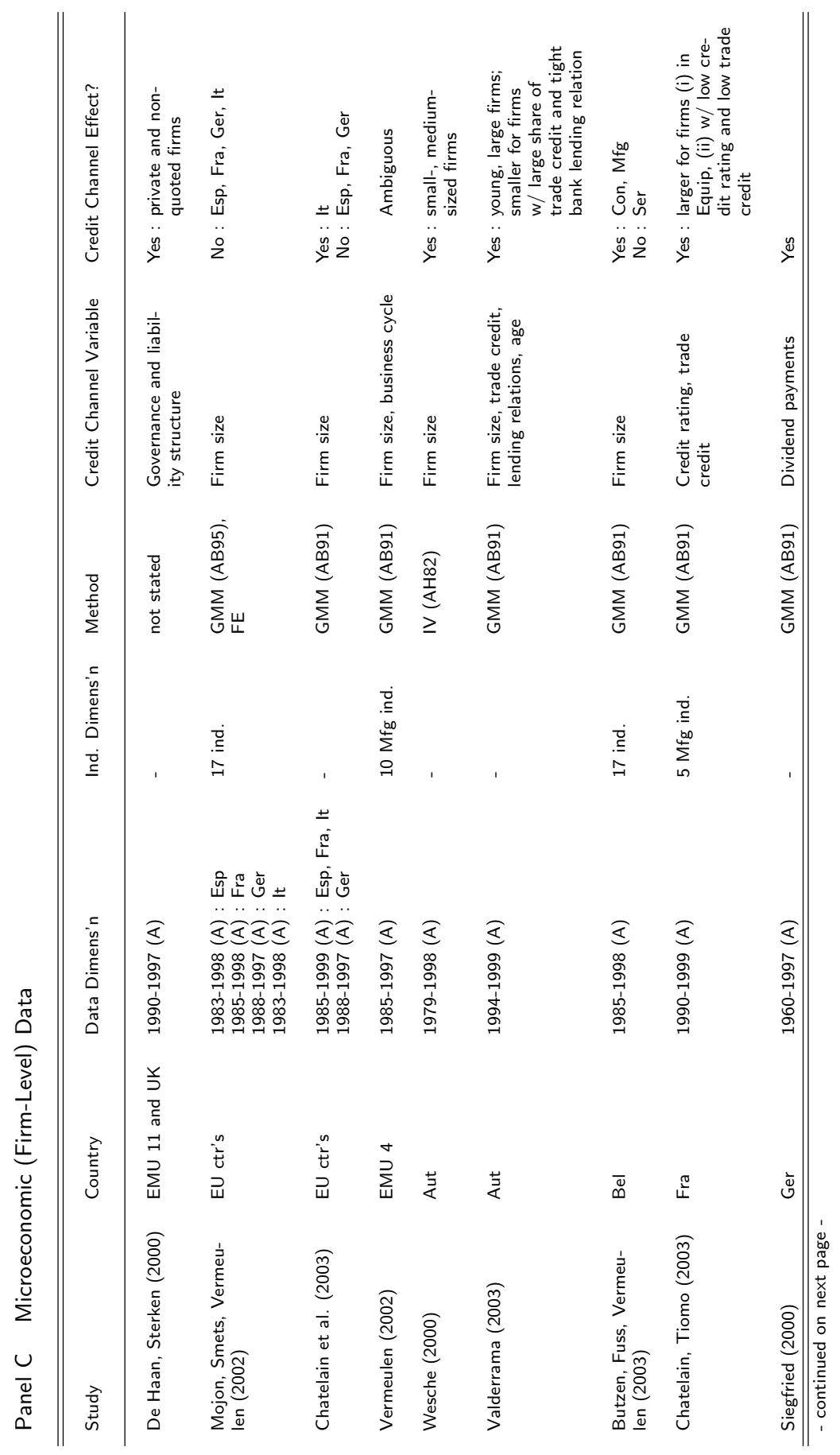




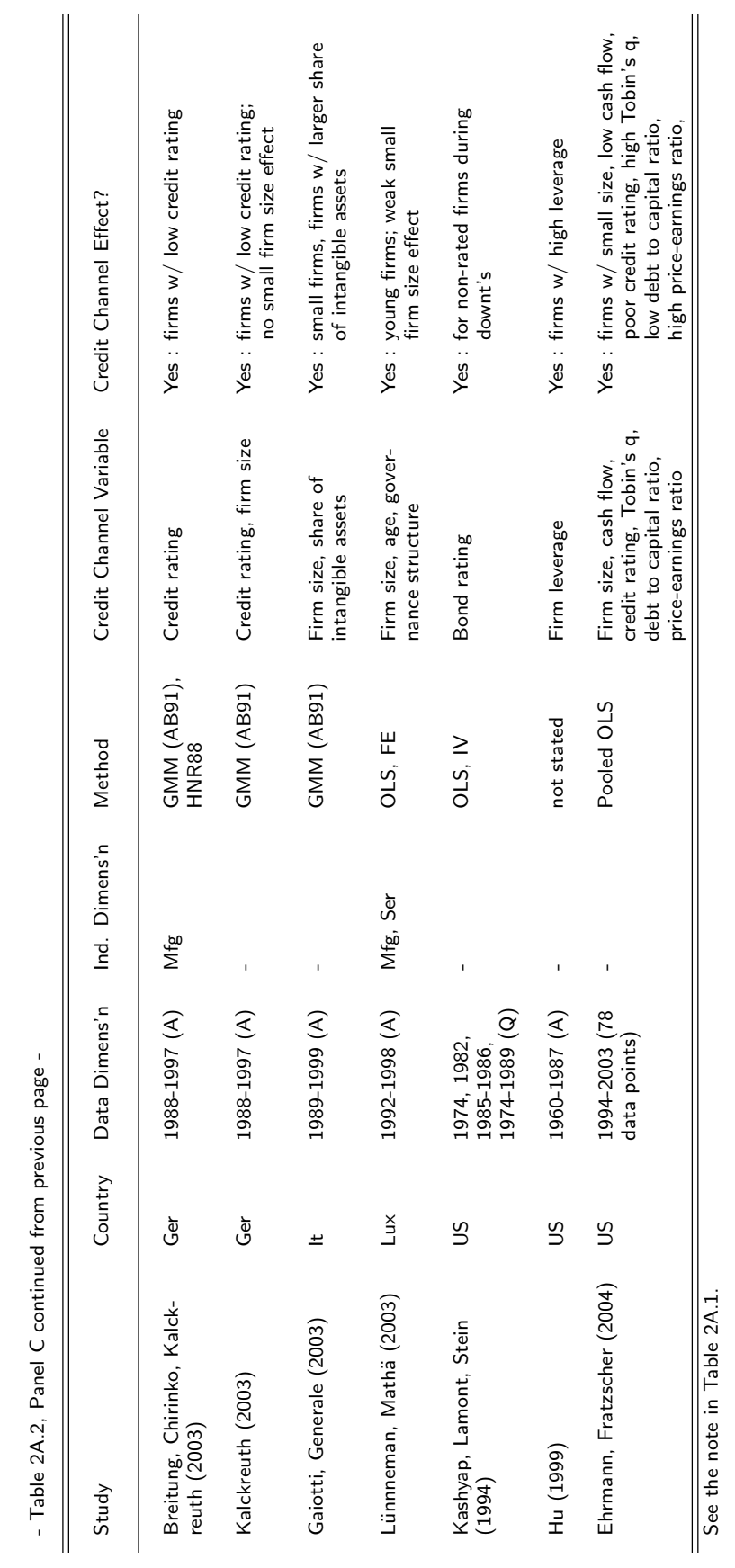




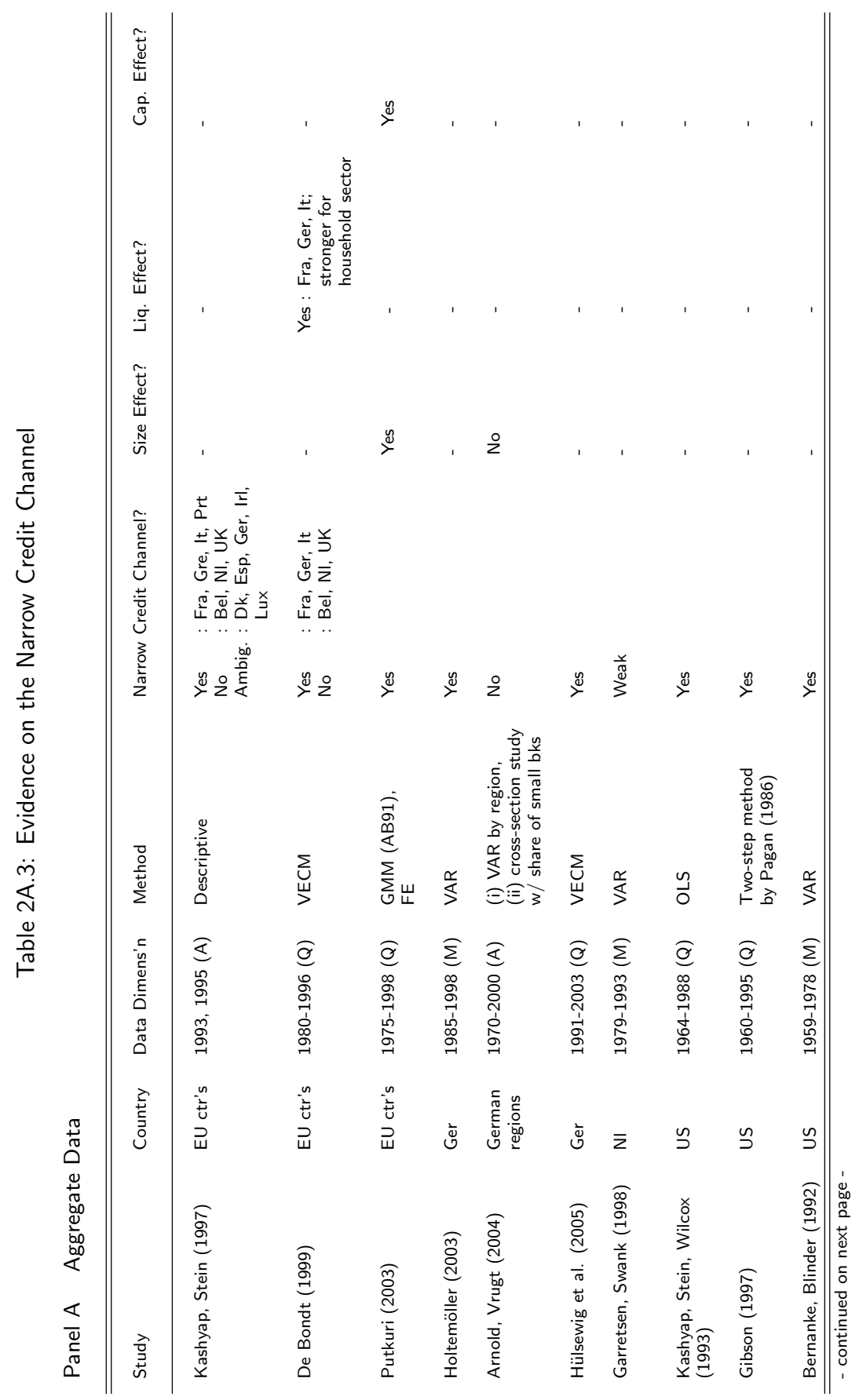




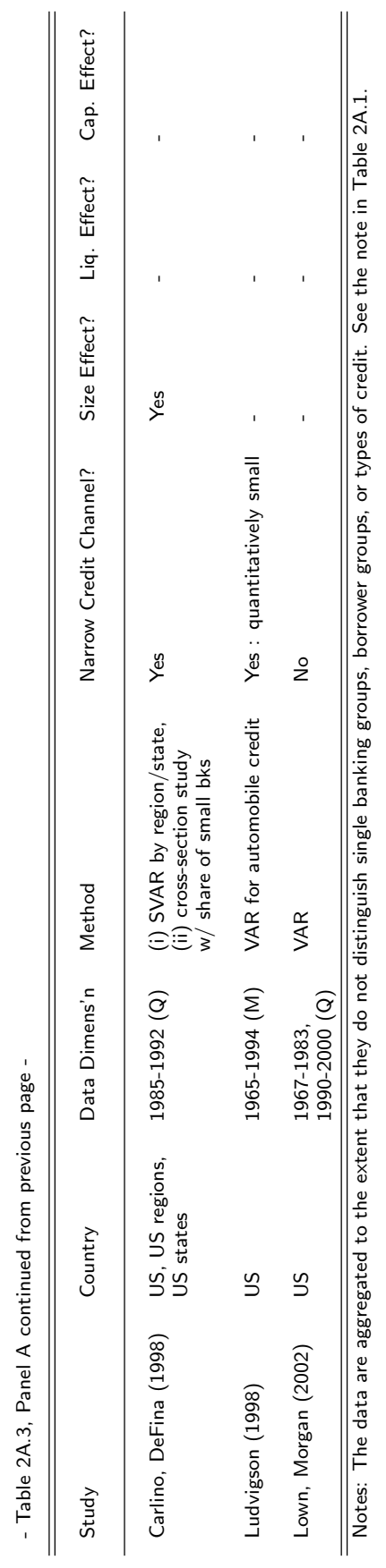




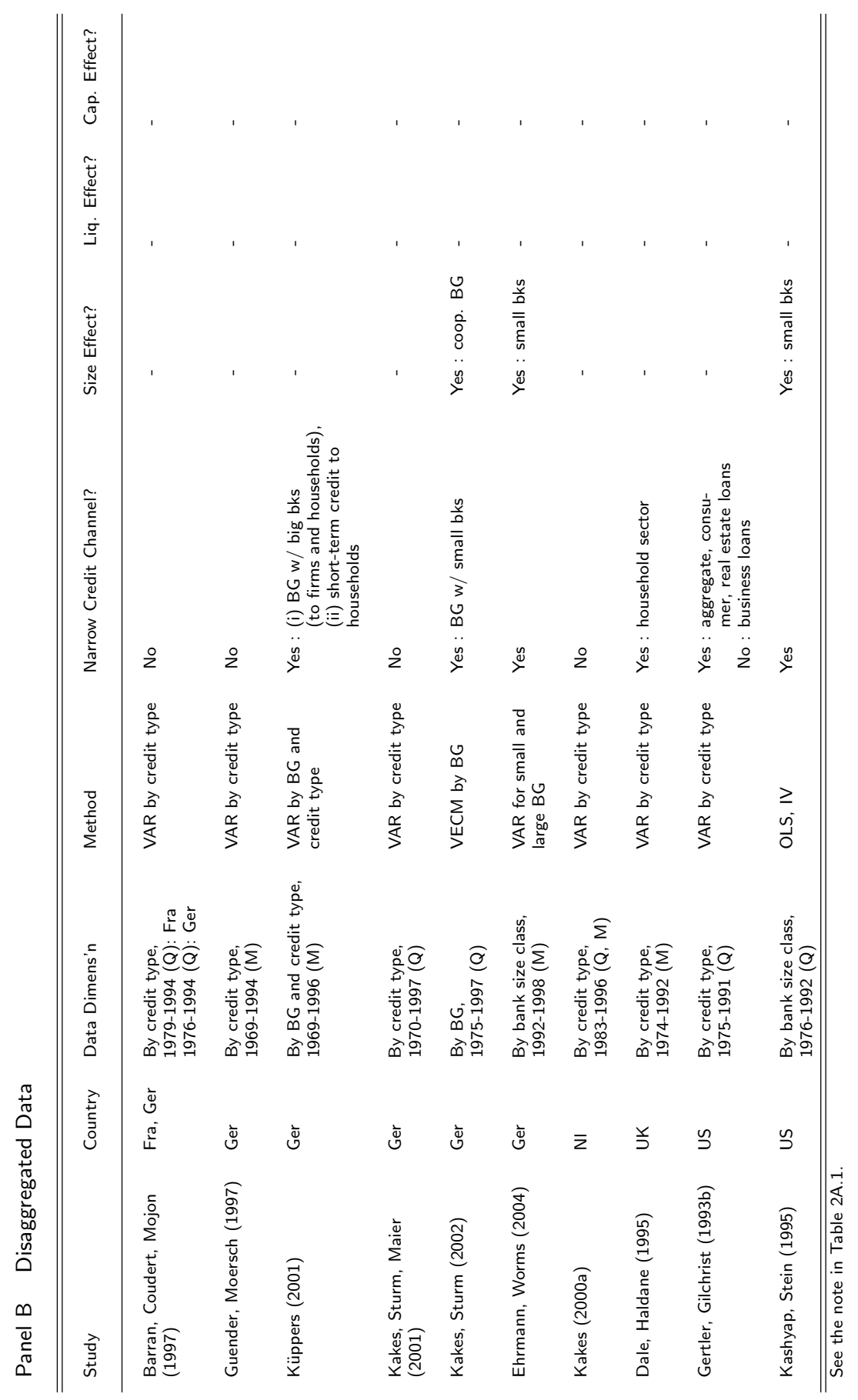




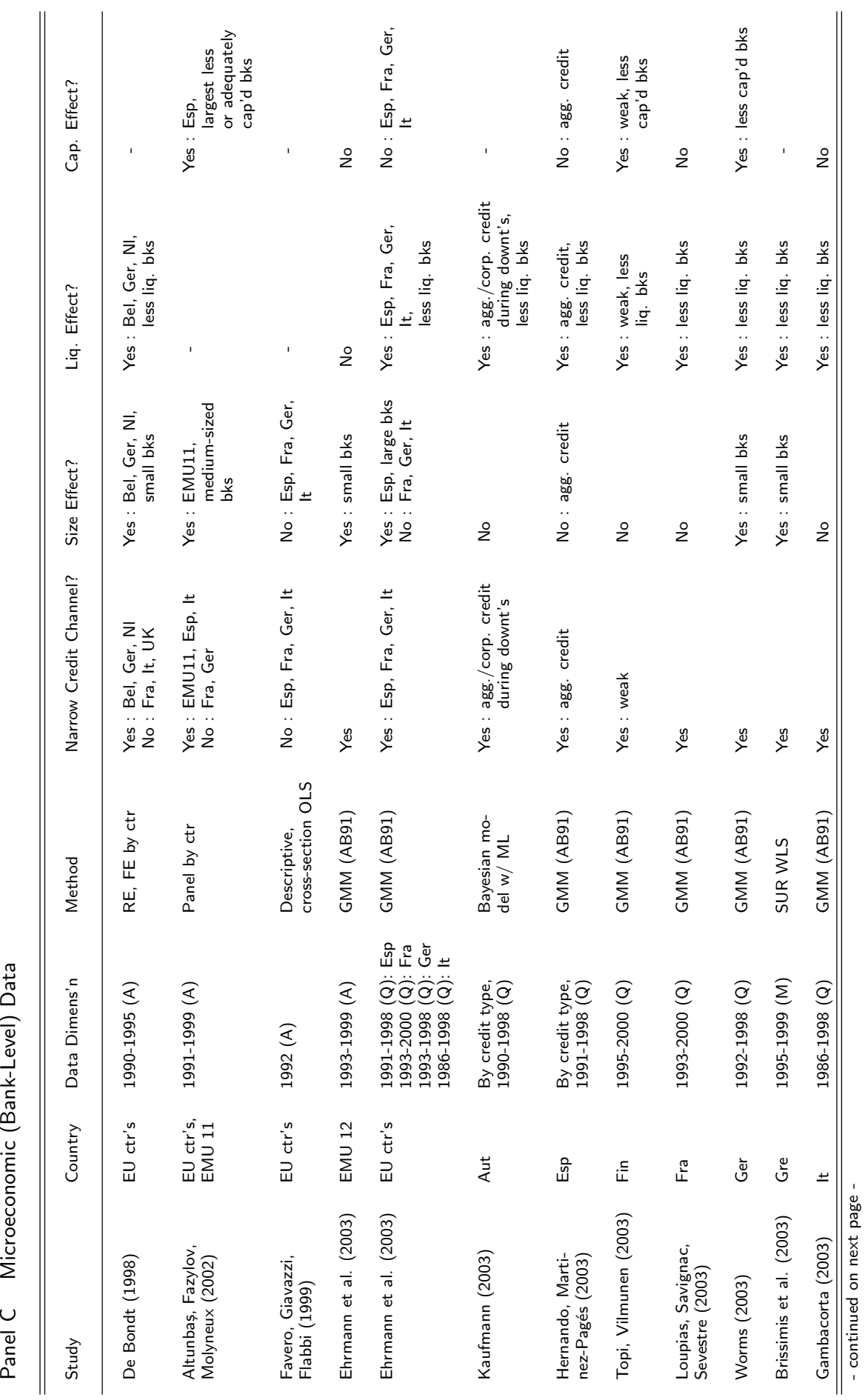




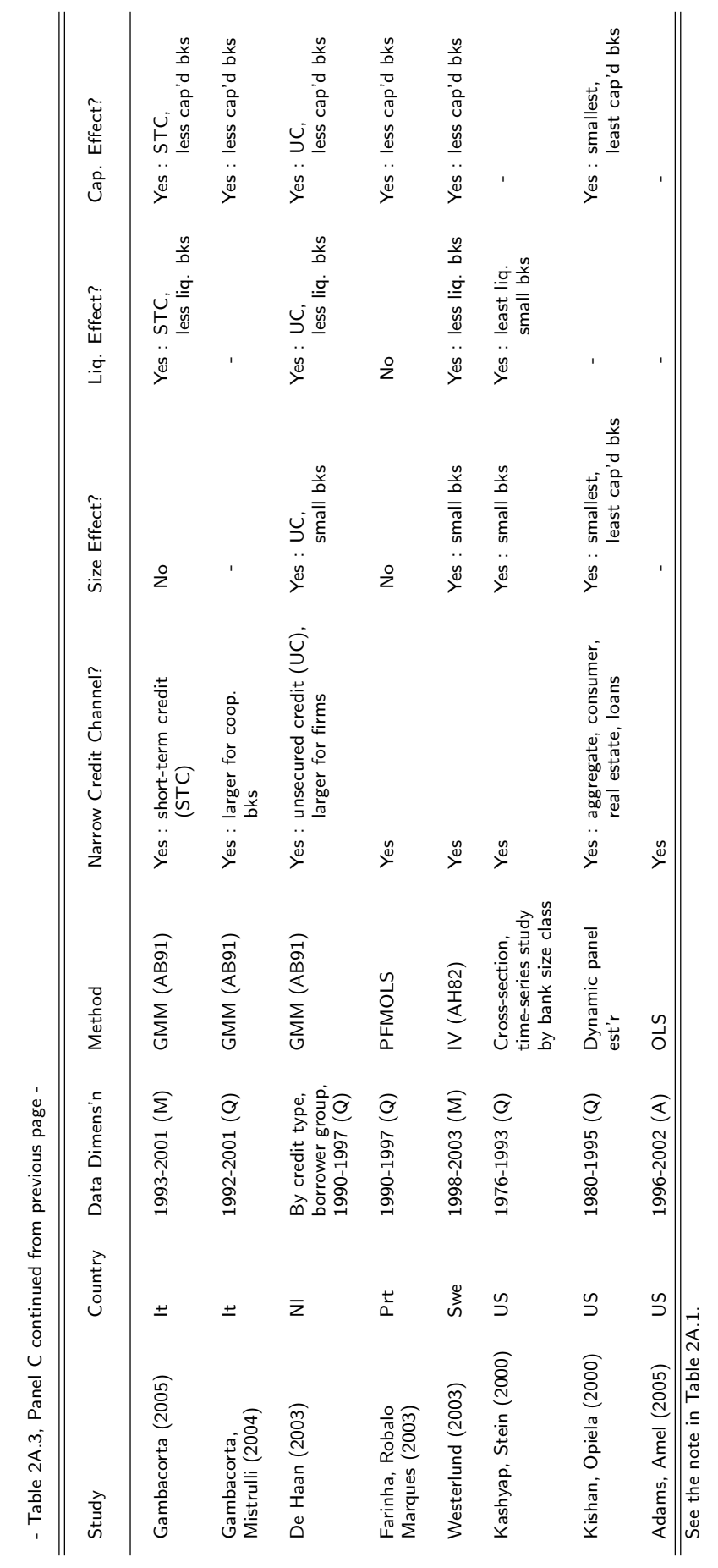




\section{Firm Size and Monetary Policy Transmission:}

\section{A Theoretical Model on the Role of Capital Investment Expenditures}

\subsection{Introduction}

The review in chapter 2 shows that existing theoretical and empirical work links the effectiveness of monetary policy actions to the size distribution of firms. ${ }^{1}$ Common to these studies is that they view firm size as a proxy variable of the credit channel. According to the credit channel theory, credit market imperfections and financing constraints arising from information asymmetries amplify the effects of monetary policy. Because asymmetric information problems are viewed to be more severe for small than for large firms, small firms are usually considered to be more affected by monetary policy actions. Monetary policy effectiveness is thus assumed to increase with the proportion of small firms in an economy. However, empirical evidence on the firm size effects of monetary policy provides ambiguous support for this relationship. Gertler and Gilchrist (1994), Oliner and Rudebusch (1996), Ganley and Salmon (1997), De Bondt (2000), Dedola and Lippi (2000), and Ehrmann (2005), among others, find small firms to be relatively more sensitive to interest rate shocks than large firms. Evidence against firm size effects is reported by, for example, Carlino and DeFina (1998, 1999a, 1999b, 2000), Mojon, Smets, and Vermeulen (2002), and Arnold and Vrugt (2004). The ambiguity of the empirical results suggests that firm size effects of monetary policy are not exclusively driven by information asymmetries and credit constraints. Motivated by this finding, the present analysis does not attribute possible firm size effects of monetary policy to credit market imperfections. Instead, we stress differences in the investment behavior of small and large firms as an alternative channel through which firm size may transmit monetary policy actions. At the core of this 'investment' channel are size-related differences in the degree of investment irreversibility. ${ }^{2}$

\footnotetext{
${ }^{1}$ See section 2.4 .2 and Table $2 \mathrm{~A} .2$ in chapter 2 for a summary of the firm size effects of monetary policy.

${ }^{2}$ Note, there is theoretical and empirical research on firm investment patterns for explicit adjustment cost functions or credit constraints (see, e.g., Bond and Meghir, 1994; Chatelain and Teurlai, 2004; Whited, 1992). However, the underlying evidence does not distinguish investment by firm size. Moreover, there is a large body of empirical evidence on the dynamic relations that describe the investment behavior of small
} 
Investment irreversibility not only helps to explain the response of small and large firms to monetary policy actions, but also the size distribution of firms. Industries typically host a combination of small- and large-sized firms, with the size distribution being skewed within an industry and being different across industries. In order to explain the skewness in firm size distribution, we need to stress an industry structure that allows for the coexistence of small and large firms. Following Boone and Van Witteloostuijn (1999) and Boone, Bröcheler, and Carroll (2000), industries can assume a dual, concentrated, fragmented, or uniform market structure, with the differences pertaining to the degree of market concentration and density. ${ }^{3}$ Table 3.1 summarizes the properties of the different market structures in terms of market concentration and density.

Table 3.1: Classification of Market Structures

\begin{tabular}{lll}
\hline \hline & High Density & Low Density \\
\hline $\begin{array}{ll}\text { High Concentration } \\
\text { Low Concentration }\end{array}$ & $\begin{array}{l}\text { Dual market structure } \\
\text { Fragmented market structure }\end{array}$ & $\begin{array}{l}\text { Concentrated market structure } \\
\text { Uniform market structure }\end{array}$ \\
\hline \hline
\end{tabular}

Source: Boone and Van Witteloostuijn (1999).

Among the dual, concentrated, fragmented, and uniform market structure, only the dual market structure features the coexistence of small- and large-sized firms, operating in quasiindependent sub-markets. Industries with this structure are characterized by a high degree of market concentration and market density. Besides, the dual market structure also allows for differences in the optimal investment behavior of small and large firms and directly links these to structural properties of the market segment in which either small or large firms operate.

This study assumes the existence of dual market structures to show that differences in the optimal investment behavior of small and large firms account for size-related differences in the sensitivity of firms to monetary policy actions. To this end, we present a theoretical investment model that links the investment behavior of small and large firms to the level of sunk investment expenditures and hence to the degree of investment irreversibility. One may argue that the assumption of a dual market structure is overly restrictive, limiting the

and large firms (see, e.g., Angeloni, Kashyap, Mojon, and Terlizzese, 2003, for a compilation of studies). However, investment patterns are not linked to sunk costs and typically assume the absence of irreversibility, uncertainty, delivery lags, and costs of capital adjustment.

${ }^{3}$ Market concentration refers to the size distribution of firms in a market and market density describes the absolute number of firms in a market. See the paper industry, dental laboratories, professional consultancy services, furniture and related product manufacturing as examples for the dual market structure; guided missile and space vehicle manufacturing as examples for the concentrated market structure; construction, agriculture, wholesale and retail trade as examples for the fragmented market structure; basic chemical manufacturing, pharmaceutical and medicine manufacturing as examples for the uniform market structure. The examples are chosen for the United States, using information on the size distribution of firms from the US Bureau of Economic Analysis. 
applicability of the theoretical model. We will refute this concern and show that market dualization emphasizes and generalizes the main conclusions of the model because it stresses multiple sources of investment irreversibility as cause of size-related differences in optimal investment behavior. It will become evident that other types of market structure also feature differences in the optimal investment behavior of small and large firms and hence size-related asymmetries in the monetary policy response of investment. However, the size-related differences are less pronounced since alternative market structures only allow for single sources of investment irreversibility.

The chapter proceeds as follows. Section 3.2 describes the process of market dualization and the characteristics of dual markets in terms of firm size distribution and investment behavior. We also review the existing literature on investment behavior in the presence of adjustment costs and investment irreversibility. Section 3.3 develops the theoretical investment model that we use to discuss the 'investment' channel of monetary policy. We will show that size-related differences in sunk capital investment expenditures are an important source of differences in small- and large-firm investment behavior. Section 3.4 builds on the theoretical model and illustrates that size-related dissimilarities in sunk capital investment expenditures account for differences in the sensitivity of small- and large-firm investment to monetary policy shocks. Section 3.5 concludes.

\subsection{Existing Literature}

The discussion of the interest rate behavior of small- and large-firm investment assumes the coexistence of small and large firms in a dual market structure. This section starts out by reviewing theories of market dualization. In a next step, we discuss the principles of static and dynamic investment patterns and present studies which link firm size and investment behavior.

\subsubsection{The Process of Market Dualization}

The literature views dual market structures as the outcome of two different processes: scale economies and scope economies. Scale economies are at the core of Carroll's (1985) resource partitioning theory. He argues that dual market structures can evolve in industries characterized by scale economies and environmental resource heterogeneity. In this view, the market center is occupied by large firms that try to survive competitive pressures through scale economies. These firms produce generalized goods by exploiting a wide range of environmental resources. The market periphery is characterized by small specialized firms. These survive by using a narrow spectrum of environmental resources which differs from that exploited by large firms. In that sense, small firms search for viable market niches through local 
product differentiation. ${ }^{4}$

Scope economies are at the core of Sutton's $(1991,1998)$ sunk cost theory. Since this theory underlies the subsequent theoretical model, we will assume that dual market structures are exclusively driven by scope rather than scale economies. Sutton $(1991,1998)$ explains the existence of dual market structures by stressing endogenous sunk costs resulting from irreversible investment in the field of, e.g., research and development (R\&D). ${ }^{5}$ Endogenous sunk costs differ from exogenous sunk costs in that production is augmented by but not dependent on the associated investment. Closely related, endogenous sunk costs are not necessarily paid by all firms in a market, while exogenous sunk costs are. ${ }^{6}$ Firms incur endogenous sunk costs to gain a competitive lead through scope economies, which are realized through sunk investment in product differentiation. In being irreversible and driven by product differentiation rather than by cost and price advantages, Sutton $(1991,1998)$ argues that endogenous sunk costs may result in investment escalation. Since investment escalation is only sustainable by a small number of large firms, endogenous sunk costs split the market into two quasi-independent sub-markets. At the center of the dual market are those firms that sustain the competitive escalation of endogenous sunk costs, offering largely generalized (standardized) products. These firms are large. The market periphery hosts small firms which cannot sustain the endogenous sunk cost expenses, but continue to serve small-scale market niches by offering customized goods. Because small and large firms produce different goods (customized vs. standardized), the degree of inter-segment competition is low. This suggests that the relative importance of endogenous sunk costs determines the structure of the underlying market and the presence of small and large firms across market segments.

\subsubsection{Investment Behavior and Firm Size}

This chapter argues that differences in the sensitivity of small- and large-sized firms to monetary policy actions arise from the presence of sunk investment expenditures which influence the investment and, correspondingly, capacity choice of firms. ${ }^{7}$ The literature views investment decisions as being the outcome of static or dynamic optimization problems. These differ in that they describe either the demand for the stock of capital or the demand for the flow of capital (investment). Jorgenson (1963) specifies a static model that describes the demand for the stock of capital as a function of the user cost of capital. The model generates

\footnotetext{
${ }^{4}$ See also Boone and Van Witteloostuijn (1999) for a detailed description of the underlying theory and related criticism.

${ }^{5}$ Sutton $(1991,1998)$ also uses advertising outlays as an example of endogenous sunk costs. For reason of tractability, we do not analyze the role of these expenses as a force behind market dualization.

${ }^{6} \mathrm{An}$ example of exogenous sunk costs are those costs that are associated with the acquisition of production facilities of minimum efficient scale.

${ }^{7}$ Note, sunk investment costs can also be seen as determinant of a firm's industry entry/exit decision. In contrast to sunk costs associated with capacity choice, sunk entry/exit costs are independent of firm size and determined at the industry level.
} 
a straightforward rule of optimal investment behavior which requires investment up to the point where the marginal revenue product of the stock of capital is equal to the real user cost. Empirical studies cast doubt on the reasonability of this neoclassical investment model. In assuming costless reversibility of investment and the absence of capital adjustment costs, it cannot account for the observed gradual response of investment to changes in economic conditions. Dynamic models describe the demand for the flow of investment. The dynamics arise from market distortions related to investment irreversibility, capital adjustment costs, and uncertainty. ${ }^{8}$ These factors are interdependent and influence investment behavior by creating an option value of delaying investment until new information arrives. The underlying market frictions preclude the instantaneous adjustment of the capital stock to changes in economic conditions and may give rise to threshold investment behavior. ${ }^{9}$

Most studies on the investment effects of irreversibility abstain from establishing a direct link between firm size and investment behavior. An exception is Cabral (1995) who develops a game-theoretic model that stresses the relationship between sunk capacity costs (i.e., cost incurred in building production capacity), firm size, and firm growth. The model builds on the empirical regularity that small firms are more likely to exit an industry than large firms. Investment patterns of large and small firms are modeled in a two-period framework. In each period, optimal investment behavior is determined by the probability at which small and large firms exit the industry. Large firms are assumed to exit with low (or zero) probability in all periods. Their optimal choice therefore involves investment to the optimum long-run capacity level in all investment periods. Small firms, in contrast, exit with positive probability in period one, but stay with positive probability in period two. The relative ease at which small firms quit production in the presence of sunk capacity costs causes them to invest less than the optimal long-run capacity level in period one. When small firms still operate in period two, they adjust capacity to the long-run level. The gradual investment in turn predicts small firms to grow faster than large firms. Although the theoretical model explains the negative relationship between firm size and firm growth, it does not allow for inferences as to the interest rate sensitivity of small- and large-sized firms.

On the empirical side, only Lensink, Van Steen, and Sterken (2000) and Ghosal and Loungani (2000) control for the possible relationship between firm size and firm investment and the role of firm size as determinant of the relationship between firm investment behavior and investment uncertainty. While Lensink, Van Steen, and Sterken (2000) explicitly distinguish the investment behavior of small and large firms, Ghosal and Loungani (2000) make a distinction between industries dominated by either small or large firms. Both studies assume that sunk investment expenditures and hence investment irreversibility increase with firm size. ${ }^{10}$

\footnotetext{
${ }^{8}$ See, for example, Carruth, Dickerson, and Henley (2000), Lensink, Van Steen and Sterken (2005), Ninh, Hermes, and Lanjouw (2004) for surveys of theoretical and empirical investment models.

${ }^{9}$ See Abel and Eberly (1994, 1996, 1997), Barnett and Sakellaris (1998), Bloom, Bond, and Van Reenen (2001) for theoretical and empirical threshold investment studies.

${ }^{10} \mathrm{Ghosal}$ and Loungani (2000) derive the positive relationship between firm size and sunk costs indirectly
} 
Because sunk costs are an option value of waiting to invest, Lensink, Van Steen, and Sterken (2000) and Ghosal and Loungani (2000) expect the probability of a negative investmentuncertainty relationship to be higher for large than for small firms. A different relationship exists for financing constraints. Both studies argue that financing constraints increase the probability of a negative relationship between investment and uncertainty. Since financing constraints tend to be more pronounced for small rather than large firms, both studies expect the probability of a negative investment-uncertainty relationship to be higher for small than for large firms.

Ghosal and Loungani (2000) determine the investment-uncertainty relationship for a sample of Italian firms. Confirming theoretical predictions, the evidence from a panel analysis points to a negative relationship between investment and uncertainty. This relationship is stronger for industries that are dominated by small firms. Ghosal and Loungani (2000) conclude that the larger effect of uncertainty on investment for industries dominated by small firms points to the importance of financing constraints for small-firm investment, but not to the role of sunk costs. Lensink, Van Steen, and Sterken (2000) provide contrasting evidence. They employ survey data of Dutch firms to identify the investment-uncertainty relationship using a cross-section approach. The corresponding empirical results point to the existence of a positive investment-uncertainty relationship for small firms and to a negative relationship for large firms.

According to theoretical predictions, the observation that large firms reduce investment in response to higher uncertainty, whereas small firms increase investment points to the role of sunk costs as determinant of investment under uncertainty. In order to determine whether sunk costs are indeed a significant source of size-related differences in the investmentuncertainty relationship, Lensink, Van Steen, and Sterken (2000) test whether sunk costs and hence the degree of investment irreversibility increase with firm size. Descriptive evidence supports the positive link. Measured as the share of investment in construction to total investment, sunk costs are larger for large than for small firms. Sunk costs therefore seem to increase the probability of a negative investment-uncertainty relationship. In order to assess the robustness of their results, Lensink, Van Steen, and Sterken (2000) also introduce financing constraints as mechanism which may influence the nature of the investment-uncertainty relationship for small and large firms. In contrast to Ghosal and Loungani (2000), descriptive statistics suggest that neither small nor large firms face a restricted capital market access and that financing constraints therefore do not explain the observed investment-uncertainty relationship. Obviously, the evidence on the importance of sunk costs and financing constraints is indirect and needs to be interpreted with some caution.

Summarizing the literature on capital investment, capital adjustment is subject to real rigidi-

from the observed negative impact of sunk costs on the degree of market entry (see Baumol, Panzer, and Willig, 1982; Tirole, 1989). Because sunk costs are a barrier to entry, they are concluded to lead to concentrated markets, consisting of large firms. 
ties which result from investment irreversibility, where investment irreversibility is due to sunk investment costs. Even though sunk costs are argued to be positively related to firm size, existing studies do not explicitly model the relationship between sunk costs and firm size and the corresponding size-related effect of sunk costs on optimal investment behavior. Furthermore, theoretical and empirical studies are silent as to the effect of sunk costs on the sensitivity of small- and large-firm investment to changes in monetary policy. The remainder of this chapter discusses these issues and asks whether size-related differences in sunk investment costs cause differences (i) in the optimal investment behavior of small and large firms and (ii) in the sensitivity of small- and large-firm investment to monetary policy changes? The following section presents the investment model which is used to answer these questions. Throughout this chapter, we use the money market interest rate as proxy variable of the monetary policy stance.

\subsection{A Model of Firm Investment}

Dynamic investment models frequently specify investment behavior by following the q-approach (Tobin, 1969), which views optimal investment behavior as a function of the shadow value of installed capital. The q-approach is criticized on theoretical and empirical grounds (cf. Bond and Van Reenen, 2003, chapter 3). At the theoretical level, the most apparent weakness concerns the restrictive structure that needs to be imposed to equate unobservable marginal $q$ with observable average q. In that respect, it is typically questioned whether the assumptions of constant returns to scale in production and perfect competition yield adequate descriptions of actual investment decisions. At the empirical level, the weakness of the q-approach originates both in the assumed equality of marginal and average $q$ and in the estimation of average $q$ as a function of a firm's stock market valuation. Given the focus on stock-exchange listed companies, empirical investigations are subject to a large firm bias and to measurement errors in share prices. ${ }^{11}$ The general interest in the q-model is attributable to its strengths. These predominantly arise at the theoretical level and involve the specification of expectations, the formulation of explicit investment decision rules and the identification of threshold levels of optimal investment. The specification of investment decision rules is unique to the q-approach and cannot be found in alternative investment models such as the Euler equation approach (Abel, 1980) or the Abel and Blanchard (1986) approach. ${ }^{12}$ It is for this reason that we employ the q-approach.

The present analysis is carried out for a discrete infinite time framework that allows for the partial irreversibility of investment. The discrete-time model builds on the continuous-time work by Abel and Eberly $(1994,1997) .{ }^{13}$ We extend the investment models by explicitly

\footnotetext{
${ }^{11}$ The weaknesses are to some extent refuted by Erickson and Whited (2000).

${ }^{12}$ See Kalckreuth (2003) and Bond and Van Reenen (2003, chapter 3) for a description of these investment models.

${ }^{13}$ Theoretical explanations regarding discrete as well as continuous models are also provided by Dixit and
} 
linking the investment decision of firms to the level of sunk costs associated with R\&D. As we will show, the solutions to the optimal investment path allow for inferences regarding the interest rate sensitivity of small- and large-sized firms. A limitation of the study is that it does not discuss the options that firms have to finance investment projects, although these also affect the costs of finance. Instead, we assume that firms raise external funds at no other costs than the required interest rate. In assuming perfect credit markets, no attention is paid to the influence of financing constraints on firm investment, firm size, and firm size distribution. ${ }^{14}$ Furthermore, the model does not specify the effect of taxation on investment and optimal investment behavior. Finally, in order to compare the investment decisions of small- and large-sized firms, the present analysis assumes that the structure of the optimization problem is the same for small and large businesses. The following sections define the production and investment cost function and develop the intertemporal value maximization problem of firms and the optimal solution.

\subsubsection{Production Function}

Our model assumes the existence of $\mathrm{j}=1, \ldots, \mathrm{M}$ firms in a dual industry $\mathrm{i}$. The assumption of a dual market structure is imposed to explicitly allow for the co-existence of small- and large-sized firms in an industry. Furthermore, it sets the stage for the discussion of the investment decision of large- and small-sized firms across the quasi-independent sub-markets. Firms in each industry $\mathrm{i}=1, \ldots, \mathrm{N}$ are assumed to be risk-neutral and to produce a good that is characterized by a degree of product heterogeneity. The inclusion of product heterogeneity is necessary for the discussion of endogenous sunk costs. If firms were to produce completely homogenous goods, endogenous sunk costs on R\&D would not help to differentiate products from each other. ${ }^{15}$

Market dualization implies that small and large firms produce, respectively, customized and standardized goods. The present model assumes that large firms produce standardized goods with customized capital, where the use of customized capital raises productive efficiency. Labor is non-specialized and only needed for the operation of customized capital. Small firms employ standardized capital in the production of specialized goods. The customization of products is achieved through craftsmanship which requires the use of specialized labor. Given these specifications, the two market segments are assumed to draw labor from two independent pools: the market center uses non-specialized (unskilled) labor and the market periphery employs specialized (skilled) labor. ${ }^{16}$ Table 3.2 summarizes the characteristics of the dual market.

\footnotetext{
Pindyck (1994) and Bond and Van Reenen (2003, chapter 3).

${ }^{14}$ The model can be extended to the case of credit market imperfections, where firms differ in their access to external funds. See Bond and Van Reenen (2003, chapter 2) for details.

${ }^{15}$ See Sutton $(1991,1998)$ and Boone and Van Witteloostuijn (1999) for details.

${ }^{16}$ Alternatively, the market center and market periphery can also be said to employ low- and high-skilled labor. The same conclusions apply.
} 
Table 3.2: Dual Market Structure

\begin{tabular}{llll}
\hline \hline Market Segment & Firm Size & Input & Output \\
\hline Market center & Large & $\begin{array}{ll}\text { - Customized capital } \\
\text { Market periphery }\end{array}$ & Range of generalized goods \\
& Small & - Standalled labor & \\
& & - Skilled labor & \\
\hline
\end{tabular}

Despite these differences, small and large firms operate the same production function. In each period, the output level of firm $\mathrm{j}$ in industry $\mathrm{i}\left(\mathrm{Y}_{\mathrm{ji}}\right)$ depends on firm-specific Hicks-neutral technology $\left(\mathrm{A}_{\mathrm{ji}}\right)$, labor $\left(\mathrm{N}_{\mathrm{ji}}\right)$, physical capital $\left(\mathrm{K}_{\mathrm{ji}}\right)$, and human capital $\left(\mathrm{H}_{\mathrm{ji}}\right)$ according to the following Cobb-Douglas production function:

$$
\mathrm{Y}_{\mathrm{ji}, \mathrm{t}}=\mathrm{A}_{\mathrm{ji}, \mathrm{t}} \mathrm{K}_{\mathrm{ji}, \mathrm{t}}^{1-\alpha}\left(\mathrm{N}_{\mathrm{ji}, \mathrm{t}} \mathrm{H}_{\mathrm{ji}, \mathrm{t}}\right)^{\alpha}
$$

The production function displays constant returns to scale in capital and labor, but increasing returns to scale when taking into account labor-augmenting (Harrod-neutral) human capital. Furthermore, the production function is characterized by the unit elasticity of substitution of the input factors.

The technology parameter of firm $j$ in industry $i\left(A_{j i}\right)$ follows a random walk with drift specified as

$$
\mathrm{A}_{\mathrm{ji}, \mathrm{t}}=\alpha_{\mathrm{Ai}}+\mathrm{A}_{\mathrm{ji}, \mathrm{t}-1}+\beta_{\mathrm{Aji}}\left(\Delta \mathrm{RD}_{\mathrm{ji}, \mathrm{t}}\right)+\epsilon_{\mathrm{Aji}, \mathrm{t}} .
$$

The parameter $\alpha_{\mathrm{Ai}}$ is a time-invariant industry-specific positive drift that reflects the importance of technical progress in production at the industry level. $\Delta R \mathrm{D}_{\mathrm{ji}, \mathrm{t}}$ reflects the periodic improvement in technology resulting from firm-specific $R \& D$. The variable is included to account for cross-firm differences in R\&D-related productive efficiency and accordingly for cross-firm differences in output and size. $\epsilon_{\mathrm{Aji}}$ is an i.i.d. random variable with zero mean and constant variance, i.e., $\mathrm{N} \sim\left(0, \sigma^{2}\right)$.

Human capital is included to control for differences in the level of skills of specialized and non-specialized labor and hence for differences in the nominal wage paid in the market center and market periphery. Human capital evolves as a deterministic process defined as

$$
\mathrm{H}_{\mathrm{ji}, \mathrm{t}}=\alpha_{\mathrm{Hi}}+\mathrm{H}_{\mathrm{ji}, \mathrm{t}-1}+\beta_{\mathrm{Hji}} \mathrm{S}_{\mathrm{ji}, \mathrm{t}}{ }^{17}
$$

\footnotetext{
${ }^{17}$ Human capital is modeled as a deterministic process to allow for a clear relationship between technology and prices. This assumption does not affect the conclusions of the model.
} 
Again, the parameter $\alpha_{\mathrm{Hi}}$ is a time-invariant industry-specific positive drift, reflecting the effects of, e.g., learning by doing. The variable $S_{j i, t}$ is a binary positive dummy that controls for the positive differential between the level of human capital in the market periphery and market center. The dummy equals one if the firm operates in the market periphery and hence employs specialized labor and zero otherwise.

Labor and capital are assumed to become immediately productive in period t. ${ }^{18}$ Throughout the model, labor adjustment is assumed to be instantaneous and costless. ${ }^{19}$ The capital stock $\mathrm{K}_{\mathrm{ji}, \mathrm{t}}$ of firm $\mathrm{j}$ in industry $\mathrm{i}$ at time $\mathrm{t}$, however, changes according to

$$
\mathrm{K}_{\mathrm{ji}, \mathrm{t}}=(1-\delta) \mathrm{K}_{\mathrm{ji}, \mathrm{t}-1}+\mathrm{l}_{\mathrm{ji}, \mathrm{t}}
$$

The parameter $\delta$ denotes the rate of capital depreciation which is assumed to be constant across firms and industries, with $0<\delta<1$. The variable $\mathrm{I}_{\mathrm{t}}$ describes gross capital investment per unit of time and hence the capacity choice of firm $j$. Dependent on its focus, the firm may direct investment towards the accumulation of physical capital that functions on the basis of old established or new innovative technologies. ${ }^{20}$ Investment is assumed to add to the capital stock immediately rather than with a one period delay.

Summarizing, firm-specific production crucially depends on technology and the stock of human and physical capital. Motivated by the importance of physical capital as determinant of firm output, the capital stock in period $t$ is used as a proxy variable of firm size. We assume that small firms employ less capital than large firms. ${ }^{21}$ As will be shown below, the size-related differences in the stock of capital are associated with size-related dissimilarities in investment behavior which feed back into the interest rate sensitivity of small and large firms. Although the predictions of the model do not depend on assumptions regarding the relationship between firm size and labor input, one may also assume that capital-intensive firms employ more labor. ${ }^{22}$ This relationship is in line with the credit channel literature that frequently approximates firm size with employment.

\subsubsection{Investment Cost Function}

According to equation (3.4), changes in the stock of capital require costly investment. In order to capture the effect of investment costs on capital accumulation, we specify an 'augmented'

\footnotetext{
${ }^{18}$ One can argue that capital only becomes productive at a lag. Since the introduction of a lag confounds the readability of the model, none is included. This does not affect the conclusions.

${ }^{19}$ See Hall (2004) for evidence of low labor adjustment costs.

${ }^{20}$ Section 3.3.2 provides details on the investment options of firms.

${ }^{21}$ Kumar, Rajan, and Zingales (1999) show that firms in capital-intensive industries are larger compared with firms in capital-extensive industries.

${ }^{22}$ This assumption is consistent with the finding of Adams (1999) who shows that capital-intensive firms are factor-biased towards labor.
} 
investment cost function $C\left(I_{t}, K_{t}\right) .{ }^{23}$ In line with Abel and Eberly $(1994,1996,1997)$, Dixit and Pindyck (1994), and Letterie and Pfann (2003), the augmented investment cost function of small and large firms consists of three cost components: a convex capital adjustment cost function $\left(\gamma \mathrm{I}_{\mathrm{t}}^{\mathrm{m}} \mathrm{K}_{\mathrm{t}}^{-1}\right)$, a capital purchase/sale cost function $\left(\mathrm{p}_{\mathrm{It}} \mathrm{I}_{\mathrm{t}}\right)$, and a cost function related to the existing stock of capital $\left(\mathrm{p}_{\mathrm{K}} \mathrm{K}_{\mathrm{t}}\right.$ ). Following convention (e.g., Abel and Eberly, 1994; Caballero and Leahy, 1996; Bond and Van Reenen, 2003), the function $\mathrm{p}_{\mathrm{K}} \mathrm{K}_{\mathrm{t}}$ will be referred to as fixed cost function. As will be shown, the fixed cost function helps to explain the partial irreversibility of investment and accounts for infrequent and lumpy capital adjustment.

Interpreting the variables of the augmented investment cost function, $\gamma$ is a price parameter that is assumed to be size-independent and constant for positive and negative investment. The variable $\mathrm{p}_{\mathrm{It}}$ denotes the price of one unit of capital investment $\mathrm{I}_{\mathrm{t}}$ and $\mathrm{p}_{\mathrm{K}}$ describes the fixed adjustment cost per unit of installed capital $K_{t}$ at time $t$. We assume throughout this study that the unit price of investment $p_{l}$, the fixed adjustment cost per unit of installed capital $\mathrm{p}_{\mathrm{K}}$, and $\gamma$ exceed zero. That is, $\mathrm{p}_{\mathrm{I}}, \mathrm{p}_{\mathrm{K}}, \gamma>0$. The parameter $\mathrm{m}$ determines the functional form of the augmented investment cost function, which is specified to be nonnegative for all parameters $\mathrm{m}^{24}$ and hence for positive and negative investment values.

Combining the three cost components and suppressing subscripts $\mathrm{j}$ and $\mathrm{i}$ for firm and industry for ease of notation, the augmented investment cost function of firm $j$ is defined as

$$
\mathrm{C}\left(\mathrm{I}_{\mathrm{t}}, \mathrm{K}_{\mathrm{t}}\right)=\mathrm{p}_{\mathrm{tt}} \mathrm{I}_{\mathrm{t}}+\nu\left(\mathrm{p}_{\mathrm{Kt}} \mathrm{K}_{\mathrm{t}}\right)+\gamma \frac{\mathrm{I}_{\mathrm{t}}^{\mathrm{m}}}{\mathrm{K}_{\mathrm{t}}}
$$

$\nu$ depicts a dummy variable that equals one for non-zero investment and zero otherwise. The dummy variable is included to ensure that the fixed costs of capital adjustment only arise for non-zero investment. The fixed adjustment costs can be viewed as exogenous sunk costs which small- as well as large-sized firms incur in the process of capital accumulation. For example, small and large firms incur managerial and administrative costs when they decide on the acquisition of new capital. Once a new machine is purchased, its installation may require existing machines to be temporarily turned off, which results in costs of lost production. These costs are exogenous to each firm.

Reflecting managerial and administrative costs and expenses related to lost production, the fixed adjustment cost per unit of existing capital $p_{K}$ is identical for positive and negative investment. The fixed cost parameter $p_{K}$ is assumed to increase with the existing stock of capital $\mathrm{K}$ and therefore with the size of firms. That is, $\mathrm{p}_{\mathrm{K}}$ is a positive function of $\mathrm{K}$. This relationship rests on organizational and informational inefficiencies at the level of the firm. These arise from complex hierarchical and governance structures and are more severe for

\footnotetext{
${ }^{23}$ In the existing literature, the augmented investment cost function is also referred to as augmented adjustment cost function (e.g., Abel and Eberly, 1994; Bond and Van Reenen, 2003, chapter 3).

${ }^{24}$ In more detail, $m$ is defined as $m=2 k$ with $k \in \mathbb{Z}$. Also see Bond and Van Reenen (2003, chapter 3 ) for additional explanations regarding the properties of a convex capital adjustment cost function.
} 
large than for small firms. The inefficiencies result in conflicts of interests and moral hazard, which impede the coordination of tasks and the exchange of information. ${ }^{25}$

Considering the purchase/sale cost per unit of capital $\mathrm{p}_{\mathrm{l}}$, this price variable consists of an industry-specific component $\epsilon_{\mathrm{i}}$ and a firm-specific component $\epsilon_{\mathrm{j}}$ according to $\mathrm{p}_{\mathrm{lt}}=\epsilon_{\mathrm{it}}+v \epsilon_{\mathrm{jt}}$. The structure of the capital purchase/sale cost function reflects two options that firms are left with to achieve a chosen capacity. The first option involves the use of standardized capital in the production process, which is available at the industry-specific price $\epsilon_{\mathrm{i}}{ }^{26}$ The second option specifies the use of customized capital, which requires the firm-specific price $\epsilon_{\mathrm{j}} . \epsilon_{\mathrm{j}}$ is an endogenous sunk cost on technical progress that represents the price of R\&D and the cost of capital customization. ${ }^{27}$ This variable is included to approximate the endogenous sunk cost argument by Sutton $(1991,1998)$ and the underlying objective of large-sized firms to realize economies of scope and scale. ${ }^{28} v$ is a zero-one dummy variable that captures these two choices. The variable equals unity if a firm pays the firm-specific price $\epsilon_{\mathrm{j}}$ and zero otherwise. In including only a dummy on investment in customized capital, firms which invest in customized capital at $\operatorname{cost} \epsilon_{\mathrm{j}}$ are also required to invest in industry-specific capital at price $\epsilon_{\mathrm{i}}$. Customized capital therefore supplements rather than replaces standardized capital.

In order to introduce partial irreversibility of investment, positive investment $\mathrm{I}>0$ and negative investment $\mathrm{I}<0$ take place at the purchase price $\mathrm{p}_{\mathrm{l}}^{+}$and sale price $\mathrm{p}_{\mathrm{l}}^{-}$per unit of capital, respectively. Given the prevalence of asymmetric information problems in the market for used physical capital, the sale cost per unit of capital is contemplated to be lower than the corresponding purchase cost. That is, $\mathrm{p}_{1}^{+}>\mathrm{p}_{\mathrm{I}}^{-}>0$. The difference between the purchase and sale price measures the extent to which expenses are sunk. Considering the components of the capital purchase price, the model assumes that the purchase price of firm-specific capital equals the purchase price of industry-specific capital, with $\epsilon_{\mathrm{j}}^{+}=\epsilon_{\mathrm{i}}^{+}>0 .{ }^{29}$ As regards the sale price of firm-specific capital, it satisfies $\epsilon_{\mathrm{j}}^{-}=0$ because the costs of R\&D and capital customization are sunk. This implies that the endogenous sunk cost on technical progress is only defined for positive investment levels. Industry-specific capital can be sold at price

\footnotetext{
${ }^{25}$ See Ramírez and Espitia (2002) for a survey of the literature that discusses these issues.

${ }^{26}$ Alternatively stated, the industry-specific component reflects the cost of operating capital of average technological quality.

${ }^{27}$ The model does not control for the possibility that firm-specific technological innovations are used at the industry level. The reason is that the adoption of a firm-specific innovation at the industry level requires adjustment that needs to be captured by another cost variable. The inclusion of another cost measure confounds the readability of the model without providing additional details.

${ }^{28}$ The realization of scope economies gives rise to market dualization through a first-order inter-segment effect. A second-order intra-segment effect of market dualization results from large firms incurring endogenous sunk costs to gain a competitive lead in the market center via scale economies (cf. Boone and Van Witteloostuijn, 1999). The present model neglects this second-order scale effect and assumes that endogenous sunk costs affect output only through technology rather than scale economies.

${ }^{29}$ Note, the conclusions of the model are not sensitive to the more restrictive assumption that differences in the degree of capital customization and sophistication cause the purchase price of firm-specific capital to exceed that of industry-specific capital.
} 
$\epsilon_{\mathrm{i}}^{-}>0$, where $\epsilon_{\mathrm{i}}^{+}>\epsilon_{\mathrm{i}}^{-}>0$ due to asymmetric information problems in the market for used capital.

As stated, the capital cost variable $\mathrm{p}_{\mathrm{I}}$ reflects the price that accompanies the acquisition and disposal of one unit of either standardized or customized capital. Because $\epsilon_{i}^{+}=\epsilon_{j}^{+}$and $\epsilon_{\mathrm{i}}^{-}>\epsilon_{\mathrm{j}}^{-}$, the expenses associated with the purchase and sale of firm-specific customized capital are higher than those that result from positive and negative investment in industryspecific standardized capital. The present analysis assumes that the willingness of firms to incur the cost $\epsilon_{\mathrm{j}}$ per unit of customized capital depends positively on the underlying capital stock and consequently on firm size. This relationship reflects the dependence of large-firm production on customized capital and suggests a positive link between the stock of capital used in production and the need for customized physical capital. ${ }^{30}$ Summarizing these relationships, large firms base their investment decisions on $\epsilon_{\mathrm{i}}$ and $\epsilon_{\mathrm{j}}$, whereas small firms only view $\epsilon_{\mathrm{i}}$ as the relevant investment decision parameter. Cross-firm differences in technologies are hence attributable to cross-firm dissimilarities in the decision to invest in either industry- or firm-specific technologies.

Except for zero investment $I=0$, the augmented investment cost function (3.5) is continuous and twice differentiable with respect to investment at all investment levels, with $\frac{\partial \mathrm{C}\left(\mathrm{I}_{\mathrm{t}}, \mathrm{K}_{\mathrm{t}}\right)}{\partial \mathrm{I}_{\mathrm{t}}}>0$. The discontinuity at $\mathrm{I}=0$ results from the discrepancy between the purchase and sale cost per unit of capital, i.e., $p_{1}^{+} \neq p_{1}^{-}$. Attributable to the difference between the purchase and sale price of capital, it also holds that $\frac{\partial \mathrm{C}\left(\mathrm{I}_{\mathrm{t}}^{+}, \mathrm{K}_{\mathrm{t}}\right)}{\partial \mathrm{I}_{\mathrm{t}}^{+}}>\frac{\partial \mathrm{C}\left(\mathrm{I}_{\mathrm{t}}^{-}, \mathrm{K}_{\mathrm{t}}\right)}{\partial \mathrm{I}_{\mathrm{t}}^{-}}$, where $\mathrm{I}_{\mathrm{t}}^{+}$and $\mathrm{I}_{\mathrm{t}}^{-}$depict positive and negative investment, respectively.

\subsubsection{Short-Run Profit Optimization}

The production and augmented investment cost function in section 3.3.1 and 3.3.2, respectively, determine small- and large-firm investment behavior. As will be illustrated in section 3.3.4 and 3.3.5, investment is optimal when it maximizes the fundamental value of a firm. The underlying intertemporal maximization problem takes into account the level of instantaneous operating profits and the evolution of technology, human capital, and output prices. So far, we only discussed the periodic development of technology and human capital as stochastic and deterministic process, respectively (see section 3.3.1). This section presents the short-run profit function of firms and the process that describes the evolution of the output price. The underlying discussion highlights the short-run profit optimization problem of firms.

The short-run profit maximization problem of the firm is defined as

$$
\pi\left(\mathrm{P}_{\mathrm{t}}, \mathrm{A}_{\mathrm{t}}, \mathrm{K}_{\mathrm{t}}, \mathrm{N}_{\mathrm{t}}, \mathrm{H}_{\mathrm{t}}\right)=\max \left[\mathrm{P}_{\mathrm{t}} \mathrm{f}\left(\mathrm{A}_{\mathrm{t}}, \mathrm{K}_{\mathrm{t}}, \mathrm{N}_{\mathrm{t}}, \mathrm{H}_{\mathrm{t}}\right)-\mathrm{C}\left(\mathrm{N}_{\mathrm{t}}\right)\right]
$$

\footnotetext{
${ }^{30}$ This claim does not interfere with the assumption that large and small firms produce generalized and standardized goods, respectively (cf. section 3.3.1).
} 
where $P_{t}$ is the output price, $f(\cdot)$ denotes the production function, and $C\left(N_{t}\right)$ describes the costs of production. The function $C\left(N_{t}\right)$ equals $C\left(N_{t}\right)=w_{t} N_{t}$ and summarizes the costs of employing $\mathrm{N}$ units of labor at wage $\mathrm{w}$ at time $\mathrm{t}$. In the short run, the physical and human capital stock is quasi-fixed and firms maximize profits by varying the input factor labor. Labor adjustment is assumed to be costless, i.e., costs related to retraining do not arise. An additional unit of labor is therefore instantaneously available at cost $w_{t}$.

The model features cross-segment differences in the price of labor. Because small firms produce customized goods with specialized labor, while large firms produce generalized goods with non-specialized labor, small firms are assumed to pay higher wages than large firms. The higher wage in the market periphery is needed to compensate workers for the costs associated with acquiring the necessary skill. ${ }^{31}$ Given that small-firm production depends on the availability of specialized labor, small firms may also pay higher wages to discourage workers from turning over to competitors in the same market segment or from moving to the market center.

Although the conclusions of the model do not depend on this assumption, the cross-segment differences in wages are assumed to result in cross-segment differences in the output price. Given the use of skilled labor and the consequent higher wage, the output price of firms in the market periphery is likely to exceed that of firms in the market center. Besides cross-segment differences in the price of labor, the differential between prices in the market periphery and market center is also attributable to cross-segment differences in technology. Again, small firms are assumed to impose larger prices compared with large firms. This relationship reflects the R\&D-related technology advantage of firms in the market center and the negative effect of technological advances on the costs of production through higher factor productivity. ${ }^{32}$

Because technology is assumed to evolve as a stochastic process, the interdependence of output price and technology causes prices to follow a stochastic process as well. In particular, we assume that the price level of firm $j$ in industry $i$ evolves as an $A R(1)$ process with positive drift according to

$$
\mathrm{P}_{\mathrm{ji}, \mathrm{t}}=\alpha_{\mathrm{Pi}}+\mathrm{P}_{\mathrm{ji}, \mathrm{t}-1}+\epsilon_{\mathrm{Pji}, \mathrm{t}}
$$

where $\epsilon_{\mathrm{Pji}}$ is an i.i.d. random variable. The error term is included to control for unexpected price disturbances, resulting from technology shocks or from supply shocks. Equation (3.7) can be criticized in that it describes the development of a firm's output price on the basis of ad hoc arguments rather than explicit pricing rules. Two reasons justify this approach. Firstly,

\footnotetext{
${ }^{31}$ This in turn implies that the value of product customization accrues to the worker and not as mark up to the firm.

${ }^{32}$ See, for example, Rochelle, Laubach, and Williams (2003) for empirical evidence of the negative effect of technology on prices. Note, firms in the market center may also charge lower prices in response to technological advances in order to sustain intra-segment competition. This relationship describes the second-order intrasegment effect of market dualization through scale economies.
} 
the derivation of explicit pricing rules for firms in the market center and market periphery is beyond scope of the present study since it requires additional (ad hoc) assumptions about the curvature of the demand and cost functions in each market segment. Secondly, complex pricing structures are not derived since neither the periodic development of prices nor the predictions of the investment model depend on the underlying pricing rule.

Having specified the process that describes a firm's output price, technology, and human capital and given the investment cost and short-run profit function, we have introduced all variables which define the intertemporal investment problem of firms. The next two sections discuss the intertemporal investment problem and accordingly optimal investment behavior. We will show that optimal investment behavior maximizes the fundamental value of a firm. To facilitate the readability, subscript $\mathrm{j}$ and $\mathrm{i}$ for firm and industry are subsequently suppressed.

\subsubsection{Fundamental Firm Value}

In the long run, firm $j$ is free to adjust the stock of productive capital. Since capital adjustment is costly, the firm decides on the optimal degree of investment activity by maximizing the expected present value of net operating profits in each period. Net operating profits are defined as the difference between instantaneous operating profits and the costs of capital investment. In each period, the firm faces an intertemporal investment problem that arises from the periodic depreciation of capital and the costly adjustment thereof. In order to solve the optimization problem, the firm maximizes the expected present value of net profits with respect to investment according to

$$
V\left(P_{t}, A_{t}, K_{t}, N_{t}, H_{t}\right)=\max _{I_{t+s}} E_{t}\left\{\sum_{s=0}^{\infty} \beta_{t+s}\left[\pi\left(P_{t+s}, A_{t+s}, K_{t+s}, N_{t+s}, H_{t+s}\right)-C\left(I_{t+s}, K_{t+s}\right)\right]\right\} .
$$

Here, $\beta$ is the firm's discount factor defined as $\frac{1}{1+r_{t}}$, where $r_{t}$ is the money market interest rate $r_{M, t}$ at time $t$ adjusted for firm-specific risk $r_{F P, t}$. That is, $r_{t}$ is defined as $r_{t}=r_{M, t}+r_{F P, t}{ }^{33}$ $E_{t}$ is an expectations operator conditional on information available at time t. Equation (3.8) illustrates that the fundamental value of a firm is the present value of current and future net operating profits. Following the Bellman principle of optimality, the fundamental value of a firm equals the expected capital gain from future investment decisions and the level of net operating profits at time $t$ (see equation 3.9$).{ }^{34}$

$$
\mathrm{V}\left(\mathrm{P}_{\mathrm{t}}, \mathrm{A}_{\mathrm{t}}, \mathrm{K}_{\mathrm{t}}, \mathrm{N}_{\mathrm{t}}, \mathrm{H}_{\mathrm{t}}\right)=\max _{\mathrm{I}_{\mathrm{t}}}\left\{\pi\left(\mathrm{P}_{\mathrm{t}}, \mathrm{A}_{\mathrm{t}}, \mathrm{K}_{\mathrm{t}}, \mathrm{N}_{\mathrm{t}}, \mathrm{H}_{\mathrm{t}}\right)-\mathrm{C}\left(\mathrm{I}_{\mathrm{t}}, \mathrm{K}_{\mathrm{t}}\right)+\beta_{\mathrm{t}+1} \mathrm{E}_{\mathrm{t}}\left[\mathrm{V}_{\mathrm{t}+1}\right]\right\}
$$

\footnotetext{
${ }^{33}$ The discount factor may also include an industry-specific premium. Because the analysis is only interested in the investment patterns of firms in the market center and market periphery of a particular industry, the discussion ignores industry-specific effects. This does not affect the conclusions of the model.

${ }^{34}$ Dixit and Pindyck (1994, chapter 4) define the expected capital gain as the continuation value of operation.
} 
Net operating profits are influenced by two sources of uncertainty, i.e., by the stochastic behavior of output prices and firm-specific technology.

The optimization problem in equation (3.9) is constrained by the process of capital accumulation (3.4) and by the evolution of technology (3.2), human capital (3.3), and output price (3.7). For these constraints, the intertemporal maximization problem at time $t$ is put in terms of the Lagrangian expression

$$
\begin{aligned}
\mathrm{L}_{\mathrm{t}}= & \pi\left(\mathrm{P}_{\mathrm{t}}, \mathrm{A}_{\mathrm{t}}, \mathrm{K}_{\mathrm{t}}, \mathrm{N}_{\mathrm{t}}, \mathrm{H}_{\mathrm{t}}\right)-\mathrm{C}\left(\mathrm{I}_{\mathrm{t}}, \mathrm{K}_{\mathrm{t}}\right)+\beta_{\mathrm{t}+1} \mathrm{E}_{\mathrm{t}}\left[\mathrm{V}_{\mathrm{t}+1}\right]+\lambda_{\mathrm{t}}\left[(1-\delta) \mathrm{K}_{\mathrm{t}-1}-\mathrm{K}_{\mathrm{t}}+\mathrm{I}_{\mathrm{t}}\right]+ \\
& \mathrm{V}_{\mathrm{Pt}}\left(\alpha_{\mathrm{P}}+\mathrm{P}_{\mathrm{t}-1}-\mathrm{P}_{\mathrm{t}}+\epsilon_{\mathrm{Pt}}\right)+\mathrm{V}_{\mathrm{At}}\left(\alpha_{\mathrm{A}}+\mathrm{A}_{\mathrm{t}-1}-\mathrm{A}_{\mathrm{t}}+\beta_{\mathrm{A}}\left(\Delta \mathrm{RD}_{\mathrm{t}}\right)+\epsilon_{\mathrm{At}}\right)+ \\
& \mathrm{V}_{\mathrm{Ht}}\left(\alpha_{\mathrm{H}}+\mathrm{H}_{\mathrm{t}-1}-\mathrm{H}_{\mathrm{t}}+\beta_{\mathrm{H}} \mathrm{S}_{\mathrm{t}}\right) .
\end{aligned}
$$

$V_{A}, V_{P}$, and $V_{H}$ represent the shadow value of technology, output price, and human capital, respectively, and $\epsilon_{\mathrm{A}}$ and $\epsilon_{\mathrm{P}}$ denote random shocks to technology and output price, respectively. $\lambda_{t}$ denotes the shadow value of an extra unit of capital at time $t$. That is, it reflects the contribution of one additional unit of capital to the fundamental value of a firm and thus measures the desirability of firm-specific investment.

Because the shadow value of capital $\lambda_{t}$ is a crucial determinant of optimal investment behavior, the remainder of this section summarizes the variable's properties in more detail. A theoretical expression for the shadow value of capital at time $t$ is obtained by differentiating equation (3.10) with respect to capital

$$
\frac{\partial \mathrm{L}_{\mathrm{t}}}{\partial \mathrm{K}_{\mathrm{t}}}=\frac{\partial \pi_{\mathrm{t}}}{\partial \mathrm{K}_{\mathrm{t}}}-\frac{\partial \mathrm{C}_{\mathrm{t}}}{\partial \mathrm{K}_{\mathrm{t}}}+\beta_{\mathrm{t}+1} \frac{\partial \mathrm{E}_{\mathrm{t}}\left\{\mathrm{V}_{\mathrm{t}+1}\right\}}{\partial \mathrm{K}_{\mathrm{t}}}-\lambda_{\mathrm{t}}=0
$$

where $\frac{\partial \pi_{\mathrm{t}}}{\partial \mathrm{K}_{\mathrm{t}}}=\frac{1}{\theta}\left(\mathrm{P}_{\mathrm{t}} \mathrm{A}_{\mathrm{t}}\right)^{\theta}\left(\frac{\alpha \mathrm{H}_{\mathrm{t}}}{\mathrm{w}_{\mathrm{t}}}\right)^{\theta-1}$ and $\frac{\partial \mathrm{C}_{\mathrm{t}}}{\partial \mathrm{K}_{\mathrm{t}}}=\left(\nu \mathrm{P}_{\mathrm{Kt}}-\gamma \frac{\mathrm{I}_{\mathrm{t}}^{\mathrm{m}}}{\mathrm{K}_{\mathrm{t}}^{2}}\right) . \frac{\partial \mathrm{E}_{\mathrm{t}}\left\{\mathrm{V}_{\mathrm{t}+1}\right\}}{\partial \mathrm{K}_{\mathrm{t}}}$ is the contribution of one additional unit of physical capital today to the expected fundamental firm value at time $t+1$. This component can be written as the expected shadow value of inheriting one additional unit of capital from period $\mathrm{t}$ in period $\mathrm{t}+1$ : $\frac{\partial \mathrm{E}_{\mathrm{t}}\left\{\mathrm{V}_{\mathrm{t}+1}\right\}}{\partial \mathrm{K}_{\mathrm{t}}}=(1-\delta) \mathrm{E}_{\mathrm{t}}\left\{\lambda_{\mathrm{t}+1}\right\}{ }^{35}$ Summarizing terms, equation (3.11) can be expressed as

$$
\lambda_{\mathrm{t}}=\frac{\partial \pi_{\mathrm{t}}}{\partial \mathrm{K}_{\mathrm{t}}}-\frac{\partial \mathrm{C}_{\mathrm{t}}}{\partial \mathrm{K}_{\mathrm{t}}}+(1-\delta) \beta_{\mathrm{t}+1} \mathrm{E}_{\mathrm{t}}\left\{\lambda_{\mathrm{t}+1}\right\}
$$

This equation indicates that the shadow value of capital $\lambda_{t}$ at time $t$ combines the marginal operating profit of capital at time $t$, the marginal contribution of capital to capital installation costs at time $t$, and the expected shadow value of capital at time $t+1$. The expectations operator is solved by forward iteration. The corresponding result indicates that the shadow value of installed capital at time $t$ equals the discounted expected present value of the

\footnotetext{
${ }^{35}$ See Bond and Van Reenen (2003, chapter 3) for additional details.
} 
future stream of marginal operating profits net the future marginal capital adjustment costs according to

$$
\lambda_{\mathrm{t}}=\mathrm{E}_{\mathrm{t}}\left\{\sum_{\mathrm{s}=0}^{\infty}(1-\delta)^{\mathrm{s}} \beta_{\mathrm{t}+\mathrm{s}}\left(\frac{\partial \pi_{\mathrm{t}+\mathrm{s}}}{\partial \mathrm{K}_{\mathrm{t}+\mathrm{s}}}-\frac{\partial \mathrm{C}_{\mathrm{t}+\mathrm{s}}}{\partial \mathrm{K}_{\mathrm{t}+\mathrm{s}}}\right)\right\} .
$$

Because $\frac{\partial \pi_{t}}{\partial \mathrm{K}_{\mathrm{t}}}>0$ and $\frac{\partial \mathrm{C}_{\mathrm{t}}}{\partial \mathrm{K}_{\mathrm{t}}}<0$, the shadow value of one unit of installed capital is positive. ${ }^{36}$ The property of the first-order condition of the instantaneous profit function results from the evolution of output price and technology as random walk with positive drift.

\subsubsection{Intertemporal Value Maximization}

This section identifies the value maximizing investment level of small and large firms. Because $\lambda_{t} I_{t}$ and $C\left(I_{t}, K_{t}\right)$ are the only components in equation (3.10) that contain investment, we follow Abel and Eberly (1994) and summarize the intertemporal maximization problem in equation (3.10) as

$$
\Phi\left(\lambda_{\mathrm{t}}, \mathrm{K}_{\mathrm{t}}\right)=\max _{\mathrm{I}_{\mathrm{t}}}\left\{\lambda_{\mathrm{t}} \mathrm{I}_{\mathrm{t}}-\mathrm{C}\left(\mathrm{I}_{\mathrm{t}}, \mathrm{K}_{\mathrm{t}}\right)\right\}
$$

where $\Phi_{t}$ describes the net value of investment at time t. The solution to this optimization problem is subject to two distortions, which give rise to lumpy and infrequent capital adjustment. The first distortion arises from the purchase and sale cost per unit of capital $\mathrm{p}_{\mathrm{I}}$ and is subsequently referred to as unconstrained case. It is unconstrained because it defines optimal investment behavior to depend on the shadow value of capital and on the price of capital, while it disregards the investment effect of the fixed capital adjustment cost $\mathrm{p}_{\mathrm{K}}$. The second distortion results from the fixed adjustment cost per unit of installed capital $\mathrm{p}_{\mathrm{K}}$. We will illustrate that this cost component constrains investment behavior beyond the effect of the purchase/sale price of capital $\mathrm{p}_{\mathrm{I}}$. We introduce the corresponding investment behavior as constrained case. In order to facilitate the readability of the derivations, the profit, value, investment, net value, and augmented investment cost function are subsequently reported without arguments. That is, they are abbreviated as $\pi_{t}, V_{t}, I_{t}, \Phi_{t}$, and $C_{t}$.

In order to derive an expression of the value maximizing unconstrained investment level, equation (3.14) is solved for the first-order condition with respect to investment. The firstorder condition

\footnotetext{
${ }^{36}$ Note, the first-order condition of the investment cost function might also be positive. Since $\gamma$ is assumed to be the same for small and large firms, while $\mathrm{p}_{K}$ increases with firm size, this might be particularly true for large firms. To exclude this possibility, the present analysis assumes that technology raises the marginal operating profit of capital above the marginal contribution of capital to lower installation costs such that the shadow value of capital is still positive for large firms.
} 


$$
\frac{\partial \Phi_{\mathrm{t}}}{\partial \mathrm{I}_{\mathrm{t}}}=\lambda_{\mathrm{t}}-\frac{\partial \mathrm{C}_{\mathrm{t}}}{\partial \mathrm{I}_{\mathrm{t}}}=\lambda_{\mathrm{t}}-\left(\mathrm{p}_{\mathrm{It}}+\gamma \mathrm{m} \frac{\mathrm{I}_{\mathrm{t}}^{\mathrm{m}-1}}{\mathrm{~K}_{\mathrm{t}}}\right)
$$

shows that optimal investment is determined by the relationship between the marginal benefits (i.e., the contribution of one additional unit of capital to the fundamental firm value) and the marginal costs of investment. Solving equation (3.15) and using the information on the augmented investment cost function (3.5), optimal investment at time $t$ is defined as

$$
\mathrm{I}_{\mathrm{t}}^{*}=\left[\frac{\left(\lambda_{\mathrm{t}}-\mathrm{p}_{\mathrm{It}}\right) \mathrm{K}_{\mathrm{t}}}{\gamma \mathrm{m}}\right]^{\frac{1}{\mathrm{~m}-1}} .
$$

In line with Hayashi (1982), current and future expected output demand, output supply, and ultimately operating profits do not appear to have a direct impact on optimal investment, while it positively depends on the existing stock of capital. Equation (3.16) indicates that optimal investment is strictly increasing in the shadow value of installed capital $\lambda$. Furthermore, it shows that gross capital investment is only positive (negative) if the value of an additional unit of capital is larger (less) than the purchase (sale) price of capital. No investment arises if the shadow valuation of capital is in-between the sale and purchase price of capital. Summarizing these relationships between gross capital investment and the shadow value of capital, it holds that

$$
\begin{array}{lll}
\mathrm{I}^{*}\left(\lambda_{\mathrm{t}}, \mathrm{K}_{\mathrm{t}}\right)<0 & \text { for } & \lambda_{\mathrm{t}}<\mathrm{p}_{\mathrm{It}}^{-}, \\
\mathrm{I}^{*}\left(\lambda_{\mathrm{t}}, \mathrm{K}_{\mathrm{t}}\right)=0 & \text { for } & \mathrm{p}_{\mathrm{It}}^{-} \leq \lambda_{\mathrm{t}} \leq \mathrm{p}_{\mathrm{It}}^{+}, \\
\mathrm{I}^{*}\left(\lambda_{\mathrm{t}}, \mathrm{K}_{\mathrm{t}}\right)>0 & \text { for } & \lambda_{\mathrm{t}}>\mathrm{p}_{\mathrm{It}}^{+}
\end{array}
$$

The shadow value of one unit of installed capital $\lambda$ is closely related to Tobin's marginal value of installed capital defined as $\mathrm{q}_{\mathrm{t}}=\frac{\lambda_{\mathrm{t}}}{\mathrm{p}_{\mathrm{t}}}$. For ease of exposition, we predominantly present the optimization problem in terms of the shadow rather than marginal value of capital. ${ }^{37}$

Section 3.3.2 modeled the purchase price of capital as $\mathrm{p}_{\mathrm{lt}}^{+}=\epsilon_{\mathrm{it}}^{+}+v \epsilon_{\mathrm{jt}}^{+}$. Given this specification of the price, the expression for positive investment in equation (3.17) shows that the decision process of firms involves two possible outcomes. Firms invest in standardized capital if $\epsilon_{\mathrm{it}}^{+}<\lambda_{\mathrm{t}} \leq \epsilon_{\mathrm{it}}^{+}+\epsilon_{\mathrm{jt}}^{+}$. By assumption, these firms are small. Investment in customized capital only arises if $\lambda_{\mathrm{t}}>\epsilon_{\mathrm{it}}^{+}+\epsilon_{\mathrm{jt}}^{+}$. Again by assumption, only large firms incur the endogenous sunk costs to purchase innovative capital which is needed for the realization of product differentiation advantages.

The relationships in equation (3.17) describe the value maximizing investment level for the unconstrained case, but do not represent the solution for constrained optimal investment. The

\footnotetext{
${ }^{37}$ For details regarding the relationship between the shadow and marginal value of capital see Hayashi (1982) and Bond and Van Reenen (2003, chapter 3).
} 
difference originates from the nonnegative fixed costs of investment that have been ignored so far. Arising for non-zero investment, these costs affect the payoff function $\Phi\left(\lambda_{t}, K_{t}\right)$ and widen the range of inaction for which non-zero investment is costly. In order to be profitable, the shadow value of capital $\lambda$ must be such that the underlying payoff function $\Phi\left(\lambda_{\mathrm{t}}, \mathrm{K}_{\mathrm{t}}\right)$ assumes positive values for non-zero investment. In order to determine this value, the expression for optimal investment $l_{t}^{*}$ from expression (3.16) is substituted into equation (3.14) according to

$$
\Phi^{*}\left(\lambda_{\mathrm{t}}, \mathrm{K}_{\mathrm{t}}\right)=\left(\lambda_{\mathrm{t}}-\mathrm{p}_{\mathrm{lt}}\right)\left[\frac{\left(\lambda_{\mathrm{t}}-\mathrm{p}_{\mathrm{lt}}\right) \mathrm{K}_{\mathrm{t}}}{\gamma \mathrm{m}}\right]^{\frac{1}{\mathrm{~m}-1}}-\left(\nu\left(\mathrm{p}_{\mathrm{Kt}} \mathrm{K}_{\mathrm{t}}\right)+\gamma \frac{\left[\frac{\left(\lambda_{\mathrm{t}}-\mathrm{p}_{\mathrm{tt}}\right) \mathrm{K}_{\mathrm{t}}}{\gamma \mathrm{m}}\right]^{\frac{\mathrm{m}}{\mathrm{m}-1}}}{\mathrm{~K}_{\mathrm{t}}}\right) .
$$

Rewriting and summarizing terms yields

$$
\Phi^{*}\left(\lambda_{\mathrm{t}}, \mathrm{K}_{\mathrm{t}}\right)=\Omega\left(\lambda_{\mathrm{t}}-\mathrm{p}_{\mathrm{It}}\right)^{\frac{\mathrm{m}}{\mathrm{m}-1}} \mathrm{~K}_{\mathrm{t}}^{\frac{1}{\mathrm{~m}-1}}-\nu\left(\mathrm{p}_{\mathrm{Kt}} \mathrm{K}_{\mathrm{t}}\right),
$$

where $\Omega=\left(1-\frac{1}{m}\right)(\gamma \mathrm{m})^{\frac{-1}{m-1}}$. In order to identify optimal investment behavior, expression (3.19) is solved for the threshold levels of $\lambda$ for which optimal investment behavior asks for positive, negative, or zero investment. The thresholds are identified by imposing the condition $\Phi=0$ for $\mathrm{p}_{\mathrm{lt}}^{+}$and $\mathrm{p}_{\mathrm{lt}}^{-}$, alternatively. For this condition, positive and negative investment describe optimal investment behavior if

$$
\begin{aligned}
& \lambda_{\mathrm{t}}>\bar{\lambda}_{\mathrm{t}}=\mathrm{p}_{\mathrm{It}}^{+}+\left(\nu \mathrm{p}_{\mathrm{Kt}} \Psi_{\mathrm{t}}\right)^{\frac{\mathrm{m}-1}{\mathrm{~m}}}, \\
& \lambda_{\mathrm{t}}<\underline{\lambda}_{\mathrm{t}}=\mathrm{p}_{\mathrm{It}}^{-}-\left(\nu \mathrm{p}_{\mathrm{Kt}} \Psi_{\mathrm{t}}\right)^{\frac{\mathrm{m}-1}{m}},
\end{aligned}
$$

respectively, where $\Psi_{t}=\frac{K_{t}^{1-\frac{1}{m-1}}}{\Omega}$. Evidently, the relationship between the purchase/sale price per unit of capital $\mathrm{p}_{\mathrm{I}}$ and the fixed price per unit of existing capital $\mathrm{p}_{\mathrm{K}}$ is influenced by the interpretation of the price variables. The purchase price of capital $\mathrm{p}_{1}^{+}$is a cost to the firm, while the sale price $\mathrm{p}_{\mathrm{I}}^{-}$needs to be interpreted as a gain. Notably, the capital stock does not influence the range of zero and non-zero activity if investment and capital are linearly homogenous (i.e., $\mathrm{m}=2$ ). ${ }^{38}$

Using equation (3.20), the regime of zero investment reflects the optimal investment decision for values of $\lambda$ in the interval $\underline{\lambda}_{t} \leq \lambda_{t} \leq \bar{\lambda}_{t}$, where $\bar{\lambda}$ and $\underline{\lambda}$ denote the upper and lower threshold of $\lambda$ below and above which zero investment is undertaken. Given these relations, optimal investment behavior $\hat{\imath}\left(\lambda_{t}, K_{t}\right)$ can be summarized as

$$
\left.{ }^{38} \text { For } \mathrm{m}=2 \text {, the term }\left(\frac{\nu \mathrm{p}_{\mathrm{Kt}} \mathrm{K}_{\mathrm{t}}^{1-\frac{1}{\mathrm{~m}-1}}}{\Omega}\right)^{\frac{\mathrm{m}-1}{\mathrm{~m}}} \text { in equation (3.20) simplifies to }\left(\frac{\nu \mathrm{pKKt}^{\frac{1}{2}}}{\frac{1}{2 \gamma}}\right)\right)^{\frac{1}{2}} \text {. }
$$




$$
\hat{\imath}\left(\lambda_{t}, K_{t}\right)= \begin{cases}I^{*}\left(\lambda_{t}, K_{t}\right)<0 & \text { if } \lambda_{t}<\underline{\lambda}_{t} \\ I^{*}\left(\lambda_{t}, K_{t}\right)=0 & \text { if } \lambda_{t} \leq \lambda_{t} \leq \bar{\lambda}_{t} \\ I^{*}\left(\lambda_{t}, K_{t}\right)>0 & \text { if } \lambda_{t}>\bar{\lambda}_{t} .\end{cases}
$$

The region of inactivity is positively related to the cost components of the augmented investment cost function $\mathrm{C}\left(\mathrm{I}_{\mathrm{t}}, \mathrm{K}_{\mathrm{t}}\right)$, i.e., $\mathrm{p}_{\mathrm{It}}, \mathrm{p}_{\mathrm{Kt}}$, and $\gamma$. The higher these costs are, the larger the region of inactivity where investment is zero between the lower and upper threshold value of $\lambda .^{39}$

Considering the threshold level of $\lambda$ at which positive investment guarantees a positive payoff, the assumed positive relationship between the stock of capital and the purchase price per unit of capital $\mathrm{p}_{1}^{+}$suggests a threshold value that is higher for large than for small firms. Following the same argumentation as before, small firms invest in standardized capital if $\lambda_{t}>\bar{\lambda}_{t}$ for $\mathrm{p}_{\mathrm{lt}}^{+}=\epsilon_{\mathrm{it}}^{+}$, while large firms invest in new innovate capital if $\lambda_{\mathrm{t}}>\bar{\lambda}_{\mathrm{t}}$ for $\mathrm{p}_{\mathrm{lt}}^{+}=\epsilon_{\mathrm{it}}^{+}+\epsilon_{\mathrm{jt}}^{+}$. The size-related difference in the use of firm- and industry-specific capital becomes irrelevant in the case of negative investment. With the costs on firm-specific capital being sunk, large and small firms obtain the same per unit price for the sale of capital, i.e., $\epsilon_{\mathrm{i}}^{-}$. On the basis of this price measure, large and small firms disinvest at the same threshold level of $\lambda$.

Size-related differences in the thresholds of negative investment arise from the fixed price per unit of existing capital $p_{K}$. For disinvestment, the variable $p_{K}$ has to be interpreted as a price that firms pay rather than receive. Because large firms pay a higher fixed cost per unit of installed capital than small firms, the threshold level of disinvestment is negatively related to the size of firms. Along the same line, the positive relationship between the fixed cost per unit of installed capital $p_{K}$ and the size of firms causes the threshold level of positive investment to be higher for large than for small firms. ${ }^{40}$ Given the properties of the price variables $p_{I}$ and $p_{K}$, the range of zero investment is a positive function of firm size. Figure 3.1 summarizes the relationships for the case when the purchase price per unit of capital $p_{1}^{+}$ differs between small and large firms, while the sale price per unit of capital $p_{I}^{-}$is the same.

The relationships so far attribute differences in the threshold levels of zero and non-zero investment between small and large firms to size-related asymmetries (i) in the type and hence per unit price of capital $\mathrm{p}_{\mathrm{I}}$ and (ii) in the degree of organizational and informational inefficiencies and hence in the fixed price per unit of installed capital $p_{K}$. While the type of capital affects the cost per unit of investment $p_{\mathrm{I}}$, inefficiencies determine the fixed adjustment

\footnotetext{
${ }^{39}$ Given the assumption that $\lambda$ is nonnegative, $\underline{\lambda}$ can also be nonnegative. If these conditions are met, negative investment can constitute an optimal investment decision.

${ }^{40}$ Recall, the fixed cost per unit of installed capital is assumed to be larger for large than for small firms. This relationship rests on organizational and informational inefficiencies at the firm level which are assumed to be more pronounced for large firms.
} 
Figure 3.1: Small- and Large-Firm Investment Behavior with Size-Dependent Capital

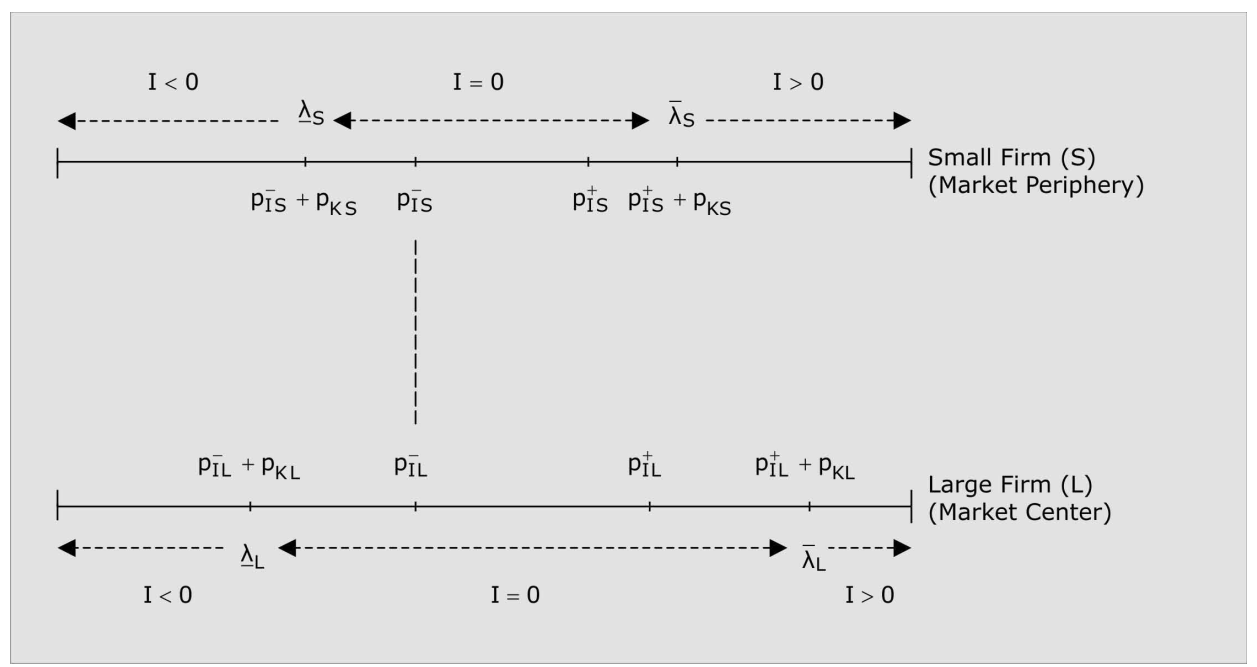

$\underline{\lambda}_{S}$ and $\underline{\lambda}_{\mathrm{L}}$ denote the lower investment threshold levels for small and large firms, respectively and $\bar{\lambda}_{\mathrm{S}}$ and $\bar{\lambda}_{\mathrm{L}}$ represent the corresponding upper threshold levels. The variables $\mathrm{p}_{\mathrm{I}}^{-}$and $\mathrm{p}_{\mathrm{I}}^{+}$describe the sale and purchase price per unit of capital, respectively. The variable $\mathrm{p}_{K}$ denotes the fixed cost of capital adjustment per unit of existing capital.

cost per unit of installed capital $\mathrm{p}_{\mathrm{K}}$. One may argue, however, that the assumed dependence of small- and large-firm production on different types of capital is overly restrictive and that the cost per unit of capital investment $p_{1}$ does not differ between small and large firms. Alternatively, one may question the dual market assumption. Disregarding this assumption and assuming that small and large firms employ similar types of capital, we still find the range of investment inactivity to increase with firm size. The size-related asymmetries in the threshold levels of zero and non-zero investment are due to differences in the fixed adjustment cost per unit of installed capital $\mathrm{p}_{\mathrm{K}}$. This price variable is thus the stronger source of asymmetry in the investment behavior of small and large firms. Differences in the type of capital only amplify asymmetries in the optimal investment behavior of small and large firms. Figure 3.2 illustrates the corresponding relationships.

Summarizing the results, the discussion shows that the solution to the intertemporal investment problem depends on two factors. The first factor is the actual firm-specific shadow value of installed capital $\lambda$. The second factor refers to the components of the augmented investment cost function which determine the threshold levels of $\lambda$ above and below which positive and negative investment is undertaken. Because these boundaries do not coincide, they also define the region in which firms do not invest. Differences in the investment decisions of small and large firms in a dual market structure arise from size-related dissimilarities 
Figure 3.2: Small- and Large-Firm Investment Behavior with Size-Independent Capital

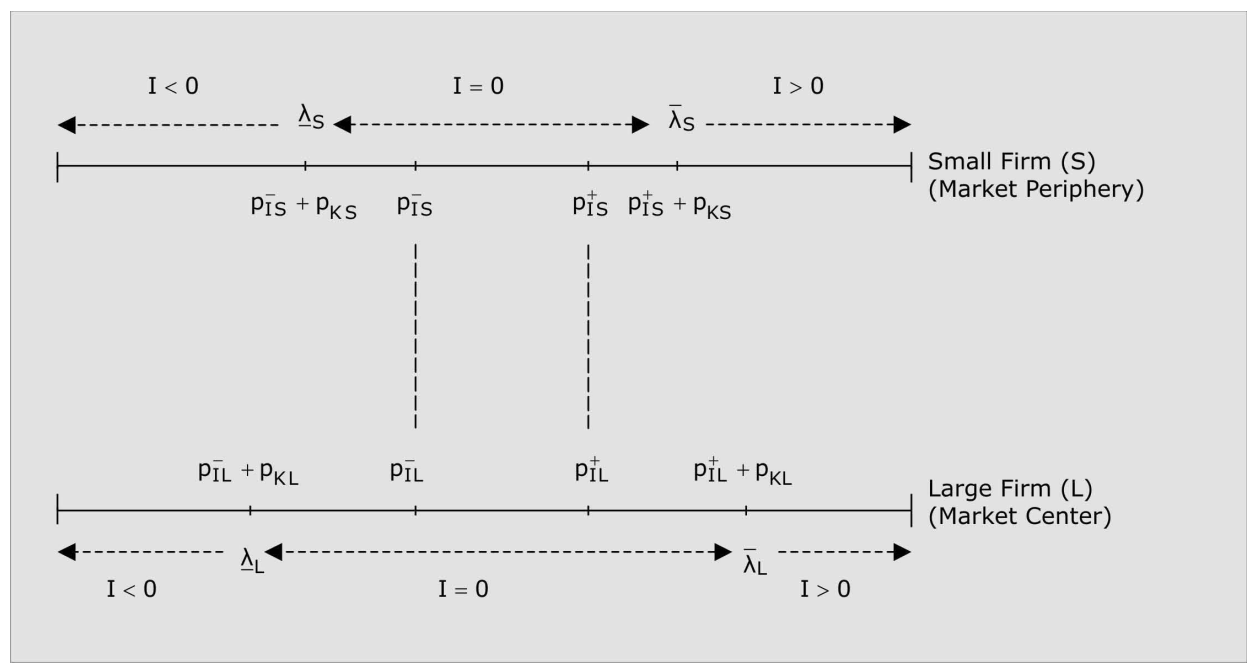

See the notes to Figure 3.1. Figure 3.2 has the same dimension as Figure 3.1. The sale and purchase price per unit of capital $\mathrm{p}_{\mathrm{I}}^{-}$and $\mathrm{p}_{\mathrm{I}}^{+}$is the same for small and large firms, which reflects the size independence of the type of capital. Size-related differences only prevail with respect to the fixed adjustment cost per unit of existing capital $\mathrm{p}_{\mathrm{K}}$.

in the fixed (exogenous) adjustment cost per unit of installed capital $p_{K}$ and in the endogenous sunk cost per unit of capital $\mathrm{p}_{\mathrm{I}}$. We find the fixed adjustment cost per unit of installed capital to be the more important source of asymmetries in the investment behavior of small and large firms.

The present model also allows for inferences regarding the degree of gradualism at which small and large firms adjust investment. In line with Cabral (1995), we predict small firms to invest more gradually in comparison to large firms given a smaller range of inaction. However, the size-related differences in investment behavior do not result from size-related asymmetries in the probability of industry exit as in Cabral (1995), but from dissimilarities in the capital purchase/sale cost per unit of capital $\mathrm{p}_{\mathrm{I}}$. In addition, we propose that discrete jumps in investment due to the fixed adjustment cost per unit of installed capital $\mathrm{p}_{\mathrm{K}}$ are less accentuated for small than for large firms. The following section uses the results of the theoretical model to answer the question whether size-related differences in the relative importance of fixed capital adjustment costs and endogenous sunk costs explain differences in the sensitivity of small- and large-firm investment to changes in monetary policy. 


\subsection{Firm Size and Interest Rate Sensitivity}

Equation (3.10) in combination with equation (3.13) illustrates that fluctuations in the fundamental value of a firm do not only stem from changes in technology and capital. Instead, changes in the firm-specific interest rate $r$ - defined as the money market interest rate $r_{M}$ adjusted for firm-specific risk $r_{F P}$ - also influence the fundamental firm value and accordingly optimal investment behavior. This section discusses the response of small- and large-firm investment to an increase in the money market interest rate, i.e., to a tightening in monetary policy. We will show that the interest rate response of small- and large-firm investment differs and that size-related differences are due to size-related dissimilarities (i) in the range of zero and non-zero investment activity and (ii) in the fixed adjustment cost per unit of installed capital $\mathrm{p}_{\mathrm{K}}$.

In reality, investment decisions do not depend on the money market (i.e., short-term) interest rate, but on long-term rates. We approximate monetary policy changes with the money market interest rate for illustrative purposes, noting that long-term rates are a function of short-term rates. Motivated by the expectations theory of the term structure (Hicks, 1939) and the observation of upward sloping yield curves, we assume that a money market interest rate shock changes the long-term interest rate in the same direction given that long-term rates reflect the average expected level of short-term interest rates over the relevant horizon. ${ }^{41}$ Because of these relationships, we discuss the interest rate response of small- and large-firm investment in terms of the money market interest rate.

In order to focus the analysis, we impose the following simplifying assumptions. Firstly, small and large firms do not differ in terms of firm-specific risk $r_{F P}$ and with respect to the interest rate sensitivity of the firm-specific risk premium. These assumptions ensure that the theoretical results are attributable to size-related differences in the investment expenditures per unit of capital and not to size-related asymmetries in the degree of riskiness which may result in credit constraints due to credit market imperfections. The main conclusions are robust to these assumptions. In fact, the results would even strengthen when we would follow the common literature and assume that small firms are riskier than large firms. ${ }^{42}$

\footnotetext{
${ }^{41}$ We ignore any perverse effects of expected inflation on the long-term interest rate and assume that term and risk premiums are time-invariant. Term and risk premiums are therefore not allowed to offset the effect of changes in the short-term interest rate on long-term rates. Evans and Marshall (1998) and Diebold, Rudebusch, and Arouba (2003), among others, provide empirical evidence in favor of the expectations hypothesis. Ellingsen and Söderström $(2001,2003)$ develop a theoretical model and report evidence according to which endogenous (exogenous) monetary policy changes cause long-term interest rates to be positively (negatively) related to short-term interest rates. Endogenous changes are related to the state of the economy, while exogenous changes are due to changes in the monetary policy preferences of central bankers.

${ }^{42}$ See Baas and Schrooten (2005) for a theoretical model that reports higher loan interest rates for small than for large firms even in relationship banking. Elsas and Krahnen (1998), Harhoff and Körting (1998), and Gambacorta (2005), among others, report empirical evidence of an inverse relationship between firm size and credit spreads in Germany and Italy.
} 
Secondly, we contemplate that small and large firms operate in the region of investment inactivity prior to the interest rate shock. The position of all firms within the range of zero investment is determined by the shadow value of capital in equation (3.13) which is assumed to be the same for small and large firms, i.e., $\lambda_{\text {small }} \cong \lambda_{\text {large }}$ at the time of the change in the money market interest rate. This is a long-run equilibrium condition that holds when the degree of risk in the market center equals the degree of risk in the market periphery. For equal risk, persistent differentials in the shadow value of capital cannot prevail because they are eliminated in course of an arbitrage process between the market center and market periphery. ${ }^{43}$

Analytical conclusions are drawn by assuming that the interest rate response of the shadow value of capital of small and large firms is identical. In order to define the sensitivity of the shadow value of capital to a change in the money market interest rate, we start by explicitly defining the time discount factor $\beta$ as the combination of the money market interest rate $r_{M}$ and the firm-specific risk premium $r_{F P}$ according to

$$
\beta_{\mathrm{t}}=\frac{1}{1+\mathrm{r}_{\mathrm{M}, \mathrm{t}}+\mathrm{r}_{\mathrm{FP}, \mathrm{t}}}=\frac{1}{1+\mathrm{r}_{\mathrm{t}}}
$$

The firm-specific risk premium is a function of the money market interest rate defined as $\mathrm{r}_{\mathrm{FP}, \mathrm{t}}=\alpha \mathrm{r}_{\mathrm{M}, \mathrm{t}}$, where $\alpha>0$. The time discount factor at time $\mathrm{t}$ accordingly equals

$$
\beta_{\mathrm{t}}=\frac{1}{1+\mathrm{r}_{\mathrm{t}}}=\frac{1}{1+(1+\alpha) \mathrm{r}_{\mathrm{M}, \mathrm{t}}}
$$

Because small and large firms are equally risky, we have $\alpha_{\text {small }}=\alpha_{\text {large }}$. For small and large firms, the response of the shadow value of capital at time $t$ with respect to a change in the money market interest rate at time $t+1$ and at time $t+s$ then equals

$$
\begin{gathered}
\frac{\partial \lambda_{\mathrm{t}}}{\partial \mathrm{r}_{\mathrm{M}, \mathrm{t}+1}}=-\frac{(1-\delta)(1+\alpha) \mathrm{r}_{\mathrm{M}, \mathrm{t}+1}}{\left(1+(1+\alpha) \mathrm{r}_{\mathrm{M}, \mathrm{t}+1}\right)^{2}} \mathrm{E}\left(\lambda_{\mathrm{t}+1}\right), \\
\frac{\partial \lambda_{\mathrm{t}}}{\partial \mathrm{r}_{\mathrm{M}, \mathrm{t}+\mathrm{s}}}=\mathrm{E}_{\mathrm{t}}\left\{\sum_{\mathrm{s}=0}^{\infty}-\frac{(1-\delta)^{\mathrm{s}}(1+\alpha) \mathrm{r}_{\mathrm{M}, \mathrm{t}+\mathrm{s}}}{\left(1+(1+\alpha) \mathrm{r}_{\mathrm{M}, \mathrm{t}+\mathrm{s}}\right)^{2}}\left(\frac{\partial \pi_{\mathrm{t}+\mathrm{s}}}{\partial \mathrm{K}_{\mathrm{t}+\mathrm{s}}}-\frac{\partial \mathrm{C}_{\mathrm{t}+\mathrm{s}}}{\partial \mathrm{K}_{\mathrm{t}+\mathrm{s}}}\right)\right\},
\end{gathered}
$$

respectively. ${ }^{44}$ As indicated, the interest rate response of small- and large-firm investment is the same when the shadow value of capital is at the size-independent long-run equilibrium

\footnotetext{
${ }^{43}$ Note, the long-run equilibrium condition $\lambda^{*} \cong \lambda_{\text {small }} \cong \lambda_{\text {large }}$ holds even if small and large firms differ in terms of risk. The cross-firm heterogeneity in riskiness is reflected in the risk-adjusted discount factor $\beta$ and hence in the fundamental firm value (cf. equation 3.8).
}

${ }^{44}$ Equation (3.25) is derived using equation (3.13). 
value $\lambda^{*}$ at the time of the interest rate change. Furthermore, we assume that the rate of capital depreciation is independent of firm size and hence the same for customized and standardized capital and that persistent differentials in net operating profits are infeasible because of arbitrage.

Given these preliminaries, we illustrate the response of large- and small-firm investment to a monetary policy contraction for two cases which differ in terms of the assumed magnitude of the interest rate shock. Case 1 discusses the investment effects of a small increase in the money market interest rate. For this scenario, large firms are assumed to move within their range of investment inactivity without crossing the threshold level of negative investment. Opposite to this, small firms are assumed to leave the range of zero investment, starting to disinvest. Case 2 represents the investment effects of a large increase in the money market interest rate. The contraction in monetary policy is such that small as well as large firms cross the threshold levels associated with negative investment. The discussion of case 1 and 2 will show that size-related differences in the interest rate response of investment are primarily due to size-related differences in the fixed cost per unit of installed capital $p_{k}$. The fixed cost affects the interest rate sensitivity of investment through its effect on the magnitude of the discrete jump in capital, which prevails once the shadow value of capital $\lambda$ crosses the threshold of zero and non-zero investment.

Figure 3.3 illustrates the effect of a small (case 1) and large (case 2) interest rate shock on the investment behavior of small and large firms. ${ }^{45}$ The picture is drawn by assuming that small and large firms, respectively, employ standardized and customized capital. As noted in section 3.3.5, the conclusions of the model are robust to this assumption. In line with the arguments above (cf. equation 3.24 and 3.25), the shadow value of large- and small-firm capital reacts to the same extent to a change in the money market interest rate.

Considering case 1 of a change in monetary policy, a small increase in the money market interest rate lowers the shadow value of capital of small and large firms from $\lambda^{*}$ to $\lambda_{\mathrm{SI}}$. The change in the shadow value of capital causes small firms to adjust their investment behavior: small firms move from the region of investment inactivity to the range of disinvestment. Small-firm investment falls by $\overline{\mathrm{OA}}$ in due course, with the strength of the effect being determined by the fixed adjustment cost per unit of installed capital $p_{K}$. Different to small firms, the interest rate response of large-firm investment is confined to adjustments within the range of zero investment. Large firms move closer to the boundaries of negative investment, but do not cross the threshold. The asymmetry in the interest rate sensitivity of small- and large-firm investment reflects the size-related difference in the range of investment inactivity which originates from size-related differences in the investment expenditures per unit of capital $\left(\mathrm{p}_{\mathrm{I}}, \mathrm{p}_{\mathrm{K}}\right)$.

The size-related asymmetry in the interest rate sensitivity of small and large firms coheres

\footnotetext{
${ }^{45}$ Note, Figure 3.3 reflects arbitrary values. The shape of the graph is chosen for illustrative purpose.
} 
Figure 3.3: The Investment Effects of a Small and Large Interest Rate Shock

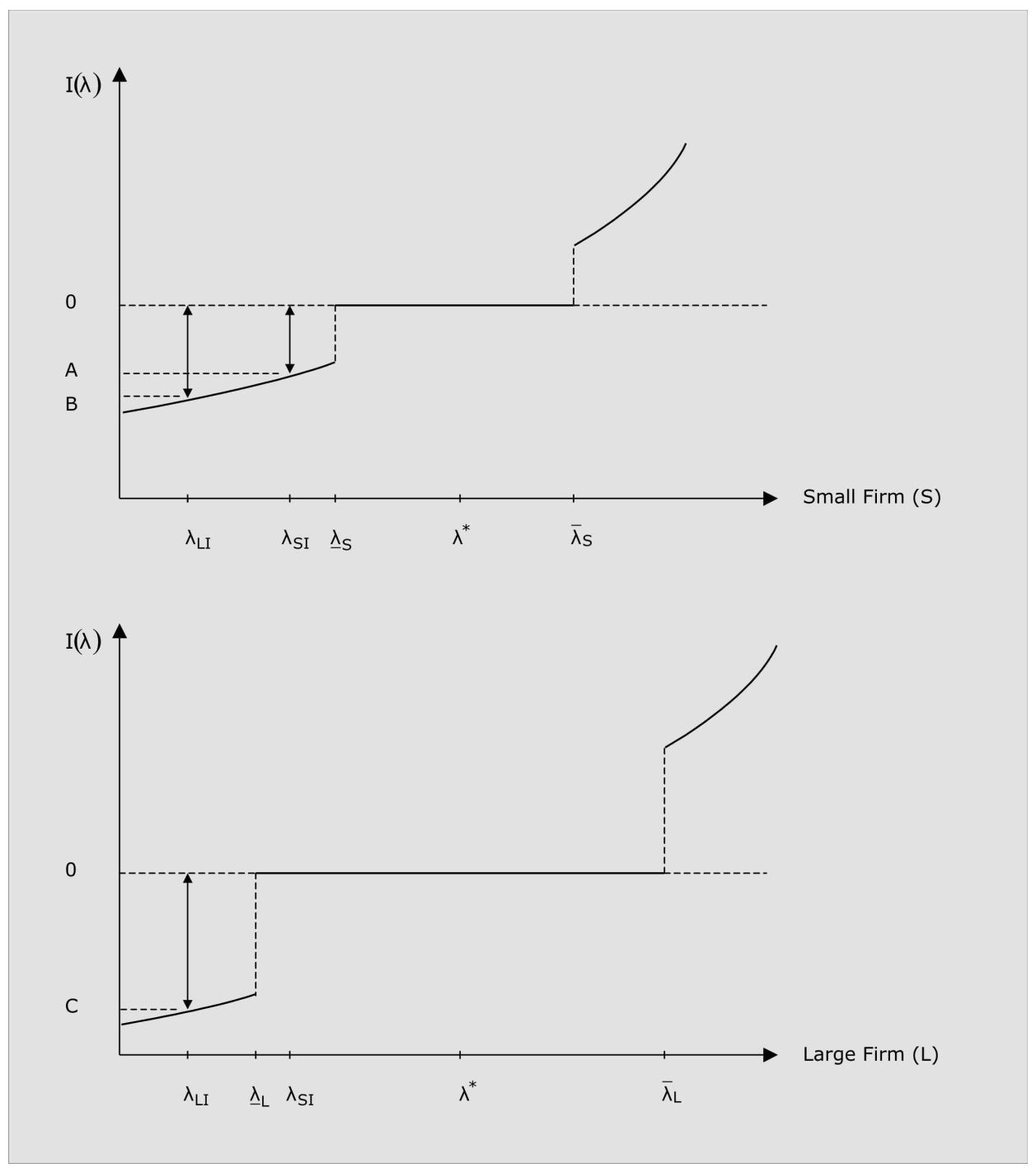

Figure 3.3 is adopted from Böhm and Funke (1999). The solid lines denote the investment path of firms. $\lambda^{*}$ denotes the equilibrium shadow value of capital, which is the same for small and large firms. $\lambda_{\mathrm{SI}}$ and $\lambda_{\mathrm{LI}}$ represent the shadow value of capital prevailing after the 'small' and 'large' interest rate shock, respectively. Figure 3.3 is drawn for the case of linear homogeneity of investment and capital in the investment cost function. Note, the small firm panel has the same dimension as the large firm panel. For example, $\lambda^{*}, \lambda_{\mathrm{SI}}$, and $\lambda_{\mathrm{LI}}$ are at the same position in both panels. 
well with the empirical finding in, for example, Gertler and Gilchrist (1994), Oliner and Rudebusch (1996), Ganley and Salmon (1997), De Bondt (2000), Dedola and Lippi (2005), and Ehrmann (2004) according to which small firms are relatively more responsive to interest rate shocks than large firms. However, it contradicts the evidence in Carlino and DeFina (1998, 1999a, 1999b, 2000), Mojon, Smets, and Vermeulen (2002), and Arnold and Vrugt (2004). The latter evidence can theoretically be explained with case 2 which stresses the response of investment to a large interest rate shock. Figure 3.3 illustrates a large interest rate shock as a decline in the shadow value of capital of small and large firms from $\lambda^{*}$ to $\lambda_{\mathrm{LI}}$. The decline in $\lambda$ causes small as well as large firms to adjust their investment behavior: small and large firms move from the region of investment inactivity to the region of disinvestment. When crossing the threshold levels, small- and large-firm investment behavior displays discrete jumps. Investment by small and large firms falls by $\overline{\mathrm{OB}}$ and $\overline{\mathrm{OC}}$, respectively. Because the fixed cost per unit of installed capital $p_{K}$ increases with the size of firms, the discrete jumps are more accentuated for large than for small firms, with $\overline{\mathrm{OC}}>\overline{\mathrm{OB}}$. Stated differently, largefirm investment is more interest rate sensitive than small-firm investment for large interest rate changes.

Summarizing the results, we stress the role of size-related asymmetries in investment irreversibility as source of differences in the interest rate response of small and large firms. We show that the interest rate sensitivity of small- and large-firm investment depends on the cost per unit of capital investment through its effect on the range of non-zero and zero investment activity. Furthermore, the interest rate response depends on the magnitude of the monetary policy change, which determines the extent to which small- as well as large-firm investment displays discrete jumps. We find that large firms do not move as often as small firms, but when they move, the change in investment is more pronounced than that of small firms. Overall, we illustrate that monetary policy shocks of different magnitudes have asymmetric effects on large- and small-firm investment. This, however, suggests that conclusions as to the existence of small firm size effects of monetary policy crucially depend on the magnitude of the monetary policy change.

\subsection{Conclusion}

This chapter presented a dynamic investment model that aimed at explaining differences in the interest rate sensitivity of small- and large-sized firms. Different to existing studies on the firm size effects of monetary policy, the importance of firms as monetary transmission channel does not result from credit market imperfections, but from investment irreversibility. The theoretical model suggests that conclusions as to the interest rate sensitivity of small and large firms depend on two interacting factors: the cost of capital investment and the magnitude of the monetary policy shock.

As to the first factor, the augmented investment cost function was modeled to consist of 
endogenous and exogenous (fixed) investment expenditures. Endogenous sunk costs relate to $R \& D$ expenditures and affect the type of capital that firms operate, while exogenous sunk costs arise from organizational and informational inefficiencies. We have shown that the adjustment costs per unit of capital investment determine the width of the region for which zero and non-zero investment is optimal. Assuming a dual market structure, the adjustment costs per unit of capital investment and hence the region of investment inactivity are positively related to firm size. The size-related differences in the adjustment costs per unit of capital investment and hence in the range of investment inactivity suggest, on the one hand, that small firms change investment regimes more frequently than large firms. On the other hand, if small and large firms change investment regimes, size-related differences in the fixed cost per unit of existing capital cause swings in large-firm investment to be more accentuated than swings in small-firm investment. This finding is in line with the prediction by Cabral (1995) according to which small firms invest more gradually than large firms.

Considering the second factor, the magnitude of the interest rate change was shown to determine the investment response of small and large firms: small firms change investment regimes for smaller monetary policy shocks than large firms. For pronounced changes in monetary policy, the investment response of large firms was predicted to be stronger than that of small firms. Again, the size-related asymmetries arise from differences in the adjustment cost per unit of capital investment and from the consequent dissimilarities in the width of the range of investment inactivity.

We also argued that the size-related differences in investment behavior and in the interest rate sensitivity of firm investment prevail even if large firms do not incur endogenous sunk costs and small and large firms consequently operate similar types of capital. While the assumption of a dual market structure amplifies the main conclusions of the present model, they do not depend on it. Fixed adjustment costs per unit of existing capital have the strongest effect on the investment behavior of small and large firms and on the interest rate response of firm investment. Being at the core of size-related organizational and informational inefficiencies, fixed capital investment expenditures affect investment behavior regardless of the underlying market structure.

In summary, the interest rate sensitivity of small and large firms is determined by the cost of capital investment and by the magnitude of the change in the money market interest rate. Because the interest rate response of small and large firms depends on the relative importance of these factors, conclusions as to the nature of the relationship between the interest rate sensitivity of firm investment and firm size cannot clearly be drawn. This finding indicates that the effectiveness of monetary policy cannot unambiguously be linked to the relative share of small firms in an economy as is frequently done in empirical work. Instead, we conclude that large firms may also drive monetary policy effectiveness via an investment channel and the underlying degree of investment irreversibility. This in turn suggests that tests for firm size effects of monetary policy should allow for small and large firm size effects. 


\section{New Evidence on the Firm Size Effects in US Monetary Policy Transmission}

\subsection{Introduction}

The United States and the Euro area constitute the most prominent monetary unions of our time. In the years preceding the formation of the European economic and monetary union (EMU), the United States were frequently treated as the natural yardstick against which to assess the appropriateness of the European countries' decision to adopt a common currency. The usefulness of the United States as benchmark country arises from two sources. Firstly, similar to the Euro area, the United States comprise a large set of heterogeneous regions whose economic performance is influenced by the actions of a single central bank. Secondly, in contrast to the Euro zone countries, the United States report high-quality data of sufficient length on the structural characteristics of its regions. Regional disaggregated data are the necessary prerequisite for the appropriate identification of factors that determine the process of monetary transmission and that cause cross-region differences in the effects of monetary policy. Since disaggregated data are not available for a comprehensive sample of Euro zone regions, investigations of the transmission of US monetary policy may provide insights into the regional effects of the monetary policy of the European Central Bank (ECB).

A large theoretical and empirical literature exists that stresses relative asset prices, wealth, exchange rates, financial structure and the interest rate sensitivity of industries, firms, and banks as mechanisms that propagate and amplify the effects of monetary policy on economic activity. Because these transmission channels do not work independently from each other, regional differences in the effectiveness of monetary policy are attributable to regional dissimilarities in their relative importance. This chapter acknowledges the importance of the numerous mechanisms as source of cross-region differences in the effectiveness of monetary policy. It seeks to provide further evidence for the role of industry mix and firm size distribution as monetary transmission channels. As is illustrated in chapter 2 , these variables are typically used to study monetary policy transmission through an interest rate channel or credit channel, respectively.

Most empirical studies of monetary policy effectiveness report results that point to the role 
of small-sized businesses as monetary transmission mechanism. ${ }^{1}$ The statistical significance of the business size variable is usually taken as evidence of the importance of credit market imperfections. Explanations which attribute the firm size effects of monetary policy to the operation of an investment channel (cf. chapter 3) are not considered. In attributing the business size effect to the operation of a credit channel, existing studies largely neglect the possible interaction between business size and the cyclical sensitivity of industries. However, as Eichenbaum (1994) notes, the potential interdependence of business size and industry complicates the identification of factors associated with either the credit channel or interest rate channel. For example, if business size would be correlated with the cyclical behavior of industries, the neglect of industry effects in empirical work could explain the significance of business size, even in the absence of any credit market imperfections.

Motivated by the argument of Eichenbaum (1994), this chapter aims to analyze the industry effects of monetary policy in more detail. To this end, we first analyze the interest rate sensitivity of US industry earnings over the period 1958-2000/01. Having documented differences in the interest rate sensitivity of industries, we next investigate whether the industry characteristics business size and capital intensity can explain the cross-industry heterogeneity of monetary policy effects. This will enable an assessment of the nature of the interrelationship between business size and the cyclical sensitivity of industries. Does business size indeed pick up industry effects, as Eichenbaum (1994) suggests, or is there an independent effect of business size? Attention is also paid to the capital intensity of production as an additional determinant of monetary policy effectiveness. In contrast to business size, this industry characteristic is more closely associated with the interest rate channel of monetary policy than with the credit channel. ${ }^{2}$

The remainder of this chapter is structured as follows. Section 4.2 reviews the role of interest rates and credit market conditions as monetary transmission mechanisms and as potential sources of regional differences in the effects of monetary policy. ${ }^{3}$ Section 4.3 reports the results of the time-series analysis of the interest rate channel. Cross-section differences in the effects of monetary policy are detected by determining the interest rate sensitivity of economic activity by industry sector and by US state. Building on the estimates of the time-series study, section 4.4 describes the cross-section analysis that links the long-run interest rate sensitivity of industries to the size distribution of businesses and to the degree of capital intensity. Estimates are derived for specifications that exclude and include interrelationships between business size and industry. Section 4.5 contains concluding comments and presents lines of future research. Annex 4B reports empirical evidence on the firm size effects for countries in Europe. The evidence is mainly reported for completeness and should not be used to draw

\footnotetext{
${ }^{1}$ Section 4 in chapter 2 and section 2 in the present chapter provide details.

${ }^{2}$ Chapter 2 provides theoretical arguments for the role of capital intensity as monetary transmission mechanism and chapter 6 reports additional (although weak) empirical evidence.

${ }^{3}$ Because of data unavailability, the present study cannot determine whether the firm size effects of monetary policy are also attributable to the operation of an investment channel (cf. chapter 3 ).
} 
inferences as to the industry effects of monetary policy in Europe. Given the unavailability of data of sufficient quality for a sample period of sufficient length, the explanatory power of the models is very low and the quality of the results is poor.

\subsection{Transmission Mechanisms of Monetary Policy}

The literature attributes the effectiveness of monetary policy to the operation of numerous monetary transmission channels. Regional differences in the relative strength of these monetary transmission mechanisms explain regional dissimilarities in the effects of monetary policy. This section reviews the transmission of monetary policy through the interest rate and credit channel. ${ }^{4}$ In most empirical work, the factors the present study focuses on - industry effects, business size, and capital intensity - are associated with one of these two channels.

The discussion about the role of interest rates in the monetary transmission process is also referred to as the debate on the relevance of the money view. ${ }^{5}$ According to this latter approach, market interest rates constitute the main avenue through which monetary policy operates. The interest rate channel results from price stickiness that causes changes in monetary policy to have real short-run effects. Following a contraction in monetary policy, the real effects arise from an increase in the user cost of capital that lowers the degree of physical capital investment and durable goods consumption. This development comes at the expense of lower industry output, especially in industries producing investment goods and durable consumption goods. These industries tend to be capital intensive in production.

The interest rate channel attributes regional differences in the real effects of monetary policy to regional dissimilarities in the relative importance of capital-intensive and interest-sensitive industries and hence to regional differences in economic structures. ${ }^{6}$ Previous empirical research has shown that regions with a large share of capital-intensive industries like goods manufacturing, mining, construction, and transportation are likely to respond more strongly to interest rate disturbances than less capital-intensive industries like the service, government, and agricultural sector. ${ }^{7}$

Different to the traditional interest rate approach, the credit view goes beyond the concept

\footnotetext{
${ }^{4}$ See, for example, Bernanke and Gertler (1995), Christiano, Eichenbaum, and Evans (1999), Dornbusch, Favero, and Giavazzi (1998), Kieler and Saarenheimo (1998), De Bondt (1998), and chapter 2 for surveys of the different theoretical and empirical analyses of monetary policy transmission channels.

${ }^{5}$ See Hubbard (1995), Kashyap and Stein (1995), Mojon (2001), Kakes, Sturm, and Maier (2001), and Kuttner and Mosser (2002) for a detailed discussion of the traditional interest rate channel.

${ }^{6}$ Because the strength of the interest rate effects depends on industry structure, the interest rate channel can also be referred to as the industry channel.

${ }^{7}$ Ganley and Salmon (1997) provide evidence of cross-industry differences in the interest rate sensitivity of output for the United Kingdom. Evidence of regional or cross-country disparities in the strength of the interest rate channel is provided by Carlino and DeFina (1998, 1999a, 1999b, 2000), Hayo and Uhlenbrock (2000), Arnold (2000), Dedola and Lippi (2005), Arnold and Vrugt (2004), and Peersman and Smets (2005).
} 
of sticky prices in that it also considers frictions in financial markets. Dependent on whether capital market imperfections are modeled to be more important at the level of banks or firms, a distinction is made between the narrow and broad credit channel, respectively. Both credit channels require external and internal funds to be imperfect substitutes because of information asymmetries in financial markets. ${ }^{8}$ The narrow credit view, also known as the bank lending channel, emphasizes the influence of monetary policy actions on bank lending through their effect on bank reserves. ${ }^{9}$ At the core of this monetary transmission channel is the practice of banking institutions to finance loans in part with liabilities that are subject to reserve requirements. Considering a tightening in monetary policy, the level of bank reserves declines due to the consequent sale of securities. In the presence of credit market imperfections, banks cannot offset the fall in reserves with alternative forms of non-reservable finance. Their ability and willingness to supply loans therefore deteriorates. If firms or households are bank-dependent and lack substitutes for bank loans, the cutback in bank lending raises competition for loans among debtors. In worsening the terms under which debtors can obtain funds from banks, the decline in loan supply may curtail consumption and investment and thus aggregate spending.

The broad credit view, also known as the balance sheet channel, works through the influence of monetary policy on the balance sheet position of potential borrowers such as firms. ${ }^{10}$ Following a monetary tightening, the balance sheet position of firms deteriorates. Because of asymmetric information problems in credit markets, this development causes an increase in the risk premium on external funds. Reflecting the decline in the creditworthiness of firms, the higher risk premium comes along with a cutback in lending to debtors on the part of bank and non-bank financial institutions. Similar to the bank lending channel, the decline in the supply of external funds comes at the expense of lower investment. ${ }^{11}$

Given the reasoning of the broad and narrow credit view, regional dissimilarities in the strength

\footnotetext{
${ }^{8}$ See Bernanke and Blinder (1988), Bernanke and Mihov (1998), Bernanke, Gertler, and Gilchrist (1999), and Gertler and Gilchrist (1993b, 1994). Chrystal and Mizen (2002) develop a structural flow of funds model for firms, households, and financial institutions to describe the money-determined supply and demand effects of credit supply.

${ }^{9}$ See Bernanke and Blinder (1988), Gertler and Gilchrist (1993), Kashyap, Stein, and Wilcox (1993) for a discussion of the bank reserve channel. See Romer and Romer (1990), Kashyap and Stein (2000), and Van den Heuvel (2002a, 2002b) for a criticism on the significance of the bank lending effects of monetary policy. Kashyap and Stein (1997) and Angeloni, Kashyap, Mojon, and Terlizzese (2003), among others, report evidence in favor of a bank lending channel. Garretsen and Swank (1998), Favero, Giavazzi, and Flabbi (1999), Kakes, Sturm, and Maier (2001), and Topi and Vilmunen (2003) present results which lend weak or no support to the bank lending effects of monetary policy.

${ }^{10}$ See Gertler and Gilchrist (1994), Oliner and Rudebusch (1996), Ganley and Salmon (1997), De Bondt (2000), Dedola and Lippi (2005), Perez-Quiros and Timmermann (2000), Audretsch and Elston (2002), and Ehrmann (2005) for studies that lend support to the operation of a balance sheet channel. Kalckreuth (2003) finds firm size to be weakly important. Carlino and DeFina (1998, 1999a, 1999b, 2000), Siegfried (2000), and Arnold and Vrugt (2004) do not find evidence for the broad credit channel.

${ }^{11}$ Similar arguments can be used to explain the negative relationship between interest rates and household consumption spending.
} 
of the credit channel reflect disparities in the structure of financial markets. The narrow credit view attributes these differences to regional asymmetries in the size distribution of banks. Regions with a relatively large share of poorly capitalized banks would respond more strongly to changes in the monetary policy stance than regions with a large proportion of wellcapitalized banks. The broad credit view links regional differences in monetary transmission to differences in the size distribution of firms. Information asymmetries and a lower level of net worth increase the bank dependence of small firms relative to large businesses and hence the susceptibility of small firms to fluctuations in bank loan supply. ${ }^{12}$ So, regions with a high share of small firms should respond more strongly to monetary policy shocks.

According to Eichenbaum (1994), firm size is an appropriate measure of the credit channel only if size and industry are not interdependent. If this condition does not hold, the unique identification of the credit channel effects and interest rate effects of monetary policy will not be possible. Evidence in favor of a credit channel - based on a significant firm size effect - will hence be biased in estimations that do not control for industry effects. Gertler and Gilchrist (1994) and Ehrmann (2005) try to solve this problem in the following ways. Gertler and Gilchrist (1994) assess the independence properties for the United States by computing the ratio of durable sales over total manufacturing sales for five size classes. Since the evidence points to equal ratios for the sampled size categories, size distribution is concluded to be unrelated to industry. Ehrmann (2005) addresses the interdependence problem by comparing the distribution of firm size across 27 sub-sectors of the German manufacturing industry. Because all size categories are present in almost all sub-sectors, he decides not to model the interaction between firm size and industry.

Yet in our view, neither Gertler and Gilchrist (1994) nor Ehrmann (2005) succeed in satisfactorily solving the independence problem. The industry classification in Gertler and Gilchrist (1994) lacks detail. Regarding Ehrmann's (2005) solution: even the presence of all size categories in every sub-sector does not exclude the possibility of interdependence. Arnold and Vrugt (2004) formally test the independence assumption by identifying the relative contribution of regions and industries to the variation in firm size for German data. ${ }^{13}$ Their results show that industries are the main source of variation in business size, suggesting that business size and industry are related. Motivated by their results of the independence tests, Gertler and Gilchrist (1994) and Ehrmann (2005) test for the existence of a credit channel excluding industry effects, whereas Arnold and Vrugt (2004) include industry dummy variables. The first two studies subsequently report evidence in favor of a credit channel, while the third study provides counter-evidence. Apparently, controlling for industry effects can strongly affect the empirical outcomes. ${ }^{14}$

\footnotetext{
${ }^{12}$ See also Gertler and Gilchrist (1993b), Oliner and Rudebusch (1996), Kashyap and Stein (1995, 1997) for a discussion of the differential regional effects.

${ }^{13}$ The study also stresses the sensitivity of empirical evidence to the stratification criteria of firm size.

${ }^{14}$ Carlino and DeFina $(1998,1999 a, 1999 b, 2000)$ unconsciously control for industry effects by including industry variables. The corresponding regression results point to the absence of a credit channel.
} 


\subsection{The Industry Effects of Monetary Policy}

This study explores the relevance of industries in monetary policy transmission by building on the estimation framework in Carlino and DeFina (1998) ${ }^{15}$ and Arnold (2000). Whereas the investigation uses the same structural estimation framework, it adds to the existing work by combining the geographical and sectoral dimension of the earlier studies. In particular, the present investigation resembles Carlino and DeFina (1998) by estimating models for 51 US states, the eight main BEA regions, and the US aggregate. It also follows Arnold (2000) by estimating interest rate sensitivities for a set of industries.

\subsubsection{Empirical Model}

In order to examine the short-run and long-run impact of exogenous monetary policy changes on the performance of industries in US regions ${ }^{16}$, the time-series study involves the estimation of a structural vector autoregressive system. In line with the study of Carlino and DeFina (1998) and Arnold (2000), the vector of endogenous variables consists of real earnings of industry $\mathrm{i}$ in region $\mathrm{j}\left(\mathrm{Y}_{\mathrm{ij}, \mathrm{t}}\right)$, a measure of US energy prices $\left(E P_{\mathrm{t}}\right)$, and $\mathrm{US}$ core consumer prices $\left(\mathrm{CP}_{\mathrm{t}}\right){ }^{17}$ Energy prices and core consumer prices are included to control for supply shocks and to capture developments in the aggregate price level, respectively. Next to these non-policy factors, the Federal funds rate $\left(F F R_{t}\right)$ is included as monetary policy instrument. ${ }^{18}$ The vector of endogenous variables is thus defined as

$$
Z_{i j, t}=\left[\begin{array}{llll}
Y_{i j, t} & C P_{t} & E P_{t} & F F R_{t}
\end{array}\right]^{\prime},
$$

with $\mathrm{i}=1, \ldots, 13$ and $\mathrm{j}=1, \ldots, 60$. That is, we estimate the system separately for each industry $i$ in each region $j$. Except for the Federal funds rate, all variables are expressed in logarithm.

In order to determine whether the vector autoregressive system should be specified in levels or in first differences, we first determine the stationarity properties of the variables. The test statistics of augmented Dicky-Fuller tests (ADF, 1979) and Phillips-Perron tests (PP, 1988)

\footnotetext{
${ }^{15}$ Carlino and DeFina (1999a, 1999b, 2000) build on the same framework as Carlino and DeFina (1998). Given the similarities in the structure of the estimations, the present study uses Carlino and DeFina (1998) as reference.

${ }^{16}$ The term region equally refers to the US aggregate, a US region, or a US state.

${ }^{17}$ The vector of endogenous variables can also include variables that affect the policy variable only with a lag, but respond contemporaneously to policy shocks. Examples of such variables are monetary aggregates and the real exchange rate. Because the estimation results are robust to the inclusion of such variables in the present analysis, they are not further considered.

${ }^{18}$ See, for example, Bernanke and Blinder (1992) and Garcia and Schaller (2002) for arguments which justify the use of the Federal funds rate as measure of the US monetary policy stance.
} 
suggest that the individual time series are integrated of order one. ${ }^{19}$ Standard unit root tests are criticized for not being able to discriminate between near-unit root and unit root processes in small samples. ${ }^{20}$ In order to control for this criticism, the unit root properties are also determined by means of the Kwiatkowski-Phillips-Schmidt-Shin test (KPSS, 1992). The results of the KPSS tests largely confirm the first-difference stationarity of the time series.

Given the unit root behavior of the time series, we test for the presence of cointegrating relationships. For most state-industry combinations, Johansen cointegration tests point to the existence of one or more cointegrating relations in test specifications that include all four endogenous variables. Sims, Stock, and Watson (1990) argue that a vector autoregressive model can be specified in levels when the non-stationary endogenous variables of the system are linked by some cointegrating relations. However, a VAR needs to be specified in first differences when the endogenous variables do not represent a cointegrated system. Because the cointegration tests point to the existence of cointegrating relationships for many, but not all industry-state combinations, the present analysis estimates all state-industry VARs in levels as well as in first differences. Similar to the findings in Carlino and DeFina (1998), the empirical results tend to be robust to the vector autoregressive representation in levels or in first differences. ${ }^{21}$ The remainder of this chapter therefore emphasizes the results of the VAR in levels in order to avoid the exclusion of cointegrating relationships from the vector autoregressive system. ${ }^{22}$

Throughout this study, monetary policy shocks are approximated with one standard deviation shocks to the Federal funds rate. These are identified by means of a recursive Choleski decomposition, with the variables ordered as in equation (4.1). ${ }^{23}$ This ordering implies that the interest rate is contemporaneously affected by changes in industry earnings, core consumer prices, and energy prices. These non-policy variables with inertia, in turn, respond to a shock in the interest rate only with a lag. Furthermore, each of the endogenous variables displays a contemporaneous response to its own shocks.

The Choleski decomposition method is criticized for its seemingly arbitrary assumptions regarding the direction of the causal relationship between monetary policy and measures of economic performance. Kieler and Saarenheimo (1998) and Christiano, Eichenbaum, and Evans (1999), among others, argue that the Choleski factorization does not sufficiently control for the endogeneity of monetary policy changes and that conclusions regarding the causal effect

\footnotetext{
${ }^{19}$ In some cases, ADF and PP statistics provide contrasting evidence. The inconclusive border cases are assumed to be first-difference stationary.

${ }^{20}$ See Nelson and Plosser (1982), DeJong and Whiteman (1991), and Caner and Kilian (2000).

${ }^{21}$ The results of the Johansen cointegration tests and of the first-difference VARs are available on request.

${ }^{22}$ Ramaswamy and Sloek (1997), Ganley and Salmon (1997), Kieler and Saarenheimo (1998), and Carlino and DeFina (1998) also estimate the VAR in levels in order to account for the weakness of unit root test statistics.

${ }^{23}$ More precisely, monetary policy shocks are identified with a lower triangular Choleski factorization of the residual covariance matrix.
} 
of monetary policy on the economy are sensitive to the underlying identification scheme. ${ }^{24}$ We acknowledge the shortcomings of the recursive Choleski identification scheme. In order to determine the robustness of the results to the ordering in equation (4.1), we compute the impulse response functions for different orderings of the variables in the VAR system. The change concerns the position of the money market interest rate (the policy variable) and industry earnings (the non-policy variable) in the vector of endogenous factors. ${ }^{25}$ In putting the policy variable at the first position and the industry earnings variable at the fourth position in the model, the two-year cumulative impulse response estimates change quantitatively, but not qualitatively. While the quantity effect is sizeable for some industry-region combinations, it is marginal for others. Because the change in the ordering of the policy and non-policy variable leaves the nature of the cumulative impulse response effect unaffected, it is assumed not to influence the sign properties of the subsequent cross-section estimates.

The model in equation (4.1) is subject to one more limitation. The structure of the VAR model generates monetary policy shocks which are likely to differ across the individual industry-region specifications. The reason is that the system in equation (4.1) is separately estimated for each industry $\mathrm{i}$ in each region $\mathrm{j}$ given the assumption that interest rates are endogenously determined by industry-specific earnings. ${ }^{26}$ Because the relationship between earnings and interest rates differs between industries and regions, the corresponding monetary policy shock differs and the cumulative interest rate response of earnings cannot be compared across industry-region combinations. An alternative procedure would identify monetary policy shocks from a specification that derives monetary policy shocks from a measure of US aggregate rather than industry-specific output. The cumulative impulse response of region-specific industry earnings could then be determined by adding region-specific industry earnings as exogenous (i.e., last) variable to the aggregate VAR. In the present sample, the approach in equation (4.1) is preferred to the estimation of an integrated system with aggregate output since it yields results which can be compared with those in Carlino and DeFina (1998) and Arnold (2000). Future research will determine the sensitivity of the main conclusions to monetary policy shocks from the alternative specification with aggregate output.

\footnotetext{
${ }^{24}$ For the United States, event studies offer a more promising avenue to address the identification problem of monetary policy. Ehrmann and Fratzscher (2004) and Bernanke and Kuttner (2005) employ information on market expectations and identify the exogenous component of monetary policy changes as the difference between (i) survey-based market expectations regarding the future monetary policy stance and (ii) announcements of the Federal funds rate target (cf. section 2.3.1). While intrinsically appealing, the underlying approach cannot be applied in the present analysis since it requires high-frequency information on industry activity at the state and region level.

${ }^{25}$ The results are robust to a change in the ordering of the variables within the set of non-policy variables. See Christiano, Eichenbaum, and Evans (1999) for an explanation of the invariance property.

${ }^{26}$ Carlino and DeFina (1998) and Arnold and Vrugt (2004) adopt a comparable approach and assume that the monetary policy stance is endogenous to region-specific output in the United States and in Germany, respectively. Arnold (2000) treats US monetary policy as being endogenous to US industry output.
} 


\subsubsection{Time-Series Data}

The VAR specifications model the relationship between earnings in industry $\mathrm{i}$ in region $\mathrm{j}$, price measures, and the Federal funds rate by using annual data. Considering the regional dimension of the study, estimates are computed for each US state, the main eight regions of the Bureau of Economic Analysis (BEA), and a measure of the US aggregate. Turning to the sectoral dimension of the analysis, the empirical estimates are derived for mainly those industries for which business size data are available. In employing two-dimensional disaggregated data, we control for criticisms regarding the use of aggregated data put forward by Carlino and DeFina (1998), Guiso, Kashyap, Panetta, and Terlizzese (1999), and Dedola and Lippi (2005). According to their reasoning, data aggregates are only useful to assess the overall effect of monetary policy, whereas they are unable to capture the direct effects of monetary policy at the industry and regional level. Finally, in order to have a benchmark to compare the interest rate sensitivity of industries, impulse-response estimates are also computed for region-specific personal income - a proxy variable of aggregate industry earnings. Annex 4A contains a detailed description of the data.

Personal income and earnings in industry $\mathrm{i}$ in region $\mathrm{j}$ are expressed in 1996 prices by means of the US implicit GDP deflator. ${ }^{27}$ Besides the indirect incorporation of price developments by deflating nominal industry earnings, the VAR model includes two more measures of prices, i.e., core consumer prices and energy prices. Core consumer prices are approximated by the consumer price index less the effects of food and energy prices. Energy prices are measured by the producer price index for fuels, related products, and power relative to the total producer price index. The monetary policy instrument is approximated by the Federal funds rate. The VAR models are computed by using data for the sample period 1958-1997 and 1958-2000/01. Differences in the endpoint of the sample are due to missing values in some industry earnings series for 1998 and 2001.

The time-series analysis of the interest rate channel is subject to two shortcomings. One weakness concerns the computation of impulse response functions for annual but not for quarterly data. The reason for the limited analytical focus is the unavailability of quarterly data of sufficient quality. In choosing only one time frequency, the analysis cannot account for time aggregation problems that will arise if data of similar quality but different frequencies follow econometric processes that do not mirror each other. If time aggregation matters, it might be that high frequency data generate results that differ from those of low frequency data. Besides, annual data and the underlying assumption that monetary policy shocks only have real effects after one year may amplify the weaknesses of the Choleski decomposition method. The second shortcoming arises from the fact that the short sample period for which annual data are available prevents the computation of impulse response estimates for sub-

\footnotetext{
${ }^{27}$ In using the implicit GDP deflator for the US aggregate, the estimates of real earnings reflect differences in regional industry structures, but do not account for differences in regional prices. It would certainly be more appropriate to deflate the nominal data by using US state price indices. However, if at all, the corresponding data are only available as of 1986 .
} 
sample periods. As a consequence, the analysis cannot control for structural breaks and hence parameter instability in the VAR models and resulting impulse response functions.

\subsubsection{Empirical Results of the Time-Series Analysis}

The empirical results are influenced by the number of lags that are used in the estimation of the VAR model. ${ }^{28}$ The present analysis determines the optimal lag length by minimizing the Akaike information criterion (AIC, 1974). The quality of the estimation results is assessed by testing for serial correlation, normality, and heteroscedasticity in the residuals. Given the interest in the impulse response of industry earnings, the Ljung-Box Q-statistic (Ljung and Box, 1978), Jarque-Bera statistic (Jarque and Bera, 1980, 1987), and Lagrange multiplier test statistic for heteroscedasticity are only computed for the earnings specification of the VAR system. The results of these residual tests indicate that the error terms are well-behaved for almost all cross sections. ${ }^{29}$ In view of this finding, the ordinary least squares (OLS) estimators of the earnings equation are not only unbiased and consistent, but also efficient.

The dynamic impact of a monetary policy shock on industry performance is summarized by the two-year cumulative impulse response of industry earnings. ${ }^{30}$ In order to ascertain the significance of the cumulative impulse response estimates, the impulse response functions of the US aggregate and the US regions are computed with 95 percent analytic asymptotic standard error bands. Since the asymptotic standard error bands are by and large different from zero, the VAR models are concluded to do well in explaining the dynamic response of industry earnings. ${ }^{31}$

Since the time-series analysis is carried out for a large set of industries and regions, complications arise as to the presentation and interpretation of the empirical findings. In order to ensure the readability of the results, this section only discusses the interest rate responsiveness of industries in the eight BEA regions and in the US as a whole. In our view, the restricted focus of the analysis is appropriate given the results of the two-way analysis of variance (ANOVA) of the two-year cumulative impulse response estimates of all cross sections. The analysis of variance reported in Table 4.1 shows the relative contribution of industries and regions as source of variation in the interest rate sensitivity of earnings.

\footnotetext{
${ }^{28}$ Because we employ annual data, the optimum number of lags is allowed to vary between one and two.

${ }^{29}$ The Q-statistic is computed at residual lag one, two, and four. The corresponding diagnostic test statistics are available on request.

${ }^{30}$ Carlino and DeFina (2000) use an eight-quarter horizon to determine the cumulative response of output to a monetary policy shock. The choice of this window is suggested by Monte Carlo studies. These indicate that the maximum cumulative response of output arises around eight quarters (i.e., two years) after the occurrence of a monetary policy disturbance. Also see Arnold (2000) and Arnold and Vrugt (2004) for studies that compute the cumulative impulse responses for a two-year period.

${ }^{31}$ The impulse responses are insignificant for some industry-state combinations. Because the impulse responses are at the core of the subsequent cross-section analysis, this may affect the corresponding evidence. See section 4.4.3 for a discussion of this issue.
} 
Table 4.1: Two-Way Analysis of Variance of the Cumulative Impulse Responses

\begin{tabular}{|c|c|c|c|c|c|c|c|c|}
\hline \multirow[b]{2}{*}{ Source of Variation } & \multicolumn{4}{|c|}{ US States } & \multicolumn{4}{|c|}{ US Regions } \\
\hline & SS & DF & MS & F-Value & SS & DF & MS & F-Value \\
\hline Industries & 0.315 & 10 & 0.0315 & $71.49 *$ & 0.0437 & 10 & 0.0044 & $46.22^{*}$ \\
\hline Regions & 0.105 & 50 & 0.0021 & $4.79^{*}$ & 0.0037 & 7 & 0.0005 & $5.67^{*}$ \\
\hline Error & 0.220 & 500 & 0.0004 & & 0.0066 & 70 & 0.0001 & \\
\hline Total & 0.641 & 560 & & & 0.0540 & 87 & & \\
\hline
\end{tabular}

Note $^{1}$ : SS $=$ sum of squares, DF = degrees of freedom, MS = mean squares (i.e., SS Source divided by $\mathrm{DF}_{\text {Source }}$ ), and $\mathrm{F}$-value $=\mathrm{F}$-statistic (i.e., $\mathrm{MS}_{\text {Source }}$ divided by $\mathrm{MS}_{\text {Error }}$ ). Differences between the MSand F-statistics in the table and the MS- and F-statistics determined in calculations with the reported SS-statistics and the degrees of freedom are due to rounding. Note ${ }^{2}$ : * denotes the statistical significance at the one percent level. Note ${ }^{3}$ : We exclude real personal income and total goods manufacturing from the ANOVA analysis. Columns 2 to 5 summarize the results of the two-way analysis of variance for 51 US States and 11 industries. Columns 6 to 9 present the results of the analysis for the $8 \mathrm{BEA}$ regions and 11 industries.

Formally, the two-way analysis of variance is defined for the hypothesis that the long-run earnings effect of monetary policy is the same across either industries or regions. The entries in Table 4.1 indicate that this hypothesis can be rejected on the state level and the regional level because of discernible cross-industry and cross-region dissimilarities in the effects of monetary policy. Even though impulse responses differ across both industries and regions, the industry effects appear to be the main source of variation in the interest rate effects of monetary policy. This conclusion arises from the observation that the F-value for the industry effect is much larger than the F-value for the regional effect. ${ }^{32}$ Since differences in the effects of monetary policy are predominantly accounted for by differences in the interest rate sensitivity of industries, this study proceeds by evaluating the long-run earnings response of industries for the US aggregate and the main BEA regions rather than for individual US states. $^{33}$

The analysis of variance points to significant cross-industry differences in the effects of monetary policy. Evaluating the two-year cumulative impulse response estimates in Table 4.2, negative long-run interest rate effects are reported for all industries except for the government and mining sector. Since the mining industry is supply-shock rather than demand-shock driven, this finding indicates that the energy price variable in the VAR system does not fully capture supply shock effects. There are two explanations of this result. Theoretically, the positive response of the mining industry to higher interest rates could be attributed to the opportunity costs of not extracting resources. Empirically, the oil crises in the 1970s stimulated the mining sector through their positive effect on the demand for US oil, but obviously invoked higher interest rates from the central bank.

\footnotetext{
${ }^{32}$ Similar conclusions apply for the cumulative impulse responses from the first-difference specification.

${ }^{33}$ The cumulative impulse response estimates of the individual US states are available on request.
} 


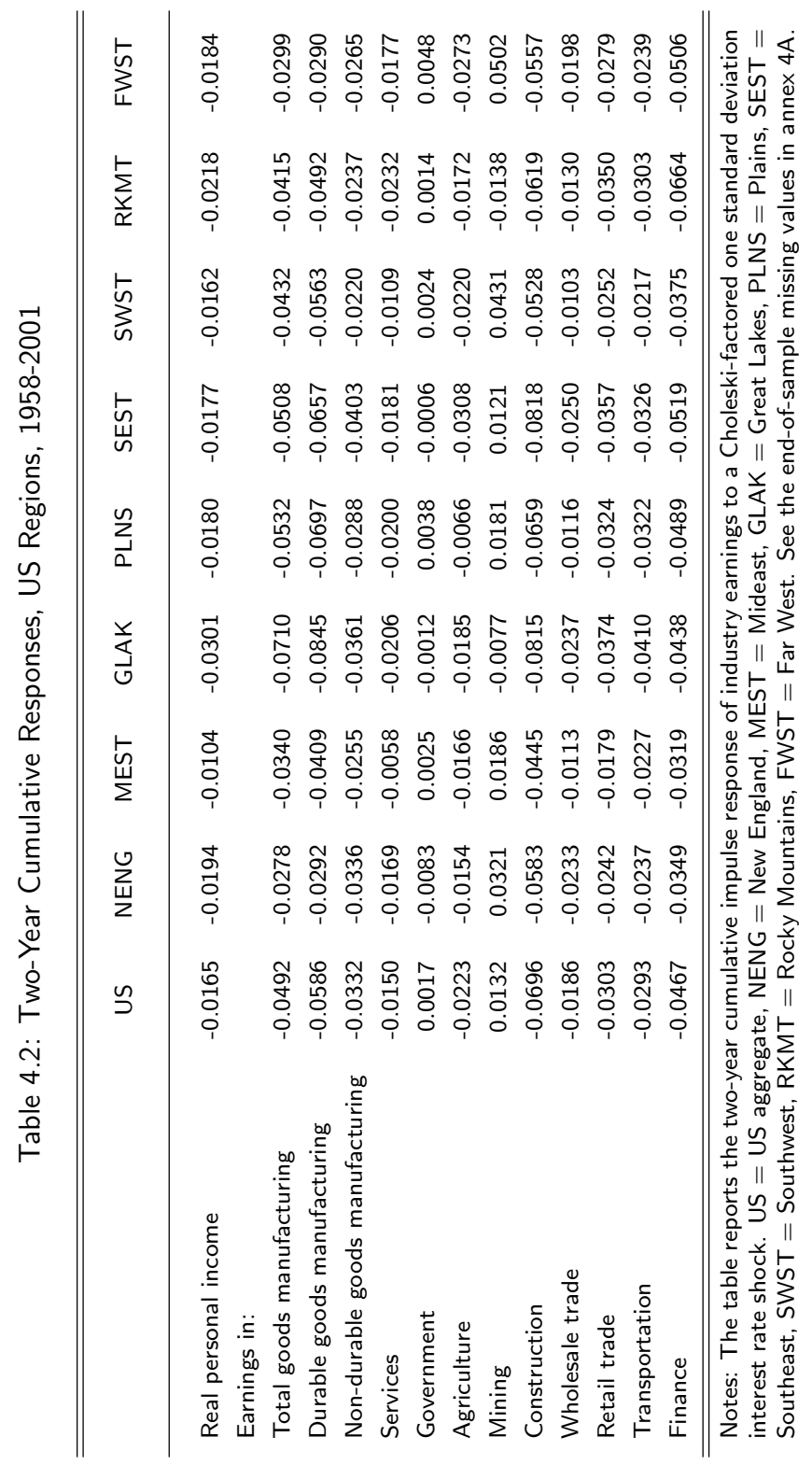


Although an exact quantitative comparison with Carlino and DeFina (1998) and Arnold (2000) is not possible because of differences in the specification of the model, the present results qualitatively confirm the earlier findings. Higher interest rates trigger a decline in real personal income, with the negative effect of monetary policy being most pronounced for the Great Lakes economy. Corroborating the sectoral findings in Arnold (2000), the magnitude of the interest rate response of real personal income is largely attributable to the negative impulse responses of earnings in (durable goods) manufacturing, finance, and construction. The mining sector mitigates the negative effects of higher interest rates in almost all US regions. The exceptions are the Great Lakes economy and the Rocky Mountains area, where earnings in the mining sector decline in response to higher interest rates. Again similar to the findings in Arnold (2000), the weakest interest rate response is visible in the government and service sector. Since these industries are less capital-intensive than the manufacturing, construction, and mining sector, the evidence suggests a positive relationship between the degree of capital intensity and the interest rate responsiveness of earnings.

\subsection{Factors Behind the Industry Effects of Monetary Policy}

The time-series evidence lends support to the existence of an interest rate channel of monetary policy transmission. In line with existing empirical research, the strength of this channel is determined by the relative interest rate sensitivity of industries. Since industries differ in their responsiveness to monetary policy, regional differences in the effects of monetary policy are predominantly attributable to cross-region dissimilarities in industry composition. Building on this result of the time-series analysis, this section aims to explain the variation in impulse responses across industries and consequently across regions, using two industry characteristics. The first factor is business size. As discussed above, differential effects of monetary policy may arise from differences in the relative importance of small- and large-sized businesses. The second factor is a proxy of the capital intensity of industries. By including a measure of capital intensity, the analysis investigates whether the interest rate response of industry earnings is indeed positively related to the degree of capital intensity.

\subsubsection{Cross-Section Framework}

The analysis adopts a cross-section approach to investigate the influence of business size and capital intensity on the industry effects of monetary policy shocks. The underlying models are defined along two dimensions: by industry $\mathrm{i}$ and by geographic unit $\mathrm{j}$. In order to make efficient use of all available information, cross-section estimates are derived for US states rather than for US regions. The use of state-level data is motivated by the observation that some of the cross-section variation in the size distribution of firms and in the degree of capital intensity is eliminated in regional data. In using disaggregated data, the cross-section model by region and by industry builds on a grid that consists of 50 US states and nine 
industries. The upper bound on the number of industries is imposed by data constraints and data weaknesses. ${ }^{34}$ Annex $4 \mathrm{~A}$ contains a summary of the source and the industries for which data on business size and capital intensity are collected.

The degree of capital intensity in industry $i$ of US state $j$ is approximated as the ratio of employment to real gross product in industry $i$ of US state $j$. Using this definition, the degree of capital intensity is inversely related to the relative importance of employment per unit value of output. In line with existing empirical studies, the present analysis measures and classifies business size by employment. Because of data limitations and disagreements on the definition of small business size, empirical studies make different choices on the number of employees that classifies businesses as being small. This study uses the definition of small business size as presented by Loveman and Sengenberger (1991) and reports results for entities with less than 100 employees. Henrekson and Johansson (1999) argue that the adoption of broad size categories prevents the efficient use of information since the majority of businesses employs fewer than 10 employees. Therefore, broad measures of small business size may capture effects that cannot be attributed to small firm or establishment size. To account for this criticism and to determine the robustness of the empirical results to the definition of small business size, the present study divides small businesses into entities with up to $4,9,19$, and 99 employees. Furthermore, existing studies employ measures of either firm size or establishment size. ${ }^{35}$ As there are marked differences between the size distribution of firms and establishments, this choice may also have a quantitative and qualitative effect on the cross-section evidence. To determine whether the choice of the business variable matters, the present study uses information on both the size of firms and establishments.

Throughout the cross-section analysis, we measure capital intensity and business size as averages over the period for which each explanatory variable is available. The degree of capital intensity represents the average over the period 1977-2001 and business size is measured as the average over the period 1992 and 1997-2000. Following Carlino and DeFina (1998) and Dedola and Lippi (2005), among others, averaging is appropriate given that the estimated cumulative impulse responses of industry earnings illustrate the average behavior of industries during the sample period. As to business size, the use of averages is also motivated by the degree of variability in the variable. Visual inspection of the two-dimensional data indicates that there is not much year-to-year variation between 1992 and 1997 and 1998-2000, while there is a break from 1997 to 1998. In taking the average of the 1992 and 1997-2000 data points, the analysis tries to account for the break that results from the shift in the industry classification scheme from SIC to NAICS.

\footnotetext{
${ }^{34}$ Descriptive statistics suggest that information on the District of Columbia is an outlier. The cross-section analysis therefore omits this state.

${ }^{35}$ Dedola and Lippi (2005) and Arnold and Vrugt (2004) employ measures of firm size. As regards the work of Carlino and DeFina (1998, 1999a, 1999b, 2000), no clear distinction is made between firm size and establishment size data.
} 
The empirical cross-section analysis is carried out for two sets of model specifications; one without and one with industry effects. The analysis without industry effects determines the role of small business size as monetary transmission mechanism by estimating the model

$$
\Psi_{\mathrm{ij}}=\mu+\Theta_{\mathrm{ij}} \alpha+\epsilon_{\mathrm{ij}}
$$

$\Psi_{\mathrm{ij}}$ depicts the non-absolute value of the two-year cumulative impulse response of earnings in industry $\mathrm{i}$ in US state $\mathrm{j}$, where $\mathrm{i}=1, \ldots, 9$ and $\mathrm{j}=1, \ldots, 50{ }^{36} \Theta_{\mathrm{ij}}$ denotes the exogenous business size variable that equals the percentage share of small firms or establishments in industry $\mathrm{i}$ of US state $\mathrm{j}$. The coefficient $\alpha$ measures the significance of cross-state and crossindustry differences in the average interest rate response of industry earnings. $\epsilon_{\mathrm{ij}}$ depicts the error term.

Section 4.3.3 attributed regional differences in the effectiveness of monetary policy changes to regional dissimilarities in the relative share of interest-sensitive industries. Since interestsensitive industries usually produce capital-intensive goods, regional disparities reflect differences in the relative importance of capital-intensive industries. In order to determine the relevance of capital intensity as monetary transmission channel, a univariate cross-section model is estimated that includes the proxy of capital intensity as exogenous variable. ${ }^{37}$ The corresponding model specification equals

$$
\Psi_{\mathrm{ij}}=\mu+\Phi_{\mathrm{ij}} \beta+\epsilon_{\mathrm{ij}},
$$

where $\Phi_{\mathrm{ij}}$ represents the measure of capital intensity and $\beta$ measures the significance of cross-state and cross-industry differences in explaining the average interest rate response of industry earnings. Finally, the analysis also investigates the importance of capital intensity next to business size as joint determinants of the interest rate sensitivity of industry earnings. The corresponding model specification is

$$
\Psi_{\mathrm{ij}}=\mu+\Theta_{\mathrm{ij}} \alpha+\Phi_{\mathrm{ij}} \beta+\epsilon_{\mathrm{ij}}
$$

\footnotetext{
${ }^{36}$ Carlino and DeFina (1998) determine the ability of business size to explain the absolute impulse response estimate. The use of the absolute value of the cumulative impulse response estimate as dependent variable is advantageous since it generates results whose interpretation is straightforward and intuitive. However, the results of the corresponding cross-section models will present a biased view on the direction, magnitude, and significance of the business size effect on the long-run interest rate response if the non-absolute cumulative impulse response estimates of the $\mathrm{i}$ industries are neither completely negative nor completely positive. In including the non-absolute cumulative impulse response estimate as dependent variable, the present analysis controls for this bias.

${ }^{37}$ An alternative model specification includes the ratio of operating surplus to gross value added of industry $i$ in US state $j$ as measure of industry internal funds of finance. The relationship between the industry sensitivity of an industry and industry operating surplus is expected to be negative: industries with positive and high operating surplus are less dependent on external finance than industries with low or even negative operating surplus. The empirical results are ambiguous and not robust to the choice of business size class or industry dummy.
} 
The expected signs of the coefficient estimates on business size and capital intensity are determined by the way in which the variables are defined. As regards capital intensity, economic theory stipulates a positive relationship between the degree of capital intensity and the long-run interest rate response of industry earnings. Since capital intensity is defined on the labor side, this relationship holds if the variable displays a positive sign in the cross-section estimations.

Considering the measure of business size, the effectiveness of monetary policy is anticipated to be negatively related to the size of firms and establishments. In contemplating this relationship, the analysis follows the argumentation of Gertler and Gilchrist $(1993,1994)$ and Bernanke, Gertler, and Gilchrist (1999). According to their reasoning, differences in the scope for production smoothing render large-sized firms less sensitive to cyclical demand fluctuations than small-sized businesses. The size-dependent differences in the cyclical exposure of firms suggest a positive relationship between the interest rate sensitivity of industries and regions and their relative share of small-sized firms. For the non-absolute value of the cumulative impulse response estimate, the evidence supports these theoretical predictions if the small business size variable enters with a negative sign.

Common to model specifications (4.2) to (4.4) is the exclusion of possible interrelationships between business size and industry or between capital intensity and industry. In order to assess the robustness of the empirical results to the independence assumption, all crosssection equations are revised to also include industry dummy variables. The next section illustrates the need to model interrelationships between business size and industry and capital intensity and industry.

\subsubsection{Independence Tests}

This section reports ANOVA test statistics to illustrate the need to account for linkages between industry and industry characteristics. The two-way analysis of variance is computed to test whether variations in the distribution of business size and in the degree of capital intensity are accounted for by industry sectors or by regions. If capital intensity and business size are unrelated to industry, differences in the degree of capital intensity or in the relative share of small firms and establishments should prevail across regions rather than across industries. Table 4.3 summarizes the results for the share of small businesses (defined as businesses of up to 4 employees) and for the measure of capital intensity. ${ }^{38}$ The evidence indicates that the null hypothesis of equal average capital intensity and of equal average business size across industries and regions can be rejected at least at the one percent significance level. ${ }^{39}$

\footnotetext{
${ }^{38}$ Since the results for businesses with 0 to 9,0 to 19 , and 0 to 99 employees do not differ from those for businesses with 0 to 4 employees, the corresponding test statistics are not reported. The results are available on request.

${ }^{39}$ Additional support for the interdependence of industry and business size is provided in contingency tables for Chi-square tests of independence. The results are not reported, but available on request.
} 
Furthermore, the F-statistic for the industry effect is much larger than the F-value for the regional effect. Differences in the average size of firms and establishments and in the average degree of capital intensity are consequently predominantly accounted for by industries rather than by regions.

Eichenbaum (1994) suggests that the interdependence of industry and business size is also reflected in the degree of correlation between the cyclical sensitivity of industries and the size distribution of businesses, with small firms being particular to volatile industries. In the presence of such a relationship, small and large firms are contemplated to react differently to monetary policy shocks even in the absence of credit market imperfections. In order to assess the relevance of this claim, the degree of correlation between the cyclical sensitivity of industries and business size has been computed. Approximating cyclical sensitivity by the standard deviation of industry-specific real earnings growth, we determine the correlation coefficient for two sets of data. The first dataset includes all sampled industries, while the second excludes data on the mining industry for reasons presented in section 4.4.3. For almost all definitions of small business size, the correlation coefficients in Table 4.4 point to a statistically significant and positive relationship between the relative share of small-sized businesses with up to four employees ${ }^{40}$ and the cyclical volatility of real earnings growth. The evidence in favor of a positive relationship is particularly strong for the dataset that excludes the mining industry.

Summarizing the results of the independence tests, business size and industry and capital intensity and industry appear to be interdependent. This finding has two interrelated implications. Firstly, conclusions as to the role of business size and capital intensity as monetary transmission mechanisms are likely to depend on the structure of the cross-section model. Specifications that disregard the relationship between industry and either business size or capital intensity are expected to yield evidence that also captures the industry effects of monetary policy, i.e., those effects caused by the unobserved determinants of industry-specific firm size distribution and capital intensity. Secondly, small business size effects of monetary policy may also prevail in the absence of credit market imperfections. Keeping these inferences in mind, the following sections report the cross-section evidence.

\footnotetext{
${ }^{40}$ As regards the dataset with the mining industry, significant and positive firm size correlation coefficients are specific to the size class of zero to four employees.
} 


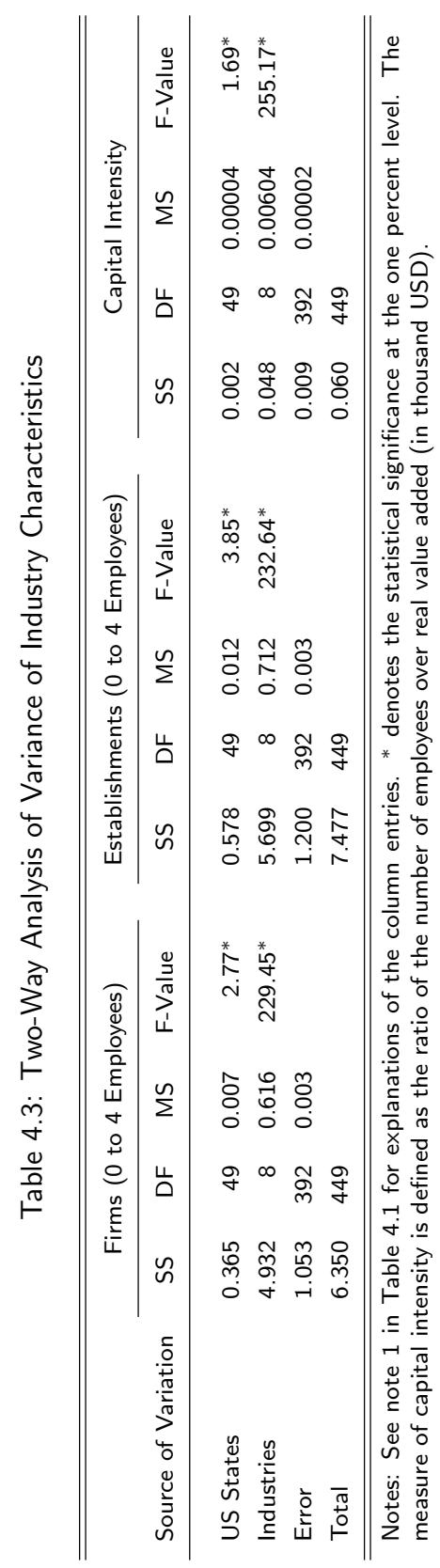


Table 4.4: Correlation between Business Size and the Volatility of Industry Earnings

\begin{tabular}{|c|c|c|c|c|}
\hline Business Entity & 0-4 Employees & 0-9 Employees & 0-19 Employees & 0-99 Employees \\
\hline Firm (i) & $0.08^{* * *}$ & 0.01 & -0.03 & $-0.15^{*}$ \\
\hline Establishment (i) & $0.16^{*}$ & $0.13^{*}$ & $0.17^{*}$ & $0.21^{*}$ \\
\hline Firm (ii) & $0.44^{*}$ & $0.42^{*}$ & $0.40^{*}$ & $0.32 *$ \\
\hline Establishment (ii) & $0.59 *$ & $0.54^{*}$ & $0.60^{*}$ & $0.61^{*}$ \\
\hline
\end{tabular}

Notes: (i) indicates that the correlation coefficient is computed across all US states (except the District of Columbia) and across all sampled industries including the mining sector. The number of observations $\mathrm{T}$ is 450 . (ii) indicates that the correlation coefficient is computed across all US states (except the District of Columbia) and across all sampled industries excluding the mining sector. The number of observations $\mathrm{T}$ is $400 .{ }^{*}, * *, * *$ depict the statistical significance at the one, five, and ten percent level, respectively, for critical values from the two-tailed student t-distribution.

\subsubsection{Cross-Section Evidence}

The cross-section models are estimated by assuming cross-section heteroscedasticity and residual heteroscedasticity. In order to correct for heteroscedastic residuals, all cross-section equations are estimated by using White's (1980) heteroscedasticity consistent covariance matrix estimator. To deal with cross-section heteroscedasticity, the cross-section estimates are weighed by means of generalized least squares. The resulting empirical evidence is subject to data limitations. One major shortcoming of the present dataset relates to the small number of cross sections for which estimates are computed. The upper bound on the number of cross sections is imposed by constraints on the availability of business size data at the industry level. Since a cross-section analysis should ideally build on a large set of cross-section observations, the present study may report inefficient coefficient estimates. Another weakness concerns the short sample period for which business size data are available. Consisting of five disjointed data points, the dataset cannot be used to investigate the role of business size as monetary transmission mechanism at different stages of the business cycle.

A different limitation results from the observation that the impulse responses from the recursive Choleski identification scheme are insignificant for some industry-state combinations. The cross-section study thus partly builds on insignificant long-run responses. If the sign of the cumulative impulse response is correctly estimated, the inclusion of insignificant long-run estimates is expected to have no qualitative effect on the cross-section estimates. Because this assumption is certainly restrictive, future research needs to establish the robustness of the sign of the long-run monetary policy response to the choice of alternative decomposition and estimation methods. 
Even though all cross-section models are estimated for measures of firm size and establishment size, the subsequent sections only report the evidence of the estimations with firm size. ${ }^{41}$ The restricted focus is motivated by two observations. Firstly, the cross-section estimates do not differ in terms of sign across model specifications with firm and establishment size. Secondly, the coefficient estimates are quantitatively close to each other in estimations with firm and establishment size. While the choice of the business size measure does not influence the cross-section results, the choice of the business size category matters in some instances. In view of this finding, the empirical outcomes are reported for the four sampled size classes. The analysis proceeds by first discussing the results of the cross-section estimations without industry dummies and next the evidence of the estimations with industry dummies.

\section{(i) Cross-Section Evidence without Industry Effects}

Table 4.5 summarizes the results of the cross-section models that do not control for industry effects. The coefficient estimates are statistically significant and have the expected negative sign regardless of the size category. Absent industry dummy variables, the relative interest rate responsiveness of industries therefore seems to increase with the relative share of smallsized businesses. This in turn lends support to the operation of a credit channel. Including the measure of capital intensity does not influence the results. The firm size variable is still significant and correctly signed in all estimations in Table 4.5. Different to this, capital intensity only explains the long-run earnings effect of interest rate disturbances in the model that uses the firm size category of 0 to 99 employees. The measure is insignificant or wrongly signed in the remaining cases.

The findings from the cross-section models without industry effects thus seem to support the operation of a credit channel. Since the strength of the channel is suggested to increase with the relative share of small-sized firms in an industry, regional differences in the effectiveness of monetary policy arise from cross-region dissimilarities in the relative importance of small firms. In contrast to firm size, the degree of capital intensity has no effect on the interest rate sensitivity of industries in estimations that do not account for industry effects.

${ }^{41}$ The empirical results of the estimations with establishment size are available on request. 


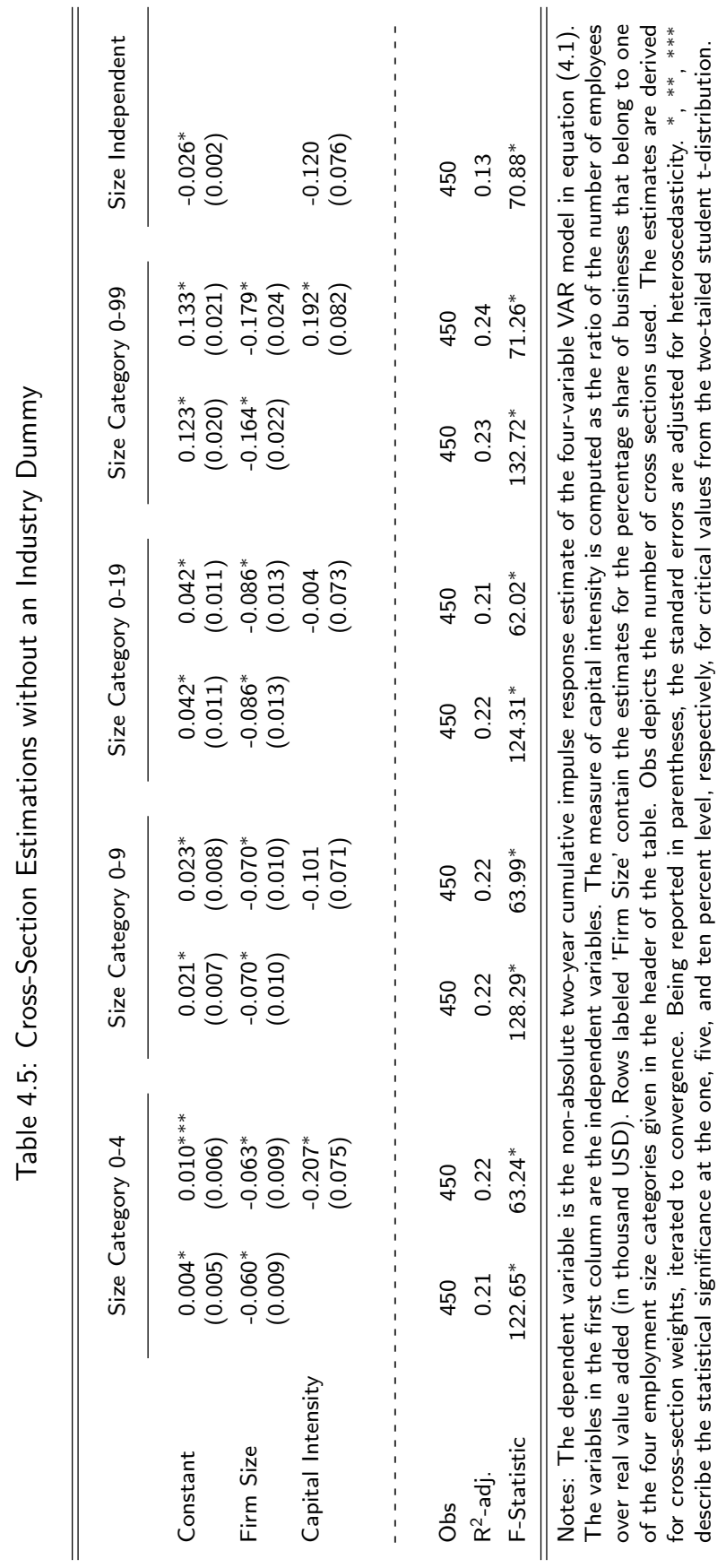




\section{(ii) Cross-Section Evidence with Industry Effects}

In order to determine the robustness of the empirical evidence to the independence assumption of business size and industry or capital intensity and industry, the specifications (4.2) to (4.4) are re-estimated by including industry dummy variables. Two main conclusions arise. Firstly, inferences as to the operation and strength of the credit channel and interest rate channel are extremely sensitive to the incorporation of industry dummies. Secondly, the strength of the industry effect differs across sectors. The need to control for the interdependence of industry and firm size or industry and capital intensity is most apparent for the mining sector. Motivated by the strength of the empirical evidence for the mining industry, the discussion of the interdependence effects predominantly centers on the results obtained for this sector. Table 4.6 reports the estimation results of the cross-section specifications (4.2) to (4.4) with the mining dummy.

For each specification of the cross-section model, the estimate of the mining dummy is statistically discernible from zero. The variable's positive sign corresponds to the sign of the cumulative impulse response estimate and indicates that the long-run interest rate sensitivity of earnings decreases with the relative share of mining. The coefficient estimates of the mining dummy are very close to each other for all cross-section models. After controlling for the mining sector, firm size becomes statistically insignificant. The evidence against the existence of independent business size effects in monetary transmission points to the absence of a credit channel. This finding is robust to the choice of the size category and prevails in the cross-section model with and without the measure of capital intensity. In contrast to firm size, the measure of capital intensity now helps to explain the interest rate response of industry earnings. Since the coefficient estimate is positive in all cross-section estimations with the mining dummy, the degree of capital intensity reinforces the interest rate effects of monetary policy. The magnitude of the effect is found to be invariant to the structure of the cross-section model and to the choice of the size category. This new evidence against the existence of independent business size effects in monetary policy transmission points to the absence of a credit channel.

Summarizing the evidence, the mining industry appears to be a strong source for business size effects in estimations that do not control for industry effects. The sensitivity of the cross-section results to the inclusion of the mining dummy is attributable to the properties of the mining sector. In comparison to the other industries, the mining sector is characterized by a high degree of capital intensity and a low share of small-sized businesses. In addition, the exceptional positive interest rate sensitivity suggests that the mining industry is supplyshock rather than demand-shock driven. In being supply-shock driven, the mining dummy captures the effects of the industry's positive interest rate response on the sign and significance properties of the cross-section coefficient estimates. 


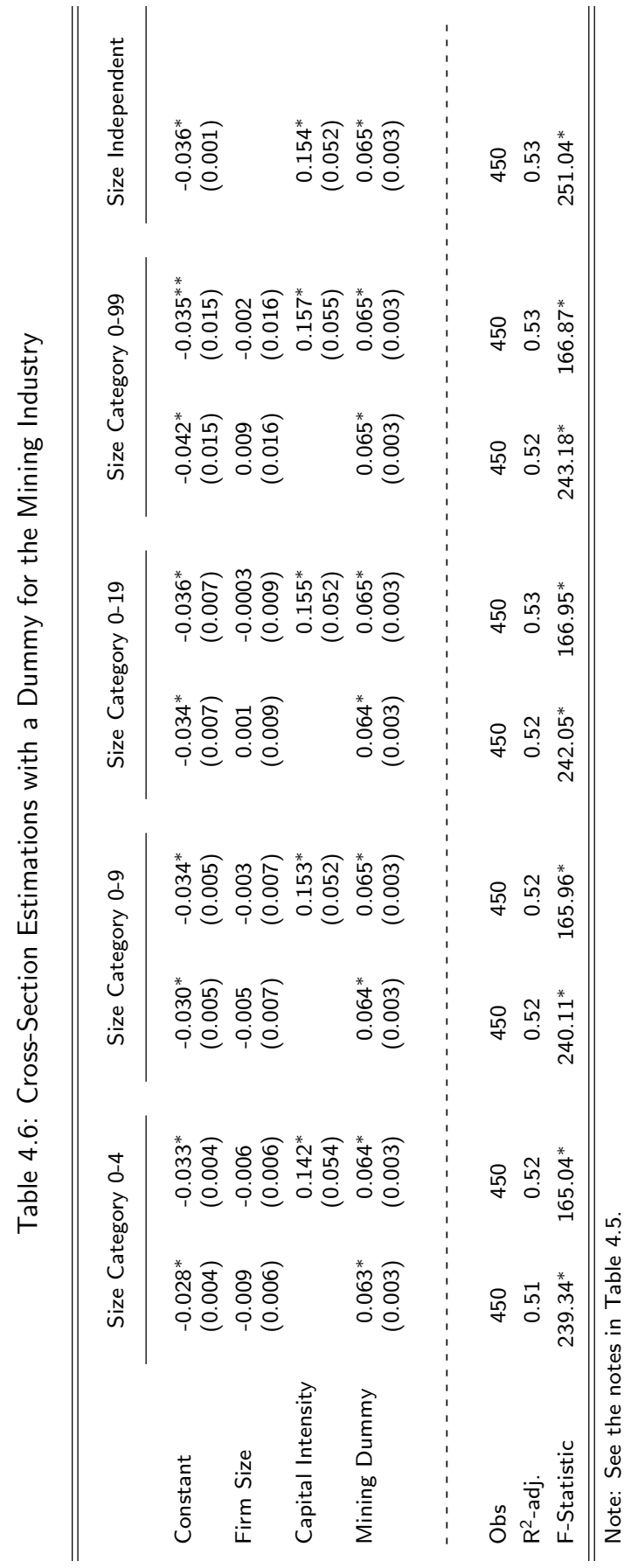


The role of the mining industry is also evident from the results of estimations that control for the effects of (i) the mining sector and the demand-shock driven industries and (ii) the demand-shock driven sectors only. ${ }^{42}$ For specification (i) and (ii), business size and capital intensity usually turn out to explain the interest rate response of industry earnings. Confirming the need to pay particular attention to the effects of the mining industry, the business size effect is stronger and the capital intensity effect is weaker in estimations that do not control for the properties of this sector. Finally, the importance of industry effects is also evident in estimations that capture the effects of each industry separately. The corresponding evidence typically points to a decline in the importance of small business size as monetary transmission channel. ${ }^{43}$

\subsection{Conclusion}

This chapter has identified and explained the industry effects of US monetary policy, using industry data from US states for the sample period 1958-2000/01. The identification of the industry effects has been accomplished by using a vector autoregressive model that provides estimates of the long-run interest rate response of industry earnings. In line with existing empirical work, the impulse response estimates point to cross-industry differences in the degree of interest rate sensitivity and accordingly to the operation of an interest rate channel that propagates and amplifies the effects of monetary policy changes. Regional differences in the effects of monetary policy originate from cross-region dissimilarities in the mix of industries and consequently from differences in regional economic structures.

In order to explain the cross-industry and cross-region heterogeneity of monetary policy effects, the analysis has introduced small business size and capital intensity as variables that may play a role in monetary policy transmission. The analysis shows that the conclusions regarding the role of business size and capital intensity as monetary transmission mechanisms depend strongly on the assumed interdependence of these variables with industries in general and with the mining sector in particular. Empirical findings are therefore very sensitive to the incorporation of industry effects. Cross-section estimates that do not control for industry effects attribute the interest rate sensitivity of industries to the relative share of small firms in an industry and hence to the operation of a credit channel. In these models, capital intensity does not improve the results. However, opposite conclusions can be drawn from cross-section specifications that account for the interrelationship between industry and either business size or capital intensity using industry dummies. The corresponding empirical results indicate that industry effects dwarf the effects of business size, but not those associated with

\footnotetext{
${ }^{42}$ The corresponding empirical results are available on request.

${ }^{43}$ Although in a different context, Mallick and Chakraborty (2002) also provide evidence that points to the role of industry effects. When estimating the magnitude of the credit constraint or credit gap for small businesses, they show that small firms are credit-constrained in manufacturing, wholesale, and services, while they are unconstrained in utilities, insurance, and mining.
} 
capital intensity. Particularly strong industry effects are found for the mining sector. The evidence hence supports the view of Eichenbaum (1994) and we conclude that any test for the existence of a credit or interest rate channel of monetary transmission should control for industry effects.

Evaluating the relevance of the present empirical investigation, the evidence of the crossindustry and cross-region differences in the effects of US monetary policy provide insights into the likely sectoral and regional impact of the common monetary policy in the Euro area. Similar to the United States, Euro member countries and regions differ in terms of industry structure. Given the empirical results for the United States, the heterogeneity of Euro zone regions hints at cross-region differences in the effects of a common monetary policy. These dissimilarities will be aggravated if the European integration process triggers an increase in the degree of regional specialization that deepens the regional differences in the industry mix and in the size distribution of businesses. Annex 4B reports empirical evidence for these hypothetical relationships and explores the role of industry mix and business size as source of cross-industry and cross-country differences in the effects of monetary policy in Europe. ${ }^{44}$ In order to avoid that the evidence overemphasizes the importance of business size as monetary transmission mechanism, the corresponding investigations explicitly control for the possible relationship between business size and industry.

\footnotetext{
${ }^{44}$ In order to increase the degrees of freedom in the cross-section estimation, the analysis does not only consider the Euro zone countries, but European economies in general.
} 


\section{Annex 4A Data Sources and Descriptions}

This annex summarizes the availability of information on industry earnings and business size distribution for US states, US regions, and the US aggregate. Industry earnings data are collected from the US Bureau of Economic Analysis (Regional Economic Information System, 2002) for the sample period 1958-2001. Information is available on the following industries:

- Total (personal income)

- Agriculture, forestry, fishing, and other

- Mining

- Construction

- Manufacturing

- Durable goods manufacturing

- Non-durable goods manufacturing

- Wholesale trade

- Retail trade

- Transportation and warehousing

- Transportation and public utilities

- Finance and insurance

- Real estate, rental, and leasing

- Services (total)

- Government

The variables on transportation and finance also contain information on other industry sectors. In the subsequent tables, transportation and finance are used as synonym for the wider classification. For some industries, the sample period does not extend to 1958-2001 due to missing observations (see Table 4A.1).

Table 4A.1: Missing Values

\begin{tabular}{|c|c|c|}
\hline Industry & US State/Region & Sample Period \\
\hline \multicolumn{3}{|l|}{ 1. End-of-Sample Missing Values } \\
\hline $\begin{array}{l}\text { - Agriculture, forestry, fishing } \\
\text { - Mining } \\
\text { - Retail trade } \\
\text { - Transportation and warehousing } \\
\text { - Real estate, rental, and leasing }\end{array}$ & $\begin{array}{l}\text { Delaware } \\
\text { Idaho, Minnesota, Mideast, Plains, } \\
\text { Rocky Mountains } \\
\text { Florida } \\
\text { US Aggregate } \\
\text { US Aggregate }\end{array}$ & $\begin{array}{l}1958-1998 \\
1958-1998 \\
1958-2000 \\
1958-2000 \\
1958-2000\end{array}$ \\
\hline \multicolumn{3}{|l|}{ 2. In-Sample Missing Values } \\
\hline $\begin{array}{l}\text { - Agriculture, forestry, fishing } \\
\text { - Mining } \\
\text { - Real estate, rental, and leasing }\end{array}$ & $\begin{array}{l}\text { Idaho, Minnesota, District of Columbia, } \\
\text { Mideast, Plains, Rocky Mountains } \\
\text { Delaware, District of Columbia, Hawaii } \\
\text { Connecticut, Delaware, lowa, Maine, } \\
\text { Michigan, Montana, Ohio, Pennsylvania, } \\
\text { Rhode Island, South Dakota, Vermont, } \\
\text { West Virginia, Wisconsin, Wyoming }\end{array}$ & $\begin{array}{l}1958-1997 \\
1958-1997 \\
1958-1997\end{array}$ \\
\hline
\end{tabular}


Table 4A.2 reports the industries for which business size data can be compiled. The data are obtained from the US Bureau of Economic Analysis (2003) along two dimensions, i.e., by industry and by US state. Information on the size distribution of businesses is available for the data points 1992 and 1997 (SIC classification) and for the period 1998-2000 (NAICS classification). Caused by the shift in the industry classification scheme from SIC to NAICS in 1998, the definition of industry sectors changed. We find the differences in the classification of industries to be particularly pronounced for the agricultural, finance, and transportation sector.

Table 4A.2: Overview of Industries by Classification Scheme

\begin{tabular}{|c|c|}
\hline SIC Classification $(1992,1997)$ & NAICS Classification (1998-2000) \\
\hline $\begin{array}{l}\text { - } \text { Grand total } \\
\text { - } \quad \text { Agriculture, forestry, fishing } \\
\text { - } \quad \text { Mining } \\
\text { - } \quad \text { Manufacturion } \\
\text { - } \quad \text { Wholesale trade } \\
\text { - } \quad \text { Retail trade } \\
\text { - } \quad \text { Finance, insurance, and real estate } \\
\text { - } \quad \text { Services (total) }\end{array}$ & $\begin{array}{l}\text { - } \text { Grand total } \\
\text { - } \quad \text { Agriculture, forestry, fishing, and hunting } \\
\text { - } \quad \text { Construction } \\
\text { - } \text { Manufacturing } \\
\text { - } \quad \text { Rholesale trade } \\
\text { - Trail trade } \\
\text { - } \quad \text { Finance and insurance } \\
\text { - } \quad \text { Services (total) } \\
\text { - Real estate, rental, and leasing } \\
\text { - } \quad \text { Stilities } \\
\text { - Subcategories of services }\end{array}$ \\
\hline
\end{tabular}

Note $^{\mathrm{A}}$ : The level of aggregate services is computed as the sum of the service sub-sectors. 


\section{Annex 4B Firm Size Effects in Europe}

This annex extends the analysis for the United States to countries in Europe. We specifically ask: are business size effects of monetary policy in European countries attributable to the operation of a credit channel or are they driven by industry effects? Because the empirical analysis is heavily influenced by poor data availability in terms of data frequency and the very small number of observations, the results are only reported for completeness. If at all, the evidence for Europe is indicative and much care needs to be exercised in its interpretation. The structure of the analysis closely follows that of the study for the United States. That is, we first determine the long-run interest rate response of industry earnings to country-specific monetary policy shocks and then explain the cumulative impulse response with industry characteristics. Again, the industry characteristics refer to firm size as measure of the credit channel and capital intensity as measure of the interest rate channel.

\section{B.1 Empirical Model}

We first estimate a vector autoregressive (VAR) system to determine the interest rate responsiveness of industries in European countries to exogenous monetary policy changes. Given the focus on individual countries in Europe rather than on country-specific regions, the vector of endogenous variables in the VAR model is separately defined for each industry $i$ in country j according to

$$
Z_{i j, t}=\left[\begin{array}{lllll}
V_{i j, t} & C P_{j t} & E P_{j t} & I R_{j t} & R E E R_{j t}
\end{array}\right]^{\prime},
$$

with $\mathrm{i}=1, \ldots, \leq 23$ and $\mathrm{j}=1, \ldots, 13 .{ }^{45}$ The sample of 23 industries refers to 22 industry sectors and the grand total of all industries. We consider the long-run interest rate response of aggregate value added as benchmark to evaluate the interest rate sensitivity of the individual industries. For each country $j$, the model includes information on the level of real value added of industry $\mathrm{i}\left(\mathrm{VA}_{\mathrm{ij}, \mathrm{t}}\right)$, country-specific energy prices $\left(\mathrm{EP}_{\mathrm{jt}}\right)$, consumer prices $\left(C \mathrm{P}_{\mathrm{jt}}\right)$, and the real effective exchange rate $\left(R E E R_{j t}\right)$. Energy prices and consumer prices are included to control for country-specific supply shocks and to capture developments in the aggregate price level, respectively. Besides these variables, we also include the real effective exchange rate to account for external effects associated with the degree of international competitiveness. The monetary policy stance is approximated by the country-specific short-term nominal interest rate $\left(I R_{j t}\right)$. Except for the short-term interest rate, all variables are expressed in logarithm.

As in the US study, monetary policy shocks are identified by means of a recursive Choleski decomposition, with the variables ordered as in expression (4B.1). We again define the VAR

\footnotetext{
${ }^{45}$ In order to ensure that the error terms display white noise properties, the VAR specifications for most industry-country combinations also include single time dummies as exogenous variables. These capture the effects of historical events like, for example, the 1992 EMS crisis and the consequent recession.
} 
in levels to allow for cointegrating relationships. This approach is preferred to first-difference specifications given that unit root test statistics find most sampled variables to be integrated of order one. ${ }^{46}$ The exception is the nominal interest rate that appears to be level stationary for some countries regardless of the selected test statistic.

\section{B.2 Time-Series Data}

The VAR models are estimated by using annual data on industry-specific value added, internal and external price measures, and the short-term interest rate. As concerns the industry dimension of the data, industry data on output and employment are collected from the OECD's STAN database for Industrial Analysis for the sample period 1980-1999. We mainly include those industries for which data on firm size are available. The industry output data are adjusted for price developments by means of the GDP deflator at market prices which is available from the OECD Economic Outlook. Also published by the OECD are data on country-specific consumer prices. The corresponding index variable captures the price effects of demand-driven developments. In order to measure the price effects of supply-driven developments, we use the international oil price expressed in terms of national currency as proxy variable of country-specific energy prices. The underlying information is available from the US Energy Information Administration. ${ }^{47}$ The real effective exchange rate enters the analysis as a measure of external competitiveness and is available from the IMF. Finally, the monetary policy instrument is approximated by the short-term interest rate. Dependent on the country, the interest rate is measured by the money market interest rate, discount rate, or central bank rate. The data are again compiled from the IMF.

The cumulative impulse response estimates are derived for two different sets of data. The first (second) dataset includes industries for which observations are available for each year in the period 1970-1999 (1980-1999). ${ }^{48}$ The first dataset combines information on a much smaller number of industries than the second dataset. Since the reliability of the cross-section analysis depends on the industry dimension, we subsequently discuss the results for the short sample period 1980-1999. This choice is not expected to significantly affect the conclusions of the empirical analysis given that the impulse response estimates of industries included in the short- as well as long-sample dataset are mostly positively and significantly correlated.

Considering the case of Germany, industry-specific value added data need to be adjusted for the reunification effect. Industry information on value added and other industry characteristics

\footnotetext{
${ }^{46}$ The unit root test statistics of the augmented-Dicky-Fuller test (1979), Phillips-Perron test (1988), and Kwiatkowski-Phillips-Schmidt-Shin test (1992) are available upon request.

${ }^{47}$ The corresponding data are available at http://www.eia.doe.gov/emeu/aer/txt/ptb1107.html and correspond to the price of Saudi Arabian light oil.

${ }^{48}$ Country-specific data are usually available until 2001. The exceptions are Portugal and Sweden for which the sample period only extends to 1999 . To ensure the comparability of the results across countries, the estimates are derived for the sample period that ends in 1999 .
} 
only refer to West-Germany until 1991, but to West- and East-Germany (i.e., Germany) as of 1991. In order to control for the consequent break in the time series, we first compute the ratio of value added of industry $i$ for aggregate Germany over the corresponding value for West-Germany in 1991. We then multiply this ratio with the pre-1991 value added data of industry i for West-Germany to obtain a pre-1991 measure for aggregate Germany. Although this procedure mitigates the reunification effect in the data, it can be criticized for its assumption that the ratio of value added of Germany over that of West-Germany is time-invariant. However, this approach is preferred to the inclusion of dummy variables in light of the short sample period.

\section{B.3 Time-Series Evidence}

Similar to the US study, the optimal lag length in the VAR is determined by minimizing the Akaike information criterion (AIC, 1974). Testing for serial correlation, normality, and heteroscedasticity in the residuals, the results of the underlying test statistics suggest that the error terms of the output equations are generally well-behaved. ${ }^{49}$ Even though the ordinary least squares (OLS) estimator of the industry output equations appears to be unbiased, consistent, and efficient, the estimated long-run output effect of monetary policy should be interpreted with caution since the results might be driven by the short-sample period and the consequent low number of observations.

Table 4B.1 displays the two-year cumulative impulse response of industry value added. The evidence suggests that higher interest rates suppress value added for the grand total of industries, with the negative effect of monetary policy being most pronounced for Portugal. For many countries, the magnitude of the interest rate response of total value added is mainly attributable to the negative impulse responses of value added in the construction sector, the non-metallic mineral product sector, the basic metals and fabricated metal products sector, and the wood and products of wood and cork sector. It is evident that the importance of these industries as source of the negative interest rate response of aggregate value added differs across countries. As will be illustrated in section B.4, the country heterogeneity seems to be caused by cross-country differences in the capital intensity of industry-specific production.

Different to the US evidence, the mining sector propagates rather than alleviates the negative effects of higher interest rates in almost all sampled countries, including resource-rich countries like the United Kingdom and the Netherlands. The exceptions are Germany and Norway, with the positive interest rate effect reflecting the relative importance of oil drilling in Norway and coal mining in Germany during the 1980s and 1990s. Similar to the US evidence, the positive interest rate sensitivity of mining indicates that the energy price variable in the VAR system does not fully capture the effects of supply shocks in the case of Germany and Norway.

\footnotetext{
${ }^{49}$ The Ljung-Box Q-statistics (Ljung and Box, 1978), Jarque-Bera statistics (Jarque and Bera, 1980, 1987), and Lagrange multiplier test statistics for heteroscedasticity are available upon request.
} 


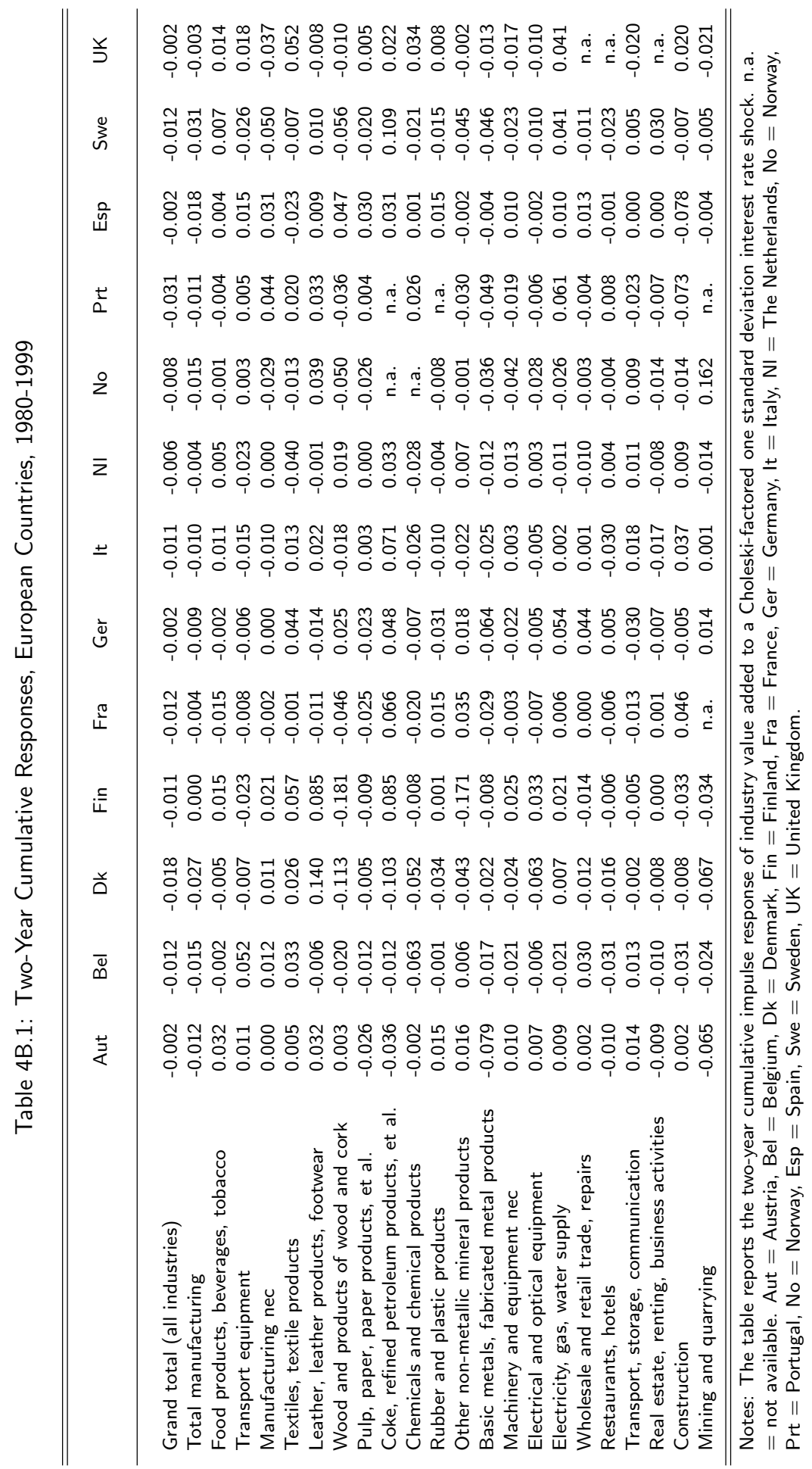


In order to determine the relative contribution of countries and industries as source of variation in the interest rate response of value added, two-way analysis of variance tests (ANOVA) are computed. Given missing values on some industries for some countries, the tests are carried out for two sets of industries and countries. The first set (sample I) includes all 21 industries, but excludes some countries. ${ }^{50}$ The second set (sample II) is composed of all 13 countries, but contains fewer industries. Table 4B.2 reports the corresponding results. Regardless of the underlying sample, the evidence shows that industries but not countries explain the variation in the long-run interest rate effects of monetary policy. This finding suggests the operation of an industry channel of monetary policy transmission, but casts doubt on the operation of a credit channel. However, these results need to be interpreted with caution given that many cumulative impulse response estimates lack statistical significance. Furthermore, since we employ country rather than regional data, much of the regional cross-section variation in industry output is lost. Cross-country heterogeneities, however, might be too small to cause significant cross-country differences in the long-run interest rate sensitivity of industry output.

Table 4B.2: Two-Way Analysis of Variance of Impulse Responses

\begin{tabular}{|c|c|c|c|c|c|c|c|c|}
\hline \multirow[b]{2}{*}{ Source of Variation } & \multicolumn{4}{|c|}{ Sample I } & \multicolumn{4}{|c|}{ Sample II } \\
\hline & SS & DF & MS & F-Value & SS & DF & MS & F-Value \\
\hline Industries & 0.041 & 20 & 0.002 & $1.74 * *$ & 0.039 & 16 & 0.002 & $2.55^{*}$ \\
\hline Countries & 0.008 & 9 & 0.001 & 0.78 & 0.006 & 12 & 0.001 & 0.56 \\
\hline Error & 0.212 & 180 & 0.001 & & 0.183 & 192 & 0.001 & \\
\hline Total & 0.261 & 209 & & & 0.229 & 220 & & \\
\hline
\end{tabular}

Notes: See note 1 in Table 4.1 for explanations of the column entries. ${ }^{*}$ and ${ }^{* *}$ depict the statistical significance at the five and ten percent level, respectively. Sample I excludes France, Norway, and Portugal. Sample II excludes the mining and quarrying sector, the coke, refined petroleum products and nuclear fuel sector, the chemicals and chemical products sector, and the rubber and plastic products sector.

\section{B.4 Factors Behind the Industry Effects of Monetary Policy}

The time-series evidence lends support to the existence of an interest rate channel of monetary transmission for industries in European countries. Cross-country differences in the strength of the interest rate channel are predominantly attributable to country heterogeneity in industry mix. This section aims to explain the variation in impulse responses across industries and consequently across countries. To this end, we again assess the explanatory power of business size and capital intensity, using the cross-section approach in equation (4.2) to equation (4.4) in the main text. The cross-section models are estimated for a grid of 13 countries and 21 industries. ${ }^{51}$

\footnotetext{
${ }^{50}$ See the notes in Table 4B.2 for details.

${ }^{51}$ Note, the cross-section model excludes the grand total of industries and total manufacturing.
} 
We emphasize the size distribution of firms rather than establishments and define business size in terms of employment. The corresponding data by industry and country are compiled for firms with 1 to 9,1 to 19,1 to 49 , and 1 to 99 employees from Eurostat's New Cronos database, which contains annual information for the sample period 1995-2001. Even for this short period, the coverage of firm size data differs between countries and industries and frequently does not extend to the whole sample period. We therefore estimate the crosssection specifications for an unbalanced panel and approximate the size distribution of firms by country and industry as the average of the years for which data exist. The degree of capital intensity in industry $i$ of country $j$ is again measured as the ratio of employment to real value added in industry $i$ of country $j$. We estimate the cross-section models for the 1980-1999 average of this proxy variable.

Similar to the US analysis, the cross-section study will control for the interdependence of industry and either firm size or capital intensity. The interdependence is evident from the results of ANOVA independence tests. The corresponding evidence in Table 4B.3 illustrates that variations in the distribution of firm size and in the degree of capital intensity are explained by industry mix and by countries. ${ }^{52}$ That is, the independence tests suggest that firm size and industry and capital intensity and industry are correlated. However, the relative importance of industries and countries as source of variation differs. Industry effects appear to be the stronger (weaker) source of differences in firm size (capital intensity) compared with country effects. This is suggested by the observation that the F-statistic is larger for the industry effect (country effect) in the ANOVA tests for firm size (capital intensity).

Table 4B.3: Two-Way Analysis of Variance of Industry Characteristics

\begin{tabular}{|c|c|c|c|c|c|c|c|c|}
\hline \multirow[b]{2}{*}{ Source of Variation } & \multicolumn{4}{|c|}{ Firm Size (1 to 9 Employees) } & \multicolumn{4}{|c|}{ Capital Intensity } \\
\hline & SS & DF & MS & F-Value & SS & DF & MS & F-Value \\
\hline Countries & 0.614 & 12 & 0.051 & $14.76^{*}$ & 0.070 & 12 & 0.00586 & 49.69* \\
\hline Industries & 1.517 & 11 & 0.138 & $39.77^{*}$ & 0.013 & 13 & 0.00102 & $8.66^{*}$ \\
\hline Error & 0.458 & 132 & 0.003 & & 0.018 & 156 & 0.00012 & \\
\hline Total & 2.589 & 155 & & & 0.102 & 181 & & \\
\hline
\end{tabular}

Notes: See note 1 in Table 4.1 for explanations of the column entries. * depicts the statistical significance at the one percent level. The measure of capital intensity is defined as the industryspecific ratio of the number of employees over real value added (in thousand Euros).

In order to determine whether industry effects influence conclusions as to the existence of firm size and capital intensity effects of monetary policy, we estimate the cross-section models in equation (4.2) to equation (4.4) with and without industry dummy variables. The empirical evidence is subject to data limitations. One shortcoming concerns the plausibility of the

\footnotetext{
${ }^{52}$ Since the conclusions regarding the interdependence of firm size and industry are invariant to the choice of firm size category, Table 4B.3 only reports the results for firms with 1 to 9 employees.
} 
cumulative impulse response estimates in view of the short sample period and the low number of degrees of freedom. Another weakness concerns the small number of observations in the cross-section specifications. The upper bound is imposed by the small number of sampled countries and by the limited availability of industry-specific firm size data. In order to obtain the largest possible set of cross sections, we also consider Norway despite the country's economic and political independence from the rest of Europe. ${ }^{53}$ Nonetheless, we need to be aware that the cross-section models display poor goodness of fit properties according to the adjusted $R^{2}$-value and the F-statistic especially in estimations without industry effects (see Table 4B.4 and Table 4B.5). Given the apparent mis-specification of the models, the evidence of firm size effects is far less conclusive for European countries than for the United States. US estimations without and with industry effects explain at least 20 percent and 50 percent of the variation in the cumulative impulse response estimates, respectively (cf. Table 4.5 and Table 4.6). In addition, the US explanatory variables are jointly significant according to the F-statistic.

Table 4B.4 reports the empirical results of the cross-section models without industry dummies. The coefficient estimates have the expected negative sign for all sampled business size categories, but are only statistically significant in estimations which include firms with up to 49 or 99 employees. Including the measure of capital intensity does not affect the results. The evidence of estimations without industry effects thus suggests that the smallest firms do not display a stronger response to monetary policy shocks and that the credit channel effects of monetary policy arise for broader definitions of small firm size. Considering the capital intensity coefficient, it is correctly signed but statistically insignificant in all estimations. That is, the degree of capital intensity does not determine the interest rate sensitivity of industries in estimations that do not account for industry effects.

In order to determine the robustness of the empirical evidence to the independence assumption of business size and industry or capital intensity and industry, the specifications (4.2) to (4.4) in the main text are re-estimated with an industry dummy variable. The industry dummy is a binary indicator that equals unity if industry i produces durable goods and zero otherwise. $^{54}$ Table 4B.5 reports the results. Regardless of the specification of the crosssection model, the dummy variable enters with a statistically significant and negative sign. This sign lends support to the common view that the earnings effect of monetary policy is stronger in industries producing durable goods. ${ }^{55}$

\footnotetext{
${ }^{53}$ The results of estimations without Norway do not differ qualitatively from those with Norway.

${ }^{54}$ The durability dummy is closely related to the definition suggested by Dedola and Lippi (2005) and includes (i) wood and products of wood and cork, (ii) basic metals and fabricated metal products, (iii) machinery and equipment, (iv) transport equipment, ( $v$ ) pulp, paper, paper products, printing, and publishing, and (vi) chemical, rubber, plastics, and fuel products. An alternative definition of the industry dummy variable excludes the last two sectors. Since the corresponding results are not different, they are not reported.

${ }^{55}$ Dedola and Lippi (2005) report comparable evidence.
} 


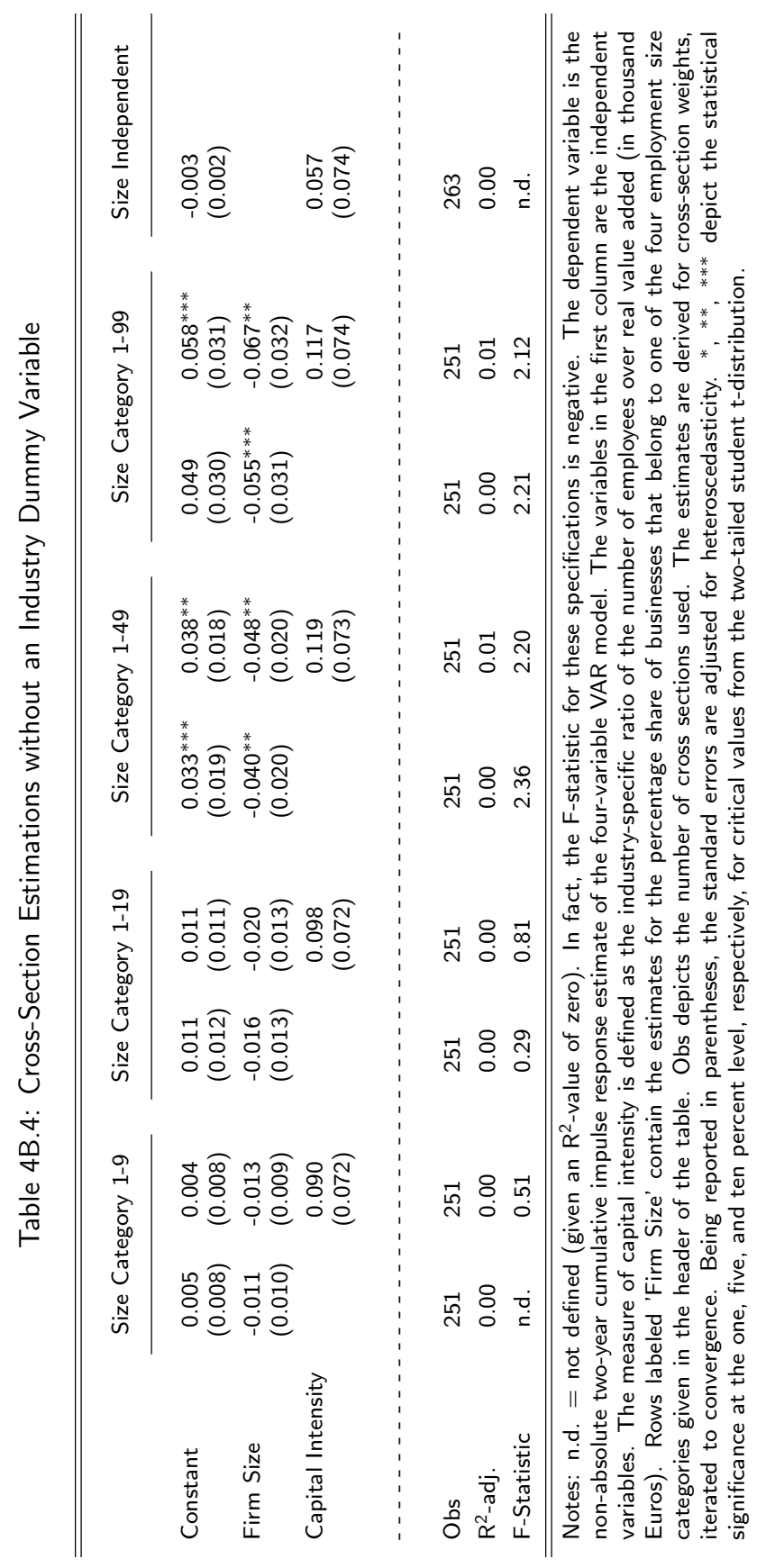




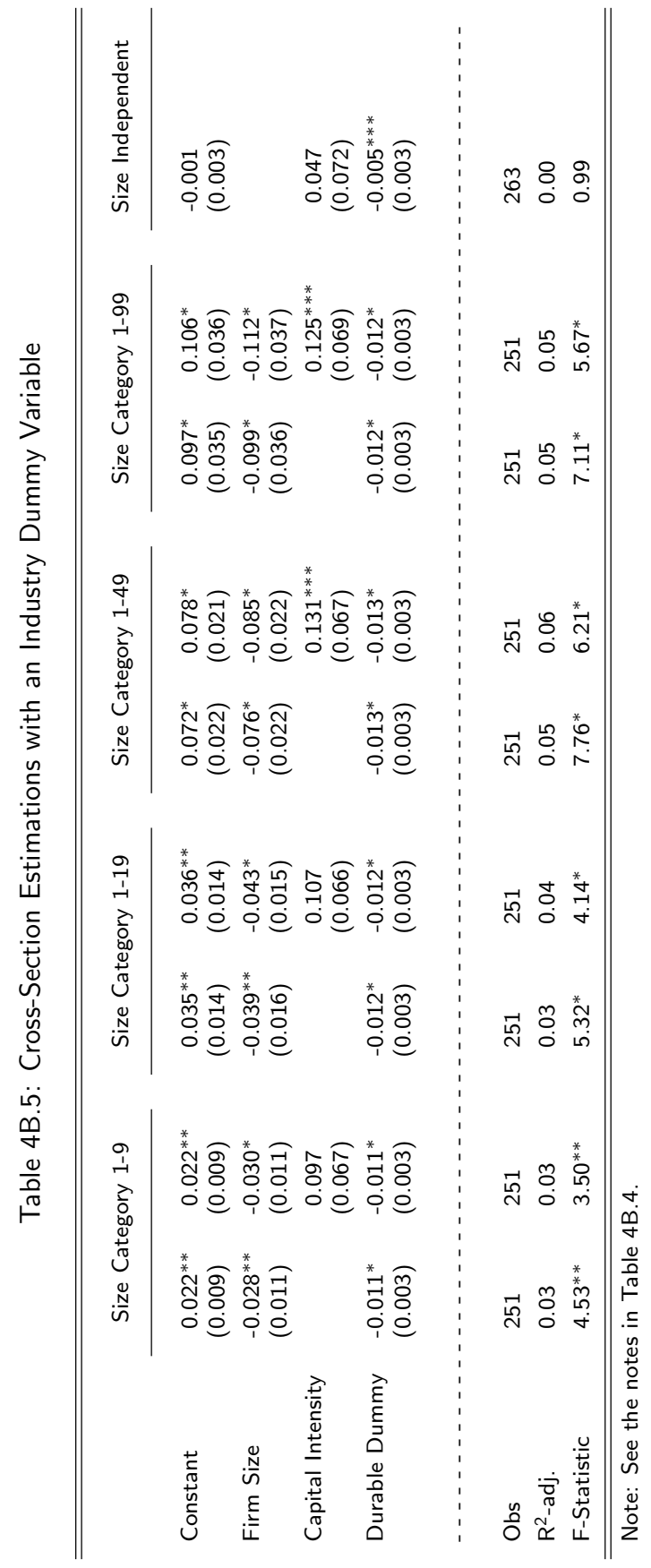


When controlling for durable goods producing industries, firm size turns out to have a statistically significant and negative effect on the cumulative impulse responses. In fact, the small firm size effect is even stronger than in estimations without the industry dummy. This empirical finding is robust to the choice of the size category and prevails in the cross-section model with and without the measure of capital intensity. The evidence therefore lends support to the existence of independent firm size and hence credit channel effects of monetary policy transmission. Even more important, it illustrates that demand-shock driven (i.e., durable goods producing) industries amplify the firm size effects of monetary policy. Considering the measure of capital intensity, the variable is positively signed in all estimations. However, a statistically significant effect of capital intensity only prevails in estimations for firms with up to 49 and 99 employees.

Summarizing, the results of the cross-section models with the industry dummy point to the transmission of monetary policy shocks through independent firm size effects and hence to the operation of a credit channel in Europe. We find that effects associated with durable goods producing industries amplify the firm size effects of monetary policy.

\section{B.5 Conclusion}

This annex has extended the analysis of the industry effects of US monetary policy to the case of Europe. To this end, we have used data on value added for 22 industries in 13 European countries for the sample period 1980-1999. In line with the evidence for the United States, the vector-autoregressive evidence points to cross-industry differences in the interest rate response of industry output and hence to the operation of an industry channel of monetary policy. Using the time-series results, the analysis has investigated whether the cross-industry differences in monetary policy effects can be explained by the industry characteristics firm size and capital intensity. In contrast to the US analysis, the European study cannot be used to draw sensible conclusions about the industry effects of monetary policy and the role of firm size and capital intensity as monetary transmission channels in Europe. This is evident from the very poor goodness of fit properties of the European models. These are conditioned by data shortcomings related to the small number of cross-section observations, the short sample period, the low frequency of the data, and the use of country rather than regional data. In view of these weaknesses, the empirical results for Europe are not reliable and at most indicative. Although indicative, the evidence for Europe lends cautious support to the US finding according to which studies on monetary policy transmission need to control for possible industry effects. 



\section{5}

\section{Industries and the Bank Lending Effects of Bank Credit Demand and Monetary Policy in Germany}

\subsection{Introduction}

Chapter 2 emphasizes the importance of the interest rate and credit channel as propagation and amplification mechanisms of monetary policy changes. Both types of transmission channels predict bank lending to change in response to monetary policy actions. While the direction of the change is the same in the credit and interest rate view, the underlying reasons differ. The credit channel view explains monetary-policy-induced movements in bank lending with changes in bank loan supply, whereas the interest rate channel stresses changes in bank loan demand. Apparently, the correlation of monetary policy shocks with loan demand and loan supply and the consequent role of interest rates as joint determinant of credit demand and credit supply precludes the unique identification of the interest rate and credit channel effects of monetary policy.

In order to identify the loan supply effects of monetary policy, empirical studies usually rely on disaggregated macro- or microeconomic data. These illustrate the distributional effects of monetary policy by stressing the within-group and between-group heterogeneity of banks in terms of asset size (e.g., Kashyap and Stein, 1995), liquidity (e.g., Kashyap and Stein, 2000), and capitalization (e.g., Peek and Rosengren, 1995). When stressing bank characteristics, the identification of bank credit supply effects rests on several assumptions. Firstly, it is assumed that bank heterogeneity in bank size, liquidity, and capitalization reflects cross-bank differences in the severity of asymmetric information problems and consequently differences in the ability of banks to offset monetary-policy-induced changes in deposits with other types of finance. Cross-bank differences in bank characteristics are not allowed to reflect differences in bank customers. Secondly, the response of bank lending to changes in bank credit demand is assumed to be homogenous across all banks. ${ }^{1}$ Thirdly, banks are assumed to serve customers

\footnotetext{
${ }^{1}$ For details see Deutsche Bundesbank (2001), Worms (2003), and the theoretical and empirical review on the bank lending effects of monetary policy in chapter 2 . This is comparable to the credit channel assumption that the interest rate sensitivity of credit demand does not depend on firm size.
} 
which do not differ in terms of bank credit demand. These are strong assumptions and their potential violation suggests the persistence of the identification problem.

The identification bias is likely to be particularly strong for Germany for two reasons. The first reason refers to the housebank principle in German banking. German banks belong to banking groups that confine their business to customers which differ in the degree of bank dependence: commercial banks are the housebank to large corporations and savings and cooperative banks are the housebanks to small- and medium-sized firms. ${ }^{2}$ Small firms tend to be more dependent on banks as source of external finance than large firms. The greater bank dependence results from credit market imperfections, which are more severe for small than for large firms given that reporting and accounting standards become more stringent with firm size. Credit market imperfections therefore cause the portfolio of savings and cooperative banks to be biased towards bank-dependent firms and that of commercial banks to be biased towards firms with access to non-bank sources of finance (cf. Deutsche Bundesbank, 1998a, 2002a). In view of these relationships, banking groups are likely to differ in the extent to which they (i) face changes in credit demand and (ii) adjust credit supply.

The second reason refers to the existence of pronounced cross-industry differences in credit demand. The Deutsche Bundesbank (1996) attributes these to heterogeneities in the cyclical and structural characteristics of industries. The cyclicality of industry output affects the need for external finance through its impact on the availability of internal funds of finance. Cross-industry differences in bank credit demand reflect dissimilarities in the amplitude and frequency of cyclical fluctuations and in the sensitivity of cash flow to cyclical demand changes. Structural characteristics such as the degree of capital intensity, firm size distribution, or openness to trade emphasize industry differences (i) in the costs of maintaining and expanding production structures and (ii) in the severity of credit market imperfections as source of differences in credit demand.

Existing studies on the bank lending effects of monetary policy primarily assume that bank credit demand does not differ between debtors in general and industries in particular. The underlying analyses involve the estimation of bank lending functions for the aggregate economy, where macroeconomic aggregates approximate credit demand. ${ }^{3}$ Although the macroeconomic data are useful since they are available for long time periods at relatively high frequencies, the underlying models only illustrate the bank lending effects of credit demand changes for the average industry. Differences in credit demand across industries are ignored. In addition, macroeconomic data do not control for possible differences in the monetary policy response of industry-specific bank lending. The effectiveness of monetary policy is thus considered to be independent of the industry structure of bank credit portfolios. Furthermore, most studies

\footnotetext{
${ }^{2}$ See Elsas and Krahnen (2004) for evidence on the role of housebanks as source of finance for small and large firms in Germany.

${ }^{3}$ See, for example, Deutsche Bundesbank (2002c), De Bondt (1998), Kakes and Sturm (2002), Ehrmann et al. (2003), Worms (2003), Gambacorta and Mistrulli (2004), Hülsewig, Winker, and Worms (2004).
} 
do not account for possible cross-banking group differences in the response of bank lending to changes in bank credit demand or monetary policy. Instead, they typically provide evidence for an aggregate measure of all banks, disregarding cross-banking group effects. ${ }^{4}$

In our view, however, knowledge regarding the industry effects and banking group effects of bank lending is important as the results illustrate whether the effectiveness of monetary policy depends on the industry composition of bank credit portfolios and on the institutional setting of the banking system. The results may help to anticipate the effect of banking sector consolidation and industry specialization on future monetary policy efficacy. Besides, an understanding of industry effects is also of importance since they determine the availability of bank credit to industries and - through this channel - industry performance. To illustrate this point, note that German banks are not restricted in the maximum share of credit they can grant to a particular industry. ${ }^{5}$ The availability of bank credit to individual industries hence depends on the allocation of bank credit between industries. If there would indeed be industry effects of bank lending, a monetary policy change could cause the reallocation of bank credit between industries. For a monetary policy contraction, the shift in bank credit between industries may leave some industries credit constrained beyond what is suggested by the monetary-policy-induced decline in aggregate lending.

This chapter is motivated by these considerations. We do not impose the assumption of homogenous bank credit demand, but use the industry dimension of bank lending data to identify the response of bank credit supply to changes in industry-specific bank credit demand and monetary policy in Germany. We do not only compile evidence for the aggregate banking sector. Instead, we distinguish the savings banking group and the sub-groups of the credit cooperative banking sector in order to identify the bank lending effects that are due to cross-banking group differences in the industry composition of bank credit portfolios. We hypothesize that industries and banking groups determine the response of bank lending to changes in bank credit demand and monetary policy. In particular, we argue that changes in bank lending are industry-specific and that the industry composition of a bank's loan portfolio determines the effectiveness of monetary policy through credit channel effects.

We discuss two questions. Firstly, are changes in the industry-specific volume of bank credit explained by bank lending effects of monetary policy or do they reflect changes in industryspecific bank credit demand? ${ }^{6}$ Secondly, does the sensitivity of bank lending to changes in monetary policy or bank credit demand differ between industries or between banking groups?

\footnotetext{
${ }^{4}$ The notable exceptions are Küppers (2001) and Kakes and Sturm (2002) who distinguish banking groups in empirical studies for Germany.

${ }^{5}$ Limits only prevail with respect to the maximum exposure to a single debtor.

${ }^{6}$ Throughout this chapter, we cannot control for the response of bank lending to monetary-policy-induced changes in credit demand. However, to the extent that monetary policy affects industry output or industry price only with a lag, changes in the volume of bank loans can still predominantly be attributed to changes in bank credit demand. Also see section 5.7 and chapter 7 for additional caveats of the present empirical analysis.
} 
We address these problems for Germany by using the Bundesbank database on bank lending and bank balance sheet information. The answer to these questions will show that industry bank lending predominantly responds to changes in industry bank credit demand rather than to monetary policy changes. Furthermore, the results lend very strong support to the existence of industry effects of bank lending, whereas banking group effects are comparatively weak. Evidence in favor of credit channel effects of monetary policy crucially depends on the choice of industry and banking group. In view of these findings, we conclude that empirical studies which do not control for the industry structure of bank credit provide an incomplete view on the bank lending effects of bank credit demand and monetary policy. The underlying results only reflect the impact of the average industry. However, neglecting banking group effects is unlikely to affect the overall conclusions as to the determinants of bank lending.

The chapter is structured as follows. Section 5.2 reviews the existing evidence on the credit channel effects of monetary policy via bank lending in Germany. Section 5.3 describes the German banking industry. Within this framework, the discussion stresses the balance sheet structure of the main banking groups and the industry structure of the corresponding loan portfolios. Section 5.4 discusses the empirical model and the empirical estimation strategy. Section 5.5 presents the industry and bank data and describes the bank outlier detection procedure. Section 5.6 reports the empirical results from dynamic panel estimations and robustness checks. We will ask whether differences in the response of bank lending to changes in bank credit demand and monetary policy are explained by effects associated with banking groups or industries. We conclude in section 5.7.

\subsection{The Credit Channel Effects of Monetary Policy in Germany}

This section reviews the existing empirical evidence on the bank lending effects of monetary policy. Common to the existing studies is that they typically do not determine the response of bank lending to changes in bank credit demand. ${ }^{7}$ When studies control for the bank lending effects of bank credit demand, they do not allow bank credit demand to differ between different types of customers. ${ }^{8}$ Given the lack of evidence for the response of bank lending to changes in bank credit demand, this section primarily analyzes the existing evidence with respect to the bank lending effects of monetary policy.

There is a wide range of studies on the bank lending effects of monetary policy in Europe. Because individual firm- and bank-level data are only available to a limited extent, the empirical investigations largely rely on aggregate data. The studies differ in terms of the geographical scope of the analysis, the empirical approach, and the variables used to characterize banks.

\footnotetext{
${ }^{7}$ Dale and Haldane (1995) implicitly allow for differences in bank credit demand between the corporate and household sector. Unfortunately, the analysis does not identify the response of bank lending to changes in bank credit demand.

${ }^{8}$ See, for example, Ehrmann et al. (2003) and Worms (2003).
} 
Furthermore, dissimilarities prevail as to the dimension of the data. Many studies on the credit channel effects of monetary policy ignore the microeconomic structure of the bank credit market and employ highly aggregated loan variables. The corresponding evidence differs in terms of conclusions as to the operation of a credit channel in Europe in general and Germany in particular. As regards the aggregate evidence for Germany, Holtemöller (2003), Hülsewig, Winker, and Worms (2004), Hülsewig, Mayer, and Wollmershäuser (2005) report evidence that is consistent with the existence of credit channel effects of bank lending, while Guender and Moersch (1997) report unambiguous evidence against bank lending effects of monetary policy.

Aggregate studies can be criticized for providing an incomplete view on the bank lending effects of monetary policy because they only identify the monetary policy response of bank lending associated with the average bank and average debtor. Empirical studies with disaggregated lending data provide more insights into monetary policy transmission since they distinguish the monetary policy response of the individual components of bank lending. The corresponding evidence points to the sensitivity of the results to the type of bank loan and to the choice of banking group. Kakes, Sturm, and Maier (2001) and Kakes and Sturm (2002) employ disaggregated data on short-, medium-, and long-term lending to households and firms and aggregate lending data by banking groups, respectively, to test for a credit channel in Germany. Kakes, Sturm and Maier (2001) report evidence against bank lending effects of monetary policy in Germany. Lending to most loan categories is found to expand rather than to contract in response to a monetary contraction. Kakes and Sturm (2002) report weak evidence supporting the credit channel effects via bank lending in Germany. They find that bank lending effects of monetary policy only exist for the credit cooperative banking group, but not for the commercial or savings banking group. The discrepancy in the result for credit cooperatives and savings banks is interesting since both banking groups operate under comparable institutional setups and serve comparable customers. Küppers (2001) identifies the credit channel effects of monetary policy in Germany for a sample of heterogeneous banks, operating in different banking sectors. He reports significant bank size effects of monetary policy. However, inconsistent with the credit channel theory, size effects originate with big banks rather than with savings banks or credit cooperatives.

While studies using disaggregated data allow for more detail on the determinants of bank lending, they still provide an incomplete view. This is because they identify the bank lending effects of monetary policy by exploiting the between-group, but not the within-group dissimilarities of agents and markets. For example, Kakes and Sturm (2002) capture differences in bank size by estimating separate models for different banking groups. The corresponding evidence allows for behavioral asymmetries between different banking groups, but not between banks within each banking group. In contrast to macroeconomic and disaggregated studies, microeconomic studies exploit heterogeneities within samples to identify the bank credit demand and the bank credit supply effects of monetary policy. The remainder of this section reviews the evidence from microeconomic studies. Given the focus of the present 
project, we only discuss those studies which contain Germany. ${ }^{9}$

Microeconomic studies for European countries including Germany are reported by De Bondt (1998), Favero, Giavazzi, and Flabbi (1999), Altunbaș, Fazylov, and Molyneux (2002), Ehrmann et al. (2003), and Worms (2003). Using data from BankScope, De Bondt (1998) reports panel econometric evidence that lends support to the transmission of monetary policy shocks through bank lending in Germany. The bank lending effect is strong in comparison to other European countries and larger for small and less liquid banks. Even though Favero, Giavazzi, and Flabbi (1999) use the same database, the cross-section analysis does not yield evidence of a credit channel via bank lending in Germany. In fact, small banks are found to increase credit supply in response to monetary policy shocks. Also using BankScope data, Altunbaș, Fazylov, and Molyneux (2002) employ a panel estimation framework to provide evidence on the interest rate sensitivity of bank lending in European countries. In line with Favero, Giavazzi, and Flabbi (1999), the results do not point to the operation of a credit channel in Germany. Evidently, conclusions regarding the credit channel effects of monetary policy differ between studies. Because De Bondt (1998), Favero, Giavazzi, and Flabbi (1999), and Altunbaș, Fazylov, and Molyneux (2002) employ the same database, the differences in the empirical results are due to cross-study heterogeneities in estimation methods and sample periods.

Ehrmann et al. (2003) question the usefulness of the BankScope database given its wellknown large sample bias. They therefore test for the existence of a bank lending effect of monetary policy by using microeconomic data compiled by national central banks. Ehrmann et al. (2003) empirically account for the response of bank lending growth to changes in bank lending demand and monetary policy by estimating dynamic panel models, using bank-specific bank asset size, liquidity, and capitalization as loan supply proxy variables and macroeconomic measures of economic activity as loan demand variables. The evidence points to the transmission of monetary policy shocks through bank lending. However, cross-bank differences in the reaction of bank lending to monetary policy changes are only attributable to differences in liquidity and not to dissimilarities in asset size and capitalization. As regards loan demand factors, bank lending is found to respond to inflation, but not to output growth.

Worms (2003) presents a study closely related in terms of structure to that of Ehrmann et al. (2003). In line with the earlier study, Worms (2003) uses bank liquidity and bank capitalization next to bank asset size to test for the operation of a credit channel in Germany. Using a dynamic panel estimation methodology, the evidence largely confirms the results in Ehrmann et al. (2003). Bank lending is found to be more sensitive to changes in monetary policy, the less liquid and capitalized a bank is. Bank size per se only captures cross-bank differences in the bank lending effects of monetary policy when the analysis controls for

\footnotetext{
${ }^{9}$ See Angeloni, Kashyap, and Mojon (2003) for a compilation of microeconomic studies that document the credit channel effects of monetary policy in European countries. Also see section 2.4.2 for a review of the empirical evidence.
} 
short-term interbank deposits. Interestingly, the results strengthen if the smallest banks are excluded from the analysis. Worms (2003) attributes this result to the pronounced dependence of small banks on interbank liquidity. Very small banks are argued to hold more short-term interbank deposits to avoid discontinuous and accelerated shifts in their loan portfolio in general and in their lending to private debtors in particular. In that respect, short-term interbank deposits are seen as means to maintain close housebank relationships with bank customers especially in the presence of adverse monetary policy shocks. Finally, Worms (2003) documents a positive response of bank lending growth to an increase in real output and hence bank credit demand.

To summarize, existing studies report ambiguous results regarding the bank lending effects of monetary policy in Germany. The ambiguity prevails for micro- as well as for macroeconomic analyses. Furthermore, existing empirical studies differ in the cross-sectional dimension of the estimations. Some studies only exploit a single data dimension and divide the banking sample by either bank size, bank liquidity, or bank capitalization. Other studies also split the sample along a second dimension, using the maturity of bank credit, the banking group, or the group of debtors as additional model criterion. Among the existing studies, only Worms (2003) controls for a possible industry bias in bank lending. However, he models the interdependence between loan supply and industry indirectly by including a weighed average of real sectoral output as measure of bank credit demand. The resulting estimates do not allow for inferences as to the industry-specific effects of bank lending and as to the response of bank lending to industry-specific changes in bank credit demand.

A common caveat applies to the existing empirical studies. When identifying the bank lending effects of monetary policy, the empirical literature does not control for the observation that the identification of the bank credit supply effects is not only complicated by possible heterogeneities in bank credit demand and in the response of bank lending to changes in bank credit demand, but also by the balance sheet effects of monetary policy. The complication arises because balance sheet effects cause the volume of bank lending to be simultaneously determined by bank credit supply and bank credit demand side effects. The supply side effects are at the core of the credit channel theory of monetary policy transmission. This theory argues that the balance sheet (net worth) position of potential borrowers such as firms influences the credit supply decisions of banks. For example, bank credit supply is predicted to decline in response to a monetary contraction given the associated deterioration in the balance sheet position of firms (cf. Bernanke and Gertler, 1989). ${ }^{10}$

In contrast to bank credit supply, a monetary-policy-induced decline in net worth has an ambiguous effect on bank credit demand: it may expand or contract. On the one hand, firms may demand more bank credit in order to be able to finance fixed and inventory investment and to preserve liquidity. On the other hand, firms may not change or even reduce bank credit

\footnotetext{
${ }^{10}$ Also see Trautwein (2000) and chapter 2 for a literature review on the balance sheet effects of monetary policy and on the relationship between a firm's balance sheet position and its access to bank credit.
} 
demand in the wake of a monetary contraction. This response requires firms to be swift in adjusting production to the monetary-policy-induced decline in output demand so as to reduce the variable costs of production and to avoid the costs associated with undesired inventory accumulation. In addition, bank credit demand may decline when firms delay physical capital investment in anticipation of lower future interest rates.

Overall, the balance sheet effect of monetary policy causes bank credit supply to contract, while bank credit demand may expand or contract. Unfortunately, we can only stress this caveat. Similar to existing studies, the present analysis cannot identify the balance sheet effects on bank credit supply or bank credit demand. However, this shortcoming is not expected to affect our conclusions regarding the bank supply effects of monetary policy given that existing empirical research lends no or weak support to the existence of balance sheet effects of monetary policy in Germany. Evidence against the existence of balance sheet effects is provided by Siegfried (2000), Mojon, Smets, and Vermeulen (2002), Chatelain et al. (2003), and Arnold and Vrugt (2004). Von Kalckreuth (2003) reports supportive evidence. However, the balance sheet effect of monetary policy is small and attributable to firm creditworthiness rather than to firm size. The relative unimportance of firm size effects is explained with tight housebank relationships, which mitigate the severity of the link between firm size and financial constraints.

\subsection{Banks and Industries in Germany: An Overview}

In order to provide the framework for the subsequent discussion, this section describes the German banking system. ${ }^{11}$ To this end, we compile quarterly data from the monthly bank balance sheet statistics and the quarterly borrower statistics of the Deutsche Bundesbank for the period 1992:1-2002:4. Section 5.5 and annex 5A describe the data in detail. We are specifically interested in the balance sheet structure of the main banking groups and in the industry structure of bank credit portfolios.

Throughout this study, we emphasize the industry distribution of aggregate and short-term bank credit. The focus on short-term lending is motivated by existing studies that point to an immediate response of short- rather than long-term lending to changes in monetary policy (Gertler and Gilchrist, 1993a; Kakes and Sturm, 2002). Short-term loans are also likely to respond more (i) to cyclical fluctuations in bank credit demand factors like industry output and prices and (ii) to changes in monetary policy since they are renewed at shorter intervals than long-term loans. The importance of short-term credit can be explained in terms of expectations. If firms belief that output growth, inflation, and interest rates are mean-stationary, they will expect an increase in inflation or interest rates and a decline in output growth today to be followed by an opposite movement tomorrow. Firms therefore also

\footnotetext{
${ }^{11}$ Refer to Hackethal (2004) for an extensive discussion of the properties of the German banking sector.
} 
expect real income and hence internal funds of finance to follow a predictable mean-stationary long-term growth path. As a consequence, they are more likely to cushion temporary changes in internal funds with short- rather than medium- or long-term external credit. ${ }^{12}$ As regards an increase in interest rates, short-term lending may also increase because firms shorten the maturity of debt in anticipation of lower future interest rates.

Besides these considerations, we also focus on short-term lending because long-term credit is determined by factors that cannot easily be constructed given the available information. For example, long-term financing needs depend on strategic considerations and expectations regarding future changes in industry activity and prices. Because data on expected output and prices are unavailable at a low level of industry aggregation, we cannot estimate our empirical model for long-term lending without incurring the risk of reporting biased and inconsistent estimates due to an omitted variable bias. Surely, the omitted variable bias may also affect the results of the model with aggregate lending, where aggregate lending is computed as the sum of short-, medium-, and long-term bank credit. The evidence for aggregate lending should therefore be viewed as reference point to judge the plausibility of the results for short-term lending.

\subsubsection{The Structure of the German Banking Sector}

The financing system in Germany is a bank-based system, with banks being the most important source of external finance. The banking system can be divided into two main categories: universal banks and specialized banks. At the end of 2003, the German banking sector consisted of 2,466 banks of which 2,255 were universal and 211 were special. The German banking system is hence a universal banking system. Given this property, the present analysis disregards specialized banks and focuses on the three main universal banking groups, i.e., the savings, cooperative, and commercial banking sector.

Each of the main banking groups can be divided into two tiers. The first tier consists of few large institutions, which are the Land banks, cooperative central banks, and the big banks for the savings, credit cooperative, and commercial banking sector, respectively. These banks are subsequently referred to as 'head' institutions. The second tier is composed of many primary institutions: local savings banks in the savings banking sector, credit cooperatives in the cooperative banking sector, and regional and private banks in the commercial banking sector. Commercial banks and the head institutions of the savings and credit cooperative sector operate product portfolios that differ from those of the primary savings and credit cooperative banks. The head institutions of the savings and credit cooperative banking sector are the central bank to the corresponding primary (local) banks and offer universal banking services to larger foreign and domestic banks and to non-bank customers (cf. Hackethal, 2004). Par-

\footnotetext{
${ }^{12}$ See Kakes and Sturm (2002) and Gambacorta and Mistrulli (2004) for the effect of interest rate changes on the demand for short-term finance.
} 
ticular to the head institutions of the savings banking group is their role in providing services to the government of the state in which they are located. Considering commercial banks, they structure their product portfolio around investment and wholesale banking activities, predominantly serving large rather than small- and medium-sized clients.

Table 5.1 reports summary statistics for the head and primary institutions regarding the distribution of total assets, bank capitalization, liquidity, short-term interbank claims, and non-bank lending. ${ }^{13}$ As is evident for the sample period 1992:1-2002:4, the structural differences between the head and primary institutions are reflected in the descriptive statistics of the bank balance sheet variables. Primary institutions are on average better capitalized than their respective head institutions even though they are smaller. Besides, local savings banks and regional and private commercial banks tend to be more liquid than Land banks and big banks, while the primary institutions of the cooperative banking sector are on average less liquid than their central institutions. Regardless of the banking group, a comparatively large share of liquidity is accounted for by short-term interbank claims. With the exception of regional and private commercial banks, primary institutions hold a larger share of interbank claims than their respective head institutions.

Considering the distribution of lending to non-banks ${ }^{14}$, the primary institutions in each banking sector lend on average more to non-banks than the respective head institutions. The difference is particularly pronounced for the credit cooperative sector: lending by central institutes accounts on average for 17 percent of total assets, while the corresponding number for credit cooperatives is 60 percent. The central institutions' low involvement in non-bank lending is attributable to their main role as central bank to the primary credit cooperatives. In this function, they act as clearing institutions for interbank transfers between credit cooperatives and assist primary credit cooperatives in accessing financial markets and in serving their customers. ${ }^{15}$

As regards the share of industry bank credit to non-bank credit, the primary and head institutions of the commercial or savings banking group do not differ in the degree of industry lending. A comparatively large share of aggregate non-bank lending is allocated towards industries (i.e., businesses and self-employed), exceeding 50 percent and 40 percent of total non-bank lending for the commercial and savings banking group, respectively. Pronounced differences again prevail between the primary and head institutions of the credit cooperative sector: industry lending by central credit institutes and primary credit cooperatives accounts

\footnotetext{
${ }^{13}$ As regards local savings banks, the descriptive statistics refer to public savings banks only. The present study excludes private savings banks since they operate under a different institutional setup. The existence of significant differences in the balance sheet structure of public and private savings banks is confirmed by the test statistics of one-way analyses of variance (ANOVA) for almost all sampled balance sheet items. The ANOVA test statistics are available on request.

${ }^{14}$ Non-bank lending involves bank credit supply to domestic businesses, private households, government, and foreign non-banks.

${ }^{15}$ Also see Hackethal (2004).
} 
Table 5.1: Summary Statistics of Bank Balance Sheet Variables, 1992:1-2002:4

\begin{tabular}{|c|c|c|c|c|c|}
\hline & $\mathrm{N}$ & Mean & Stdev & Skewness & Kurtosis \\
\hline \multicolumn{6}{|l|}{$\begin{array}{l}\text { 1. Assets } \\
\text { Commercial BG }\end{array}$} \\
\hline - Big B. & 144 & 19.98 & 0.44 & -0.29 & 1.90 \\
\hline $\begin{array}{l}\text { - Regional, Private B. } \\
\text { Savings BG }\end{array}$ & 6,475 & 14.25 & 1.80 & 0.28 & 3.02 \\
\hline - Land B. & 571 & 18.74 & 1.02 & -1.84 & 10.11 \\
\hline $\begin{array}{l}\text { - Savings B. } \\
\text { Cooperative BG }\end{array}$ & 25,200 & 14.69 & 0.94 & 0.06 & 3.02 \\
\hline - Central Institutes & 152 & 18.36 & 0.77 & 0.73 & 2.42 \\
\hline $\begin{array}{l}\text { - Cooperative B. } \\
\text { Aggregate BG }\end{array}$ & $\begin{array}{r}96,785 \\
128,604\end{array}$ & $\begin{array}{l}12.63 \\
13.12\end{array}$ & $\begin{array}{l}1.06 \\
1.40\end{array}$ & $\begin{array}{l}0.41 \\
0.61\end{array}$ & $\begin{array}{l}3.32 \\
3.58\end{array}$ \\
\hline \multicolumn{6}{|l|}{$\begin{array}{l}\text { 2. Capitalization } \\
\text { Commercial BG }\end{array}$} \\
\hline - Big B. & 148 & 0.06 & 0.01 & 0.28 & 1.81 \\
\hline $\begin{array}{l}\text { - Regional, Private B. } \\
\text { Savings BG }\end{array}$ & 6,770 & 0.08 & 0.04 & 1.43 & 5.05 \\
\hline - Land B. & 592 & 0.03 & 0.01 & 0.55 & 2.88 \\
\hline $\begin{array}{l}\text { - Savings B. } \\
\text { Cooperative BG }\end{array}$ & 25,800 & 0.04 & 0.01 & 0.37 & 3.12 \\
\hline - Central Institutes & 156 & 0.03 & 0.01 & 0.50 & 3.66 \\
\hline $\begin{array}{l}\text { - Cooperative B. } \\
\text { Aggregate BG }\end{array}$ & $\begin{array}{l}101,360 \\
133,673\end{array}$ & $\begin{array}{l}0.05 \\
0.05\end{array}$ & $\begin{array}{l}0.01 \\
0.02\end{array}$ & $\begin{array}{l}0.71 \\
4.46\end{array}$ & $\begin{array}{r}4.09 \\
40.27\end{array}$ \\
\hline \multicolumn{6}{|l|}{$\begin{array}{l}\text { 3. Liquidity } \\
\text { Commercial BG }\end{array}$} \\
\hline - Big B. & 148 & 0.20 & 0.04 & 0.51 & 2.53 \\
\hline $\begin{array}{l}\text { - Regional, Private B. } \\
\text { Savings BG }\end{array}$ & 7,433 & 0.29 & 0.18 & 0.84 & 3.70 \\
\hline - Land B. & 592 & 0.23 & 0.07 & 0.22 & 2.27 \\
\hline $\begin{array}{l}\text { - Savings B. } \\
\text { Cooperative BG }\end{array}$ & 26,552 & 0.32 & 0.10 & 0.84 & 3.78 \\
\hline - Central Institutes & 156 & 0.36 & 0.08 & 0.41 & 2.52 \\
\hline $\begin{array}{l}\text { - Cooperative B. } \\
\text { Aggregate BG }\end{array}$ & $\begin{array}{l}101,831 \\
135,829\end{array}$ & $\begin{array}{l}0.28 \\
0.29\end{array}$ & $\begin{array}{l}0.10 \\
0.11\end{array}$ & $\begin{array}{l}0.72 \\
0.79\end{array}$ & $\begin{array}{l}3.76 \\
4.54\end{array}$ \\
\hline \multicolumn{6}{|c|}{$\begin{array}{l}\text { 4. Short-Term Interbank Claims } \\
\text { Commercial BG }\end{array}$} \\
\hline - Big B. & 148 & 0.03 & 0.01 & 0.26 & 2.43 \\
\hline $\begin{array}{l}\text { - Regional, Private B. } \\
\text { Savings BG }\end{array}$ & 6,817 & 0.06 & 0.07 & 1.41 & 5.06 \\
\hline - Land B. & 592 & 0.06 & 0.05 & 1.75 & 7.42 \\
\hline $\begin{array}{l}\text { - Savings B. } \\
\text { Cooperative BG }\end{array}$ & 25,851 & 0.03 & 0.04 & 1.77 & 7.02 \\
\hline - Central Institutes & 156 & 0.12 & 0.08 & 0.55 & 2.59 \\
\hline - Cooperative B. & 101,183 & 0.05 & 0.05 & 1.72 & 7.02 \\
\hline Aggregate BG & 133,158 & 0.05 & 0.05 & 1.66 & 6.40 \\
\hline
\end{tabular}

-continued on next page- 


\section{N Mean Stdev Skewness Kurtosis}

\section{Lending to Non-Banks}

Commercial BG

- Big B.

- Regional, Private B.

Savings BG

- Land B.

- Savings B

Cooperative BG

- Central Institutes

- Cooperative B.

Aggregate BG

6. Total Credit to Industries

Commercial BG

- Big B.

- Regional, Private B.

Savings BG

- Land B.

- Savings B.

Cooperative BG

- Central Institutes

- Cooperative B.

Aggregate BG

7. Short-Term Credit to Industries

Commercial BG

- Big B.

- Regional, Private B.

Savings BG

- Land B.

- Savings B

Cooperative BG

- Central Institutes

- Cooperative B.

Aggregate BG

3,3

0.50

0.11

$-0.95$

3.40

$0.20-0.34$

2.74

$\begin{array}{ll}568 & 0.40\end{array}$

$0.09-0.44$

3.65

$20,386 \quad 0.61$

$0.10-1.34$

5.24

$\begin{array}{ll}156 & 0.17\end{array}$

0.07

$-0.20$

1.74

$91,683-0.60$

$0.11-0.70$

3.40

$115,595 \quad 0.60$

$0.11-0.85$

4.09

$\begin{array}{rllll}131 & 0.58 & 0.08 & -0.68 & 3.12 \\ 3,043 & 0.54 & 0.25 & -0.56 & 2.19 \\ & & & & \\ 568 & 0.45 & 0.09 & -0.19 & 2.92 \\ 20,350 & 0.45 & 0.08 & -0.28 & 3.42 \\ & & & & \\ 156 & 0.65 & 0.16 & -0.65 & 2.21 \\ 91,309 & 0.46 & 0.13 & -0.28 & 4.07 \\ 114,833 & 0.46 & 0.12 & -0.19 & 4.44\end{array}$

$114,833 \quad 0.46$

0.12

$-0.19$

4.44

$\begin{array}{rrrrr}131 & 0.40 & 0.10 & -1.69 & 5.14 \\ 3,036 & 0.54 & 0.26 & 0.13 & 2.02 \\ 568 & 0.16 & 0.09 & 5.40 & 48.64 \\ 20,342 & 0.22 & 0.06 & 1.14 & 8.20 \\ & & & & \\ 156 & 0.33 & 0.09 & 0.65 & 4.93 \\ 91,031 & 0.26 & 0.08 & 0.63 & 5.22 \\ 114,540 & 0.26 & 0.10 & 2.53 & 16.53\end{array}$

Notes: Assets (panel 1) are expressed in logarithm. The balance sheet positions capitalization (panel 2), liquidity (panel 3), interbank claims (panel 4), and total lending to non-banks (panel 5) are expressed as share of total assets. Lending to non-banks includes lending to domestic businesses, private households, government, and foreign non-banks. Lending to industries combines bank credit supply to businesses and self-employed. Aggregate lending to industries (panel 6) is expressed as share of total non-bank lending. Short-term lending to industries (panel 7) is expressed as share of aggregate lending to industries. The descriptive statistics for savings banks are for public rather than for private savings banks. The aggregate banking group only consists of the primary institutions of the commercial, savings, and cooperative banking group. $\mathrm{N}$ refers to the number of bank-quarter observations. The quarterly data are computed from the monthly bank balance sheet statistics of the Deutsche Bundesbank. 
on average for approximately two-third and four-ninth of total non-bank lending, respectively. Considering the share of short-term lending to total lending, we find considerable differences between the head and primary institutions for all banking groups. Except for the credit cooperative sector, head institutions provide on average less short-term finance than primary banks.

The entries in Table 5.1 also demonstrate that there are not only differences in the balance sheet structure within each banking group, but also between banking groups. These differences are expected to affect the conclusions regarding the bank lending effects of monetary policy for individual banking groups. For example, banks belonging to banking groups with a relatively large amount of liquid assets (group i) might be better able to insulate their lending activities from monetary policy changes than banks in banking groups with only few liquid assets (group j). If this holds, cross-bank differences in liquidity will be a less important source of the bank lending effects of monetary policy in group $i$ than in group $j$. This in turn suggests that banking group differences in liquidity may affect conclusions regarding the strength of the bank lending effects of monetary policy.

Because they constitute the focal point of the present empirical analysis, we confine the comparison to the primary institutions of the banking groups. As is evident from Table 5.1, the largest and most liquid banks operate in the savings banking sector, while the smallest and least liquid banks belong to the group of credit cooperatives. The regional and private banks in the commercial banking sector report the largest share of bank capital, exceeding that of savings and cooperative banks by more than 90 and 60 percent, respectively. The descriptive analysis also shows that each banking group reports a high share of non-bank lending to total assets. Whereas the primary institutions of the credit cooperative and savings banking sector report on average comparable shares of non-bank lending to total assets, the corresponding share tends to be lower for the commercial banking group. This reflects the greater involvement of commercial banks in lending to banks. ${ }^{16}$

However, when looking at the share of total industry lending to non-bank lending, the primary institutions of the commercial banking sector lend on average more to industries than savings banks and credit cooperatives. The descriptive evidence suggests that the difference in the average share of total industry lending reflects considerable differences in the role of banking groups as source of short-term finance to industries. Regional and private commercial banks tend to be more heavily engaged in short-term finance than credit cooperatives or savings banks. In fact, short-term lending to industries as share of total industry lending is approximately twice as large for commercial banks than for credit cooperatives and savings banks. The apparent weak role of savings banks and credit cooperatives as source of short-term finance is attributable to their practice of confining business to local areas. Superior knowledge of local market conditions facilitates assessments regarding the long-term creditworthiness of

\footnotetext{
${ }^{16}$ For 1992:1-2002:4, the share of bank lending to total assets was on average equal to 34 percent, 13 percent, and 8 percent for commercial, credit cooperative, and savings banks, respectively.
} 
debtors, and this yields a comparative advantage in long-term lending.

In order to ascertain the statistical significance of cross-banking group differences in the balance sheet structure, we analyze the variance properties of the bank characteristics by means of a one-way analysis of variance (ANOVA). Table 5.2 reports the ANOVA test statistics for asset size, liquidity, capitalization, short-term interbank claims, and the volume of bank credit. Panel A contains the results for the three main banking groups, i.e., commercial, savings, and credit cooperative banks and panel B summarizes the evidence for six sub-groups of the credit cooperative banking group. Using the classification scheme of the Deutsche Bundesbank, the credit cooperative sub-groups are commercial cooperatives, rural cooperatives, Raiffeisen banks, Sparda banks, PSD banks (Post-, Spar-und Darlehensvereine), and civil servants banks. We deem this distinction necessary to control for banking group differences in the balance sheet structure and for differences in the type of customer.

A comparison of the mean squared values in Table 5.2 illustrates that the hypothesis of equal means can be rejected for all bank characteristics and for each banking group sample. The evidence thus points to statistically significant differences in the balance sheet structure of banking groups. This in turn suggests that conclusions regarding the bank lending effects of monetary policy changes might be sensitive to the choice of banking group. To control for this possibility, we will therefore estimate industry-specific bank lending functions by explicitly allowing for individual 'sub-group' effects.

\subsubsection{The Industry Structure of Bank Loan Portfolios}

So far, the description of the structure of the German banking sector is confined to the distribution of lending to the grand total of industries. This section extends the analysis in that it stresses the industry structure of bank credit portfolios. Table 5.3 reports lending to industry $i$ in total lending by banking group for eight industries at the one-digit industry level (main industries) and for nine industries at the two-digit industry level (manufacturing subsectors). Given the focus of the present chapter, we only stress the distribution of aggregate and short-term lending as provided by commercial banks (big banks, regional, and private banks) and by the primary institutions of the savings and credit cooperative banking group. We express aggregate and short-term lending to industry $i$ as share of, respectively, aggregate and short-term lending to the grand total of industries. Because the industry distribution of aggregate and short-term credit is largely comparable, we provide a general discussion.

The statistics in Table 5.3 point to cross-industry differences in the distribution of bank credit. Banks predominantly lend to those industries that account for the largest share of output in the aggregate economy: the service, wholesale and retail trade, and manufacturing industry. Cooperative, savings, and commercial banks hold on average, respectively, 69 percent, 81 percent, and 89 percent of their bank loan portfolio with these sectors. ${ }^{17}$ As regards the

\footnotetext{
${ }^{17}$ The data suggest that approximately half of these shares is accounted for by lending to the service sector.
} 
Table 5.2: One-Way ANOVA of Bank Balance Sheet Variables, 1992:1-2002:4

\begin{tabular}{llllll}
\hline \hline Variable & Source of Variation & SS & DF & MS & F-Value \\
\hline
\end{tabular}

Panel A: Main Banking Groups

\begin{tabular}{llrrrr} 
Assets & Between Groups & 97,209 & 2 & 48,604 & $39,429^{*}$ \\
Capitalization & Within Groups & 158,911 & 128,913 & 1.23 & \\
\multirow{4}{*}{ Liquidity } & Between Groups & 7.10 & 2 & 3.53 & $19,356^{*}$ \\
& Within Groups & 24.46 & 133,982 & 0.000 & \\
Short-Term Interbank Claims & Between Groups & 29.96 & 2 & 14.98 & $1,350^{*}$ \\
& Within Groups & 1,510 & 136,138 & 0.011 & \\
Lending to Non-Banks & Between Groups & 6.25 & 2 & 3.12 & $1,290^{*}$ \\
& Within Groups & 323 & 133,467 & 0.002 & \\
Total Credit to Industries & Between Groups & 12.15 & 2 & 6.08 & $491^{*}$ \\
& Within Groups & 1,431 & 115,592 & 0.012 & \\
Short-Term Credit to Industries & Between Groups & 20.52 & 2 & 10.26 & $676^{*}$ \\
& Within Groups & 1,744 & 114,830 & 0.015 & \\
& Between Groups & 99.81 & 2 & 49.90 & $13,897^{*}$
\end{tabular}

Panel B: Cooperative Banking Groups

\begin{tabular}{llrrrr} 
Assets & Between Groups & 48,626 & 5 & 9,725 & $15,512^{*}$ \\
& Within Groups & 60,673 & 96,775 & 0.627 & \\
Capitalization & Between Groups & 0.24 & 5 & 0.047 & $493^{*}$ \\
Liquidity & Within Groups & 9.66 & 100,942 & 0.000 & \\
\multirow{4}{*}{ Short-Term Interbank Claims } & Between Groups & 34.20 & 5 & 6.84 & $713^{*}$ \\
& Within Groups & 975 & 101,683 & 0.010 & \\
Lending to Non-Banks & Between Groups & 4.06 & 5 & 0.811 & $320^{*}$ \\
& Within Groups & 254 & 100,329 & 0.003 & \\
Total Credit to Industries & Between Groups & 31.35 & 5 & 6.27 & $546^{*}$ \\
& Within Groups & 1,053 & 91,677 & 0.011 & \\
Short-Term Credit to Industries & Between Groups & 416 & 5 & 83.30 & $7,491^{*}$ \\
& Within Groups & 1,015 & 91,303 & 0.011 & \\
& Between Groups & 42.39 & 5 & 8.28 & $3,457^{*}$ \\
& Within Groups & 218 & 91,025 & 0.002 &
\end{tabular}

Note $^{1}:$ SS $=$ sum of squares, DF $=$ degrees of freedom, MS = mean squares (i.e., SS $_{\text {Source }}$ divided by $\mathrm{DF}_{\text {Source}}$ ), and $\mathrm{F}$-value $=\mathrm{F}$-statistic (i.e., $\mathrm{MS}_{\text {between }}$ divided by $\mathrm{MS}_{\text {within }}$ ). Differences between the MS- and F-statistics in the table and the MS- and F-statistics determined in calculations with the reported SS-statistics and the degrees of freedom are due to rounding. Note ${ }^{2}$ : * denotes the statistical significance at the one percent level. Note ${ }^{3}$ : The degrees of freedom related to the within groups variation refer to bank-quarter observations. Note ${ }^{4}$ : Assets are expressed in logarithm. Total and short-term credit to industries are expressed as share of non-bank lending. The remaining variables are expressed in terms of total assets. Note ${ }^{5}$ : The main banking groups are the commercial banking group and the primary institutions of the savings and credit cooperative banking sector. The cooperative banking group comprises commercial and rural credit cooperatives, Raiffeisen banks, Sparda and PSD banks, and civil servants banks. Note ${ }^{6}$ : The quarterly data are computed from the monthly bank balance sheet statistics of the Deutsche Bundesbank. 
remaining main industries, the volume of bank credit tends to be more evenly distributed across sectors. Agriculture and construction primarily obtain bank finance from the credit cooperative banking group, with rural credit cooperatives and Raiffeisen banks being the primary source of bank finance. ${ }^{18}$ The importance of credit cooperatives for agriculture and construction reflects the regional character of (i) credit cooperatives and (ii) agricultural and constructing firms: lenders and borrowers confine their activities to a particular local area. In adopting a regional focus, credit cooperatives have superior knowledge of local market conditions, which facilitates assessments regarding local economic prospects and the creditworthiness of potential debtors.

The share of bank credit is on average smallest for the finance and insurance industry. One possible explanation of this relationship is the large operating surplus in the finance sector that reduces the need for external finance in general and bank finance in particular. ${ }^{19}$ Next to the finance industry, the energy sector also receives comparatively little credit from commercial banks and from the primary institutions of the savings and credit cooperative banking group. Although not reported in Table 5.3, the Land banks are an important source of finance to the energy sector. For the period 1992:1-2002:4, 12 percent of total lending by Land banks was directed towards the energy sector, with short- and long-term bank credit accounting for 28 and 60 percent, respectively. The importance of Land banks as source of long-term finance to the energy sector is attributable to the components of this sector: mining and quarrying; electricity, gas, and water supply. Given the importance of each of these sub-sectors for the functioning of the economy, general interest is with the maintenance and improvement of the underlying infrastructures. Maintenance requires large fixed expenditures, while infrastructure investment involves costs that tend to be sunk. In order to encourage investment, Land banks grant favorable access to especially long-term finance even though investment per se might not be profitable.

\footnotetext{
While lending to the service sector is certainly substantial, no clear conclusions prevail as to the sector's absolute importance as recipient of bank lending. The reason is that the borrower statistics of the Deutsche Bundesbank report bank lending to the service sector as residual of bank lending to the remaining industries. For the remainder of this chapter, this shortcoming should be kept in mind when interpreting the empirical evidence for the service sector.

${ }^{18}$ Raiffeisen banks and rural credit cooperatives grant 26 (19) percent and 16 (12) percent of aggregate (short-term) credit to agriculture, respectively. In comparison, the corresponding number for commercial credit cooperatives is 6 (5) percent. The cross-banking group differences are less pronounced for lending to the construction industry. Raiffeisen banks, rural credit cooperatives, and commercial credit cooperatives hold 14 (19) percent, 12 (16) percent, and 12 (15) percent of aggregate (short-term) loans with construction, respectively.

${ }^{19}$ For the time period 1992:1-2002:4, the share of operating surplus to value added equals 51 percent with a standard deviation of 2.30 percent for the finance and insurance sector (own computation using the OECD's STAN database for Industrial Analysis). In comparison, operating surplus accounts for at most 31 percent of value added for the remaining industries.
} 


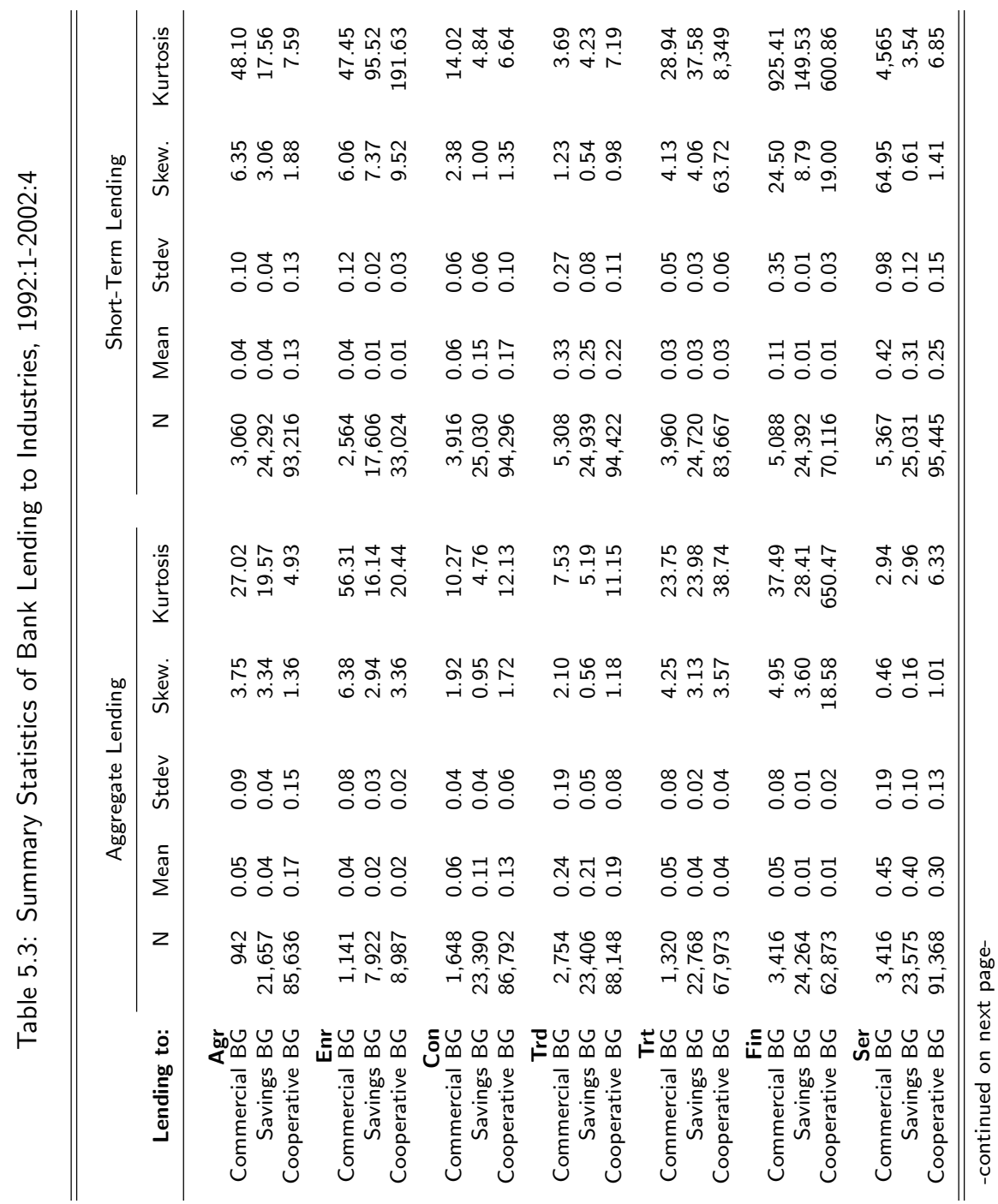




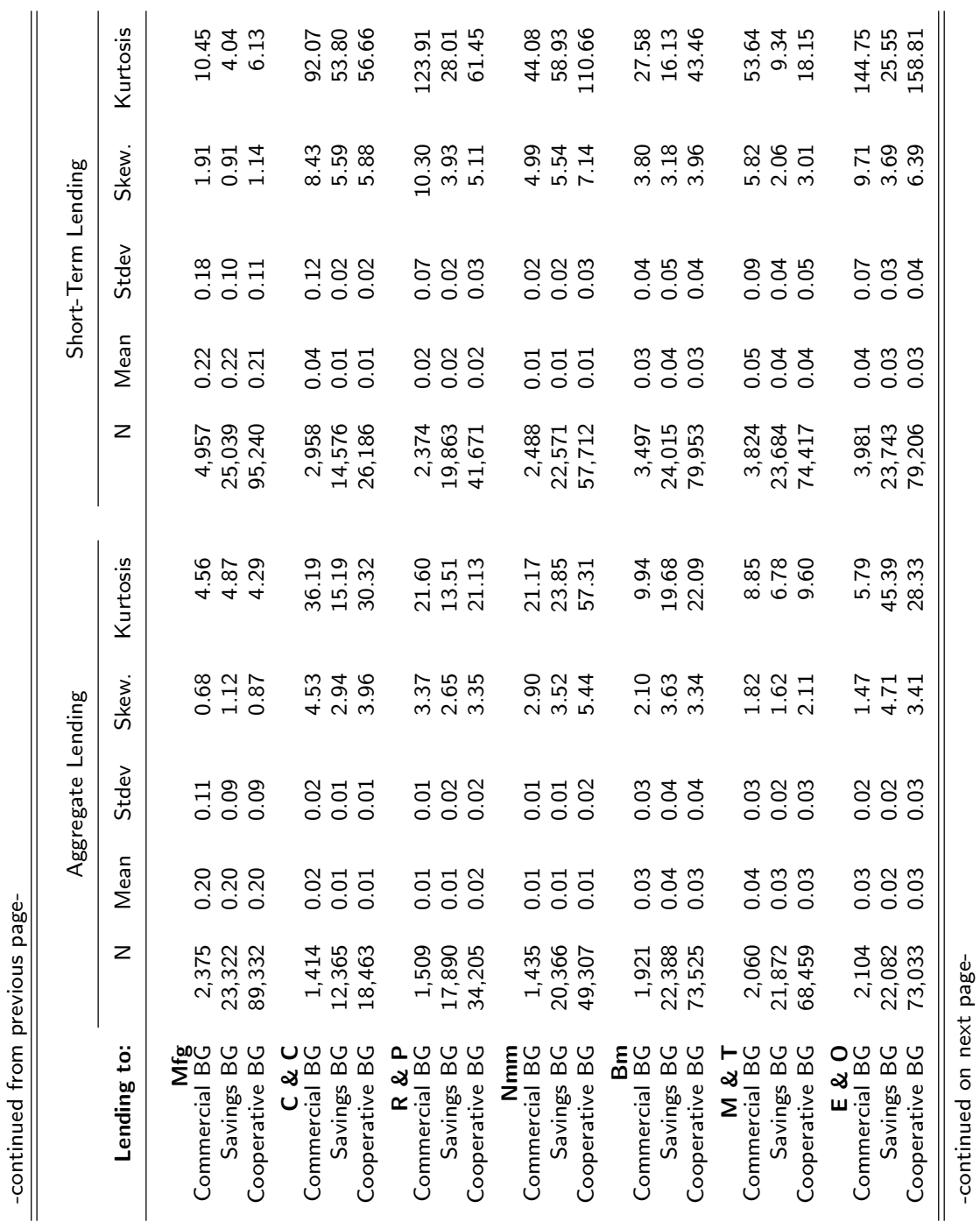




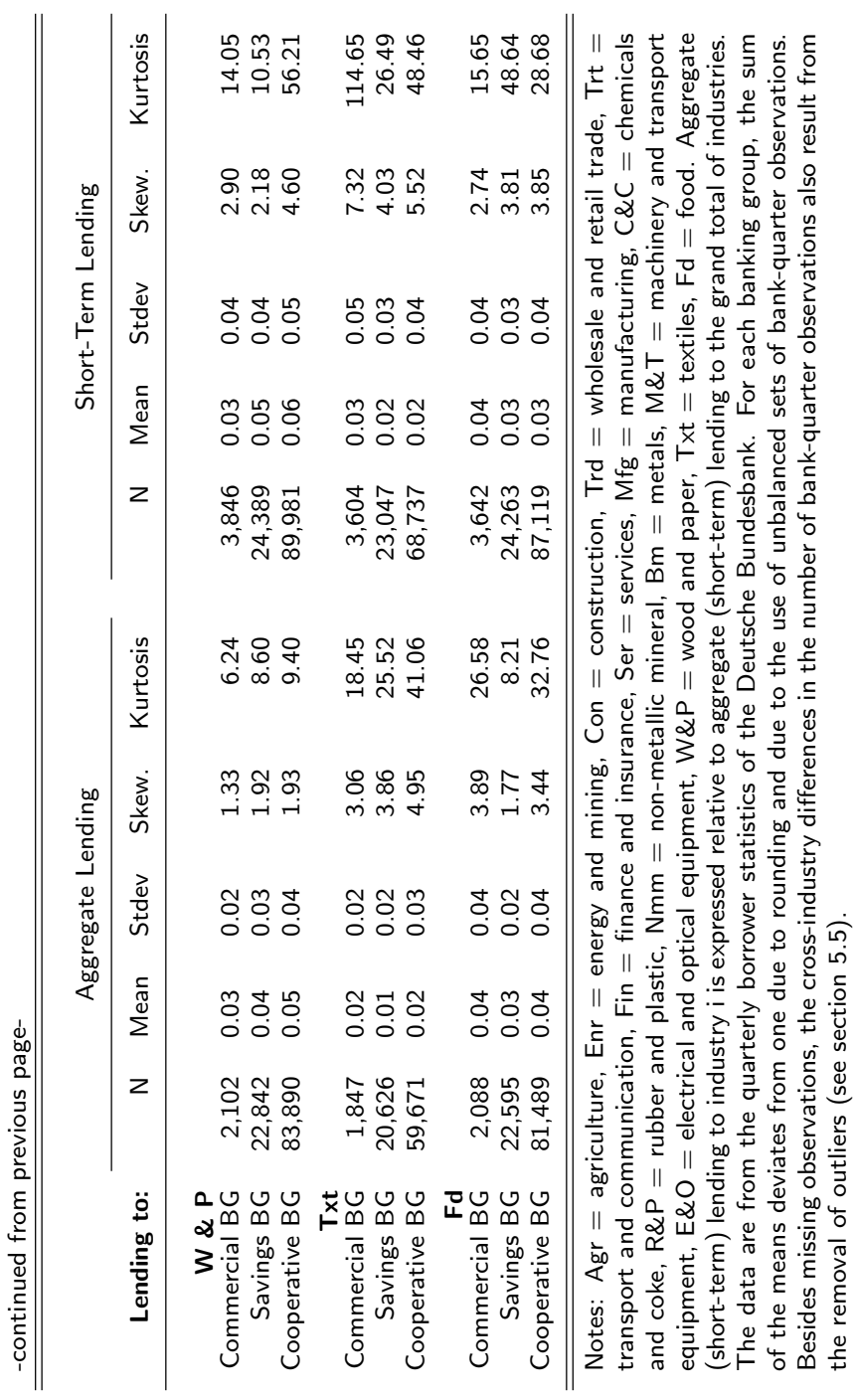


Turning to the sub-sectors of the manufacturing industry, lending to each of the sectors only accounts for a small share of total bank credit, with the share of bank credit to each sector being positively related to its size in the aggregate economy. Lending to the manufacturing sub-sectors hence tends to be unevenly distributed. The share of bank credit is comparatively small for the coke and chemicals, rubber and plastic, and non-metallic mineral goods producing sector. However, it is relatively large for the wood and paper, machinery and transport equipment, food, and metals producing sector. In fact, lending to these sectors is of approximately the same magnitude as lending to the finance and transport sector.

\subsubsection{Industry Determinants of Bank Lending}

Motivated by the cross-industry differences in the distribution of bank credit supply, this section discusses possible determinants of industry-specific bank lending related to structural properties of industries. Industry-specific cyclical determinants of bank lending will be discussed in section 5.6. We identify possible structural determinants of bank lending by determining the degree of correlation between the share of bank credit to industry $\mathrm{i}$ and either firm size distribution, openness to trade, a measure of internal funds of finance, and proxy variables of capital intensity. ${ }^{20}$ In order to avoid that the correlation coefficients are confounded by scale effects, the degree of correlation is determined for the ratio of lending to industry $\mathrm{i}$ over lending to the grand total of industries.

Capital intensity is included to control for the view that the need for external finance increases with the capital intensity of production. External financial funds are required to meet the costs associated with replacing depreciated capital, adjusting existing capital, or installing new capital. The costs of finance are hereby heavily dependent on the monetary policy stance through its effect on the opportunity cost of capital investment. This link is emphasized by the interest rate channel of monetary policy transmission. ${ }^{21}$ The literature on industry effects of monetary policy favors several measures of capital intensity. ${ }^{22}$ We use industry-specific capital intensity measures which appear to be time-invariant and hence robust to cyclical fluctuations: the ratio of the capital stock to employment and the ratio of employment to real value added in industry $\mathrm{i}^{23}$

We include firm size to test for a possible inverse relationship between firm size and the need for bank finance. The Deutsche Bundesbank (2000) uses bank finance needs as synonym for

\footnotetext{
${ }^{20}$ We also test whether the relative importance (i.e., size) of industries in an economy affects the industry composition of a bank's credit portfolio. Since the conclusions are confounded by a scale effect for absolute as well as for relative measures of industry size, they are not reported.

${ }^{21}$ See Kashyap and Stein (1995), Mojon (2001), and Kuttner and Mosser (2002).

${ }^{22}$ See Hayo and Uhlenbrock (2000), Peersman and Smets (2005), and Dedola and Lippi (2005).

${ }^{23} \mathrm{We}$ also use the ratio of the stock of capital over output as proxy variable of capital intensity. Because the results are qualitatively the same as those for the ratio of the stock of capital over employment, we do not report the corresponding evidence.
} 
bank dependence and explains the negative relationship between the demand for bank finance and firm size by stressing the transaction costs and information asymmetries associated with bond-based financing. Transaction costs such as brokerage and underwriting fees are largely independent of the amount of bonds issued and thus render only large amounts of bond issues feasible from a financial point of view. Information asymmetries arise between the issuer and potential holder of bonds. In order to mitigate asymmetric information problems, sufficient information on the bond issuing company needs to be easily available. Because large firms are subject to more stringent regulation, disclosure rules, and reporting standards than small firms, such information is more freely disseminated for large than for small companies and the degree of information asymmetries hence decreases with the size of firms. As a consequence, the ability to substitute bonds for bank lending increases with firm size and the degree of bank dependence diminishes with firm size. ${ }^{24}$ These relationships cause business size to be usually associated with the credit channel of monetary policy.

In Germany, the difference in the relative importance of bonds and bank credit as source of external finance also rests on relationship banking and the corresponding notion of banks being the housebank to especially small firms. ${ }^{25}$ The housebank principle facilitates the flow of information between creditors and debtors, establishes confidence, and reduces asymmetric information problems. Tight bank-firm relationships leave banks therefore with a comparative advantage regarding risk assessment, monitoring, and information asymmetries and lower the costs of bank-finance relative to non-bank finance. ${ }^{26}$ Because bank-firm relationships are particularly strong for small firms, we hypothesize that banks lend more to industries with a large share of small firms. In order to test this hypothesis, we use the share of small firms in industry $\mathrm{i}$ to approximate the distribution of firm size.

Besides firm size distribution, we approximate the need for external finance by including the industry-specific ratio of operating surplus over value added as proxy variable of internal funds of finance or working capital. ${ }^{27}$ Credit market imperfections cause the expected relationship between internal funds of finance and bank credit to be negative. The underlying argument is similar to that of the balance sheet effect in section 5.2 and predicts a mismatch between credit demand and credit supply.

Finally, we include openness to trade in order to determine the extent to which industry-

\footnotetext{
${ }^{24}$ Also see Deutsche Bundesbank (1998a, 2002a) and Elsas and Krahnen (2004) for a discussion of the bank dependence of small- and medium-sized companies.

${ }^{25}$ See Berger and Udell $(1998,2002)$ and the references therein for a discussion of the relationship between firm size and relationship lending.

${ }^{26}$ Harhoff and Körting (1998) report empirical evidence that lends support to the importance of housebank relations and relationship lending in Germany. Especially small firms are suggested to maintain long-term relationships with a bank.

${ }^{27}$ An alternative and more direct measure of internal finance is cash flow. However, because industryspecific information on cash flow or the components thereof (earnings, interest payments, taxes, dividend payments, depreciation) is unavailable, we use operating surplus as a simple measure.
} 
specific exposure to trade and exchange rate fluctuations affect bank credit demand. Whether bank lending to open industries responds more or less to changes in bank credit demand factors like industry production and industry price depends on the argumentation. On the one hand, open industries may not adjust loan demand in response to output growth or inflation as much as closed industries if cyclical changes in product demand abroad and at home are not synchronous but occurring at a periodic lag. This smoothes cash flow and therefore the cyclical demand for bank credit. On the other hand, lending to open industries might be more sensitive to changes in domestic output and inflation when domestic and foreign business cycles are dis-concordant and when real exchange rate developments cause adverse developments in international competitiveness.

Table 5.4 reports the degree of correlation between short-term lending and structural industry characteristics for the period 1992-2002. ${ }^{28}$ The results for aggregate lending are not reported because they do not differ qualitatively from those for short-term lending. In order to match the frequency of bank-specific and industry-specific data, the quarterly bank-level data are expressed in annual terms. Furthermore, the microeconomic data are aggregated over all banks in order to avoid that the significance properties of the correlation coefficients are driven by the number of observations. The correlation coefficients are computed for seven industries at the one-digit industry level and for nine sub-sectors of the manufacturing industry. ${ }^{29}$ Similar to the analysis in chapter 4 and 6, data on industry characteristics are obtained from the New Cronos database of Eurostat and from the STAN database for Industrial Analysis of the OECD. The firm size data refer to the size class of 1 to 19 employees; a size category which corresponds to the definition of small firm size (cf. Loveman and Sengenberger, 1991; Henrekson and Johansson, 1999). The bank lending data are compiled from the quarterly borrower statistics of the Deutsche Bundesbank. The degree of correlation between industry characteristics and bank lending is computed for the variables' ratio of industry $i$ to the grand total of industries for the aggregate banking group, the sub-groups of the credit cooperative banking sector, and for commercial and savings banks. ${ }^{30}$

Considering the relationship between the relative degree of capital intensity of industry production and the share of bank credit, banks lend comparatively less to capital-intensive industries. This finding is robust to the choice of capital intensity measure and is particularly strong for the sub-groups of the credit cooperative sector. The negative link between relative capital intensity and the relative share of bank lending is counterintuitive if one considers the costs of physical capital investment, which ask for substantial financial means. The Deutsche Bundesbank (1996) suggests that the inverse relationship between the volume of bank lending and capital intensity is due to credit rationing to capital-intensive industries on the part of

\footnotetext{
${ }^{28}$ Because of data availability constraints, the firm size correlation coefficients are constructed for the period 1999-2000.

${ }^{29}$ The aggregate manufacturing sector is excluded given that the manufacturing sub-sectors are included.

${ }^{30}$ The conclusions are robust to the definition of industry characteristics. That is, they do not change when the industry characteristics are expressed in absolute rather than in relative terms.
} 
Table 5.4: Correlation between Industry-Specific Bank Lending and Industry Characteristics, Short-Term Bank Lending

\begin{tabular}{lcccccc}
\hline \hline & Agg. BG & Comm. BG & Savings BG & Comm. CC & Rural CC & Raiffeisen BG \\
\hline Empl't/Output & $0.14^{* * *}$ & 0.03 & $0.23^{*}$ & $0.25^{*}$ & $0.40^{*}$ & $0.55^{*}$ \\
Capital/Empl't & $-0.25^{*}$ & $-0.17^{* *}$ & $-0.34^{*}$ & $-0.35^{*}$ & $-0.36^{*}$ & $-0.34^{*}$ \\
Firm Size & 0.27 & 0.15 & 0.38 & 0.40 & 0.43 & 0.47 \\
Openness & 0.04 & 0.07 & 0.004 & 0.02 & -0.06 & $-0.15^{* * *}$ \\
Op. Surplus & -0.06 & $-0.08^{* * *}$ & -0.06 & -0.05 & 0.03 & 0.12 \\
\hline \hline
\end{tabular}

Notes: Short-term lending to industry $i$ is the cumulative sum of bank-specific lending and expressed as share of short-term lending to the grand total of industries. The coefficients are derived from annual data for all sampled industries except for total manufacturing. The sample period is 1999-2000 for firm size and 1992-2002 for the remaining variables. Empl't/Output = employment over real value added; Capital/Empl't = physical capital over employment; Openness $=$ exports and imports over value added; Op. Surplus = operating surplus over value added. Because of missing values along the time and cross-section dimension, the number of observations tends to be lower than 176 (11 years times 16 industries). $*, * *, * * *$ denote the statistical significance at the one, five, and ten percent level, respectively. Own computations using the New Cronos database, the OECD's STAN database for Industrial Analysis, and the quarterly borrower statistics of the Deutsche Bundesbank.

banks. Capital rationing arises because lending to capital-intensive industries is considered to be characterized by higher probabilities of loan losses than lending to capital-extensive industries.

As regards the evidence for firm size, the correlation coefficients have the expected positive sign, which points to an inverse relationship between firm size and the share of bank credit. According to the European Commission (2003), this reflects the greater need of relatively small firms for working capital. ${ }^{31}$ Unfortunately, the correlation coefficient is statistically insignificant, which leaves the relationship indicative rather than affirmative. We attribute the insignificance to the small number of data points on firm size. Next to firm size, the correlation coefficients for operating surplus and openness also tend to be insignificant. The exception concerns lending by Raiffeisen banks which grant relatively more credit to open industries and lending by commercial banks which grant less credit to industries with relatively high operating surplus. However, the poor significance properties again cause these relationships to be suggestive at best.

Overall, the correlation coefficients provide ambiguous evidence as to the existence of a relationship between structural industry characteristics and the share of bank credit to individual industries. Significant relationships are confined to the proxy variables of relative capital intensity. Alternative industry characteristics do not have a significant effect on the industry composition of a bank's credit portfolio. We will show in section 5.6 that industry effects of bank lending arise from cyclical factors related to industry output and industry prices.

\footnotetext{
${ }^{31}$ The descriptive evidence in European Commission (2003) illustrates that (small) businesses in manufacturing, transport and communication, and wholesale require more bank credit than (small) firms in other sectors.
} 


\subsection{Empirical Model}

The remainder of this chapter disregards structural industry characteristics and stresses industry-specific cyclical determinants of bank credit demand as factors that have a strong effect on bank lending to industries. Besides cyclical credit demand factors, we will also stress the role of monetary policy as determinant of industry-specific bank lending and test for credit channel effects of monetary policy via bank lending. We ask whether differences in the bank lending effects of credit demand and monetary policy are accounted for by industries or by banking groups. The corresponding evidence allows for inferences as to the importance of the industry structure of bank credit portfolios and the structure of the German banking sector as determinants of monetary policy effectiveness and industry performance through the availability of industry-specific bank credit. Furthermore, we test whether conclusions are robust to the choice of aggregate and short-term bank credit. The remainder of this section presents the industry-specific bank lending functions and the methodological approach that will be employed to identify the industry and banking group effects of bank credit demand and monetary policy.

\subsubsection{Empirical Estimation Framework}

In order to identify the response of industry-specific bank lending to changes in monetary policy and industry-specific bank credit demand, we apply the dynamic panel estimation framework of Ehrmann et al. (2003), Worms (2003), and Gambacorta and Mistrulli (2004). Although we use the same structural estimation framework, the analysis adds to the existing work by exploring the industry dimension of bank lending. Equation (5.1) describes the empirical bank lending function for bank $b$ and industry $i^{32}$

$$
\begin{aligned}
\Delta \mathrm{L}_{\mathrm{bi}, \mathrm{t}}= & \alpha_{\mathrm{b}}+\sum_{\mathrm{j}=1}^{\mathrm{p}} \beta_{\mathrm{ij}} \Delta \mathrm{L}_{\mathrm{bi}, \mathrm{t}-\mathrm{j}}+\sum_{\mathrm{j}=1}^{\mathrm{p}} \gamma_{1 \mathrm{j}} \Delta \mathrm{r}_{\mathrm{M}, \mathrm{t}-\mathrm{j}}+\sum_{\mathrm{j}=1}^{\mathrm{p}} \gamma_{2, \mathrm{ij}} \Delta \mathrm{IP} \mathrm{P}_{\mathrm{i}, \mathrm{t}-\mathrm{j}}+\sum_{\mathrm{j}=1}^{\mathrm{p}} \gamma_{3, \mathrm{ij}} \Delta \text { Price }_{\mathrm{i}, \mathrm{t}-\mathrm{j}}+ \\
& \gamma_{4} \mathrm{X}_{\mathrm{b}, \mathrm{t}-1}+\sum_{\mathrm{j}=1}^{\mathrm{p}} \gamma_{5 \mathrm{j}} \mathrm{X}_{\mathrm{b}, \mathrm{t}-1} \Delta \mathrm{r}_{\mathrm{M}, \mathrm{t}-\mathrm{j}}+\epsilon_{\mathrm{bi}, \mathrm{t}} .
\end{aligned}
$$

The coefficient $\alpha_{\mathrm{b}}$ is a bank-specific intercept that is included to allow for fixed effects across banks and $\epsilon_{\mathrm{bi}, \mathrm{t}}$ is an i.i.d. random variable with zero mean and constant variance, i.e., $\mathrm{N} \sim\left(0, \sigma_{2}\right)$. $\mathrm{L}_{\mathrm{bi}, \mathrm{t}}$ denotes aggregate or short-term lending by bank $\mathrm{b}$ to industry $\mathrm{i}$ at time $\mathrm{t}$, with $\mathrm{b}=1, \ldots, \mathrm{N}_{\mathrm{b}}$ and $\mathrm{t}=1, \ldots, \mathrm{T}$. The autoregressive parameters $\beta_{\mathrm{ij}}$ are assumed to be the same across banks, but heterogeneous across industries. Furthermore, they may differ

\footnotetext{
${ }^{32}$ Also see section 5.6 .4 and annex $5 \mathrm{C}$ for alternative specifications of the bank lending function. An appealing alternative specification of model (5.1) stacks bank lending by industry for all industries and captures industry effects with industry dummies. Given the large number of banks and industries, computational limitations preclude the realization of this approach in the present framework.
} 
across banking groups. In order to control for cross-banking group differences, we estimate the model for individual banking groups.

$\Delta$ is the first $\log$-difference operator of variable $\mathrm{V}$ defined as $\Delta \equiv \log \mathrm{V}_{\mathrm{t}}-\log \mathrm{V}_{\mathrm{t}-1}$. With the exception of the money market interest rate, the first log-difference transformation is applied to all variables. The money market interest rate enters in first differences. Ehrmann et al. (2003) motivate the first-difference structure of the empirical model by stressing that the monetary policy effect on bank lending is confined to new loans. They hence interpret the first log-difference of bank credit as flow variable and introduce the level of loans as stock variable. When suggesting this measure of new loans, Ehrmann et al. (2003) fail to recognize that the first difference is an imperfect measure of new bank loans since it reflects the net effect of new loan issues and loan repayments. Unfortunately, the present study can only acknowledge this shortcoming, but cannot resolve it because of data unavailability. As a consequence, reductions in the volume of loans outstanding may reflect a decline in new loan issues or a net increase in loan repayments.

$\mathrm{IP}_{\text {it }}$ approximates industry-specific output at time $\mathrm{t}$, which serves as a measure of cyclically determined industry-specific bank credit demand. Price ${ }_{i t}$ denotes the industry-specific price at time $t$ and is included to capture cyclical fluctuations in industry-specific price developments. ${ }^{33}$ These variables do not only determine the external financing needs of industries, but also influence the perceptions of banks as to the riskiness of industries. Monetary policy actions are represented by the change in the three-months money market interest rate $\Delta r_{M}$. We assume that the interest rate is strictly exogenous to bank lending. ${ }^{34}$ In order to identify the bank lending effects of monetary policy, the money market interest rate $\left(r_{\mathrm{M}, t-\mathrm{j}}\right)$ at time $\mathrm{t}-\mathrm{j}$ is interacted with bank characteristics $\left(\mathrm{X}_{\mathrm{b}, \mathrm{t}-1}\right)$ at time $\mathrm{t}-1$. The vector of bank-specific characteristics $X_{b}$ includes asset size (TA), liquidity $(A)$, and capitalization $(K)$ at time $t-1$. Bank characteristics are introduced with one lag to avoid an endogeneity bias (cf. Kashyap and Stein, 1995, 2000; Ehrmann et al., 2003; Worms, 2003; Gambacorta and Mistrulli, 2004). Annex $5 B$ contains a formal definition of the bank characteristics.

Worms (2003) and Ehrmann and Worms (2004) show that the tight relationship between the primary and head institutions of the savings and credit cooperative banking sector causes bank asset size to be an inappropriate proxy variable of the bank lending effects of monetary policy. One explanation is that interbank operations enable small banks to shield their loan portfolio and funding possibilities against monetary policy shocks by providing a relatively unconstrained access to central bank money. In that sense, the interbank market helps to redistribute liquidity within the banking sector from banks with excess liquidity to banks in need of liquidity. This in turn moderates financing constraints for small banks. As a consequence, the interest rate sensitivity of small bank lending does not have to be higher

\footnotetext{
${ }^{33}$ Section 5.5 provides details regarding the definition of the industry production and price variable.

${ }^{34}$ See Worms (2003) for empirical evidence regarding the robustness of the interest rate response of bank lending to the exogeneity assumption.
} 
than that of large banks. Bank size might also be an inappropriate measure of information asymmetries because savings banks as well as credit cooperatives back their funds with mutual guarantees. This serves to recapitalize banks and creates a type of insurance scheme for creditors in case of bank insolvency. The existence of these insurance schemes implies that information asymmetries may not affect the lending behavior of banks. Consequently, size appears to be an inadequate variable to identify the loan supply effects of monetary policy and better measures might be bank capitalization or bank liquidity.

The present model employs a 'broad' and 'narrow' measure of bank liquidity. The main difference concerns the way short-term interbank claims are treated. The 'broad' measure of liquidity includes short-term interbank claims and is defined as the ratio of cash plus securities plus short-term interbank claims over total bank assets. For this definition, possible significant relationships between bank liquidity and the monetary policy response of bank lending can be driven by short-term interbank claims (cf. Worms, 2003 and Ehrmann and Worms, 2004). In order to determine whether short-term interbank claims indeed drive liquidity effects, we follow Worms (2003) and split the broad measure of liquidity into two components: (i) a 'narrow' part of liquidity defined as the ratio of cash plus securities over total bank assets and (ii) the share of short-term interbank claims to total assets. Both components are separately included in estimations of model (5.1). ${ }^{35}$ The corresponding models will subsequently be referred to as narrow liquidity and interbank specifications.

We summarize the bank lending effects of changes in monetary policy and changes in bank credit demand by computing the long-run elasticities of bank lending with respect to the explanatory variables in model (5.1). ${ }^{36}$ The industry-specific long-run coefficients $\alpha_{\mathrm{LR}, \mathrm{i}}$ are defined as the sum of the lags of the variable in question divided by one minus the sum of the coefficients on the lagged bank credit variable: $\alpha_{\mathrm{LR}, \mathrm{i}}=\frac{\sum_{\mathrm{j}=1}^{J} \gamma_{\mathrm{ij}}}{1-\sum_{\mathrm{j}=1}^{J} \beta_{\mathrm{ij}}}$, where $\mathrm{J}=4{ }^{37}$ Since the long-run coefficients are a non-linear function of the estimated parameters, we derive the corresponding standard errors by means of the delta method (cf. Rao, 1973; Greene, 2003). ${ }^{38}$

We hypothesize the long-run coefficient estimates in model (5.1) to enter with the following signs. Motivated by the negative effects of higher interest rates on bank reserves, we expect bank lending to decline in response to a monetary contraction. The distributional effects of monetary policy are anticipated to be such that the response of bank lending to monetary policy changes is less pronounced for larger, more liquid, and better capitalized banks. This

\footnotetext{
${ }^{35}$ The subsequent analysis will thus report the results for a broad and narrow definition of liquidity and for short-term interbank claims.

${ }^{36} \mathrm{We}$ follow the existing literature when referring to long-run elasticities (e.g., Deutsche Bundesbank, 2002b; Gambacorta and Mistrulli, 2004; Worms, 2003; Ehrmann et al., 2003). An alternative and more intuitive interpretation views the 'long-run' coefficient as the lasting response of bank lending growth to changes in either bank credit demand or monetary policy.

${ }^{37}$ The properties of the residuals do not change with $\mathrm{J}=5$.

${ }^{38}$ We only report the short-run coefficient for the one-period lag of the normalized bank characteristics. The short-run coefficients for the remaining variables are available on request.
} 
holds if the coefficient on the interaction term between each bank characteristic and the interest rate is positive. Ambivalent conclusions prevail with respect to the expected effect of industry output growth on bank lending growth. On the one hand, good economic conditions raise the number of investment projects with positive net present value and hence the demand for bank finance. On the other hand, economic growth stimulates internal cash flow, which may reduce credit demand. Because evidence in favor of a negative relationship between output and bank lending is hardly existing, the long-run coefficient on output growth is expected to be positive. ${ }^{39}$ Finally, industry inflation is anticipated to stimulate bank lending growth. This relationship is attributable to the negative effect of positive price changes on real income and hence real cash flow. ${ }^{40}$

The present analysis does not explicitly account for merger-driven changes in the German banking system and hence does not control for the effects of mergers on the individual characteristics of the merging banks. The appropriateness of this approach is suggested by Worms (2003) who finds the long-run bank lending effects of monetary policy to be the same for samples that do not control for mergers and for samples which treat a merged bank as single bank for the pre- and post-merger sample period. Besides, implementation lags between the time a merger is officially announced and the time a merger is legally realized makes it difficult to determine the date of a merger. For these reasons, we will eliminate most merger effects with the outlier detection procedure introduced in section 5.5.

\subsubsection{Methodology}

The system in equation (5.1) represents a fixed effects dynamic (unbalanced) panel with large $T$ and large N. Lagged values of the dependent variable are included to control for an omitted variable and endogeneity bias. Because the lagged dependent variable is correlated with the error term, dynamic panel models are usually not estimated with the static panel fixed effects estimator. Doing so would introduce a finite sample bias of order $\frac{1}{\mathrm{~T}}$ for $\mathrm{N} \rightarrow \infty$ and fixed T (see Nickell, 1981; Kiviet, 1995). In order to avoid biased and inconsistent estimates, Arellano and Bond (1991) suggest the use of a generalized method of moments (GMM) estimator. Recent studies have challenged this method. Blundell and Bond (1998) and Blundell, Bond, and Windmeijer (2000) have shown that the first-differenced GMM estimates are biased downwards in the direction of the within-group estimates and Alvarez and Arellano (2003) show that the GMM estimator is close to the fixed effects estimator for large T. Furthermore, Jung (2005) illustrates that Arrelano and Bond's (1991) test of serial residual correlation may build on inconsistently estimated residuals. Because these are used

\footnotetext{
${ }^{39}$ See De Bondt (1998), Worms (2003), Ehrmann et al. (2003), and Gambacorta and Mistrulli (2004) for evidence in favor of a positive relationship between bank lending and output. Altunbaș, Fazylov, and Molyneux (2002) report a positive output coefficient for medium-sized and undercapitalized banks and a negative coefficient for small-sized and under- or overcapitalized banks in Germany.

${ }^{40}$ Ehrmann et al. (2003) and Gambacorta and Mistrulli (2004) report evidence of a positive price effect on bank lending.
} 
to decide on the optimal over-identifying restrictions, coefficient estimates are likely to be inconsistent.

In view of these points and given a comparatively large set of data points in the time dimension, we estimate the dynamic panel model by using the fixed effects estimator. Besides, the use of the fixed effects estimator is also motivated by the Hansen J-statistic according to which the over-identifying restrictions in the present set of GMM estimations are invalid regardless of the instrumentalization. In order to ensure that the presence of autocorrelation in the residuals $\epsilon_{i t}$ does not result in inconsistent and inefficient estimators, we compute White-period standard errors (Arellano, 1987), which are robust to arbitrary serial correlation and time-varying variances in the residuals. We test for the existence of first-order and second-order serial autocorrelation by regressing the within regression residuals against their one- and two-period lag. The underlying model allows for fixed effects and White-period standard errors. ${ }^{41}$

\subsection{Data}

Ideally, the analysis of the industry-specific bank lending effects of changes in bank credit demand and monetary policy would build on firm-level as well as bank-level data. Bank-level data allow for the identification of the credit channel effects of monetary policy through bank lending and firm-level data allow for assessments regarding the operation of a credit channel through balance sheet effects. Although firm-level data are available from the corporate balance sheet statistics of the Deutsche Bundesbank, they are not useful for our purpose because they are only available at an annual frequency and subject to a large firm bias. ${ }^{42}$ Given the unavailability of adequate firm-level data, we determine the bank lending effects of changes in credit demand and monetary policy for industry aggregates. We compile industry data for 17 industries, which include eight industries at the one-digit industry level and nine industries at the two-digit industry level. The latter are sub-sectors of the manufacturing industry (see annex 5A).

Bank-level data on bank-specific balance sheet variables and bank-specific credit supply to individual industries are respectively obtained from the quarterly borrower statistics and monthly bank balance sheet statistics of the Deutsche Bundesbank for the period 1992-2003. Because data in 2003 display patterns that are irreconcilable with those in earlier years, we confine the analysis of quarterly data to the period 1992:1-2002:4. The bank-specific balance sheet and lending data display seasonal patterns. For each bank, these are removed by means of the centered-moving average method. This is an admittedly simple adjustment procedure that

\footnotetext{
${ }^{41}$ Note, the conclusions regarding the existence of serial autocorrelation are robust to the way in which the first- and second-order autocorrelation coefficient is computed. A simple least squares estimator without fixed effects and White-period standard errors produces comparable results.

${ }^{42}$ See Deutsche Bundesbank (1998b) for details.
} 
can be criticized for ignoring, for example, working day and leap year effects. However, it is the preferred method in the present analysis because it is applicable despite the large number of cross sections. Furthermore, a comparison of the seasonally adjusted and non-adjusted series shows that the centered moving average procedure captures seasonal fluctuations well.

Information on industry production and industry prices are available from the New Cronos database at a monthly frequency for most industries. The corresponding variables are indices with base year 2000. For some industries, industry output is approximated with industry value added. The corresponding data are provided by the German statistical office. The monthly data on industry output and prices are converted into quarterly data to match the frequency of the bank lending data. While data on industry output are directly obtained for the sample period 1992:1-2002:4, information on industry prices is only available as of 1995:1. In order to identify the 1992:1-1994:4 values, we regress the industry-specific price index against a constant and the contemporaneous value of the aggregate price index and use the coefficient estimates from ordinary least squares (OLS) to extrapolate the missing values on industry-specific prices. Industry prices for the wholesale and retail trade, finance and insurance, transport and communication, and service sector are not available from the New Cronos database. Instead, we construct them using information on nominal and real value added from the German statistical office for the whole sample period 1992:1-2002:4. ${ }^{43}$

The New Cronos database and the Deutsche Bundesbank's quarterly borrower statistics occasionally differ in terms of industry aggregation. In particular, the borrower statistics tend to refer to composites of industries rather than to individual units. In order to adopt the same level of industry aggregation, the New Cronos data on industry production and industry characteristics are also combined across some industries. The composite indices are constructed by controlling for the relative importance of the single industries in the composite. Limited by data availability, the weights are approximated as the 1992-2002 ratio of annual value added of industry $i$ to aggregate value added of the industries included in the composite. Since the weights are time-invariant, the use of the 1992-2002 average as weight seems to be innocuous.

In order to ensure the reliability of the empirical results, the quarterly data are screened along different lines. Firstly, the data are checked for outliers. Outlier detection concerns the relationship between variables as well as the distribution of variables. One relationship concerns the need of banks to meet their balance sheet constraint. For the requirement that total assets equal total liabilities, the study keeps all but 5 data points. ${ }^{44}$ Another relationship is defined as the need to have positive entries for credit supply and total assets. In the present

\footnotetext{
${ }^{43}$ Note, the German statistical office reports data on nominal and real value added jointly for the (i) wholesale and retail trade sector and (ii) transport and communication sector. Unfortunately, we cannot disentangle the industry-specific price for each of these sectors, but have to rely on the composite price measure.

${ }^{44} \mathrm{~A}$ data point is a single time observation associated with an individual bank (e.g., the observation associated with bank $\mathrm{i}$ in 1992:1).
} 
sample, at most 18 data points for industry-specific loans and 47 data points for total assets do not meet the non-negativity constraint. These observations are excluded from the sample.

As regards the distribution of variables, the outlier detection procedure is predominantly implemented for variables in levels. The exception concerns the volume of bank credit and total bank assets. In order to avoid the exclusion of very large and very small banks on the ground of sheer size, the outlier detection procedure for total assets and the volume of bank credit is implemented for their first log-differences. ${ }^{45}$ Regardless of the variable, outliers are detected by using the sequential outlier rejection (SOR) algorithm described in Corney (2002). In contrast to standard methods like the z-score or box plot method, this outlier detection procedure adopts a sequential approach that accounts for the effect of outliers on the standard error in the sample. Furthermore, the SOR approach does not assume the normal distribution of banks at any point in time. This property is particularly valuable since the hypothesis of normally distributed banks can be rejected for all sampled variables (see Table 5.1 and Table 5.3). The SOR algorithm requires the data to be repeatedly clustered by using any clustering algorithm. The present analysis uses k-means clustering for each of the main banking groups, with $\mathrm{k}=2 .{ }^{46}$ For each repetition, the sum-squared error for k-means is computed, which describes the sum-squared deviation of each data point in the sample to the nearest cluster center. The data point that contributes most to the sum-squared error for k-means is excluded from the sample.

For each point in time and each banking group, the clustering algorithm is iteratively applied to the dataset. The number of iterations is roughly equal to 5 percent of the number of banks at each point in time. ${ }^{47}$ That is, the first step of the procedure treats 5 percent of all banks at each point in time as potential outlier. The second step builds on the iteratively excluded observations from step one and determines the actual number of outliers by using the second difference of the sum-squared error term. Under the assumption that the sum-squared error rate is driven by outliers, the second derivative is close to zero and the cumulative sum thereof is constant for the sequence of data that excludes atypical observations. In the present study, we exclude any data point as outlier if it explains more than one percent of the cumulative sum of the second derivative. Similar to other outlier detection methods (e.g., the box plot method and the z-approach), the choice of threshold is arbitrary.

As a final remark, the analysis is confined to institutions that have the status of a monetary finance institute (MFI) throughout the whole sample period. The restricted focus is necessitated by a change in data definition. Until 1998:4, non-MFIs were treated as financial institutions and the Deutsche Bundesbank's borrower statistics reported lending by these in-

\footnotetext{
${ }^{45}$ See Worms (2003) for a similar procedure.

${ }^{46}$ The large number of observations and computer limitations preclude the definition of more than two clusters.

${ }^{47}$ The number of iterations depends on the availability of data for a given banking group at a particular point in time. The results are not sensitive to a larger number of iterations.
} 
stitutions to enterprises and households. As of 1999:1, non-MFls are treated as enterprises and the borrower statistics do no longer report lending by, but credit supply to these institutions. In order to avoid that the definitional change of non-MFIs from being creditors to being debtors biases the results, we exclude banks with a non-MFI status in any quarter during the sample period. This leads to a loss of 1400 data points from the commercial banking group and 208 data points from the cooperative banking group.

\subsection{Empirical Results}

This section reports the empirical results of the fixed effects dynamic panel estimation. In section 5.6.1, we first describe the different samples for which the benchmark model (5.1) is estimated. Section 5.6.2 then reports ANOVA test statistics that help to structure the analysis of the panel data evidence in section 5.6.3. We conclude the present section with robustness tests of the benchmark model (5.1). In the remainder of this chapter, we largely disregard the results for the bank lending functions of the metals producing industry. This is because of serially correlated residuals that cause the long-run coefficients to be biased and inconsistent. The autocorrelation properties do not improve in estimations with an alternative lag structure and are robust to the structure of the model.

\subsubsection{Sample Overview}

The empirical model is estimated for different combinations of banking groups. Table 5.5 summarizes the composition of the samples. One sample jointly includes the primary (local) institutions of the commercial, savings, and credit cooperative sector. This group is subsequently referred to as the aggregate banking group. Group-specific effects are captured with banking group dummies for the savings and commercial banking group. Because the dummies turn out to be statistically insignificant in almost all specifications, weak or no banking group effects appear to exist for savings and commercial banks relative to credit cooperatives. In view of this finding, the subsequent evidence for the aggregate banking group refers to the results of estimations without banking group dummies. We also estimate the model for the credit cooperative banking sector, with banking dummies for the commercial credit cooperative banking group and Raiffeisen banks. In contrast to the aggregate banking group, the dummies turn out to be statistically significant for most industry bank lending functions.

In order to allow for the possibility of parameter heterogeneity across banking groups, another sample is separately defined for the three main sub-groups of the credit cooperative banking group (i.e., rural, commercial, and Raiffeisen banks) and for savings banks. The importance of possible panel heterogeneity is suggested by the ANOVA evidence in section 5.3.1 that points to structural differences between (i) the savings and cooperative banking group and (ii) the sub-groups of the cooperative banking sector. When estimating individual models for 
Table 5.5: Sample Overview

Bank Lending Functions for: Banking Group Composed of:

- Aggregate banking group (BG)

- Credit cooperative BG

- Savings BG

- Commercial credit cooperatives

- Rural credit cooperatives

- Raiffeisen banks
- Commercial, savings, credit cooperative banks

- Commercial and rural credit cooperatives, Raiffeisen banks

- Public savings banks

the savings and credit cooperative banking group, we assume cross-bank homogeneity in the interest rate elasticity of loan demand and hence cross-bank similarities in the distribution of bank-dependent and bank-independent customers within each individual banking group. We do not estimate an individual model for the commercial banking group or for the head institutions of the savings and credit cooperative banking sector because they operate product portfolios which differ from those of the local savings and credit cooperative banks. Besides, estimates for an individual sample of commercial banks are not reported since the number of cross sections is low. The fixed number of observations causes the fixed effects estimator and the robust covariance matrix estimates to be inconsistent although $\mathrm{T}$ is relatively large.

\subsubsection{Analysis of Variance Tests}

The representation of the results is complicated by the cross-sectional dimension of the study. To condense the analysis, this section first reports test statistics of one- and twoway analyses of variance which illustrate the sensitivity of the results to the choice of bank characteristic, the choice of aggregate and short-term lending, and the choice of industry and banking group. The test statistics are computed for the long-run coefficients of model (5.1) irrespective of the significance properties of the coefficient estimates. If we would confine the analysis to industries for which significant estimates are reported, ANOVA would not be feasible. Despite the inclusion of insignificant estimates, the results are still deemed to be illustrative. On the one hand, we only compute test statistics for variables for which most industry-specific long-run estimates are statistically significant, i.e., for industry output growth, industry inflation, and the interest rate change. Test statistics are not reported for the interaction terms because of pronounced differences in their statistical significance across the different bank lending specifications. On the other hand, the insignificant industry-specific coefficient estimates on either industry output growth, inflation, or the interest rate change compare well with the significant estimates in terms of sign and magnitude regardless of the choice of bank characteristic.

We first investigate whether the long-run coefficient estimates for industry output growth, 
inflation, and the interest rate change are influenced by the choice of bank characteristic, i.e., bank asset size, capitalization, broad/narrow liquidity, or short-term interbank claims. Because the results of the one-way analysis of variance are robust to the choice of banking group and do not differ for aggregate and short-term lending, we only report the results for the aggregate banking group and for short-term lending. ${ }^{48}$ The results in Table 5.6 (columns 3 to 6 ) show that the null hypothesis of equal coefficients across bank characteristics cannot be rejected. The choice of bank characteristic hence does not significantly affect the long-run sensitivity of bank lending with respect to either industry-specific bank credit demand or the money market interest rate.

We next ask whether the long-run coefficients of the sampled variables depend on the choice of aggregate and short-term bank lending. Because the coefficient estimates are insensitive to the choice of bank characteristic, we only report the one-way ANOVA test statistics for bank asset size. The evidence in Table 5.6 (columns 7 to 10) points to the equality of the long-run coefficients for aggregate and short-term lending. This in turn suggests that conclusions regarding the determinants of bank lending growth do not differ for aggregate and short-term credit. This result holds with respect to all sampled variables.

We conclude the discussion by formally testing whether differences in the bank lending effects are accounted for by banking groups or by industries. To this end, we compute the test statistics of a two-way analysis of variance. Given the one-way ANOVA test statistics, we only report the results for short-term lending and bank asset size, noting that the evidence for aggregate lending and the remaining bank characteristics does not differ. ${ }^{49}$ Table 5.7 summarizes the results. The analysis of variance shows that differences in the responsiveness of short-term bank lending growth to industry output growth and industry inflation are attributable to industries, but not to banking groups. ${ }^{50}$ That is, the evidence stresses discernible industry dissimilarities in the bank lending effects of industry output growth and inflation. In contrast to output growth and inflation, differences in the long-run bank lending effects of interest rate changes are explained by banking groups and industries. However, industry effects appear to be the more important source of variation in the bank lending effects of monetary policy. This conclusion builds on the observation that the F-value for the industry effect exceeds the corresponding value for the banking group effect.

\footnotetext{
${ }^{48}$ The results for the remaining banking groups are available on request.

${ }^{49}$ The ANOVA test statistics for estimations with bank capitalization, liquidity, and interbank assets and for aggregate lending are available on request.

${ }^{50}$ We replicate the analysis of variance for a sample that excludes the construction sector. The restricted focus is motivated by the unexpected positive interest rate response of bank lending to this industry. We find the ANOVA results to be robust to this sample adjustment.
} 


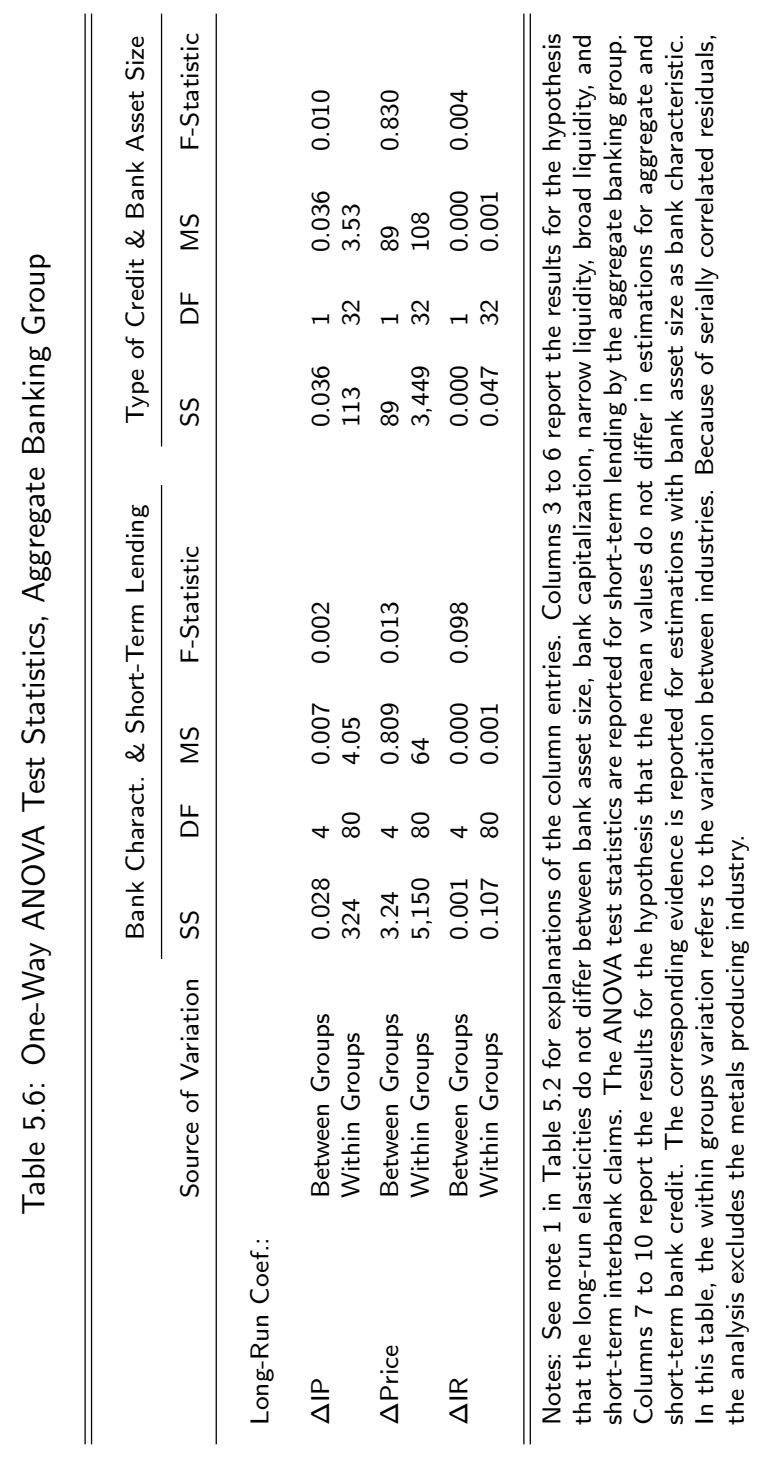


Table 5.7: Two-Way ANOVA Test Statistics, Short-Term Lending

\begin{tabular}{llllll}
\hline \hline \multirow{2}{*}{ Long-Run Coef.: } & Source of Variation & SS & DF & MS & F-Statistic \\
\hline \multirow{2}{*}{$\Delta \mathrm{IP}$} & Banking Group & 7.25 & 3 & 2.42 & 0.77 \\
& Industry & 277 & 14 & 20 & $6.32^{*}$ \\
$\Delta$ Price & Error & 132 & 42 & 3.13 & \\
& Banking Group & 7.16 & 3 & 2.39 & 0.18 \\
& Industry & 4,345 & 14 & 310 & $23.83^{*}$ \\
$\Delta \mathrm{IR}$ & Error & 547 & 42 & 13 & \\
& Banking Group & 0.006 & 3 & 0.002 & $4.61^{*}$ \\
& Industry & 0.098 & 14 & 0.007 & $16.20^{*}$ \\
& Error & 0.018 & 42 & 0.0004 & \\
\hline \hline
\end{tabular}

Note $^{1}$ : SS = sum of squares, DF = degrees of freedom, MS = mean squares (i.e., $\mathrm{SS}_{\text {Source }}$ divided by $\mathrm{DF}_{\text {Source }}$ ), and F-value $=\mathrm{F}$-statistic (i.e., $\mathrm{MS}_{\text {Source }}$ divided by $\left.\mathrm{MS}_{\text {Error }}\right)$. Differences between the MS- and F-statistics in the table and the MSand F-statistics determined in calculations with the reported SS-statistics and the degrees of freedom are due to rounding. Note ${ }^{2}:{ }^{*}$ denotes the statistical significance at the one percent level. Note ${ }^{3}$ : The table reports the ANOVA test statistics for estimations with short-term lending and bank asset size. Note ${ }^{4}$ : The banking group involves savings banks, rural and commercial credit cooperatives, and Raiffeisen banks. The industry dimension includes 7 industries at the onedigit level (excluding total manufacturing) and 8 manufacturing industries at the two-digit level (excluding the metals producing sector).

The ANOVA evidence illustrates that industries are the more important source of differences in the bank lending effects of industry credit demand and monetary policy. In addition, we find the results regarding the bank lending effects of industry output growth, industry inflation, and monetary policy to be insensitive to the choice of aggregate and short-term lending. Motivated by these findings and in order to focus the analysis, the following section presents and discusses the empirical panel evidence on the determinants of industry-specific short-term bank lending growth for the aggregate banking group.

\subsubsection{Evidence from Industry-Specific Bank Lending Functions}

The empirical evidence from the benchmark model (5.1) is discussed in two parts. In a first step, we report the response of bank lending growth to changes in bank credit demand (i.e., industry output growth, industry inflation) and to changes in the money market interest rate. We then discuss the interaction terms between bank characteristics and monetary policy to draw conclusions about the existence of credit channel effects of monetary policy through bank lending. Table 5.8 summarizes the coefficient estimates for the industry-specific bank lending functions.

\section{(i) The Bank Lending Effects of Loan Demand and Monetary Policy}

We report evidence for individual industries and for the grand total of industries. The evidence for the grand total of industries is our benchmark in the discussion of the industry-specific bank 
lending functions. Besides, when emphasizing the results for the grand total of industries, we can compare the present empirical findings with the evidence of earlier studies, which do not adopt an industry-specific focus. In order to facilitate the readability of the results, we label industries by using abbreviations. For example, the finance and insurance industry is subsequently introduced as finance sector and the transport and communication sector is referred to as transport sector. Annex 5A provides details. Because the evidence in section 5.6.2 shows that the choice of bank characteristic does not affect the long-run sensitivity of bank lending with respect to industry output growth, industry inflation, or the money market interest rate, we provide a general discussion of the results regarding the industry-specific bank lending effects of bank credit demand and monetary policy.

Considering the response of bank lending growth to industry output growth, the entries in Table 5.8 illustrate that bank lending to the grand total of industries increases in response to higher output growth. The positive output response of lending to the grand total reflects the statistically significant and positive response of lending to growth in agriculture, construction, trade, services, and the food manufacturing sector. At least for the construction sector, the positive reaction of bank lending is influenced by the 1992-1995 re-unification construction boom period that induced heavy investment. Opposite relationships exist for total manufacturing and for the sub-sectors of the manufacturing industry. This suggests that manufacturing firms demand less bank credit in response to output growth. ${ }^{51}$ Possible reasons are (i) higher internal flows of finance, which reduce external financing needs and/or (ii) the absence of promising future economic prospects, which yield disincentives for investment. The relevance of the second point is suggested by the continuous decline in the share of manufacturing value added in aggregate value added during the last decade. ${ }^{52}$ Next to the manufacturing industry, we also find an inverse relationship between bank lending growth and output growth for the finance sector. In contrast to the manufacturing industry, the finance sector accounts for an increasingly larger share of aggregate value added. The decline in bank lending may therefore reflect the effect of higher internal cash flow and the consequent lower need for bank finance.

As regards the response of bank lending growth to inflation, it is significant and positive for the grand total of industries. The positive reaction of bank lending to the grand total of industries reflects the positive response of bank lending to almost all industries. The exceptions are the transport and machinery and transport equipment manufacturing sector. In contrast to expectations, bank lending to these sectors significantly contracts in response to higher industry inflation.

\footnotetext{
${ }^{51}$ Also see Deutsche Bundesbank (1996) for a similar conclusion.

${ }^{52}$ The ratio of value added for manufacturing to value added for the grand total of industries declined from 0.26 in 1992 to 0.22 in 2002.
} 


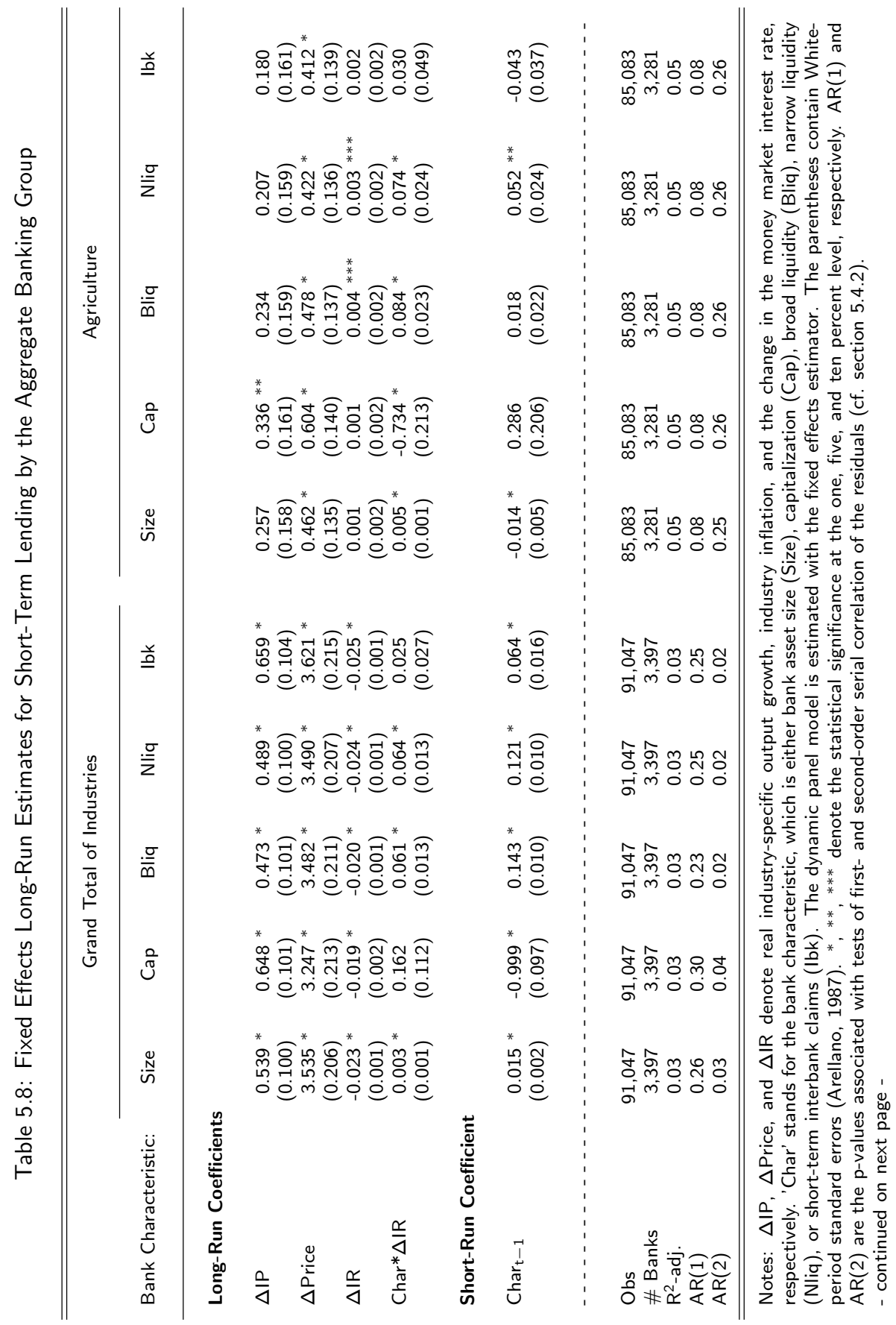




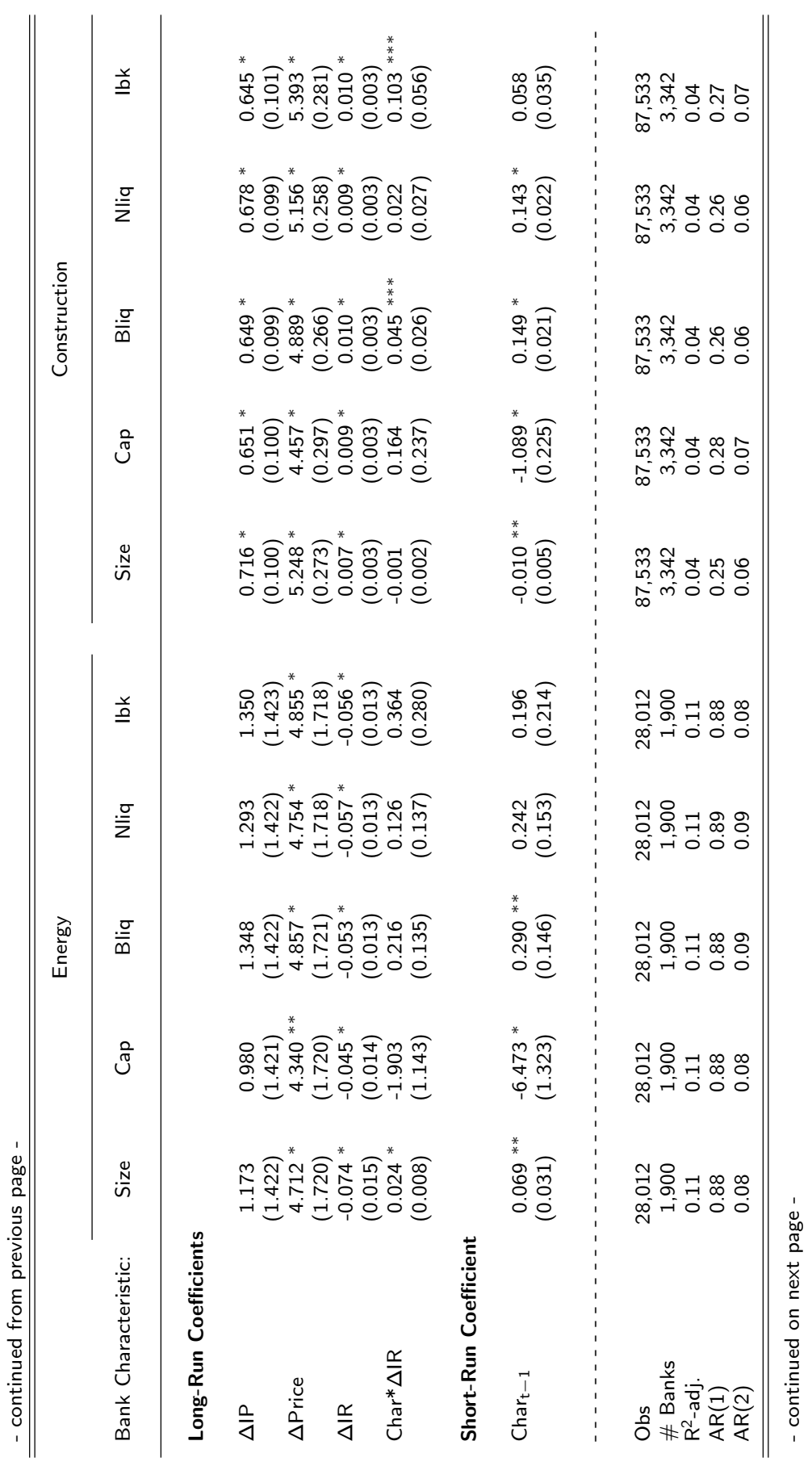




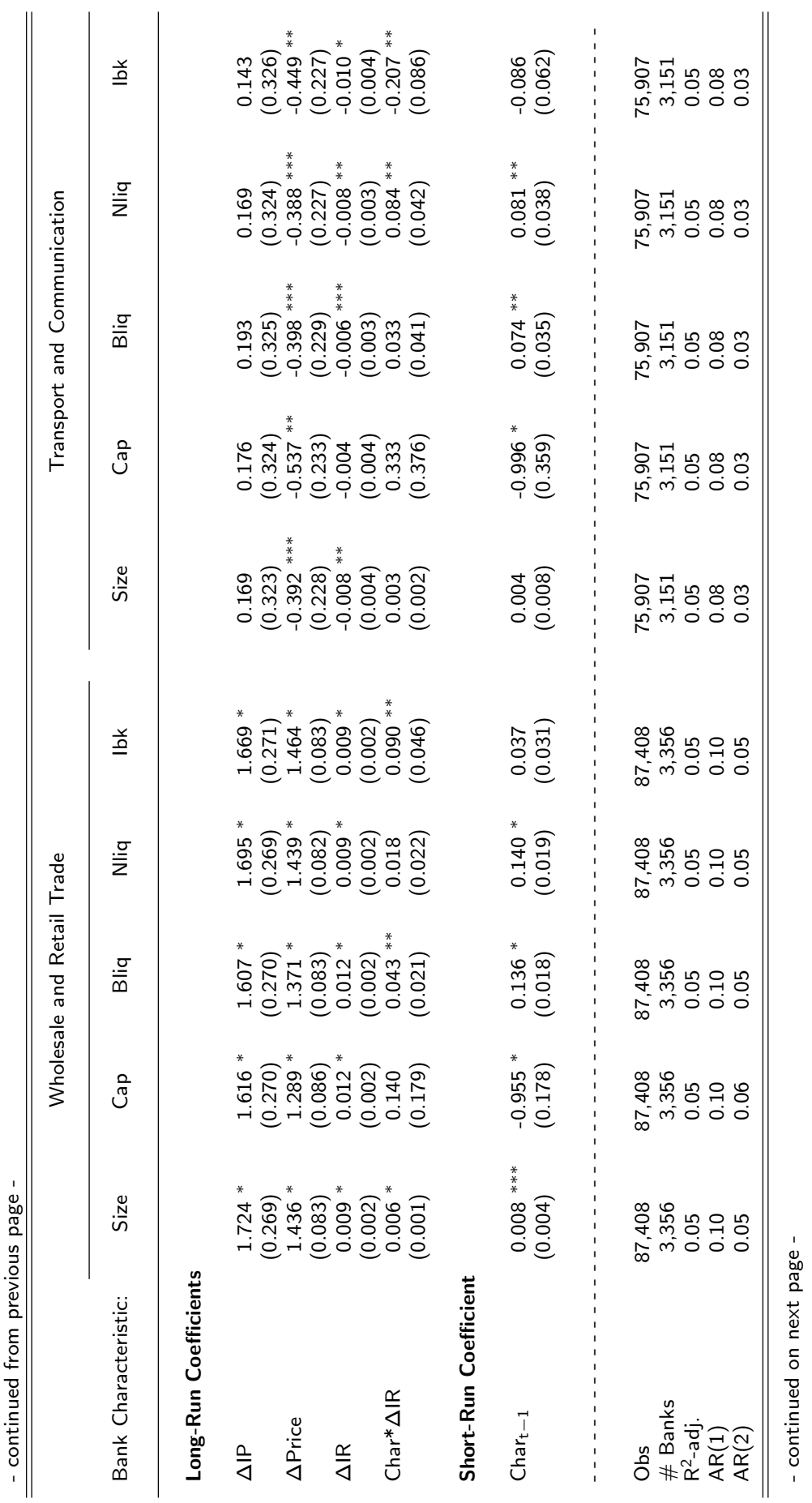




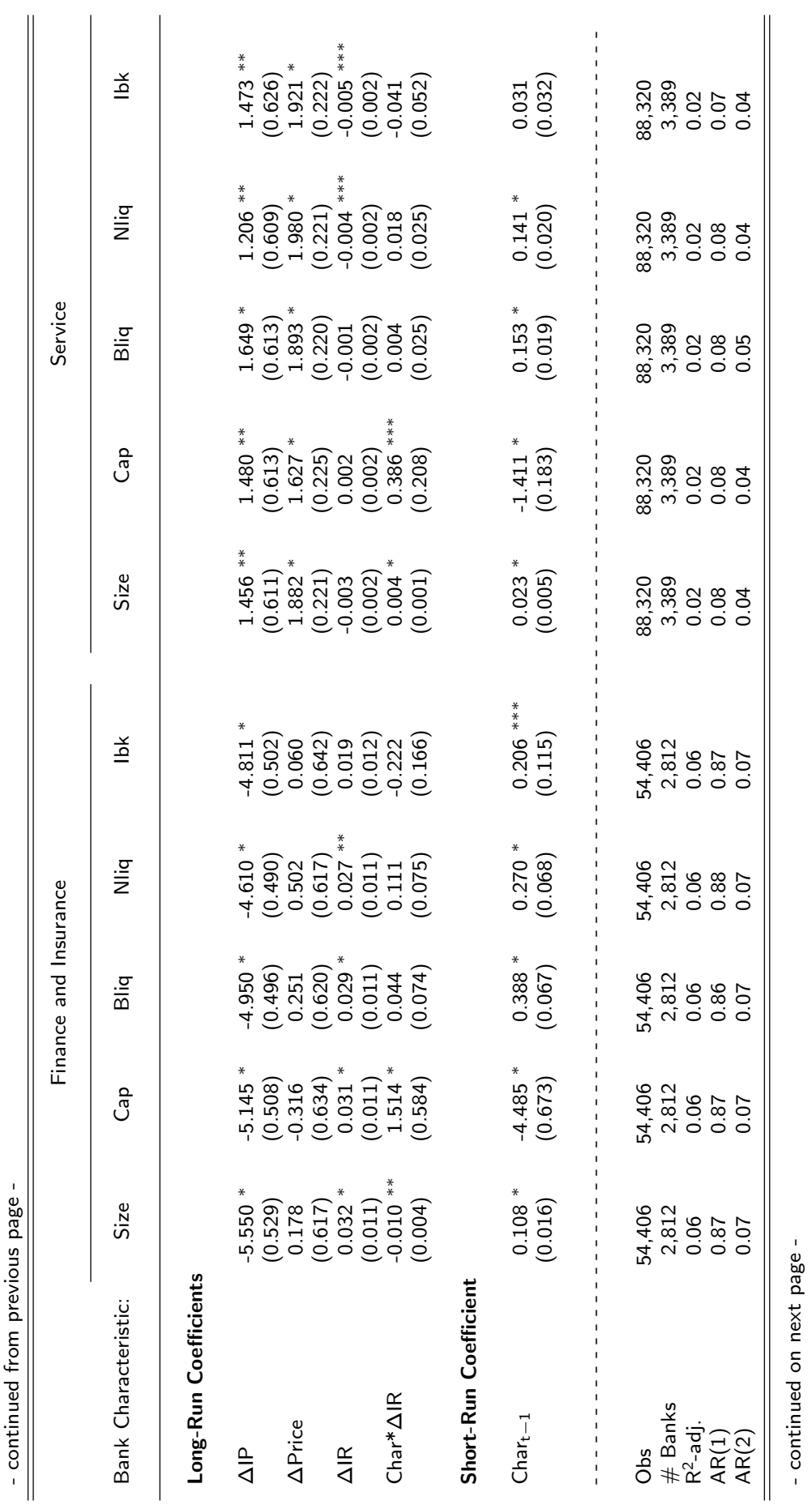




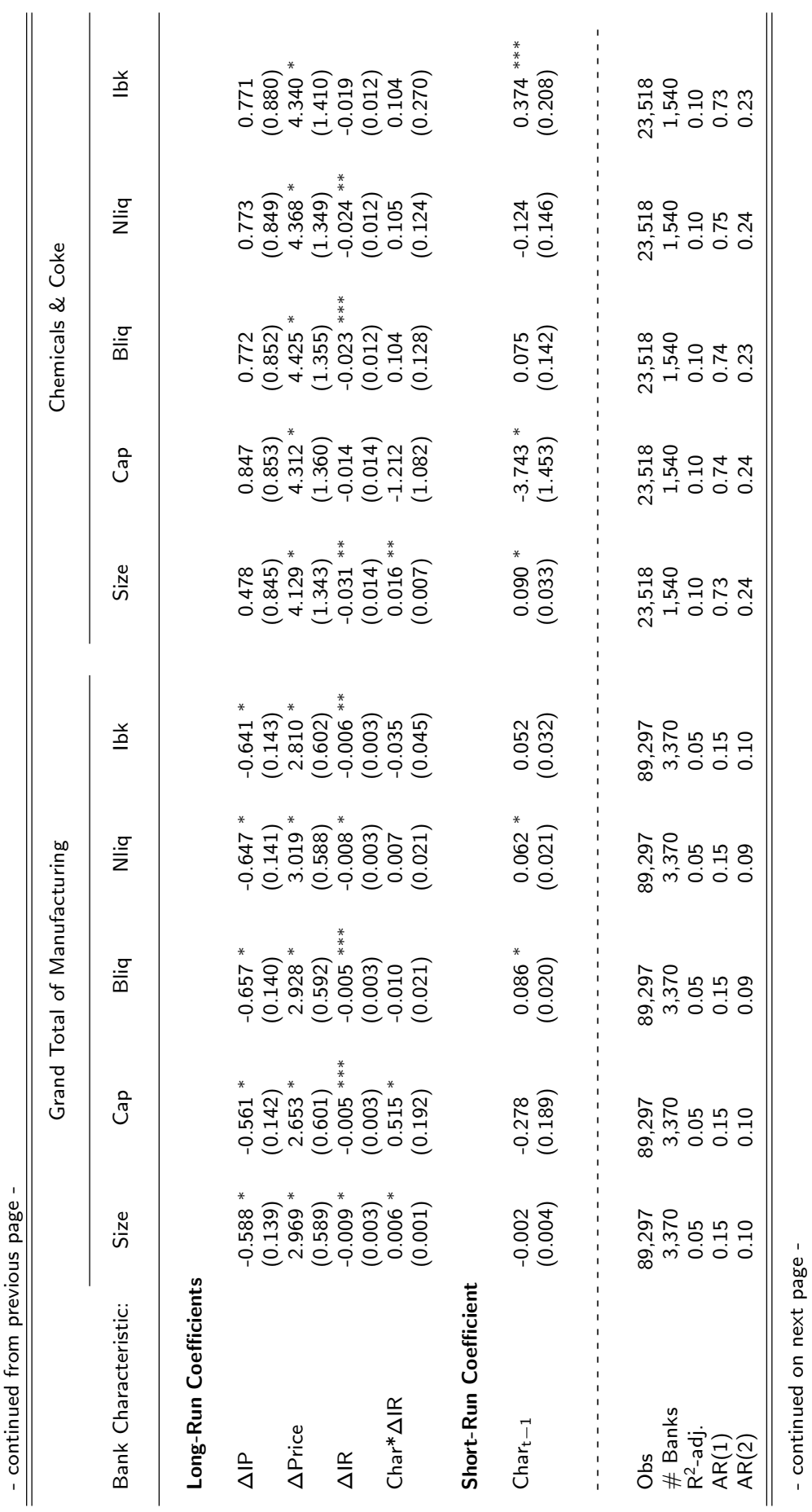




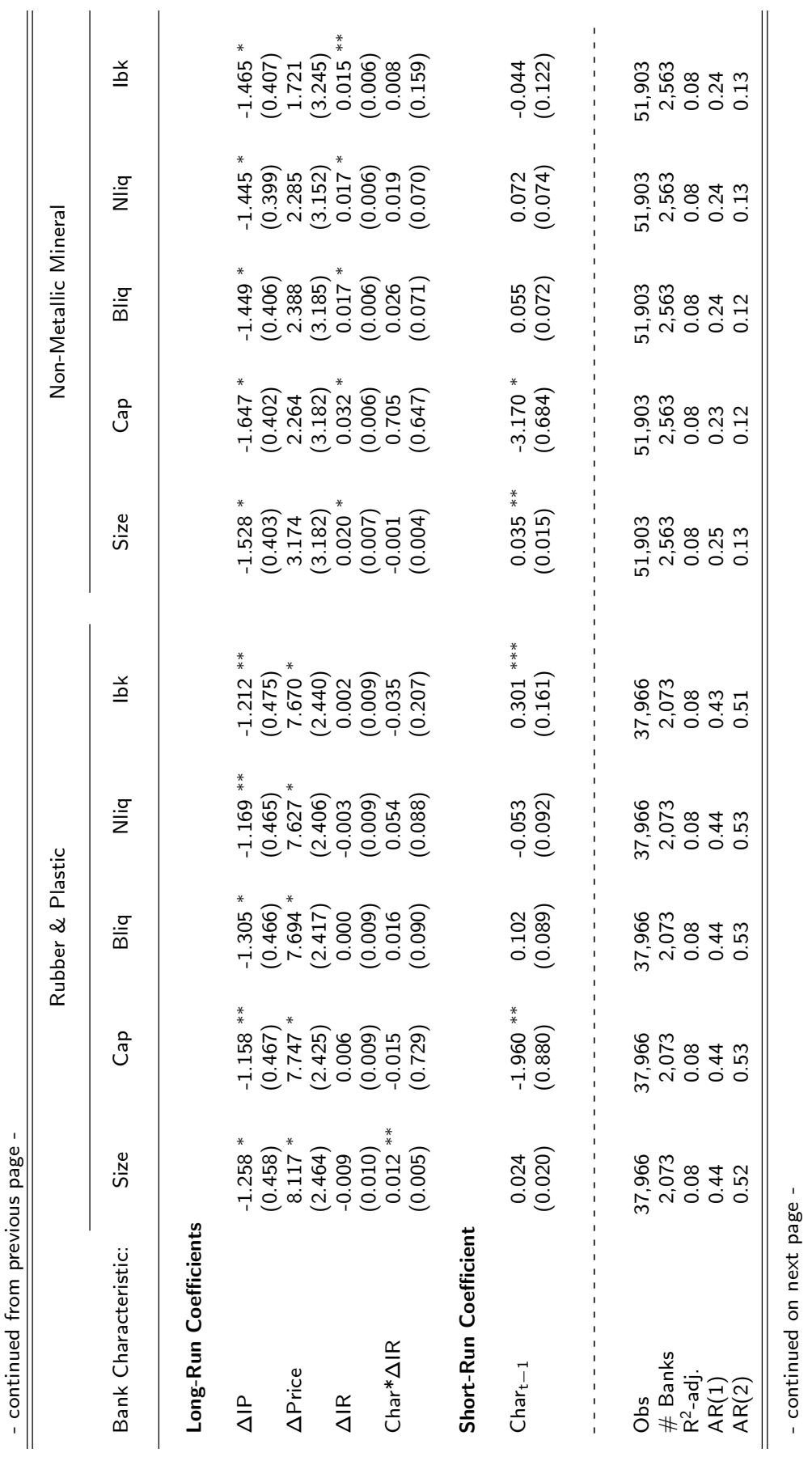




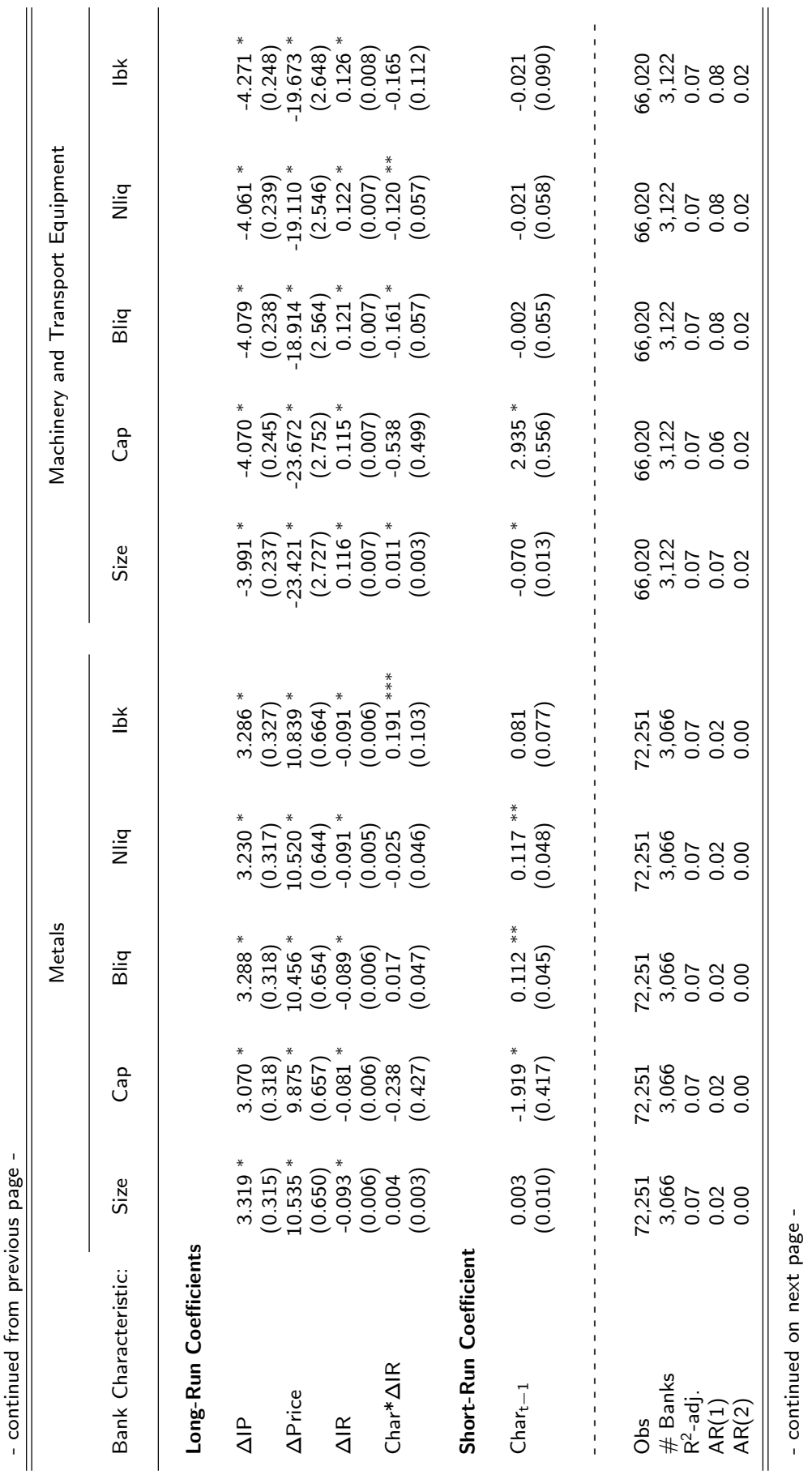




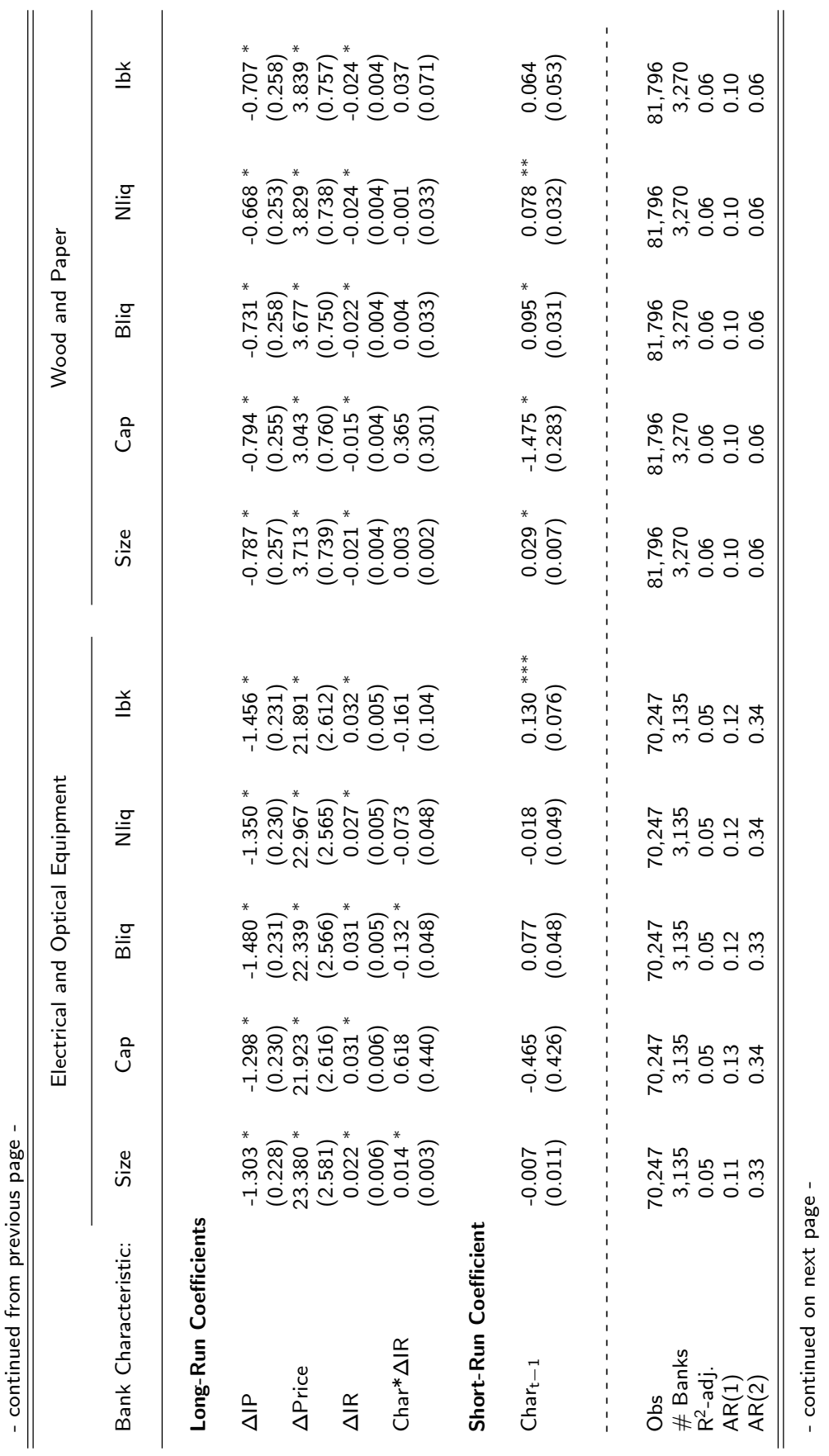




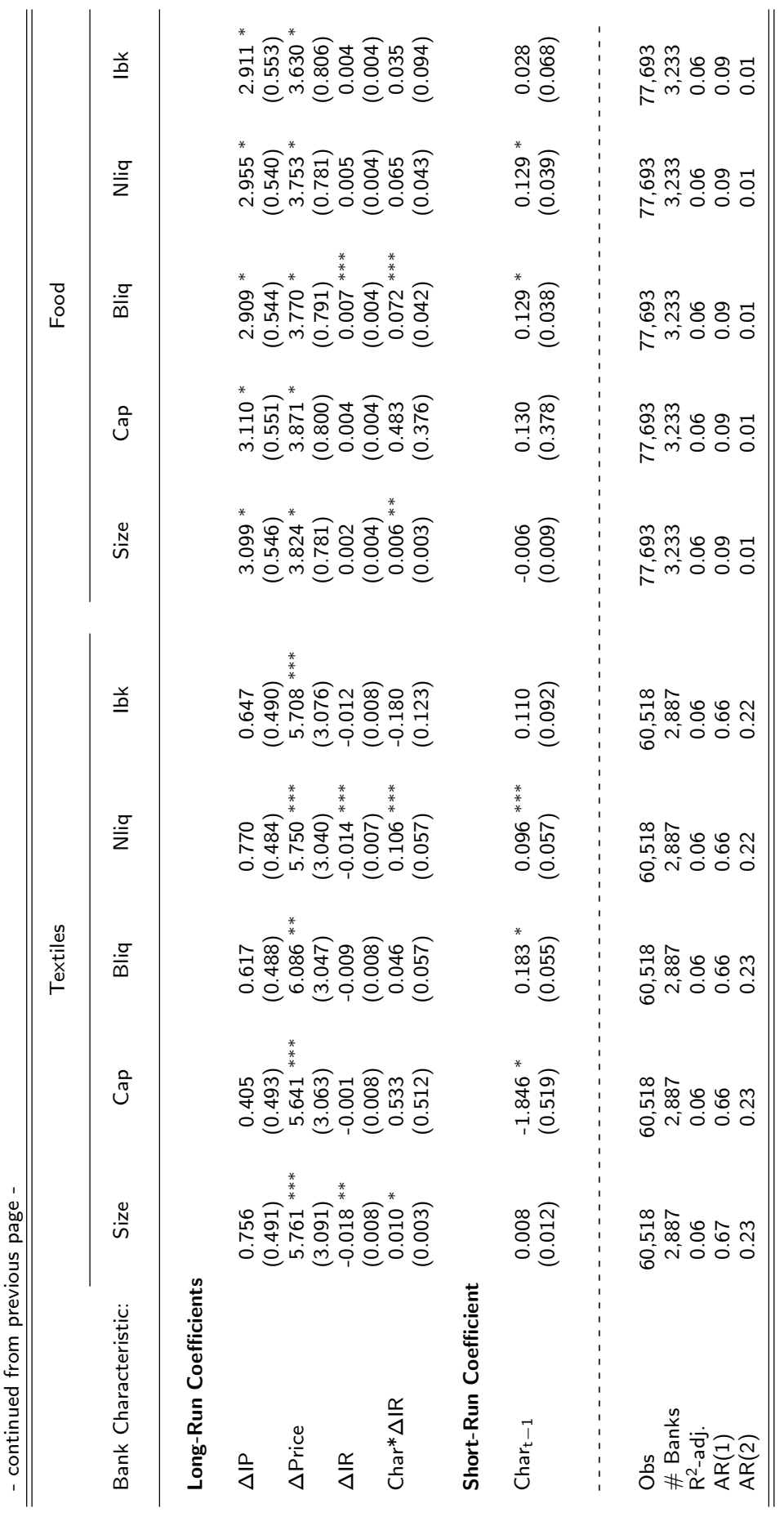


Turning to the interest rate response of bank lending, the evidence confirms the view that higher interest rates cause lending to the grand total of industries to contract. The decline in bank lending reflects the negative effect of higher interest rates on bank reserves and credit rationing on the part of banks in response to an increase in the risk of loan default. The evidence in Table 5.8 also illustrates that this response is a weighed average of the interest rate reaction of all industries. We find unanimous cross-industry differences in the nature of the interest rate response of bank lending. On the one hand, the negative interest rate response of lending to the grand total of industries reflects lower bank credit supply to the energy, manufacturing, and transport industry, with the interest rate effect being most pronounced for the first two sectors. We attribute the strength of the effect for the energy and manufacturing industry to the comparatively high capital intensity of production, which is associated with a higher probability of loan losses (cf. Deutsche Bundesbank, 1996). For the manufacturing sector, the decline in lending reveals the negative interest rate effects of bank credit supply to the chemicals and coke, rubber and plastic, wood and paper, and textiles producing sector. At least the wood and paper and textiles producing sector are again more capital-intensive in comparison to the remaining industries.

On the other hand, a monetary policy contraction induces higher lending to the construction, trade, and finance industry and to producers of non-metallic mineral, machinery and transport equipment, and electrical and optical equipment goods. The positive interest rate response of lending to construction is not consistent with expectations. However, it can be explained by the structural and cyclical characteristics of the construction sector. As regards the structural properties, the construction industry is characterized by a large share of small firms, which predominantly obtain bank credit from local credit cooperatives and regional savings banks. ${ }^{53}$ Knowledge of local market conditions and local debtors reduces information asymmetries and fosters housebank relationships. Housebank relationships, in turn, facilitate the access to bank finance in general and in periods of high interest rates and low demand in particular. Considering cyclical factors, the positive interest rate response of bank lending reflects the demand-driven re-unification boom in construction. Even during the 1991-1992 period of high interest rates, demand for residential buildings and production plants was high and continued to increase.

The positive interest rate response of bank lending to the finance industry can be explained in terms of financial stability considerations. A contraction in monetary policy lowers the net present value of financial assets and reduces the ability of finance and insurance companies to generate profits on financial asset portfolios. When portfolio holders like firms or households regard the return on their portfolio investment as unsatisfactory, they will withdraw their funds from the finance and insurance sector. Besides return considerations, portfolio holders may also withdraw funds to accommodate the negative effect of higher interest rates on internal cash flow and hence liquidity. The drain of financial funds leaves finance and insurance

\footnotetext{
${ }^{53}$ Also see section 5.3.2.
} 
companies less able to meet liquidity requirements. Due to self-fulfilling prophecies and herding behavior, this development may constitute a threat to the stability of the finance and insurance sector, with possible spillover effects to the whole financial system. In view of these relationships, the positive interest rate response of lending to the finance and insurance sector may describe the effort of banks to ensure the stability of the financial system.

The entries in Table 5.8 point to pronounced cross-industry differences in the magnitude of the bank lending effects of output growth, inflation, and interest rate changes. The largest response of bank lending to changes in monetary policy, industry inflation, and output growth is observed for the sub-sectors of the manufacturing industry. Indeed, bank lending to these sectors tends to be more responsive than bank lending to the manufacturing aggregate or to the grand total of industries. Next to the sub-sectors of the manufacturing industry, bank lending also responds comparatively strongly to output growth in the finance industry and to inflation in the construction and energy sector. The finance, construction, and energy industry and the sub-sectors of manufacturing have in common that the share of credit to these sectors is comparatively small (cf. Table 5.3). Bank lending thus seems to be more responsive to output growth and inflation in industries which only account for a small share of a bank's loan portfolio. This in turn suggests that banks primarily re-distribute credit between industries to which bank lending is relatively small and that the overall industry composition of a bank's loan portfolio is accordingly comparatively stable.

Overall, the evidence illustrates that the use of bank-level data on lending to the grand total of industries (i.e., aggregate lending) only provides an imperfect view on the bank lending effects of credit demand and monetary policy. Our results indicate that the direction and strength of aggregate bank lending effects depend on the industry structure of bank credit portfolios. This finding is particularly interesting for the definition of monetary policy as it shows that the effectiveness of monetary policy depends on industry structure.

\section{(ii) Are there Bank Lending Effects of Monetary Policy?}

So far, the discussion has focused on the direct effects of monetary policy. This section analyzes the empirical results for the interaction between bank characteristics and monetary policy in order to identify the distributional effects of monetary policy on industry-specific bank lending. As will become evident, conclusions as to the existence of cross-bank differences in the interest rate response of bank lending are sensitive to the choice of bank asset size, capitalization, liquidity, and short-term interbank claims.

The analysis of the interaction terms can be criticized. As stated, the significance properties of the interaction terms preclude tests regarding the relative contribution of industries and banking groups as source of variation. Visual inspection of significant interaction terms points, however, to considerable differences in the sign and magnitude of the underlying credit channel effects across industries as well as banking groups. The differences are such 
that a separate discussion of the coefficient estimates of all interaction terms is valuable in its own right. Unfortunately, this is beyond scope given the large number of industry-specific bank lending models by bank characteristic, banking group, and loan maturity. We can only acknowledge that conclusions regarding the credit channel effects of monetary policy depend on the choice of model specification and stress the interaction terms for short-term bank lending growth for the aggregate banking group.

Existing studies question the usefulness of capitalization and liquidity as proxy variables of the bank lending effects of monetary policy. Gambacorta and Mistrulli (2004) argue that the capital-to-asset ratio is an inappropriate measure of bank capitalization. The reason is that bank capital does not illustrate the riskiness of a bank's portfolio. It therefore does not correctly describe the severity of information asymmetries, which determines the ability of banks to obtain non-reservable funding. Kashyap and Stein (2000) contemplate that liquidity may provide a distorted view on the importance of bank balance sheet effects. This is because liquidity is also determined by cash that banks cannot freely use since it is subject to reserve requirements. Furthermore, Worms (2003) notes that bank lending reflects the liquidity preferences of banks, with more liquid banks lending less. If this holds, cross-bank differences in the interest rate sensitivity of bank lending are not uniquely attributable to cross-bank differences in liquidity. We only mention these weaknesses associated with some bank characteristics, but do not control for them for two reasons. Firstly, the share of cash in total assets relative to other liquidity components is low. Secondly, quarterly data on the riskiness of capital are not available in the present dataset. Although capitalization and liquidity might be imperfect identifiers of the bank credit supply effects of monetary policy, we report the results for these bank characteristics because we still assume that these variables influence the response of bank lending to interest rate changes.

Table 5.8 contains the industry-specific bank lending effects of monetary policy associated with cross-bank differences in asset size, capitalization, liquidity, or short-term interbank claims. Conclusions regarding the bank lending effects of monetary policy transmission are sensitive to the choice of bank characteristic and vary with the choice of industry. The evidence lends strong support to the existence of bank size effects in monetary policy transmission. For the grand total of industries and for almost all sampled industries, a monetary policy contraction causes bank lending of large banks to adjust less than bank credit of small banks. That is, large banks are better able to insulate their lending activities against monetary-policy-induced changes in the availability of reservable and non-reservable funds of finance. Inconsistent with the credit channel theory, the interest rate response of bank lending to the finance industry is more pronounced for large than for small banks. This finding possibly reflects the importance of commercial banks as source of lending to the finance industry (cf. Table 5.3) and the fact that commercial banks are on average larger in terms of asset size than savings banks and credit cooperatives (cf. Table 5.1). Insignificant effects are recorded in estimations for the construction and transport sector and for the non-metallic goods and wood and paper products producing sector. 
In contrast to bank asset size, cross-bank heterogeneities in capitalization do not explain cross-bank differences in the interest rate sensitivity of bank credit to the grand total of industries and to most individual industries. The exception is lending to agriculture, finance, services, and manufacturing. Except for the agricultural sector, better capitalized banks adjust lending less than poorly capitalized banks. The insignificance of bank capitalization lends support to the view that a risk-unadjusted measure of capitalization may imperfectly approximate the degree of information asymmetries.

Cross-bank asymmetries in the monetary policy response of bank lending to some industries are also attributable to cross-bank heterogeneities in the share of liquid assets. As discussed, the liquidity effects of monetary policy are separately identified for a broad and narrow measure of liquidity and for short-term interbank claims in order to determine whether short-term interbank claims affect the bank lending effects associated with liquidity. The evidence shows that broad and/or narrow liquidity significantly attenuates the interest rate response of lending to the grand total of industries and to the agricultural, construction, trade, transport, textiles, and food industry. However, liquidity amplifies the response of lending to the machinery and transport equipment and electrical and optical equipment producing sector. The evidence lends comparatively weak support to the role of short-term interbank claims as determinant of the liquidity effects of monetary policy. Indeed, significant short-term interbank effects are confined to very few industries: construction, trade, and transport. This suggests that short-term interbank claims are a weak driving source of liquidity effects. In addition, because interbank claims are insignificant in explaining the interest rate response of credit supply to industries for which bank asset size possesses explanatory power, bank asset size appears to capture the bank lending effects of information asymmetries. That is, the evidence in the present study does not lend support to the finding of Worms (2003) according to which interbank claims dwarf the effects associated with bank asset size.

Comparing the magnitude of the distributional effects of monetary policy, differences prevail across bank characteristics. Indeed, cross-bank asymmetries in the interest rate response of bank lending are least pronounced for bank asset size and most pronounced for estimations with bank capitalization and short-term interbank claims. The evidence hence reveals that bank size is not the main determinant of cross-bank differences in the response to monetary policy changes. However, the relative importance of the capitalization effect should not be overemphasized because we define capitalization without correcting for bank risk. Besides these results, the entries in Table 5.8 suggest that the strength of bank lending effects of monetary policy differs between industries. In contrast to direct monetary policy effects, the cross-industry differences appear to be unrelated to the relative weight of industries in a bank's credit portfolio.

Table 5.8 also reports the one-period lags of the bank characteristics. Even though the coefficients do not have an intrinsic meaning, they illustrate in combination with the direct interest rate effect whether bank characteristics or monetary policy changes drive the sig- 
nificance of the interaction terms. The evidence tends to be mixed. For the grand total of industries, the significance of the coefficient on the interest rate change and the short-run bank characteristic illustrates that the significance of the interaction term is attributable to the direct bank lending effect of monetary policy and to cross-bank differences in any of the bank characteristics. For the industry-specific bank lending functions, the distributional effects of monetary policy are determined by either monetary policy or bank characteristics, by both variables, or by none. For example, the significance of the interaction term on asset size and capitalization in the estimation for total manufacturing is driven by the direct effect of monetary policy but not by bank characteristics. For the transport sector, the absence of credit channel effects in estimations with asset size seem to be driven by asset size given the evidence in favor of significant interest rate effects.

Overall, the evidence lends comparatively weak support to the transmission of monetary policy changes through bank lending. The conclusions as to the bank lending effects of monetary policy are sensitive to the choice of industry. This in turn points to the existence of industry effects of monetary policy through bank lending. In view of this finding, studies for the grand total of industries are likely to provide an incomplete view on the bank lending effects of monetary policy.

\section{(iii) Cross-Study Comparison of the Results}

For the grand total of industries, our evidence can be compared with that of existing studies. The present results for the grand total of industries match those in Ehrmann et al. (2003) and Worms (2003) only partly. One possible source of divergence are differences in the definition of bank credit. While the earlier studies define bank credit for lending to households and the grand total of industries, we do not include household lending. ${ }^{54}$ Another source of heterogeneity concerns the outlier adjustment procedure. Ehrmann et al. (2003) and Worms (2003) identify outliers by assuming the normal distribution of banks, while we allow for skews in the distribution. The studies thus define outliers along different lines, which leads to the exclusion of different observations. The most striking difference, however, concerns the estimation methodology. Earlier studies estimate the dynamic panel model with GMM. We find this estimator to be inapplicable. Neither for the long sample period 1992-2002 nor for the short sample period 1992-1998 as used by Worms (2003) do we find valid overidentifying restrictions for our set of GMM estimations. We do not estimate the model for the short sample period with the fixed effects estimator because the finite sample bias would be stronger.

Our results are in line with those of Ehrmann et al. (2003) according to which bank lending

\footnotetext{
${ }^{54}$ Ehrmann et al. (2003) and Worms (2003) do not report evidence for short-term lending but for aggregate bank credit. Because our results for aggregate and short-term lending do not differ, we generalize our results when comparing them with earlier studies and do not make a distinction between short-term and aggregate lending.
} 
grows in response to output growth and inflation and declines in the wake of a monetary contraction. Furthermore, the present results are consistent with those in Ehrmann et al. (2003) according to which cross-bank differences in the interest rate sensitivity of aggregate bank credit cannot be attributed to differences in capitalization, but to differences in liquidity. However, the present study reports evidence that lends support to the existence of bank size effects in monetary policy transmission. In contrast to Worms (2003), the size effects are not driven by interbank claims since they also prevail in estimations which do not control for interbank claims.

\section{(iv) Synthesis}

Summarizing the results of the industry-specific bank lending functions, the evidence shows that bank lending growth is industry specific, being driven by cyclical changes in industry output growth and industry inflation and hence by factors of industry-specific bank credit demand. We find significant differences in the bank lending effects of industry output growth, industry inflation, and monetary policy changes between industries. Furthermore, regardless of the industry, the evidence lends weak support that banks differ in their lending response to monetary policy changes. If at all, cross-bank differences in the monetary policy response of bank lending are primarily attributable to bank asset size effects. Overall, it appears that bank lending growth predominantly depends on bank credit demand and on the relative importance of industries in a bank's loan portfolio.

\subsubsection{Robustness Tests}

In order to determine the robustness of the empirical findings, we modify the structure of the benchmark specification (5.1) along several lines. Table 5C.1 in annex 5C summarizes the different models. To conserve on space, we only provide a verbal description of the corresponding evidence. ${ }^{55}$ One set of estimations eliminates output growth and inflation from the benchmark model to test whether industry demand factors dwarf the bank lending effects of monetary policy changes. The test is motivated by the evidence from the benchmark model according to which bank lending growth is predominantly determined by industry output growth and industry inflation rather than by monetary policy. The results of the modified model confirm those of the benchmark specification. We find the magnitude of the direct monetary policy effects on bank lending to be in the range suggested by the benchmark specification. The evidence in favor of credit channel effects of monetary policy

\footnotetext{
${ }^{55}$ The coefficient estimates of all robustness tests are available on request. Note, existing studies on the bank lending effects of monetary policy also test for the differential response of bank lending by eliminating the effect of time-variant variables on bank lending with either time dummies or macroeconomic variables (cf. Gambacorta, 2003; Ehrmann et al., 2003; Worms, 2003). We abstain from capturing time effects with time dummies since they capture the level effect of those variables we are particularly interested in, i.e., monetary policy and the proxy variables of bank credit demand.
} 
through bank lending is still comparatively strong for asset size, but relatively weak for the remaining bank characteristics. Furthermore, the coefficient estimates from the augmented specification closely resemble those from the benchmark model.

Another set of estimations re-estimates the benchmark model with more than one bank characteristic. One specification interacts each bank characteristic individually with monetary policy (Table 5C.1, model B), while a second model interacts two bank characteristics with each other as well as with monetary policy (Table 5 C.1, model C) ${ }^{56}$ We include more than one bank characteristic simultaneously to control for the possibility that models with only one bank characteristic report evidence which also captures the effects associated with other characteristics. More precisely, we take the likely interdependence of bank asset size and liquidity and bank capitalization and liquidity into account: large or better capitalized banks might be more liquid than small or poorly capitalized banks. For Germany, the interdependence may also extend to asset size and interbank claims. Worms (2003) and Ehrmann et al. (2003) have shown that interbank claims attenuate the effects of asset size and dominate the liquidity or capitalization effects of monetary policy. Although the present evidence illustrates that asset size explains the average interest rate response of banks in estimations which do not control for interbank claims, interbank claims may still capture part of the size effects. However, when including more than one bank characteristic, the models with single and double interactions yield evidence that largely confirms the findings of the benchmark specification. Bank lending growth is predominantly determined by bank credit demand and not by monetary policy or by the distributional effects of monetary policy. The strength of the underlying effects significantly differs between industries.

The evidence from the model with more than one single interaction term (Table 5C.1, model $B$ ) suggests the independence of the effects associated with each single bank characteristic. For example, when significant, the effects associated with bank capitalization are still comparatively strong, while bank size effects are relatively small. In fact, the strength of significant bank size, capitalization, liquidity, and interbank effects does not vary much between the benchmark and augmented model. We therefore conclude that the distributional effects of monetary policy reveal size and capitalization effects that are not driven by interbank claims or by bank liquidity. Similarly, interbank assets do not influence the evidence of bank liquidity effects. For most bank lending functions, interbank assets are statistically insignificant and broad liquidity effects reflect the effects associated with narrow liquidity.

The model with double interaction terms (Table 5C.1, model C) tests whether cross-bank differences in the interest rate response of bank lending depend on the interdependence of effects associated with (i) interbank claims and either bank asset size, capitalization, or liquidity and (ii) liquidity and either bank asset size or capitalization. The hypothesis is that the effect of interbank claims or liquidity on the interest rate response of bank lending is smaller for large and better capitalized banks. Summarizing the results, we find the double

\footnotetext{
${ }^{56}$ See Ehrmann et al. (2003) and Worms (2003) for a description of the model.
} 
interaction terms to be statistically insignificant in almost all industry bank lending functions. The only significant responses are recorded for estimations with interbank claims and either asset size, capitalization, or narrow liquidity. When significant, the evidence tends to be inconsistent with expectations: interbank effects on bank lending are smaller for (i) small banks (machinery and transport equipment sector), (ii) poorly capitalized banks (electrical and optical equipment sector), and (iii) less liquid banks (construction, services, wood and paper producing sector). Anticipated relationships prevail for the grand total of industries. We find the interbank effects of monetary policy on bank lending to be smaller for large banks. In addition, interbank effects are smaller for liquid banks in estimations for the rubber and plastic and machinery and transport equipment sector.

As an alternative test we ask whether the results are sensitive to the way we define the explanatory variables of the benchmark specification. The model in equation (5.1) includes industry-specific bank lending, output, and inflation without weighing each of these components by the corresponding bank-specific aggregate. In expressing loans in absolute terms, we follow Kishan and Opiela (2000), Gambacorta and Mistrulli (2004), Ehrmann et al. (2003), Worms (2003), Hülsewig, Mayer, and Wollmershäuser (2005), among others. In reality, banks operate portfolios, with lending to industry $i$ being part of a diversification strategy. The relative importance of industries in a bank's portfolio hence differs. In order to control for differences in the importance of industries, we redefine the industry-specific variables relative to the aggregate (Table 5C.1, model D). Doing so, we do not only control for differences in the relative importance of industries, but also for structural breaks that result from redefinitions in the composition of industries. Furthermore, we can also control for the effect of those mergers which do not appear as outliers. When using ratios, merger-driven jumps in lending are ameliorated or even eliminated. Despite these changes, the empirical results do not qualitatively differ from those of the benchmark specification: bank lending growth is determined by bank credit demand rather than by monetary policy. Conclusions regarding the distributional effects of monetary policy on bank lending do not differ much between the base and augmented specification.

So far, the robustness checks involve structural changes of the base specification, using data for the sample period 1992:1-2002:4. This sample period captures years of exceptional circumstances as caused by the German re-unification. Particular to this process is above average credit demand by all industries (see Deutsche Bundesbank, 1996). In order to assess the sensitivity of the results to re-unification effects, we also estimate the benchmark specification for the period 1995:1-2002:4 (Table 5C.1, model E). For almost all industries, the results for the short and long sample period are qualitatively the same. The only exception is the manufacturing industry. In contrast to the long sample period, bank lending to this sector is predicted to expand in response to industry inflation and to contract in reaction to higher interest rates. Conclusions regarding the existence of bank lending effects of monetary policy also change for bank asset size. In contrast to the long sample, the interest rate response of bank lending does not decrease but increase with asset size. The relationships 
for output growth and the remaining bank characteristics do not change. The evidence for manufacturing is hence influenced by German re-unification. Visual inspection of the data shows that the results are driven by differences in the time-series pattern of inflation during 1992-1993 and 1994-2002. Manufacturing prices were constant during 1992-1993, while the share of short-term credit to manufacturing declined. Manufacturing prices only increased as of 1994.

Overall, conclusions as to the response of bank lending to changes in monetary policy and bank credit demand are robust to alternative model specifications. Regardless of the model, we find strong evidence that credit supply effects of monetary policy are small. Significant cross-industry differences still prevail, which demonstrates that the sensitivity of a bank's credit portfolio to monetary policy changes or economic conditions clearly depends on the industry composition of a credit portfolio.

\subsection{Conclusion}

This chapter has used a unique dataset with bank-level data on bank balance sheet items and bank industry lending to investigate the bank lending effects of bank credit demand and monetary policy for Germany over the period 1992:1-2002:4. In contrast to existing work on the credit channel effects of monetary policy, we explicitly focused on the industry effects of bank lending and estimated bank lending functions for eight industries at the onedigit industry level and for nine sub-sectors of the manufacturing industry at the two-digit industry level. The bank lending functions were defined for aggregate and short-term lending and for five individual banking groups. In line with existing studies, we used bank asset size, capitalization, liquidity, and short-term interbank claims as proxy variables of cross-bank differences in the severity of information asymmetries.

Our empirical findings lend strong support to the existence of industry effects of bank lending: industries are the more important source of variation in the bank lending effects of bank credit demand and monetary policy, with strong effects arising from industry output growth and industry inflation. Banking group effects are comparatively weak. This suggests that the institutional setting of the German banking system is a relatively unimportant determinant of bank lending growth. The evidence lends mixed support to the credit channel theory according to which cross-bank differences in the interest rate response of bank lending can be explained with cross-bank heterogeneities in bank asset size, capitalization, liquidity, and short-term interbank claims. Again, the conclusions are very sensitive to the choice of industry and also depend on the choice of bank characteristic and banking group. We conclude that the credit channel effects of monetary policy through bank lending are weak and that the industry composition of bank credit portfolios determines bank lending growth and - more important from an economic policy perspective - the effectiveness of monetary policy. 
We expect that the evidence in favor of industry effects of bank lending would also prevail in estimations that control for two shortcomings of the present analysis. One weakness concerns the assumption that positive and negative shocks to industry output growth, industry inflation, and monetary policy have a symmetric effect on bank lending growth. In reality, asymmetries are likely to prevail given that credit conditions worsen more in times of recessions than they improve in times of economic booms and that prices are sticky downwards but flexible upwards. Furthermore, we estimated a reduced-form model which does not control for the sensitivity of loan demand to monetary policy changes. That is, the interest rate sensitivity of bank lending reflects the interest rate response of bank credit supply as well as the interest rate response of bank credit demand. The interest rate sensitivity of loan demand in turn reflects the operation of alternative monetary policy transmission channels such as the interest rate or exchange rate channel.

Besides solving these issues, the present empirical results offer the following avenues for future research. Firstly, the evidence suggests that cross-industry differences in the response of bank lending to changes in bank credit demand and monetary policy cause the re-allocation of bank credit from one industry to another, ceteris paribus. ${ }^{57}$ Because industry performance also depends on the access to external finance, it would be particularly interesting from a policy perspective to determine the degree of sectoral credit shifts. If sectoral credit shifts are large, they will cause firms in some industries to be credit constrained even in the absence of credit market imperfections. Secondly, the present study has assumed that industry output growth and industry inflation affect bank lending unilaterally. However, the causal relationship is equally likely to run from bank lending growth to output growth and inflation. Panel causality tests would help to determine the nature and strength of the uni- or bi-directional relationships. Because conclusions are likely to differ between industries, the corresponding evidence would provide more details on the determinants of the industry structure of bank credit portfolios.

This list of ideas is certainly not exhaustive. It becomes evident, however, that the present study should be viewed as starting point for future research on the industry effects of bank lending.

${ }^{57}$ The ceteris paribus condition refers to the profitability and efficiency of industries. 


\section{Annex 5A Data Sources and Descriptions}

The following overview lists the industries for which data on economic activity, prices, and industry characteristics are compiled. The second column labels the industry as it will be abbreviated throughout the chapter.

\begin{tabular}{llll}
\hline \hline & & & \\
Industry & Abbreviation & Source \\
\cline { 1 - 3 } \cline { 3 - 3 } Grand total & & NC \\
Mining and quarrying; electricity, gas, and water supply & Energy & NC \\
Total manufacturing & & NC \\
Food products, beverages and tobacco & Food & NC \\
Textiles and textile products & Textiles & NC \\
Wood and products of wood and cork & Wood & NC \\
Pulp, paper, paper products, printing, and publishing & Paper & NC \\
Coke, refined petroleum products, and nuclear fuel & Coke & NC \\
Chemicals and chemical products & Chemicals & NC \\
Rubber and plastics products & Rubber and plastic & NC \\
Other non-metallic mineral products & Non-metallic mineral & NC \\
Basic metals and fabricated metal products & Metals \\
Machinery and equipment, n.e.c. & Machinery & NC \\
Electrical and optical equipment & Electrical equipment & NC \\
Transport equipment & Transport equipment & NC \\
Construction & Construction & NC \\
Agriculture, forestry, and fishing & Agriculture & GSO \\
Services & Service & GSO \\
Wholesale and retail trade, repairs & Trade & GSO \\
Transport and communication & Transport & GSO \\
Finance and insurance & Finance & GSO \\
\hline
\end{tabular}

Note: $\mathrm{NC}=$ New Cronos database of Eurostat, GSO = German statistical office.

The empirical analysis does not include all industries individually, but also combinations of sectors. An aggregation of sectors is necessitated by the definition of industry sectors in the borrower statistics of the Deutsche Bundesbank. The following industries are treated as a single unit: (i) wood and paper; (ii) coke and chemicals; (iii) machinery and transport equipment.

With few exceptions, monthly data on the industry production index and industry price index, and annual data on the number of enterprises with 1 to 19 employees are compiled from the New Cronos database of Eurostat (NC). The monthly data are converted into quarterly data. Industry data on agriculture, services, wholesale and retail trade, finance and insurance, and transport and communication are obtained from the German statistical office (GSO). Data on value added, employment, gross capital stock, imports, exports, and operating surplus are available from the OECD's STAN database for Industrial Analysis at an annual frequency.

Data on bank characteristics are compiled from the Deutsche Bundesbank's monthly bank balance sheet statistics. The analysis uses information on total assets (TA), bank capital $(\mathrm{K})$, and liquidity (A). Bank capital includes subscribed capital, reserves, capital represented 
by participation rights and by the fund for general banking risk. Liquidity is defined as the sum of cash; balances with the central banks; treasury bills, treasury certificates, and similar debt instruments issued by public authorities (eligible for refinancing); debt securities; shares and other variable-yield securities; claims on credit institutions with an agreed maturity or redeemable at notice of one year or less (short-term interbank claims). ${ }^{58}$

Data on bank-specific lending to eight main industries and nine sub-sectors of the manufacturing industry are compiled from the quarterly borrower statistics of the Deutsche Bundesbank.

\footnotetext{
${ }^{58}$ The determinants of liquidity are ranked according to liquidity. From the top to the bottom, liquidity declines. See Büschgen (1998, chapter 4.B) for details.
} 


\section{Annex 5B Variable Description}

The vector of bank characteristics $X_{b}$ in equation (5.1) includes variables related to bank efficiency and profitability: total assets (TA), liquidity $(A)$, and bank capital $(K)$. In line with existing studies (cf. Ehrmann et al., 2003; Gambacorta and Mistrulli, 2004; Worms, 2003), the level of bank-specific capital ( $\mathrm{Cap}_{\mathrm{b}}$ ), broad liquidity (Bliqb), narrow liquidity (Nliqb), and short-term interbank claims $\left(\mathrm{Ibk}_{\mathrm{b}}\right.$ ) is normalized with respect to the average across all banks and time according to

$$
\begin{aligned}
& \mathrm{Cap}_{\mathrm{bt}}=\frac{\mathrm{K}_{\mathrm{bt}}}{\mathrm{TA}_{\mathrm{bt}}}-\frac{1}{\mathrm{~T}} \sum_{\mathrm{t}=1}^{\mathrm{T}}\left(\frac{1}{\mathrm{~N}_{\mathrm{b}}} \sum_{\mathrm{b}=1}^{\mathrm{N}_{\mathrm{b}}} \frac{\mathrm{K}_{\mathrm{bt}}}{\mathrm{TA}_{\mathrm{bt}}}\right) \\
& \text { Bliq }_{b t}=\frac{A_{b t}}{\mathrm{TA}_{\mathrm{bt}}}-\frac{1}{\mathrm{~T}} \sum_{\mathrm{t}=1}^{\mathrm{T}}\left(\frac{1}{\mathrm{~N}_{\mathrm{b}}} \sum_{\mathrm{b}=1}^{\mathrm{N}_{\mathrm{b}}} \frac{\mathrm{A}_{\mathrm{bt}}}{\mathrm{TA}_{\mathrm{bt}}}\right) \\
& \mathrm{Nliq}_{\mathrm{bt}}=\frac{\mathrm{A}_{\mathrm{bt}}-\mathrm{lb} \mathrm{k}_{\mathrm{bt}}}{\mathrm{TA}_{\mathrm{bt}}}-\frac{1}{\mathrm{~T}} \sum_{\mathrm{t}=1}^{\mathrm{T}}\left(\frac{1}{\mathrm{~N}_{\mathrm{b}}} \sum_{\mathrm{b}=1}^{\mathrm{N}_{\mathrm{b}}} \frac{\mathrm{A}_{\mathrm{bt}}-\mathrm{lb} \mathrm{k}_{\mathrm{bt}}}{\mathrm{TA}_{\mathrm{bt}}}\right), \\
& \mathrm{lbk}_{\mathrm{bt}}=\frac{\mathrm{Ibk}_{\mathrm{bt}}}{\mathrm{TA}_{\mathrm{bt}}}-\frac{1}{\mathrm{~T}} \sum_{\mathrm{t}=1}^{\mathrm{T}}\left(\frac{1}{\mathrm{~N}_{\mathrm{b}}} \sum_{\mathrm{b}=1}^{\mathrm{N}_{\mathrm{b}}} \frac{\mathrm{Ibk}_{\mathrm{bt}}}{\mathrm{TA}_{\mathrm{bt}}}\right)
\end{aligned}
$$

respectively. The bank characteristics are expressed in terms of total assets to de-trend these series. To this end, we assume that bank capitalization, liquidity, and interbank claims follow similar trends as asset size. Total assets (TA) are also normalized with respect to the mean across all banks, but de-trending requires the normalization for each single data point. This yields the following measure of bank asset size

$$
\operatorname{Size}_{\mathrm{bt}}=\log \mathrm{TA}_{\mathrm{bt}}-\frac{1}{\mathrm{~N}_{\mathrm{b}}} \sum_{\mathrm{b}=1}^{\mathrm{N}_{\mathrm{b}}} \log \mathrm{TA}_{\mathrm{bt}} .
$$

Normalization with respect to the average across all banks means that the indicator variables Size, Cap, Bliq, Nliq, and Ibk sum to zero over all observations. Because of this property, the interaction terms in equation (5.1) in the main text are on average equal to zero. In addition, the coefficient estimate $\gamma_{1 \mathrm{j}}$ directly reflects the average effect of monetary policy on bank credit growth. 


\section{Annex 5C Alternative Model Specifications}

Table 5C.1 summarizes the main differences between the benchmark model and the alternative model specifications.

Table 5C.1: Summary of Model Specifications

\section{Benchmark Model}

- Bank credit demand variables; Sample period 1992:1-2002:4; 1 single interaction term.

Augmented Model A

- No bank credit demand variables; Sample period 1992:1-2002:4; 1 single interaction term.

\section{Augmented Model B}

- Bank credit demand variables; Sample period 1992:1-2002:4; 3-4 single interaction terms (SIT).

Model 1: SIT for Size, Cap, Bliq,

Model 2: SIT for Size, Cap, Nliq,

Model 3: SIT for Size, Cap, Ibk,

Model 4: SIT for Size, Cap, Ibk, Nliq.

Augmented Model C

- Bank credit demand variables; Sample period 1992:1-2002:4; 1 double interaction term (DIT).

Model 1: DIT for Size, Ibk,

Model 2: DIT for Cap, Ibk,

Model 3: DIT for Nliq, lbk.

Model 4: DIT for Size, Cap.

\section{Augmented Model D}

- Bank credit demand variables; Sample period 1992:1-2002:4; 1 single interaction term; Relative model (see equation 5C.1).

\section{Augmented Model E}

- Bank credit demand variables; Sample period 1995:1-2002:4; 1 single interaction term.

In order to control for the relative importance of industries in a bank's portfolio relative to the aggregate (panel D in Table 5C.1), the benchmark specification in equation (5.1) is rewritten as

$$
\begin{aligned}
\Delta \frac{\mathrm{L}_{\mathrm{bi}, \mathrm{t}}}{\mathrm{L}_{\mathrm{b}, \mathrm{t}}}= & \alpha_{\mathrm{b}}+\sum_{\mathrm{j}=1}^{\mathrm{p}} \beta_{\mathrm{ij}} \Delta \frac{\mathrm{L}_{\mathrm{bi}, \mathrm{t}-\mathrm{j}}}{\mathrm{L}_{\mathrm{b}, \mathrm{t}-\mathrm{j}}}+\sum_{\mathrm{j}=1}^{\mathrm{p}} \gamma_{1 \mathrm{j}} \Delta \mathrm{r}_{\mathrm{M}, \mathrm{t}-\mathrm{j}}+\sum_{\mathrm{j}=1}^{\mathrm{p}} \gamma_{2, \mathrm{ij}} \Delta \frac{\mathrm{IP}_{\mathrm{i}, \mathrm{t}-\mathrm{j}}}{\mathrm{IP}_{\mathrm{t}-\mathrm{j}}}+\sum_{\mathrm{j}=1}^{\mathrm{p}} \gamma_{3, \mathrm{ij}} \Delta \frac{\text { Price }_{\mathrm{i}, \mathrm{t}-\mathrm{j}}}{\text { Price }_{\mathrm{t}-\mathrm{j}}}+ \\
& \gamma_{4} \mathrm{X}_{\mathrm{b}, \mathrm{t}-1}+\sum_{\mathrm{j}=1}^{\mathrm{p}} \gamma_{5} \mathrm{X}_{\mathrm{b}, \mathrm{t}-1} \Delta \mathrm{r}_{\mathrm{M}, \mathrm{t}-\mathrm{j}}+\epsilon_{\mathrm{bi}, \mathrm{t}} .
\end{aligned}
$$





\section{The Asymmetric Effects of Monetary Policy on Industry Performance}

\subsection{Introduction}

There is considerable empirical research on the real effects of monetary policy actions. The studies differ in that they assume that monetary policy shocks have either symmetric or asymmetric effects on real economic activity. Asymmetric effects of monetary policy shocks are traditionally modeled in at least three different, but complementary and integrated ways. The most common type of asymmetry is the 'traditional Keynesian' asymmetry which stresses asymmetries in the real effects of monetary policy over monetary expansions and monetary contractions. The 'sign' effect of monetary policy requires prices to be rigid downwards but flexible upwards. The aggregate supply curve that coincides with these patterns is convex. For this shape of the aggregate supply curve, a monetary expansion has a larger effect on prices but a smaller effect on output than a monetary contraction. ${ }^{1}$ Empirical support for the 'traditional Keynesian' asymmetry is derived by, among others, Cover (1992), Rhee and Rich (1995), Karras (1996a, 1996b), Ravn and Sola (2004), Karras and Stokes (1999), and Lobo (2000). ${ }^{2}$ The evidence shows that a contractionary monetary policy shock has a strong negative effect on output, while the output effect of an expansionary monetary policy shock is either insignificant or less pronounced. On the other hand, Ravn and Sola (1996) document in a study for the United States that these asymmetries nearly disappear when one controls for regime shifts in monetary policy.

Another type of asymmetry is referred to as 'state' asymmetry. This concept links the real effects of monetary policy to the business cycle and argues that monetary policy is more effective during a recession than during a boom. ${ }^{3}$ Similar to the sign asymmetry, the cyclical asymmetry in the effects of monetary policy shocks is, on the one hand, attributable to

\footnotetext{
${ }^{1}$ The extreme case assumes prices to be perfectly rigid (flexible) below (above) equilibrium output. For this case, the short-run aggregate supply curve is horizontal up to equilibrium output and vertical at full employment. Monetary expansions then do not have real effects (e.g., Florio, 2004).

${ }^{2}$ Lobo (2000) adopts a different focus and stresses the sign effects of monetary policy on stock returns rather than on output. The interest rate response of stock returns is stronger for monetary contractions than for expansions.

${ }^{3}$ See section 2.2.3 for more details.
} 
downward (upward) sticky (flexible) prices and the corresponding properties of the convex aggregate supply curve. On the other hand, state asymmetry is attributable to the credit channel effects of monetary policy through either bank lending or net worth. At the core of this monetary transmission channel are credit market imperfections and information asymmetries which influence the availability of and the need for external finance. Information asymmetries are less pronounced in periods of economic booms when net worth of potential borrowers is high. Because the risk of loan losses is low compared with recession periods, external finance is more readily available and the real effects of monetary policy shocks are contemplated to be weak. ${ }^{4}$ Empirical support for state asymmetry is reported by Gertler and Gilchrist (1994), Garcia and Schaller (2002), Kakes (1998), Weise (1999), Dolado and María-Dolores (2001), and Peersman and Smets (2005). The underlying studies show that monetary policy shocks are less effective in periods of high output growth. Bruinshoofd and Candelon (2005), in contrast, only report weak evidence of state asymmetry for European countries and Thoma (1994) in a study for the United States finds monetary contractions to have stronger effects in periods of high economic growth.

The third type of asymmetry stresses differences in the size of monetary policy shocks. The 'size' effects of monetary policy asymmetry are linked to menu costs in price setting and hence to the degree of price stickiness at the production side of the economy. Menu costs cause small monetary policy shocks to have real effects since they induce firms not to adjust nominal prices. A fixed price strategy is optimal for small shocks because the cost of price adjustment then exceeds that associated with the change in product demand. On the contrary, large monetary policy shocks are neutral because profit maximization requires firms to pay the menu cost. ${ }^{5}$ Empirical research confirms the existence of size effects of monetary policy. Ravn and Sola (2004) in a study for the United States show that only small negative monetary policy shocks have real effects. ${ }^{6}$ Weise (1999) provides more detail. He illustrates that the long-run output effects of small contractionary monetary policy shocks are somewhat larger than those of large shocks when the US economy is in a recession. ${ }^{7}$ However, large contractionary monetary policy shocks cause a disproportionately larger long-run decline in output compared with small shocks when the economy is initially in a boom period.

Existing empirical research on the state, size, and sign effects of monetary policy usually builds on macroeconomic rather than on industry or even microeconomic data. Studies which use industry data differ in that they assume monetary policy shocks to have symmetric ${ }^{8}$ or

\footnotetext{
${ }^{4}$ See, for instance, Bernanke and Gertler (1989) for the underlying model and Florio (2004) for a graphical illustration. Chapter 2 surveys the credit channel literature in detail.

${ }^{5}$ See Blanchard and Kiyotaki (1987), Ball and Romer (1990), and Ball and Mankiw (1994) for details. The corresponding studies explain price rigidities by arguing that fixed-price strategies are associated with second-order (first-order) costs in the presence of small (large) shocks.

${ }^{6}$ This finding lends support to the principle of 'hybrid' asymmetry (Ball and Mankiw, 1994) that combines the predictions of the 'Keynesian' asymmetry and the 'menu cost' asymmetry.

${ }^{7}$ Weise (1999) defines the long-run response as the cumulative response over twelve quarters.

${ }^{8}$ See, for example, Ganley and Salmon (1997), Arnold (2000), Hayo and Uhlenbrock (2000), Dedola and
} 
asymmetric ${ }^{9}$ effects on industry output. The industry studies on asymmetry predominantly test whether monetary policy effects are influenced by the business cycle position of an industry. That is, they disregard possible sign and size effects of monetary policy and assume an expansionary and contractionary monetary policy change to have a symmetric, albeit opposite, effect on industry-specific output. The corresponding empirical evidence points to (i) the role of industries as propagation mechanism of monetary policy changes and (ii) to cross-industry differences in the cyclical asymmetry of monetary policy effects.

The present chapter provides evidence of the state and sign effects of monetary policy and cautious evidence of size effects. ${ }^{10}$ The study's main contribution to the existing literature on the asymmetric effects of monetary policy is that it investigates whether monetary contractions and expansions affect industry output growth (i) to the same extent (sign effects), (ii) to the same extent during economic booms and downturns (state effects), and (iii) to the same extent for different magnitudes of the monetary policy change (size effects). The answer to each question emphasizes cross-industry differences in the degree of capital intensity, trade openness, and in the availability of internal funds of finance as possible sources of cross-industry differences in the state, sign, and size effects of monetary policy. As emphasized in the preceding chapters, a detailed understanding of the industry effects of monetary policy should be of critical importance to central banks in general and the European Central Bank in particular because it facilitates assessments as to the macroeconomic real effects of a monetary policy change of particular size and sign.

This study documents asymmetries in monetary policy effects for a panel dataset of 24 industry sectors in either Germany, Italy, or Spain, using quarterly data for the period 1995:12002:4. Because the data for each country refer to the same sectoral disaggregation and sample period, our results are directly comparable across the three economies. Anticipating the results, monetary policy changes have asymmetric effects on industry output growth. Conclusions as to the direction and strength of the sign effects of monetary policy here crucially depend on the choice of country. This points to the heterogeneity of countries and explains why we do not consider a country panel dimension as done by, for example, Peersman and Smets (2005). As regards size and state effects, the evidence suggests that monetary policy effectiveness is hardly determined by the magnitude of the monetary policy change or by business cycle effects. This conclusion applies to all countries.

The remainder of this chapter is organized as follows. Section 6.2 provides theoretical reasons for the role of industry composition as determinant of the asymmetric effects of monetary policy. We emphasize the transmission of positive and negative monetary policy shocks through the interest rate, credit, and exchange rate channel. Section 6.3 describes the empirical model, the estimation approach, and the data. Section 6.4 reports and interprets

Lippi (2005), and Ehrmann and Fratzscher (2004).

${ }^{9}$ See, among others, Dolado and María-Dolores (2001) and Peersman and Smets (2005).

${ }^{10}$ See section 6.3 .1 for caveats related to the estimation of size effects. 
the empirical results. We summarize the results and conclude in section 6.5.

\subsection{Literature Review}

This study asks whether expansionary and contractionary monetary policy shocks have differential effects on industry output growth. The industry focus is motivated by the existing evidence on the industry effects of monetary policy which shows that industries differ in their sensitivity to monetary policy changes. Monetary policy effectiveness may therefore depend on the relative importance of industries in an economy. This, however, suggests that regional differences in the real effects of monetary policy can result from regional dissimilarities in industry composition. Evidence of regional or cross-country disparities in industry effects of monetary policy is provided by Hayo and Uhlenbrock (2000) and Arnold and Vrugt (2004) for Germany, by Carlino and DeFina (1998, 1999a, 1999b, 2000) and Arnold (2000) for the United States, and by Dedola and Lippi (2005) and Peersman and Smets (2005) for OECD and European countries. ${ }^{11}$

Because industries are not equally distributed across regions within countries or between countries, cross-industry heterogeneity in monetary policy sensitivity is likely to have real distributional and hence social effects in terms of output and unemployment. ${ }^{12}$ If it holds that contractionary monetary policy shocks affect industries more than expansionary shocks, these distributional effects are most prevalent in periods of tight monetary policy. Similarly, if cyclical asymmetries in monetary policy effectiveness are such that monetary policy changes are more effective during economic downturns than during booms, these distributional effects are stronger in periods of economic downturns.

The literature on the propagation of monetary policy shocks suggests several explanations for cross-industry differences in the sign and state effects of monetary policy. These involve, among others, the operation of an interest rate (cost-of-capital) channel ${ }^{13}$, credit channel, or exchange rate channel. The remainder of this section explains the expected relationships. Because the underlying explanations are equally valid for analyses of state and sign effects, the discussion of industry effects is kept general. One has to remember that the industry effects are likely to be weaker for monetary policy changes in periods of booms than in recessions.

Proponents of the interest rate channel argue that the monetary policy response of industry

\footnotetext{
${ }^{11}$ Also see the evidence for the United States and Europe in chapter 4.

${ }^{12}$ Arnold (2000) suggests that cross-industry differences in unemployment risk are compensated by crossindustry heterogeneity in wages and in the return on capital. If this is true, differences in the interest rate sensitivity of industries would not have distributional effects. However, empirical evidence lends weak support to this claim.

${ }^{13}$ The interest rate channel is also referred to as the cost-of-capital channel. This reference denotes the observation that industry output is responsive to changes in the user cost of capital, which itself is influenced by the interest rate.
} 
output is driven by supply- and demand-side adjustments, with the response on both segments working in different directions. Demand-side adjustments describe the extent to which the demand curve for industry-specific goods shifts in response to monetary policy changes. The magnitude of the demand shift is influenced by the nature of the industry good, with demand for durable consumption and investment goods being more responsive to monetary policy changes. ${ }^{14}$ Because durable consumption and investment goods tend to be produced by capital-intensive industries, monetary-policy-induced demand shifts are more pronounced for these sectors.

Supply-side adjustments refer to the extent to which industries adjust prices so as to mitigate output fluctuations due to monetary policy changes. An indicator of the degree of price stickiness in each sector is the slope of the industry supply curve. Following Caballero and Engel (1993) and Ball and Mankiw (1994), the supply curve is steeper and output fluctuations are thus smaller for industries with more flexible prices. We assume that the degree of price rigidities is less pronounced for capital-intensive industries. To illustrate, capital-intensive production is associated with large fixed costs that are incurred regardless of the degree of capital and capacity utilization. In order to respond to a monetary-policy-induced change in output demand, capital-intensive industries may therefore adjust prices faster so as to keep output and consequently inventories steady. If the monetary-policy-induced supply-side effect dominates the demand-side effect, output of capital-intensive industries may respond less to monetary policy changes than that of capital-extensive industries.

Confined to the context of open economies, the exchange rate channel attributes crossindustry differences in monetary policy effectiveness to cross-industry asymmetries in the degree of openness to trade. Again, the output response of industries involves demand- and supply-side adjustments. Considering demand-side adjustments, shifts in demand may be less pronounced for open than for closed industries in view of the fact that open industries also serve foreign markets. However, one can also argue that shifts in demand are more pronounced for open industries due to the adverse demand effects of monetary-policy-induced exchange rate developments. This effect is likely to prevail in the short run with sticky prices when monetary policy changes have real exchange rate effects. A monetary contraction, for example, may cause the decline in demand to be more pronounced for open industries given that the appreciation of the currency causes industry output to be more expensive in an international comparison. ${ }^{15}$

Supply-side adjustments can mitigate this exchange rate effect. Comparable with the interest rate channel, supply-side adjustments describe the extent to which industries mitigate output fluctuations by lowering or increasing prices. The relationship between openness and the degree of price rigidity is such that open industries are assumed to increase and lower

\footnotetext{
${ }^{14}$ Also refer to section 2.2.1 and 2.2.4 and to Kalckreuth (2003) for an overview of the factors that determine the demand for investment goods.

${ }^{15}$ Also see Peersman and Smets (2005) for a similar view.
} 
prices faster than closed industries in response to expansionary and contractionary monetary policy changes. For a monetary expansion, the depreciation of a country's currency results in higher wage demands given the shift in demand from foreign to domestic goods and the consequent increase in the utilization of production factors. This development is likely to be stronger in open than in closed industries, especially when the monetary-policy-induced increase in demand involves capacity adjustments through labor rather than through capital. In order to maintain profits, open industries increase prices. For a monetary contraction, the monetary-policy-induced currency appreciation and the consequent loss in (short-run) international competitiveness puts greater downward pressure on prices and wages in open than in closed industries given that the goods produced by the former are replaced with cheaper imported goods. Overall, the larger response of prices causes the output supply curve to be comparatively steeper in open industries. This, however, suggests that the monetary policy response of open industries primarily concerns price rather than quantity adjustments. Stated differently, the response of industry output to contractionary and expansionary monetary policy changes is less pronounced for open than for closed industries. ${ }^{16}$

Cross-industry differences in the real effects of monetary contractions and expansions are also attributable to credit channel effects. As stated in section 2.2.2, the credit channel effects of monetary policy depend on the degree of credit market imperfections and on the access of firms to external funds of finance. Regardless of the monetary policy stance, borrowers (e.g., firms) with low net worth are more constrained from accessing bank and non-bank sources of external finance and face a higher premium for external finance since they are perceived to be more risky (cf. Bernanke and Gertler, 1989). In view of these relationships, the response of investment and ultimately output to monetary policy changes is likely to be more pronounced for borrowers with low net worth and high credit demand. This line of reasoning straightforwardly extends to the case of industries: industries with low balance sheet positions face higher costs of external finance and tighter financing constraints than industries with high net worth. We expect this relationship to prevail for monetary expansions and monetary contractions. Similar to the interest rate and exchange rate channel, the credit channel effects of monetary expansions and contractions can be asymmetric due to differences in the upward and downward rigidity of the price of external finance. Again, prices are likely to be more flexible upwards than downwards. ${ }^{17}$ This suggests that the credit channel effects are potentially stronger during monetary contractions than expansions.

Among the existing industry studies, there are only few which explain the industry effects of monetary policy with industry characteristics associated with the interest rate, credit, or

\footnotetext{
${ }^{16}$ Karras (1999) uses a standard open-economy version of the IS-LM model to show that the output (inflation) effects of monetary policy shocks are weaker (stronger) in open than in closed economies. His arguments are developed for symmetric monetary policy shocks.

${ }^{17}$ Gambacorta and lannotti (2005) in a study for Italy show that interest rate adjustment in response to negative and positive monetary policy changes is asymmetric in the short run, but not in the long run. Banks are found to adjust lending rates faster in response to monetary contractions.
} 
exchange rate channel of monetary policy. Many of the corresponding studies do not allow expansionary and contractionary monetary policy shocks to have asymmetric real effects. The exception is Peersman and Smets (2005). In a study for Euro zone member countries, they identify the state effects of monetary policy and explain cyclical asymmetries in the industry effects of monetary policy shocks with industry characteristics. In order to identify the state effects, expansionary and contractionary monetary policy shocks are modeled to have symmetric, albeit opposite effects on industry-specific output. In addition, Peersman and Smets (2005) assume that all industries are at the same business cycle position at the time of the monetary policy shock. That is, they do not allow for cross-industry differences in the timing and magnitude of cyclical fluctuations. ${ }^{18}$ This is a restrictive assumption in view of the fact that the industry effects of monetary policy are determined by the actual output level. Given the explanations of state asymmetry, the output effects of monetary policy shocks are lower in periods of high output (boom) than in periods of low output (recession).

Similar to Peersman and Smets (2005), the present study also stresses asymmetries in the industry effects of monetary policy in European countries, but contributes to the earlier study in a number of ways. Firstly, although we also test for asymmetries in the real effects of monetary policy over the business cycle, the tests for state asymmetry do not treat the cyclical position of industries as being exogenous to industry output growth. Instead, we construct an industry-specific indicator variable of the business cycle stance. Secondly, the present analysis does not stop at testing for state effects, but also derives the sign effects of monetary policy on industry output. When testing for sign asymmetries of monetary policy, we also ask whether the strength of the monetary policy effect depends on the size of the monetary policy change. That is, we test for size asymmetries. Thirdly, while Peersman and Smets (2005) estimate a panel that combines the industry- and country-dimension of the data, we consider country-specific panel models for Germany, Spain, and Italy, using data on 24 industries. ${ }^{19}$ The estimation of country-specific panels avoids the potential problem of crosssectional dependence across EMU countries. A possible source of cross-sectional dependence between countries is the nature of the European exchange rate mechanism prior to 1999 when Germany was the only European economy with monetary sovereignty. Besides this factor, it is likely that the cross-sectional dependence between countries would be amplified by the cross-sectional dependence between industries. We use data on 24 industries, which include 21 manufacturing industries, two sub-sectors of the mining industry, and the electricity, gas, and water supply sector. In using a finer classification than Peersman and Smets (2005), the present analysis can draw a richer picture as to the industry effects of monetary policy by allowing for more cross-sectional variation.

\footnotetext{
${ }^{18}$ Peersman and Smets (2005) treat the probabilities of being in a boom or recession as exogenous to industry-specific output growth. The business cycle position is approximated for the aggregate Euro area.

${ }^{19}$ Peersman and Smets (2005) estimate a panel model for a sample of 11 manufacturing industries from seven European countries.
} 


\subsection{Empirical Framework}

The analysis of monetary policy asymmetry is complicated by the identification of the exogenous component of monetary policy changes. ${ }^{20}$ In order to overcome the identification problem, many studies use a vector autoregressive (VAR) model. Existing research hereby approximates the monetary policy shocks from a considerable number of variables such as, for example, short-term interest rates or measures of broad and narrow money supply. The VAR approach is criticized for the underlying ad hoc modeling assumptions regarding the causal relationship between economic performance and monetary policy. ${ }^{21}$ In response to this shortcoming, some studies adopt the narrative approach of Romer and Romer (1989) or use event studies (Kuttner, 2001; Ehrmann and Fratzscher, 2004; Bernanke and Kuttner, 2005). Unfortunately, data availability confines the applicability of narrative and event studies to the United States.

Most studies on the sign and state effects of monetary policy employ a two-step procedure to resolve the identification bias. In the first step, a measure of monetary policy (i.e., money growth or the money market interest rate) is regressed on its own lagged values and on a vector of other lagged variables like aggregate output growth and inflation. ${ }^{22}$ The residuals of the money equation are used as proxy variables of contractionary and expansionary monetary policy shocks. In the second stage of the analysis, an output equation is specified which defines aggregate output growth as a function of its own lagged values and of lagged values of the residuals from the first step estimation. Of course, the two-equation system will only resolve the identification bias inherent to the use of monetary aggregates or the money market interest rate if the monetary policy shock is exogenous to output growth. This, however, requires the residuals of the money equation to be uncorrelated with output growth. Unfortunately, this condition is hardly met. Furthermore, the empirical consistency of the results hinges on the assumption that the error terms of the money and output equation are independent. However, when the error terms of the money equation are not exogenous to output growth, the residuals of the money equation will then also be correlated with the residuals of the output equation in dynamic specifications. The present analysis acknowledges these drawbacks and tries to control for at least some.

\footnotetext{
${ }^{20}$ Refer to section 2.3.1 for a detailed discussion of the identification problem.

${ }^{21}$ Gordon and Leeper (1994), Bernanke and Mihov (1998), and Kieler and Saarenheimo (1998), among others, discuss and criticize the ad hoc nature of modeling assumptions.

${ }^{22}$ See Cover (1992), Rhee and Rich (1995), Karras (1996a, 1996b), and Karras and Stokes (1999) for studies that use monetary aggregates and Morgan (1993) for a study which employs the money market interest rate as monetary policy measure. See Florio (2004) for a survey of the literature that uses the yield spread or narrative evidence.
} 


\subsubsection{Empirical Model Specifications}

This section discusses the empirical model, the empirical methodology, and the data used to investigate the state, sign, and size effects of monetary policy for industries in Germany, Italy, and Spain. The present analysis differs from earlier studies with respect to the definition of the monetary policy stance. As stated, existing empirical research identifies monetary policy shocks as the residuals of money supply or interest rate equations. We depart from this approach and approximate monetary policy changes directly with changes in national short-term interest rates.

Interest rates are the preferred indicator of the monetary policy stance for at least four reasons. Firstly, Bernanke and Blinder (1992) argue that the short-term interest rate is less susceptible to changes in economic conditions and hence less sensitive to the endogeneity bias inherent to the two-step procedure. Secondly, Bernanke, Gertler, and Watson (1997), Bernanke and Mihov (1998), and McCallum (1999) reason that tests of monetary policy transmission should not exclusively be concerned with the effects of random exogenous shocks since their contribution to the variability in monetary policy is comparatively small. Thirdly, the contribution of unexpected interest rate changes to industry performance is likely to be small compared with expected interest rate changes. Even expected interest rate changes affect industries. The reason is that industry performance depends on the interaction of numerous supply- and demand-side factors whose interest rate response cannot be perfectly anticipated. Finally, the sample period 1995:1-2002:4 is characterized by the transition towards the European economic and monetary union. For the sampled countries, a proxy variable of monetary policy shocks would predominantly reflect effects associated with the convergence of national interest rates towards a common level rather than unexpected disturbances.

Because changes in the monetary policy stance are directly approximated with observable changes in the short-term interest rate, the present analysis only estimates a single output equation rather than a two-equation system. In order to differentiate the asymmetric output growth effects of monetary policy, we define a number of output equations. Common to all specifications is that they employ the nominal short-term interest rate as measure of the monetary policy stance. The remainder of this section presents the different specifications. ${ }^{23}$ The explanatory variables' expected signs are summarized at the end of this section.

\section{(i) Symmetric Benchmark Model}

We first define a benchmark model that does not allow for asymmetries in the output effects of monetary policy. Monetary policy transmission is defined according to

\footnotetext{
${ }^{23}$ The different models initially also include a proxy variable of energy price inflation in order to capture the output growth effects of supply shocks. Because the long-run coefficient of the energy price variable is insignificant in almost all specifications, we exclude this variable. Furthermore, we do not include industryspecific inflation in order to avoid that industry-specific supply shocks and their impact on prices blur the effect of monetary policy on industry output.
} 


$$
\Delta y_{i t}=\beta_{0 i}+\sum_{j=1}^{p} \beta_{1 j} \Delta y_{i, t-j}+\sum_{j=1}^{p} \beta_{2 j} \Delta r_{M, t-j}+\sum_{j=1}^{p} \beta_{3 j}\left(\operatorname{Char}_{i, t-j} \Delta r_{M, t-j}\right)+\epsilon_{i t} .
$$

$\Delta y_{i t}$ represents the first log-difference of real output of industry $\mathrm{i}=1, \ldots, \mathrm{N}$ at time $\mathrm{t}=$ $1, \ldots, \mathrm{T}$. The variable $\mathrm{r}_{\mathrm{M}}$ denotes the country-specific nominal money market interest rate. In order to identify the effect of industry characteristics on the output effects of monetary policy, the interest rate change $\Delta r_{M}$ at time $t-j$ is interacted with the industry characteristics $\mathrm{Char}_{\mathrm{i}}$ at time $\mathrm{t}-\mathrm{j}$. The vector of industry-specific characteristics (Char) includes a measure of capital intensity, openness to trade, and an indicator for the availability of internal financial funds. These variables, respectively, approximate the interest rate, exchange rate, and credit channel effects of monetary policy. In order to avoid that the estimates are confounded by scale effects, the industry characteristics are normalized with respect to the mean across all industries for each single point in time. The benchmark model is also estimated without industry characteristics in order to assess the robustness of the results.

\section{(ii) Sign Effects Model}

Model (6.1) assumes that positive and negative monetary policy shocks have symmetric output effects. In order to control for possible asymmetries in the output effects of positive (i.e., contractionary, $r_{M}^{+}$) and negative (i.e., expansionary, $r_{M}^{-}$) interest rate changes, the model is modified according to

$$
\begin{aligned}
\Delta y_{i t}= & \beta_{0 i}+\sum_{j=1}^{p} \beta_{1 j} \Delta y_{i, t-j}+\sum_{j=1}^{p}\left(\beta_{2 j}^{+} \Delta r_{M, t-j}^{+}+\beta_{2 j}^{-} \Delta r_{M, t-j}^{-}\right)+ \\
& \sum_{j=1}^{p} \beta_{3 j}\left(\operatorname{Char}_{i, t-j} \Delta r_{M, t-j}^{+}\right)+\sum_{j=1}^{p} \beta_{4 j}\left(\operatorname{Char}_{i, t-j} \Delta r_{M, t-j}^{-}\right)+\epsilon_{i t} .
\end{aligned}
$$

In order to be able to explain the industry output growth effects of monetary expansions and contractions, they are interacted with the structural industry characteristics. ${ }^{24}$ We define monetary expansions and contractions according to

$$
\begin{aligned}
& \Delta r_{\mathrm{M}, \mathrm{t}}^{+} \equiv \max \left(\Delta \mathrm{r}_{\mathrm{M}, \mathrm{t}}, \mu\right), \\
& \Delta \mathrm{r}_{\mathrm{M}, \mathrm{t}}^{-} \equiv \min \left(\Delta \mathrm{r}_{\mathrm{M}, \mathrm{t}}, \mu\right) .
\end{aligned}
$$

The parameter $\mu$ denotes a threshold level beyond which monetary policy is deemed to contract or expand for all industries. Here, we follow the traditional literature on the asymmetric

\footnotetext{
${ }^{24}$ Karras (1999) and Peersman and Smets (2005) employ a comparable approach.
} 
effects of monetary policy ${ }^{25}$ and set the threshold level of monetary expansions and contractions equal to zero for all industries. That is, $\mu=0$.

\section{(iii) Size Effects Model}

In a next step, we augment the existing literature on monetary policy asymmetry and allow the threshold $\mu$ to be non-zero so as to capture possible size effects of monetary policy. This approach is motivated by the menu cost argument which states that small monetary policy shocks have real effects, whereas large monetary policy shocks are neutral. ${ }^{26}$ For a non-zero threshold, the analysis is augmented by a 'midrange' of interest rate changes. These will have a significant industry output growth effect if the menu cost argument holds: only monetary policy changes which are larger than the non-zero threshold $\mu$ have a neutral effect. Figure 6.1 summarizes these relationships.

Figure 6.1: The Size Effects of Monetary Policy

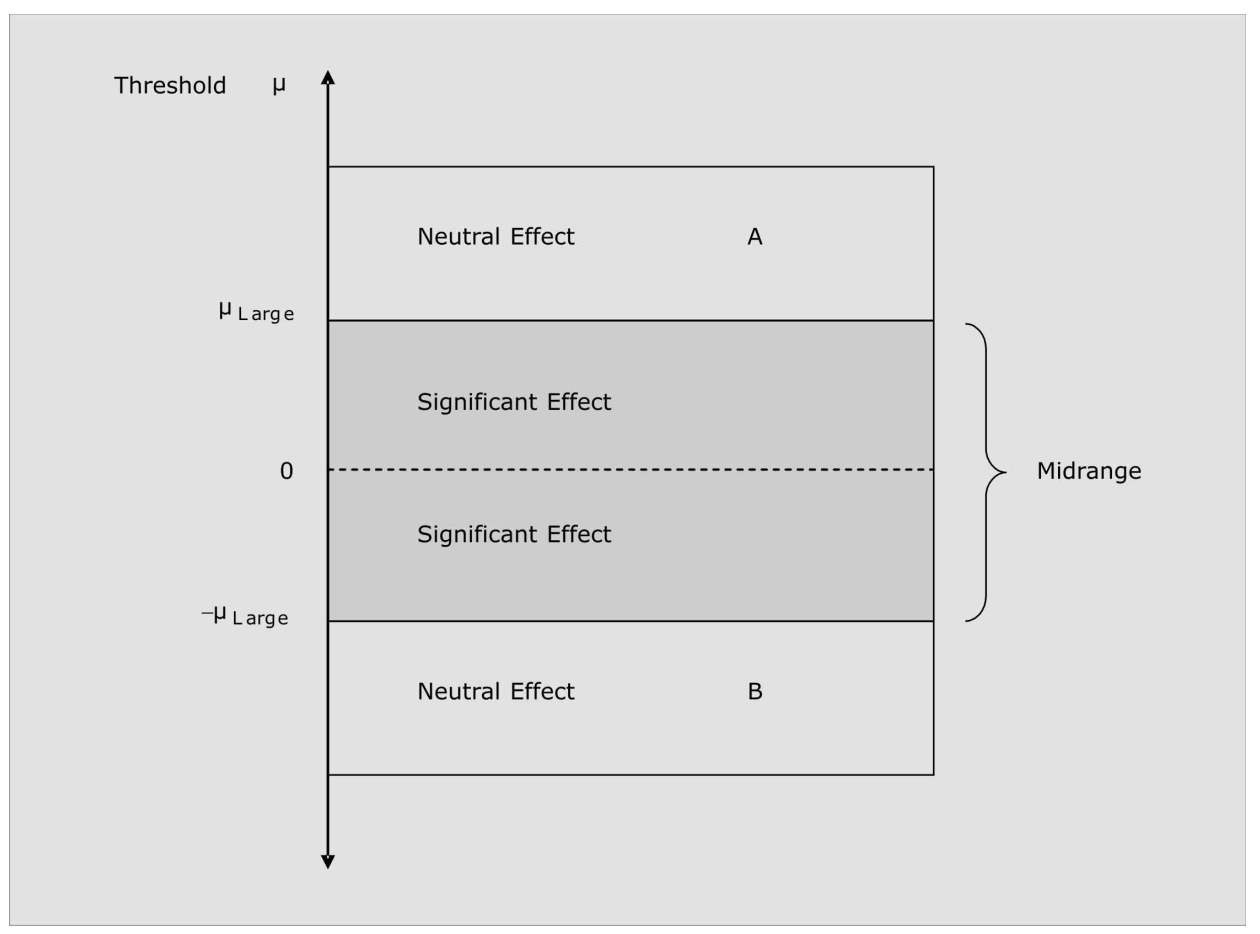

${ }^{25}$ See, for example, Rhee and Rich (1995) and Karras (1996a, 1996b).

${ }^{26}$ Section 6.1 provides details. 
In order to investigate the response of industry output growth to monetary policy changes in the midrange $-\mu<\mathrm{r}_{\mathrm{M}}^{ \pm}<\mu$, equation (6.2) is rewritten as

$$
\begin{aligned}
\Delta y_{i t}= & \beta_{0 i}+\sum_{j=1}^{p} \beta_{1 j} \Delta y_{i, t-j}+\sum_{j=1}^{p}\left(\beta_{2 j}^{+} \Delta r_{M, t-j}^{+}+\beta_{2 j}^{-} \Delta r_{M, t-j}^{-}+\beta_{2 j}^{ \pm} \Delta r_{M, t-j}^{ \pm}\right)+ \\
& \sum_{j=1}^{p} \beta_{3 j}\left(\operatorname{Char}_{i, t-j} \Delta r_{M, t-j}^{+}\right)+\sum_{j=1}^{p} \beta_{4 j}\left(\operatorname{Char}_{i, t-j} \Delta r_{M, t-j}^{-}\right)+ \\
& \sum_{j=1}^{p} \beta_{5 j}\left(\operatorname{Char}_{i, t-j} \Delta r_{M, t-j}^{ \pm}\right)+\epsilon_{i t} .
\end{aligned}
$$

Here, \pm denotes the observations associated with the midrange of interest rate changes.

Model (6.4) is certainly restrictive in that it only allows for asymmetries in the output growth effects of large shocks. Expansionary and contractionary monetary policy changes in the midrange are assumed to have symmetric output growth effects. This specification is reported for computational reasons. To illustrate, tests for size effects would ideally allow for asymmetries in the effects of small as well as large monetary contractions and expansions. In the present study, the corresponding estimations are not feasible given the small number of cross sections and the low variability in the nominal interest rate change.

An alternative more direct test of the menu cost argument would (i) allow for asymmetries in the output growth effects of small expansionary and contractionary monetary policy changes and (ii) impose the symmetry assumption on large monetary policy changes. The structure of the underlying model controls for the prediction of the menu cost argument according to which small positive and negative changes have output growth effects and large positive and negative monetary policy changes are neutral. Although this specification is intrinsically more appealing, we do not report the corresponding empirical results because the residuals do not satisfy the normality assumption in estimations for Germany, Italy, and Spain. The coefficient estimates are consequently inconsistent. The present analysis therefore uses specification (6.4) to investigate the size effects of monetary policy. Because the empirical results are derived from a restrictive model, the evidence of possible size effects needs to be interpreted with care and is only indicative.

Another limitation of the size effects specification concerns the definition of small and large monetary policy changes. In general, the analysis of the size effects requires a clear definition of small and large monetary policy changes. For example, a small and large monetary policy change can be defined as a one or two standard deviation change in the interest rate, respectively. Unfortunately, the present study cannot employ this definition because the small time and cross-section dimension precludes the estimation of the consequent model due to singularity problems. We therefore adopt a very simplistic approach and define the non-zero 
threshold $\mu$ as the largest change in the interest rate for which the model can still be estimated. If the menu cost argument applies, large positive and negative monetary policy changes are expected to have at least smaller industry output growth effects than small monetary policy changes. We use step size 0.01 to cover all possible thresholds between $\max \left(\mathrm{r}_{\mathrm{M}, \mathrm{t}}, \mu\right)$ and $\min \left(\mathrm{r}_{\mathrm{M}, \mathrm{t}}, \mu\right)$.

A different weakness results from the failure of the present model to discriminate the size effects of monetary policy which are inherent to the predictions of (i) the investment model (cf. Figure 3.3) and (ii) the menu cost model (cf. Figure 6.1). At the core of this limitation are cross-model differences in the factors that explain the size effects of monetary policy. Considering the investment model, it emphasizes investment irreversibility and capital adjustment costs as factors that determine the real effects of monetary policy. The model takes output prices as given and does not specify a pricing rule that controls for price stickiness and possible costs of price adjustment. Furthermore, the investment model assumes that expansionary and contractionary monetary policy changes have symmetric effects. In contrast to the investment model, the menu cost model argues that price adjustment is costly and asymmetric for monetary expansions and contractions. Similar to the sign and state asymmetries of monetary policy, the size asymmetries result from rigidities in price setting.

The analysis in the present chapter stresses the menu cost argument to explain possible size effects of monetary policy. The limited focus is, on the one hand, motivated by the observation that the menu cost model allows for asymmetries in the effects of monetary expansions and contractions. Besides this reason, we also emphasize the menu cost argument because the corresponding empirical investigations are less data intensive compared with tests of the investment channel. For example, tests of the menu cost model do not require information on the size distribution of firms given the model's implicit assumption that small and large firms display the same response to monetary policy changes. In contrast, the analysis in chapter 3 has shown that data on the size distribution of firms in a particular industry or on the distribution of industries dominated by either small or large firms are a necessary prerequisite for tests of the investment channel. Unfortunately, such data are unavailable for the present set of industries.

\section{(iv) State Effects Model}

In order to determine whether the sign effects of monetary policy are influenced by differences in the effectiveness of monetary policy over the business cycle, the sign effects model (6.2) is augmented with an industry-specific binary dummy $D_{i}$ that approximates the business cycle position of industries. ${ }^{27}$ The dummy is specified to equal one if industry-specific actual real output growth is lower than industry-specific real trend output growth and zero otherwise. ${ }^{28}$

\footnotetext{
${ }^{27}$ See Karras and Stokes (1999) and Karras (1996a) for comparable specifications.

${ }^{28}$ The trend growth rate is determined with the Tramo/Seats procedure, with adjustment for working day and leap year effects.
} 
The output equation (6.2) is modified to

$$
\begin{aligned}
\Delta y_{i t}= & \beta_{0 i}+\sum_{j=1}^{p} \beta_{1 j} \Delta y_{i, t-j}+\sum_{j=1}^{p}\left(\beta_{2 j}^{+} \Delta r_{M, t-j}^{+}+\beta_{2 j}^{-} \Delta r_{M, t-j}^{-}\right)+ \\
& \sum_{j=1}^{p} \beta_{3 j}\left(\operatorname{Char}_{i, t-j} \Delta r_{M, t-j}^{+}\right)+\sum_{j=1}^{p} \beta_{4 j}\left(\operatorname{Char}_{i, t-j} \Delta r_{M, t-j}^{-}\right)+ \\
& \sum_{j=1}^{p} \beta_{5 j}\left(D_{i, t-j} \Delta r_{M, t-j}^{+}\right)+\sum_{j=1}^{p} \beta_{6 j}\left(D_{i, t-j} \Delta r_{M, t-j}^{-}\right)+\epsilon_{i t} .
\end{aligned}
$$

We do not test for state (cyclical) effects in the non-zero threshold model (6.4) in view of the fact that the consequent analysis would ask for definitions of mild and strong boom and recession periods.

\section{(v) Definition of the Long-Run Coefficients and Expected Signs}

We summarize the industry output growth effects of expansionary and contractionary monetary policy changes by computing the long-run elasticities of industry output growth with respect to the explanatory variables in the benchmark, sign, state, and size specification. ${ }^{29}$ For example, the long-run coefficient of monetary expansions $\beta_{\mathrm{LR}, \mathrm{r}_{\mathrm{M}}}^{-}$and contractions $\beta_{\mathrm{LR}, \mathrm{r}_{\mathrm{M}}}^{+}$ is defined as the sum of the lags of the interest rate variable, divided by one minus the sum of the coefficients on the lagged industry output growth variable: $\beta_{\mathrm{LR}, \mathrm{r}_{\mathrm{M}}}^{-}=\frac{\sum_{\mathrm{j}=1}^{\mathrm{p}} \beta_{2 \mathrm{j}}^{-}}{1-\sum_{\mathrm{j}=1}^{\mathrm{p}} \beta_{1 \mathrm{j}}}$ and $\beta_{\mathrm{LR}, r_{\mathrm{M}}}^{+}=\frac{\sum_{\mathrm{j}=1}^{\mathrm{p}} \beta_{2 \mathrm{j}}^{+}}{1-\sum_{\mathrm{j}=1}^{\mathrm{p}} \beta_{1 \mathrm{j}}}$. The coefficients on the interaction terms are computed in the same way. Because all long-run coefficients are a non-linear function of the estimated parameters, we derive the corresponding standard errors by means of the delta method. This approach derives linear approximations of the standard errors with a one-step Taylor expansion (Rao, 1973; Greene, 2003).

In order to test for the presence of long-run asymmetric output growth effects of positive and negative monetary policy shocks, we test for $\beta_{\mathrm{LR}, r_{\mathrm{M}}}^{+}=\beta_{\mathrm{LR}, \mathrm{r}_{\mathrm{M}}}^{-}$. We adopt a simple approach to investigate the equality of the coefficient estimates and implement mean equality tests for the null hypothesis that $\beta_{\mathrm{LR}, r_{\mathrm{M}}}^{+}=\beta_{\mathrm{LR}, \mathrm{r}_{\mathrm{M}}}^{-}{ }^{30}$ If the null hypothesis is not rejected, monetary policy effects will be symmetric. If the null hypothesis is rejected and $\beta_{\mathrm{LR}, \mathrm{r}_{\mathrm{M}}}^{+}>\beta_{\mathrm{LR}, \mathrm{r}_{\mathrm{M}}}^{-}$, contractionary monetary policy changes will have more persistent effects on industry output growth than

\footnotetext{
${ }^{29}$ We follow the existing literature when referring to long-run elasticities. Alternatively, the long-run coefficient can also be interpreted as the lasting response of industry output growth to changes in the explanatory variables. Section 5.4.1 includes a comparable application.

${ }^{30}$ More appropriate log-likelihood ratio tests cannot be implemented for the long-run coefficients because these are constructed from the estimated short-run coefficients in model (6.1) to (6.5). Log-likelihood ratio tests for the short-run coefficients of the different specifications fail to produce sensible results.
} 
expansionary monetary policy changes, vice versa. This approach straightforwardly extends to the remaining variables in the output equation. The results of the equality tests are available on request.

This section concludes with an overview of the expected signs of the long-run coefficient estimates. To facilitate the readability, the expected signs are summarized in Table 6.1. In the present chapter, the sign of the long-run coefficients is influenced by the definition of monetary expansions and contractions as negative and positive interest rate changes, respectively. ${ }^{31}$ For this interpretation, a monetary expansion and contraction increases and reduces industry output growth, respectively, if the long-run coefficient on negative as well as positive interest rate changes is negative. The industry output growth effects of monetary expansions and contractions are more pronounced during business cycle downturns if the coefficient on the interaction term between the business cycle dummy and the interest rate change is statistically significant and negative.

As regards the interaction term between each industry characteristic and the interest rate change, the corresponding coefficients are expected to display the same sign in tests of sign, state, and size effects. The distributional effects of monetary policy are anticipated to be such that the response of industry output growth to monetary policy is less pronounced for industries open to trade and for industries with high operating surplus. ${ }^{32}$ This holds for monetary contractions and monetary expansions if the coefficient on the interaction term between either openness or operating surplus and the interest rate change is positive. Considering capital intensity, no clear predictions can be drawn. As is argued in section 6.2, the monetary policy response of industry output growth depends on the net effect of monetary-policy-induced demand- and supply-side adjustments. The sign, state, and size effects of monetary policy are more pronounced for capital-intensive industries if the demand-side effects are stronger. However, they are weaker if the supply-side effects are the more important determinant of output growth. Because the present chapter defines capital intensity on the labor side (see section 6.3.3), demand-side (supply-side) effects dominate the output growth response of capital-intensive industries if the interaction term between capital intensity and the interest rate change is positive (negative) for monetary expansions as well as contractions.

\subsubsection{Methodology}

Each output equation represents a fixed effects dynamic panel. Several approaches are available to estimate the system. For example, the dynamic panel could straightforwardly be estimated with the feasible generalized least squares (FGLS) approach. This method is gen-

\footnotetext{
${ }^{31}$ We only explain the expected signs for monetary contractions and expansions. The expected signs for estimations with the midrange of interest rate changes do not differ from those for $\Delta r_{M}^{-}$and $\Delta r_{M}^{+}$in $T_{a b l e}$ 6.1 .

${ }^{32}$ As to openness, we assume that the demand-side effect through exchange rate developments is comparatively weak (cf. section 6.2).
} 
Table 6.1: Overview of Expected Signs

\begin{tabular}{lcc}
\hline \hline Long-Run Monetary Policy Effect on & Expected Sign for $\Delta r_{M}^{-}$ & Expected Sign for $\Delta r_{M}^{+}$ \\
\hline Industry Output Growth & - & - \\
Interaction with Business Cycle Dummy & - & - \\
Interaction with Capital Intensity & \pm & \pm \\
Interaction with Openness & + & + \\
Interaction with Operating Surplus & + & + \\
\hline \hline
\end{tabular}

$\Delta r_{M}^{-}$and $\Delta r_{M}^{+}$represent a monetary expansion (interest rate decline) and contraction (interest rate increase), respectively.

erally advantageous since it accounts for the presence of cross-sectional heteroscedasticity and cross-sectional dependence. These issues are of particular importance in the present study which relies on a set of heterogeneous, but possibly interdependent industries. Besides FGLS, the dynamic panel could also be estimated with the generalized method of moments (GMM) approach proposed by Arellano and Bond (1991). However, recent studies have challenged this method. Blundell and Bond (1998) show that the first-differenced GMM estimator has poor finite sample properties when the degree of correlation between the lagged levels of the variables and the subsequent first differences is low. More precisely, the first-differenced estimator is downward biased and imprecise. The resulting weak instrument problem is shown to be particularly prevalent for (near) unit root processes of the dependent variable. Oguzoglu and Stengos (2005) criticize the GMM method as it attributes the same weight to all moment conditions and favor empirical likelihood methods. Jung (2005) illustrates that Arellano and Bond's (1991) test of serial residual correlation may build on inconsistently estimated residuals. Because these are used to decide on the optimal over-identifying restrictions, coefficient estimates are likely to be inconsistent. Besides, GMM results tend to be very sensitive to the instrument space used as instrument variable (Andrews and Lu, 2001).

In view of these points, we estimate the fixed effects dynamic panel specifications with the feasible generalized least squares approach. In order to determine whether the cross-section effects are indeed fixed, we compute Hausman (1978) test statistics for the zero threshold specifications in equation (6.2). ${ }^{33}$ For the present set of specifications, the test statistics suggest that a fixed effects rather than random effects estimator is better suited to capture the cross-section effects, i.e., the heterogeneity of industries. The empirical specifications therefore include industry-specific intercepts. ${ }^{34}$

\footnotetext{
${ }^{33}$ In principle, the Hausman test should also determine whether period effects are fixed or random. To focus the analysis, we capture possible period effects with time dummies, of which only the significant ones are retained in the (fixed effects) zero threshold specification.

${ }^{34}$ The Hausman test statistics for the zero threshold estimations are available on request.
} 


\subsubsection{Data}

We identify the asymmetries of monetary policy effects for Germany, Italy, and Spain over the period 1995:1-2002:4. Quarterly information on the nominal money market interest rate is obtained from Eurostat and from the IMF International Financial Statistics database. The output equations comprise information on a panel of 24 industries: 21 manufacturing sectors, two mining and quarrying sectors, and the electricity, gas, and water supply sector (i.e., utilities). For reason of comparability, the set of industries is similarly defined for Germany, Italy, and Spain. Admittedly, the country dimension of the analysis is small and the industry dimension is biased towards manufacturing sectors. These properties are attributable to data availability constraints on output and prices and industry characteristics, which restrict the choice of countries and industries. ${ }^{35}$ The annex summarizes the industries for which data are compiled. Quarterly seasonally adjusted data on the industry output and price index are compiled from Eurostat's New Cronos database for the time period 1995:1-2002:4. The length of the sample period is restricted by the unavailability of industry-specific prices before 1995.

Information on proxy variables of capital intensity, openness, and the availability of internal financial funds is available from the OECD's STAN database for Industrial Analysis for the period 1995-2001/2. ${ }^{36}$ We define capital intensity on the labor side as the ratio of employment over real value added. For this definition, the degree of capital intensity is inversely related to the relative importance of employment per unit value of output. Trade openness is measured as the ratio of the sum of imports and exports over value added. The availability of internal financial funds in each industry is approximated as the ratio of operating surplus and mixed income over value added. We expect industries with positive and high operating surplus to be less dependent on external finance and hence less responsive to monetary policy shocks than industries with low or even negative operating surplus. Unfortunately, our measure of internal financial means is an imperfect balance sheet indicator and an imperfect measure of creditworthiness for at least two reasons. Firstly, operating surplus does not identify the share of assets that can be used as collateral. Because collateral is directly related to the external finance premium, operating surplus is an imperfect proxy variable of credit constraints. Secondly, the share of operating surplus does not approximate the borrowing capacity of industries since it does not illustrate the amount of existing debt. Although operating surplus is an imperfect credit channel variable, the present analysis still employs this measure since periodic observations on alternative, more reliable credit channel variables like the size distribution of firms are unavailable.

Data on industry-specific employment, operating surplus, and openness are only available at an annual frequency. This is a clear drawback since it implies that the reliability of our

\footnotetext{
${ }^{35}$ For example, we cannot repeat the analysis for France since the panel dataset comprises at most 13 industries.

${ }^{36}$ The latest observation for capital intensity is 2002, while that for openness and operating surplus is 2001.
} 
results from panel estimations with quarterly data depends on the time invariance of the industry characteristics. Peersman and Smets (2005) deal with the unavailability of industry characteristics at a higher than annual frequency by assuming the time invariance of the data between any two years. Industry characteristics thus enter the analysis as constants. Although we use comparable data, we do not assume that industry characteristics are constant throughout time. Instead, we treat them as being time-invariant in any given year, but timevariant across years so as to capture periodic changes in the relationship between output growth and industry properties. This approach is disadvantageous to the extent that it causes the quarterly data to be discontinuous. In order to eliminate the discontinuity of the quarterly data, the annual data could be interpolated. Future research will determine the sensitivity of the conclusions to the use of interpolated data. ${ }^{37}$

\subsection{Empirical Results}

This section reports the empirical results regarding the state, sign, and size effects of monetary policy. Regardless of the focal point, the models are estimated with four lags for all sampled countries. This appears to be the optimal lag length according to the goodness of fit measures for FGLS. ${ }^{38}$ The empirical results are subject to a number of limitations. Considering the evidence for Italy, we do not report results with operating surplus because of missing data. For the same reason, the evidence from estimations with openness only reflects the information on 23 industries. ${ }^{39}$ For Spain, the empirical evidence from all model specifications refers to the sample period 1995:1-2001:4. The reason is that the residuals from estimations for the longer period 1995:1-2002:4 are not normally distributed. ${ }^{40}$

The subsequent discussion of the long-run effects of expansionary and contractionary monetary policy changes is structured as follows. Section 6.4.1 describes the results of the specification which assumes symmetric output growth effects of monetary expansions and contractions. Section 6.4.2 analyzes the empirical results on the sign effects of monetary policy as derived from the zero threshold specification. Section 6.4.3 asks whether possible sign effects of monetary policy also reflect business cycle asymmetries in monetary policy effectiveness. Finally, section 6.4 .4 summarizes the evidence regarding the existence of size effects of monetary policy.

\footnotetext{
${ }^{37}$ Note, panel unit root tests suggest that the annual normalized and non-normalized industry characteristics are usually $\mathrm{I}(0)$.

${ }^{38}$ More than four lags were not included because of the relatively short sample period.

${ }^{39}$ The utilities sector is dropped because openness for this sector is only defined as of 2001.

${ }^{40}$ Although the residuals perform better, they are still occasionally non-normally distributed in estimations for the shorter sample period. As a consequence, the interpretation of the corresponding results requires some caution.
} 


\subsubsection{Empirical Results Assuming Symmetry in Interest Rate Effects}

We start by discussing the evidence from the benchmark model in equation (6.1) which assumes that expansionary and contractionary monetary policy changes have symmetric output growth effects. The long-run coefficients are summarized in Table 6.2 for Germany, Spain, and Italy. For Germany and Spain, the results suggest that changes in the nominal interest rate have a non-neutral effect on industry performance, with industry output growth rising (falling) in response to monetary expansions (contractions). In contrast to Germany and Spain, monetary policy changes have no persistent effect on the output growth performance of industries in Italy.

As regards the distributional effects of monetary policy, the evidence for Italy, Spain, and Germany does not indicate that industries open to trade are less affected by monetary policy changes. The results of the benchmark specification hence do not point to the transmission of monetary policy changes through an exchange rate channel. As to the credit channel variable, we only document a significant effect of operating surplus on the output growth effect of monetary policy for Germany. However inconsistent with the credit channel view, industries with a higher share of operating surplus display a larger rather than smaller output growth response to a monetary contraction. Furthermore, capital-intensive industries do not appear to respond differently to monetary policy changes than capital-extensive sectors in Germany and Spain, while they display a stronger response to monetary policy changes in Italy. The evidence for Italy is consistent with the view that industry output growth of capitalintensive industries is influenced by monetary-policy-induced changes in goods demand. This lends cautious support to the transmission of monetary policy shocks through an interest rate channel.

\subsubsection{Empirical Results Assuming Asymmetric Sign Effects}

Table 6.3 to Table 6.5 report the long-run asymmetric effects of expansionary and contractionary monetary policy shocks from the zero threshold estimation (6.2). In order to facilitate the comparison of the results between model specifications, the tables also contain the evidence from the zero threshold estimation (6.5), which allows for state asymmetries. The present section only discusses the results in the 'no cycle' column. ${ }^{41}$ An investigation of the corresponding entries illustrates the sensitivity of the empirical results to the choice of country. This confirms our prior view that an integrated panel estimation by industry and country dimension may lead to misleading results (cf. Peersman and Smets, 2005). Given the cross-country differences, we separately discuss the results for each country.

For Germany, the evidence lends support to asymmetries in the output growth effects of positive and negative monetary policy shocks. In line with theoretical predictions, a positive

\footnotetext{
${ }^{41}$ Section 6.4 .3 documents the state effects of monetary policy changes.
} 
Table 6.2: FGLS Long-Run Estimates, Benchmark Model

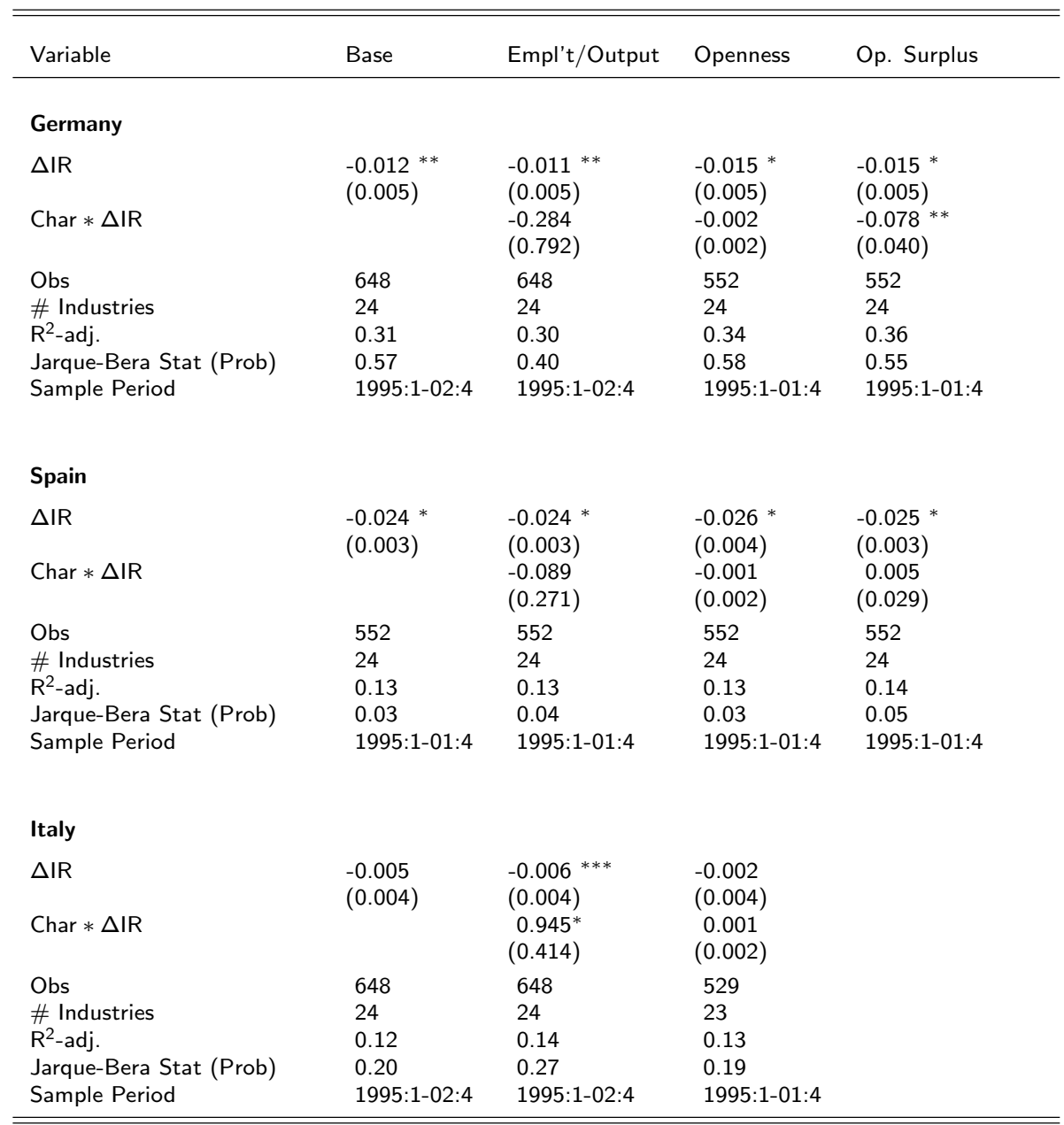

Notes: $\Delta I R$ denotes the change in the nominal short-term interest rate. Char $* \Delta I R$ refers to the interaction term between industry characteristics and the interest rate change. The industry characteristic is either the industry-specific ratio of the number of employees per real value added (in thousand Euros; Empl't/Output), the degree of openness to trade (Openness), or the ratio of operating surplus to value added (Op. Surplus). Because of missing data, no estimates are derived for operating surplus for Italy. The dynamic panel model is estimated with the FGLS estimator. The parentheses contain White diagonal standard errors. ${ }^{*},{ }^{* *},{ }^{* *}$ denote the statistical significance at the one, five, and ten percent level, respectively. 
interest rate shock (i.e., monetary contraction) has a significant and negative effect on industry output growth, while a negative interest rate shock (i.e., monetary expansion) has no significant output growth effect. This suggests that expansionary monetary policy shocks are impotent, a finding which coheres well with the country evidence reported by, among others, Cover (1992), Karras (1996a, 1996b), Karras and Stokes (1999), and Ravn and Sola (2004). Furthermore, given that monetary neutrality requires monetary expansions to be associated with an increase in prices, the finding supports the view that prices are more flexible upwards.

The results for Spain slightly differ from those for Germany. We find industry output growth to respond to expansionary as well as to contractionary monetary policy changes. Confirming expectations, higher (lower) interest rates have a negative (positive) effect on industry output growth. Here, the output growth effects appear to be symmetric. That is, monetary contractions do not have a stronger industry output growth effect than monetary expansions. ${ }^{42}$ In view of this finding, monetary expansions appear to be a useful instrument to stimulate economic activity in Spain given that the positive output effects of monetary policy are not completely offset by a consequent increase in prices. ${ }^{43}$

The empirical findings for Italy conflict with those obtained for Germany and Spain. Industry output growth predominantly responds to monetary expansions, but not to contractions. ${ }^{44}$ Furthermore, when monetary contractions affect industry output growth, it increases. The evidence in favor of a persistent positive output growth effect of a contractionary monetary policy shock is counterintuitive and does not compare well with the existing evidence on the asymmetry of monetary policy effects. This puzzling result does not seem to be driven by any particular industry given that the results do not fundamentally differ between estimations which exclude one or more industries.

Turning to the distributional effects of monetary policy, the results lend weak support to the role of structural industry characteristics as factors which amplify the real industry effects of monetary expansions and contractions. As concerns capital intensity, we have argued that the interaction term between capital intensity and the interest rate change will be positive (negative) for monetary expansions and contractions when demand-side (supply-side) effects dominate the output growth response of capital-intensive industries. For Spain, none of these relationships seems to influence monetary policy transmission given the statistical insignificance of the capital-intensity effects. The evidence for Spain therefore does not point to the transmission of monetary policy changes through interest rate effects.

\footnotetext{
${ }^{42}$ The results of the underlying equality tests are available on request.

${ }^{43}$ See Karras and Stokes (1999) for evidence according to which monetary expansions influence output even more than monetary contractions.

${ }^{44}$ In a cross-country study on the asymmetric effects of money supply shocks, Karras and Stokes (1999) also find output growth to be more responsive to positive than to negative money supply shocks in the case of Italy.
} 


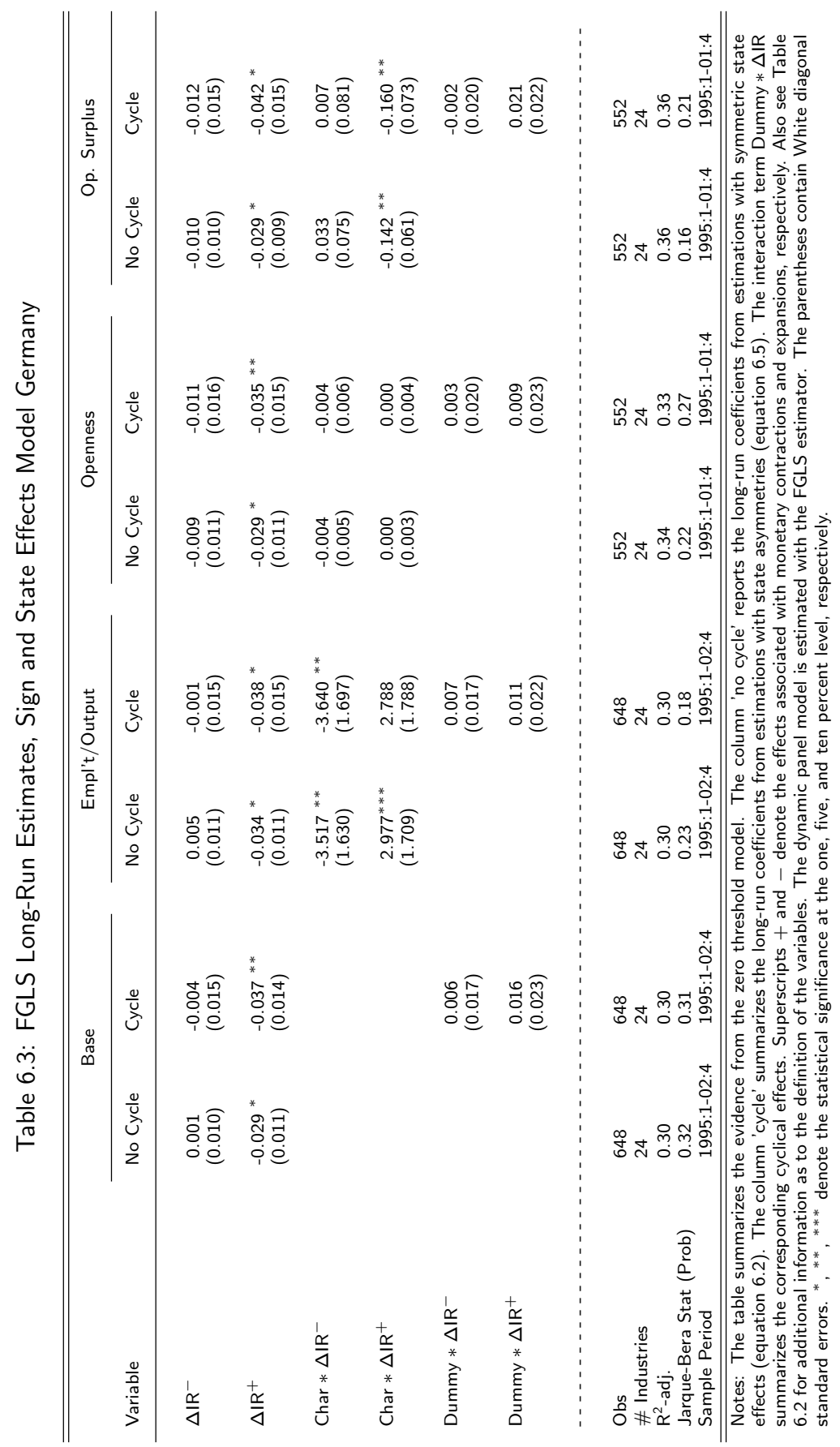




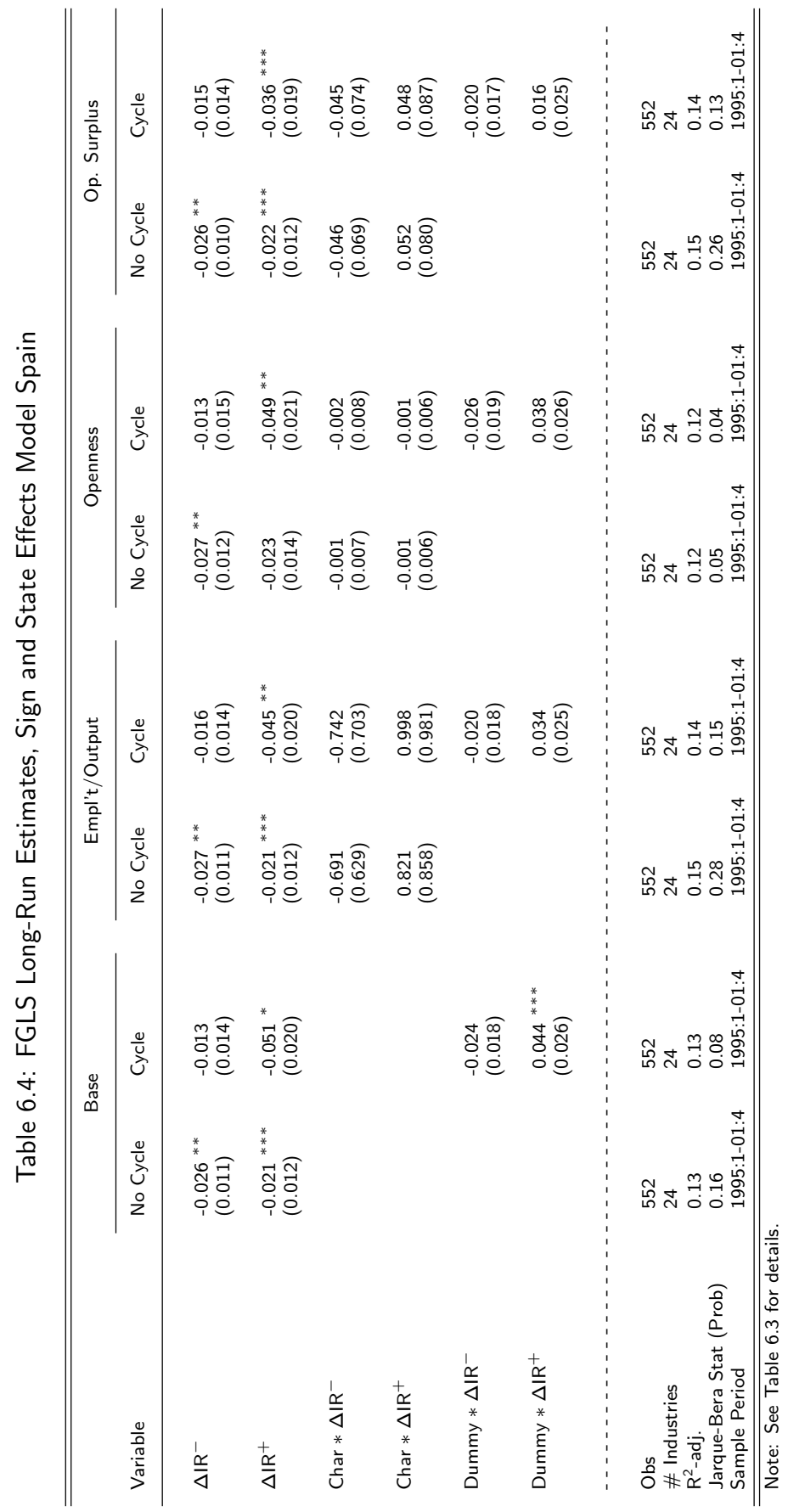




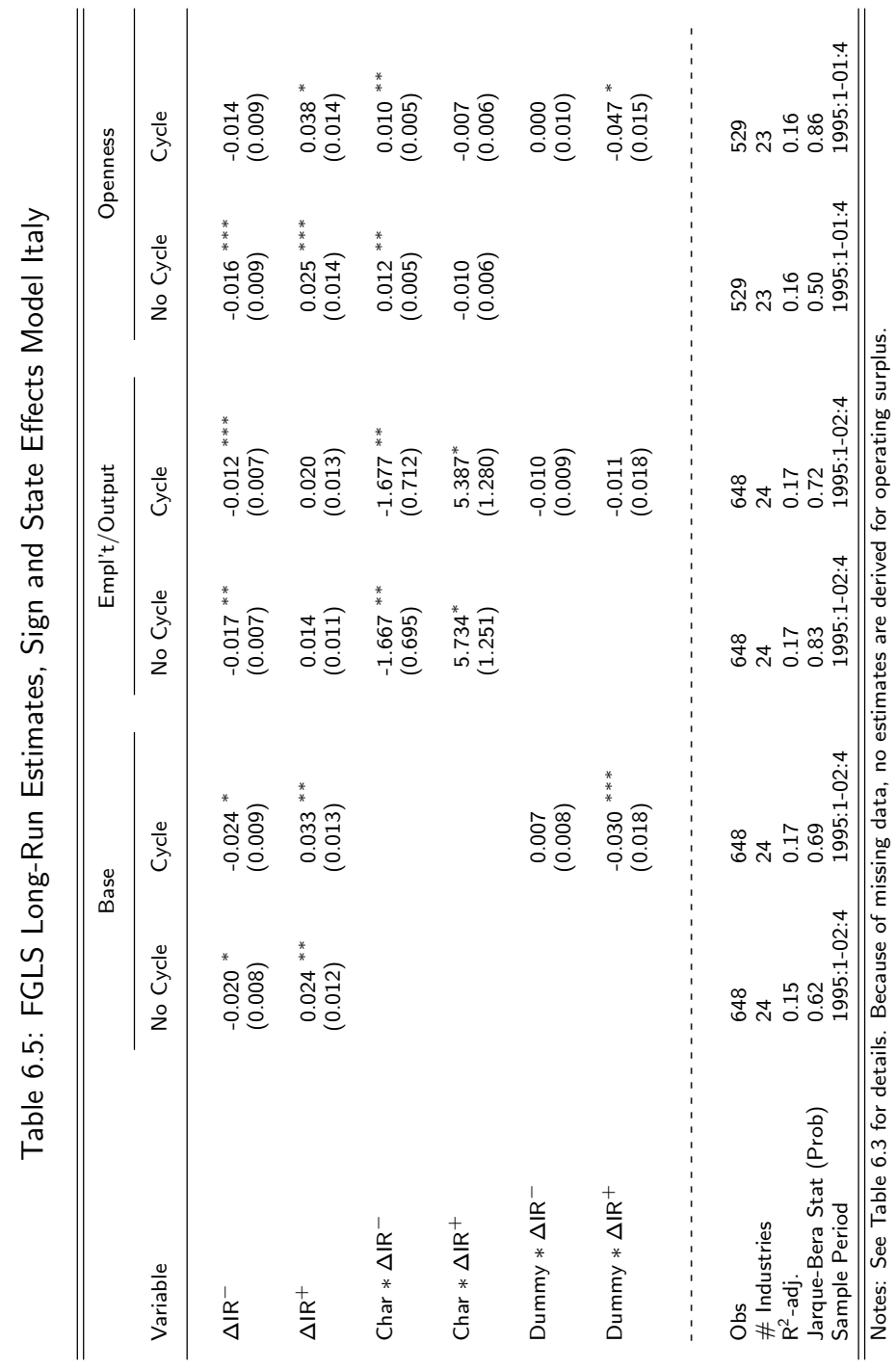


For Germany and Italy, monetary policy asymmetries prevail in terms of the direction as well as strength of the capital-intensity effect. Supply-side effects are the stronger source of crossindustry heterogeneities in the output growth effects of expansionary monetary policy changes given that the output growth effect of lower interest rates tends to be less pronounced for capital-intensive industries. For a monetary contraction, however, demand-side effects appear to be more important in view of the fact that an increase in interest rates causes industry output growth of capital-intensive industries to display a significantly larger long-run response. These relationships for a monetary expansion and contraction suggest that prices are more flexible upwards than downwards for capital-intensive industries in Germany and Italy.

Considering the proxy variable of the exchange rate channel, the evidence lends weak support to the assumption that the output growth effects of monetary contractions and expansions are less pronounced for open industries. If at all, significant effects are confined to monetary expansions for Italy. Consistent with expectations, output growth of industries open to trade is less responsive to monetary policy changes. This observation is interesting from a political point of view. As put forward in chapter 1, Berlusconi holds the European Central Bank's restrictive monetary policy stance responsible for the poor economic performance of Italy. $\mathrm{He}$ argues that a monetary expansion is needed to induce the depreciation of the Euro in order to restore the international competitiveness of Italian producers and hence output. The empirical results in this section show that an expansionary monetary policy stance is less effective in stimulating output of industries open to trade than thought. This also suggests that a persistent improvement in international competitiveness requires structural reforms.

As emphasized in section 6.3.3, the results on the credit channel effects of monetary expansions and contractions can only be indicative but not conclusive given that the ratio of operating surplus is an imperfect measure of credit market imperfections and credit constraints. For Germany, industries with a higher share of operating surplus display a larger output growth response to a contractionary monetary policy change. This result is unexpected as it suggests that credit constraints prevail for industries with high rather than low net worth. For Spain, industries with a higher ratio of operating surplus do not display a monetary policy response which differs from that of industries with a lower ratio.

Summarizing, the evidence lends weak support to the transmission of expansionary and contractionary monetary policy changes through an interest rate, exchange rate, or credit channel. More research with higher frequency data is required to establish the robustness of this result. Besides this shortcoming, it is evident that the distinction between expansionary and contractionary monetary policy changes allows for more detailed assessments of the real effects of monetary policy compared with estimations for the total effect of monetary policy. Indeed, the evidence suggests that the output effects of monetary policy in the benchmark estimation without asymmetry (cf. Table 6.2) primarily reflect the effects associated with monetary contractions for Germany and monetary contractions and expansions for Spain. For Italy, the insignificance of the monetary policy response of output in the benchmark model 
is due to the unexpected positive response of output to monetary contractions.

\subsubsection{Empirical Results Assuming Asymmetric State Effects}

The theoretical literature argues that monetary policy effectiveness depends on the business cycle, with monetary policy changes being more effective during economic downturns. In order to report evidence in favor of cyclical asymmetries, the interaction term between the cyclical dummy and the monetary policy change is required to be significant and negative in estimations of model (6.5). The 'cycle' columns in Table 6.3 to Table 6.5 (cf. section 6.4.2) summarize the long-term coefficient estimates for Germany, Spain, and Italy, respectively. To ease the comparison of the empirical findings, the tables also replicate the results of the estimations without the business cycle dummy.

In general, the evidence lends at best weak support to cyclical asymmetries in monetary policy effectiveness regardless of the choice of country. ${ }^{45}$ Industries in Germany do not react differently to a monetary policy change in periods of economic downturns. For Spain, the industry output growth effects of contractionary monetary policy changes vary over the business cycle. However, they appear to be less pronounced during economic downturns. This result is counterintuitive and cannot be explained. In addition, when state effects are allowed, the output growth effects of monetary expansions and contractions are no longer symmetric. Contractionary monetary policy changes have stronger industry output growth effects than expansionary monetary policy changes. ${ }^{46}$ In contrast to Spain, the results for Italy lend cautious support to the view that monetary contractions during recessions reduce output growth. Despite this finding, industry output growth still expands in response to contractionary monetary policy changes.

\subsubsection{Empirical Results Assuming Asymmetric Size Effects}

Table 6.6 to Table 6.8 summarize the empirical evidence from estimations which control for possible size effects of monetary policy. Again, to enhance the comparability of the results between the zero and non-zero model, the tables contain the results of both specifications. The models used to test for size effects differ from the earlier specifications in that they include a 'midrange' of interest rate changes $\left(\Delta r_{M}^{ \pm}\right)$. The midrange is constrained by a lower (i.e., $-\mu$ ) and upper (i.e., $\mu$ ) non-zero threshold of interest rate changes beyond which monetary policy changes are deemed to be large (see Figure 6.1). Empirically, the highest non-zero threshold equals the maximum change in the interest rate for which the model can still be estimated. In the present study, the largest non-zero threshold of the nominal interest

\footnotetext{
${ }^{45} \mathrm{We}$ also allow for cyclical asymmetries in the benchmark specification (6.1). The evidence does not point to cyclical effects of monetary policy. Furthermore, conclusions regarding the sign and size of (symmetric) monetary policy effects do not change. The results are not reported, but are available on request.

${ }^{46}$ The corresponding test statistics are available on request.
} 
rate amounts to 0.29 percent for Germany, 0.71 percent for Spain, and 0.69 percent for Italy. Because of singularity problems, the highest threshold in the empirical estimations is lower than the actual maximum change in the interest rate.

Interpreting the evidence, the non-zero threshold specification shows that output growth of industries displays a significant response to interest rate changes in the midrange. For Germany, Italy, and Spain, the evidence suggests that industry output growth is positively (negatively) affected by monetary expansions (contractions) in the midrange. The output growth effects associated with small monetary policy changes are thus consistent with the menu cost argument. However inconsistent with the menu cost argument, the evidence does not suggest that large positive and negative monetary policy shocks (i.e., shocks that are absolutely larger than the non-zero threshold $\mu$ and $-\mu$ ) are neutral. Regardless of the country, the output growth effects of large monetary expansions and contractions compare well in terms of sign and magnitude with the evidence on the sign effects of monetary contractions and expansions from the zero threshold model. In fact, the equality tests of the coefficient estimates generally do not point to statistically significant differences in the coefficients of the zero and non-zero threshold specification. ${ }^{47}$

For Germany, monetary contractions that are larger than the non-zero threshold $\mu$ (area $\mathrm{A}$ in Figure 6.1) have significant industry output growth effects. Confirming the results of the zero threshold estimation, output growth contracts in response to a monetary contraction. Unlike the zero threshold estimation, the non-zero threshold results for Spain point to asymmetries in the effects of positive and negative nominal interest rate changes. In particular, monetary contractions which are larger than the threshold $\mu$ (area A in Figure 6.1) have a significantly stronger effect on industry output growth than monetary expansions which are larger than the non-zero threshold $-\mu$ (area B in Figure 6.1). The effects associated with the midrange thus appear to amplify the output growth effects of large monetary contractions, while they reduce the output growth effects associated with large monetary expansions. This finding is inconsistent with the menu cost argument. One possible explanation is that prices do not move sufficiently to fully absorb the demand effects of large monetary contractions and expansions. ${ }^{48}$ For Italy, large monetary contractions and expansions do not have a neutral effect on industry output growth. Similar to the zero threshold specification, the results of the non-zero specification suggest that large monetary expansions $\left(\Delta r_{M}^{-}\right)$as well as contractions $\left(\Delta r_{M}^{+}\right)$stimulate output growth.

\footnotetext{
${ }^{47}$ The results of the mean equality tests are available on request.

${ }^{48}$ In addition, the evidence for Spain suggests that the four-quarter horizon is too short to capture the dynamics of the monetary transmission process. Longer time-series are required to investigate whether monetary policy neutrality eventually holds.
} 


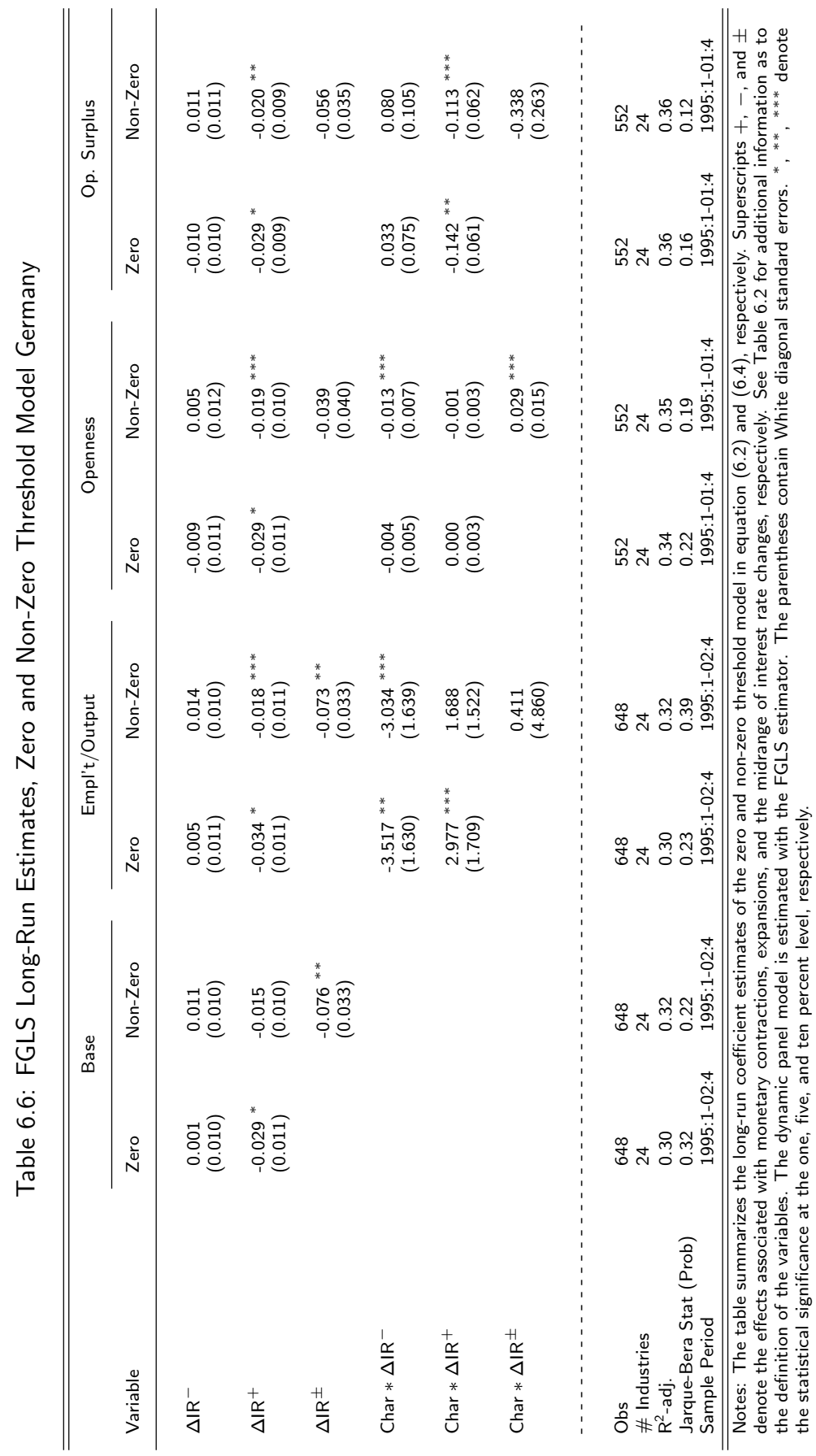




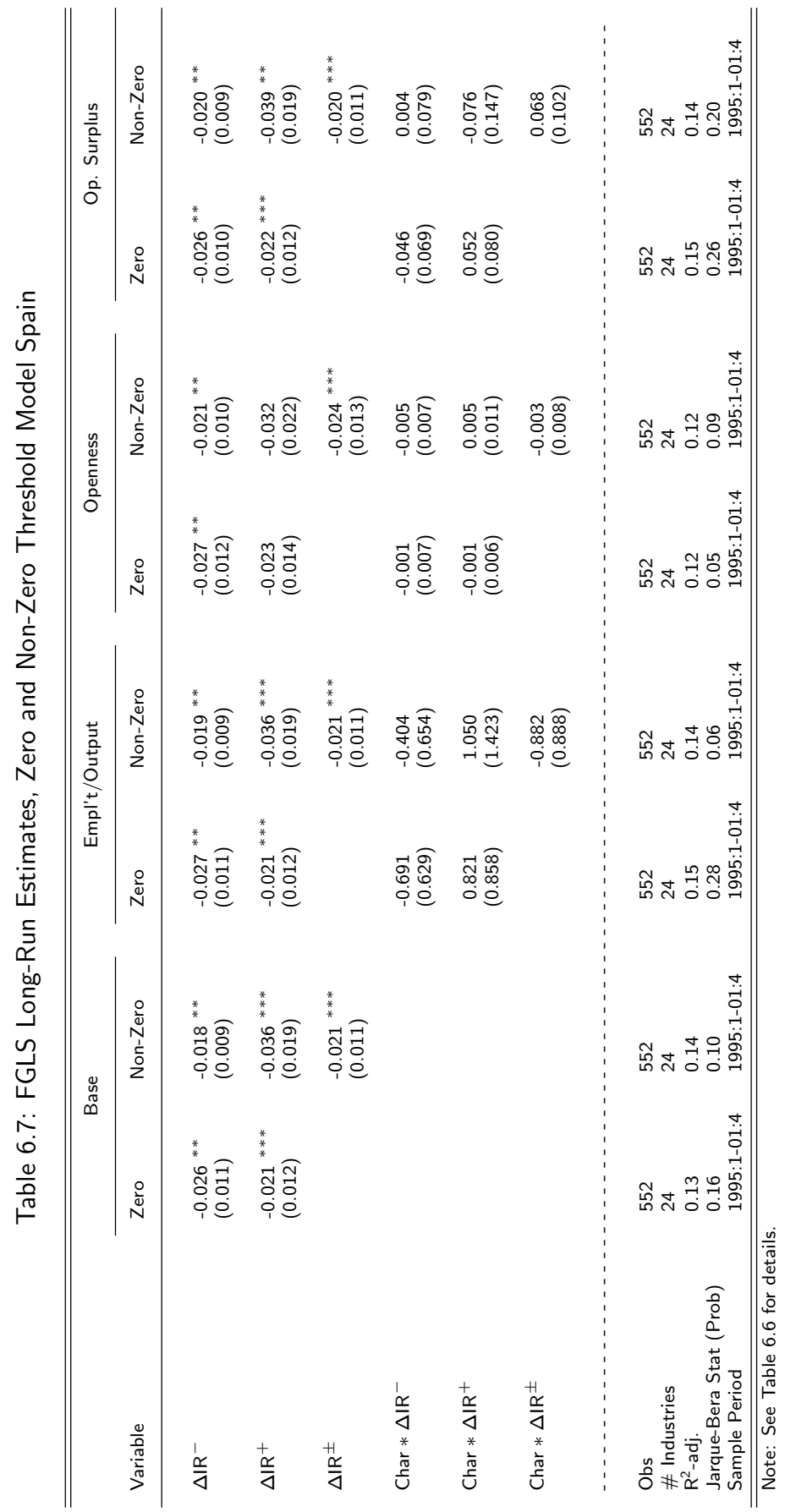




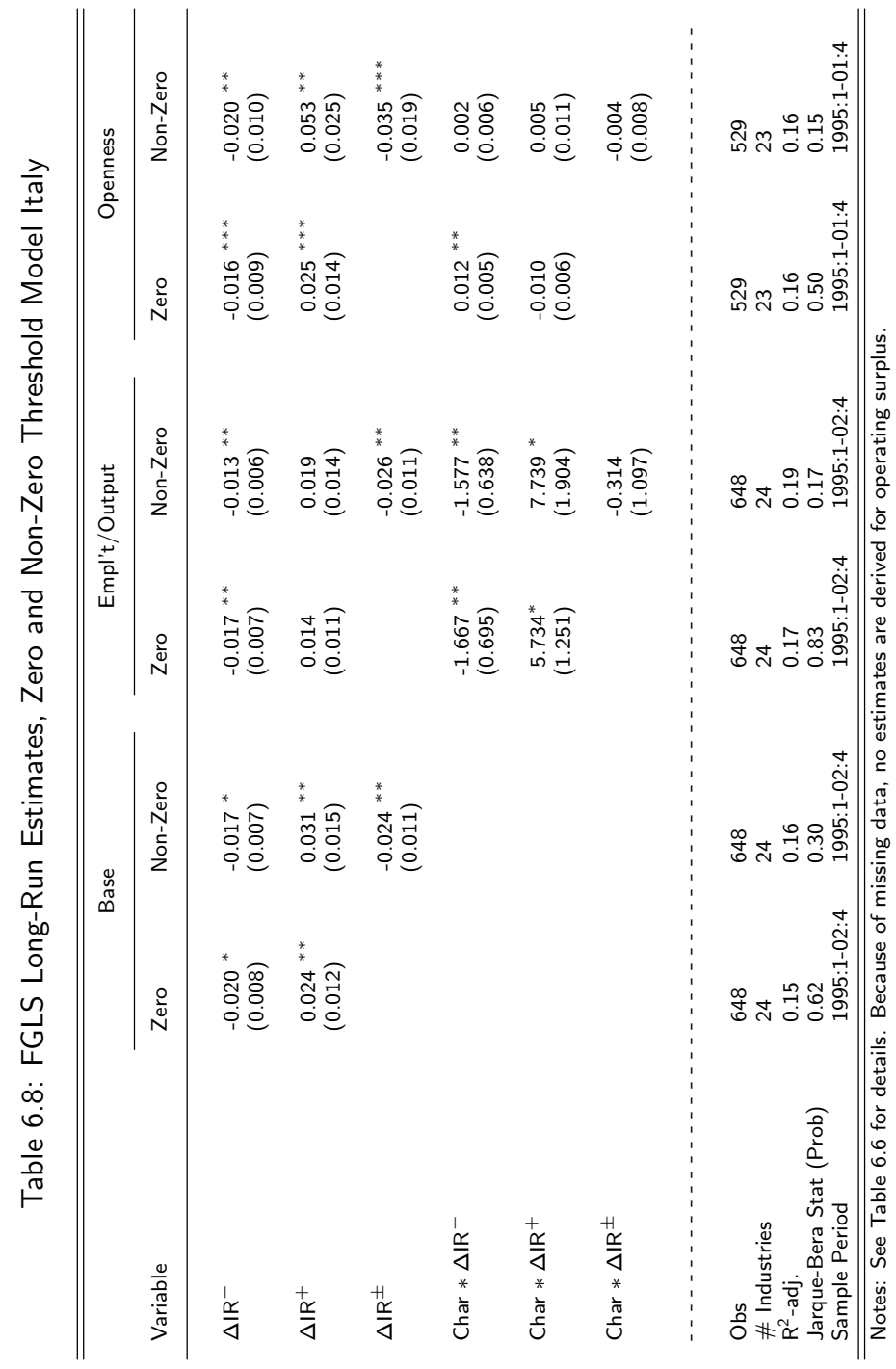


As regards the distributional effects of monetary policy, the evidence does not lend support to the role of structural industry characteristics as factors which influence the real industry effects of small monetary expansions and contractions. Conclusions as to the distributional effects of large positive and negative interest rate changes are similar to those from the zero threshold model. The observed nature of the relationships associated with capital intensity, openness, and operating surplus does not change.

Overall, the evidence lends no support to the existence of size effects. In contrast to the menu cost argument, large monetary contractions and expansions have non-neutral industry output growth effects. As stated, these results are indicative and likely to be influenced by the structure of the empirical model and by the threshold $\mu$ and $-\mu$ beyond which monetary contractions and expansions are considered to be large. Limited by the number of cross sections, the present analysis defines a threshold which is probably too low and a midrange which is therefore too narrow to appropriately capture the predictions of the menu cost argument. Stated differently, our definition of large and small monetary policy changes is likely to be inappropriate.

\subsection{Conclusion}

This chapter has contributed to the ongoing debate about possible asymmetries in the output growth effects of expansionary and contractionary monetary policy changes. Its main contribution to the existing literature is that it presents industry rather than macroeconomic evidence of the sign, size, and state effects of monetary policy. In particular, the analysis employs information on 24 industries in either Germany, Italy, or Spain to investigate whether monetary contractions and expansions affect industry output growth (i) to the same extent (sign effects), (ii) to the same extent during economic booms and downturns (state effects), and (iii) to the same extent for different magnitudes of the monetary policy change (size effects). We have examined whether structural industry characteristics explain cross-industry differences in the asymmetric effects of monetary expansions and contractions.

The evidence in this chapter is sensitive to the choice of country. For example, the long-run output growth effects of monetary expansions are insignificant for industries in Germany, whereas they are significant and positive for industries in Spain and Italy. Considering the long-run effects of monetary contractions, output growth of industries in Germany and Spain contracts. For Italy, however, contractionary monetary policy changes promote industry growth. As to the state effects, the conclusions tend to be robust to the choice of country. The main insight is that business cycle effects hardly contribute to asymmetries in the industry output growth effects of positive and negative monetary policy shocks. Similarly, the evidence does not point to size effects of monetary policy in estimations for Germany, Spain, and Italy. We argue that this result is likely to be driven by the small number of cross sections which influences the structure of the empirical model and the definition of small and large shocks. 
The present evidence lends weak support to the existence of cross-industry differences in the degree of monetary policy asymmetry. Significant industry effects are largely confined to estimations with industry-specific capital intensity. For Germany and Italy, the distributional effects are such that industry output growth of capital-intensive industries responds less to monetary policy expansions, but more to monetary contractions. This finding lends cautious support to the view that the asymmetric effects of monetary policy are influenced by industry composition. Insignificant capital intensity effects prevail for Spain. Although the evidence lends at best weak support to the role of industry composition as determinant of monetary policy efficacy, this finding should not be overemphasized. Because our panel is biased towards manufacturing industries, the cross-industry variation might be too low in order to generate significant industry effects of monetary policy in the present set of panel estimations.

Despite this limitation, the results of the present study have policy implications. The sensitivity of the results to the choice of country casts doubt on the ability of the European Central Bank to define a common monetary policy stance that accommodates the economic needs of all countries equally well. Instead, a common monetary contraction or expansion is expected to cause cross-country asymmetries in the macroeconomic output response. The differences are hereby likely to be amplified by the industry composition of countries through interest rate effects. In addition, the present study has also repercussions for future empirical work. The empirical evidence illustrates that conclusions as to the sign effects of monetary policy depend on the choice of country. Discussions of the asymmetric effects of monetary policy changes should hence account for the heterogeneity of countries. In fact, industry analyses should not consider a country panel dimension as done by, for example, Peersman and Smets (2005). 


\section{Annex 6A List of Industries}

This annex lists the industries that are included in the analysis for Germany, Italy, and Spain. The corresponding New Cronos classification code is put in brackets.

- Mining and quarrying of energy producing materials

- Mining and quarrying except energy producing materials

- Food products and beverages

- Tobacco products

- Textiles

- Wearing apparel, dressing, and dyeing of fur

- Leather, leather products, and footwear

- Wood and products of wood and cork

- Paper and paper products

- Publishing, printing and reproduction of recorded media

- Coke, refined petroleum products, and nuclear fuel

- Chemicals and chemical products

- Rubber and plastics products

- Other non-metallic mineral products

- Basic metals

- Fabricated metal products, except machinery and equipment

- Machinery and equipment, n.e.c.

- Office, accounting and computing machinery

- Electrical machinery and apparatus, n.e.c.

- Radio, television, and communication equipment

- Medical, precision and optical instruments, watches and clocks

- Motor vehicles, trailers, and semi-trailers

- Other transport equipment

- Manufacturing n.e.c.

- Electricity, gas, and water supply 



\section{7 \\ The Importance of Industry Effects - Concluding Thoughts}

\subsection{Synthesis}

There is an ongoing debate on the role of industries as propagation and amplification mechanism of monetary policy changes. The interest in industry effects reflects the view that industry characteristics are more appropriate means to identify monetary transmission channels so as to explain and understand the macroeconomic real effects of monetary policy actions. Chapter 2 illustrates that considerable empirical research discusses industry composition as determinant of the interest rate channel of monetary policy transmission, but largely disregards its importance as source of the credit channel. This thesis contributes to the debate on the role of industries as determinant of monetary policy effectiveness by qualifying and quantifying the industry effects associated with the interest rate as well as credit channel. To this end, two main questions are addressed. Firstly, do industries differ in their economic response to monetary policy disturbances? Secondly, are cross-industry differences in the monetary policy response associated with cross-industry differences in the relative strength of the interest rate and credit channel of monetary policy transmission and can possible differences be explained with cross-industry differences in structural characteristics?

The empirical analyses in this thesis yield two insights. The first result pertains to the observation that industries differ in their real response to monetary policy shocks. As a consequence, monetary policy effects at the macroeconomic level are conditioned by industry composition and regional heterogeneities in the relative importance of industries contribute to regional asymmetries in the real effects of monetary policy shocks. The second insight is that industries transmit monetary policy changes through an interest rate channel. Credit channel effects are comparatively weak. Cross-industry asymmetries in the interest rate and credit channel effects of monetary policy reflect differences in industry capital intensity or in the monetary policy response of industry-specific bank lending. The remainder of this section summarizes the results of this thesis in greater detail.

Chapter 2 reviews the existing theoretical and empirical literature on the interest rate and credit channel of monetary policy transmission. The survey shows that both the interest rate 
and credit channel have received considerable theoretical as well as empirical attention. The underlying studies emphasize different factors to explain the real effects of monetary policy and differ in the importance assigned to industries as possible determinants of monetary policy effectiveness. While interest rate channel studies discuss the importance of industry structures, credit channel studies predominantly emphasize financial structures. The review points to the sensitivity of the results to the level of data aggregation, data frequency, and the choice of estimation methodology.

The empirical evidence in chapter 2 shows that many credit channel studies employ firm size as proxy variable of credit market imperfections. Empirical support to the existence of firm size effects of monetary policy is hereby ambiguous. This, however, suggests that firm size effects are not exclusively driven by information asymmetries and credit constraints. Chapter 3 is motivated by this finding and offers an alternative theoretical explanation for the ambiguity regarding the firm size effects of monetary policy. It develops a non-linear investment model that emphasizes differences in the investment behavior of small and large firms as an alternative channel through which firm size may transmit monetary policy changes. At the core of the proposed 'investment' channel are size-related differences in the costs associated with physical capital (dis-)investment. The capital adjustment costs are defined as the combination of a purchase (sale) cost per unit of capital (dis-)investment and a fixed adjustment cost per unit of installed capital. Both cost components influence investment through their effect on the degree of investment irreversibility.

Within the framework of the dynamic investment model, the theoretical analysis shows that asymmetries in the optimal investment behavior of small- and large-sized firms are predominantly determined by size-related differences in the fixed adjustment cost per unit of installed capital. Reflecting the effect of organizational and informational inefficiencies, the fixed adjustment cost per unit of installed capital causes large firms to change investment regimes less frequently than small firms. However, when large firms change investment, the investment response is more pronounced compared with small firms. The effect is amplified by, but does not depend on, size-related differences in the type of capital employed in production.

These investment patterns have important implications for the effectiveness of monetary policy. In fact, they suggest that small and large monetary policy shocks have asymmetric effects on large- and small-firm investment, with the effects being predominantly driven by the fixed adjustment cost per unit of installed capital. For a small monetary policy shock, small-firm investment adjusts, while large-firm investment does not respond. For a large monetary policy shock, small- and large-firm investment changes. Because of larger fixed capital adjustment costs per unit of installed capital, the effect is more pronounced for large firms. Conclusions as to the existence of small firm size effects of monetary policy thus crucially depend on the magnitude of the monetary policy change. In attributing differences in the monetary policy response of small- and large-firm investment to size-related differences in capital adjustment costs, the investment channel differs from the credit channel and the 
underlying assumption of credit market imperfections.

The review in chapter 2 shows that empirical analyses on monetary policy transmission are complicated by methodological problems which arise from the interdependence of (i) industry and industry characteristics related to the interest rate and credit channel and (ii) monetary transmission channels. Chapter 4 in this thesis illustrates the significance of the first problem and chapter 5 addresses the identification problem associated with the interdependence of monetary transmission channels. Chapter 4 investigates the possible interdependence between industry structure and proxy variables of the interest rate and credit channel for the United States. The analysis employs US state level data on manufacturing and non-manufacturing industries to present new evidence on the transmission of US interest rate shocks, using a two-step estimation procedure. In the first step, the analysis determines the monetary policy sensitivity of industry earnings over the period 1958-2000/01. The identification of the industry effects is accomplished by using a vector autoregressive model. In line with existing empirical work, the corresponding evidence points to differences in the monetary policy sensitivity of industries and hence to the importance of industries as determinant of monetary policy effectiveness. Regional heterogeneities in the effects of monetary policy originate from cross-region dissimilarities in the mix of industries and consequently from differences in regional economic structures.

Building on these results, the second part of the study asks whether the industry characteristics firm size (the credit channel proxy variable) and capital intensity (the interest rate channel proxy variable) can explain the cross-industry differences in the real effects of monetary policy. The empirical analysis for the United States demonstrates that the interdependence between industry and either capital intensity or firm size affects conclusions regarding the interest rate and credit channel effects of monetary policy. A strong effect prevails for the mining industry. Including a dummy variable for the mining sector significantly reduces the explanatory power of firm size but brings to the fore the effect of capital intensity. The annex to chapter 4 reports a comparable industry study for countries in Europe. In contrast to the US evidence, the European results suggest that industry effects amplify rather than reduce the firm size effects of monetary policy. However, this result is far from conclusive because of severe data shortcomings. Overall, the evidence in chapter 4 suggests that firm size effects of monetary policy are not only attributable to credit market imperfections. This finding compares well with the theoretical analysis in chapter 3 according to which size-related differences in the degree of investment irreversibility may also matter.

Chapter 5 is motivated by the problem associated with the identification of shifts in bank lending that are due to changes in either bank credit demand or due to monetary-policyinduced changes in bank credit supply. The study adopts an industry focus and asks whether changes in industry bank credit demand or in monetary policy are the more important source of variation in industry-specific bank lending growth. An investigation of the industry effects of bank lending is important because it illustrates whether the industry structure of bank credit 
portfolios determines monetary policy effectiveness. The empirical evidence is derived from microeconomic data on bank balance sheet variables and industry bank lending for Germany and involves the estimation of individual bank lending functions for 17 manufacturing and non-manufacturing industries over the period 1992:1-2002:4. We explicitly distinguish lending by five banking groups so as to capture the bank lending effects associated with cross-banking group differences in the industry composition of bank credit portfolios.

The evidence from dynamic panel data models shows that industry-specific bank lending growth predominantly responds to changes in industry-specific bank credit demand rather than to changes in monetary policy. In fact, conclusions regarding the bank lending effects of monetary policy are very sensitive to the choice of industry. The empirical results lend strong support to the existence of industry effects of bank lending: industries are a prominent source of variation in the bank lending effects of bank credit demand and monetary policy, with strong effects arising from industry output growth and industry inflation. In view of this finding, chapter 5 concludes that the industry composition of bank credit portfolios is an important determinant of bank lending growth and monetary policy effectiveness.

Common to chapter 4 and 5 is the assumption that monetary expansions and contractions have symmetric real effects on industry performance. Chapter 6 tests for possible asymmetries. In particular, the analysis determines whether the industry output growth effects of monetary expansions and contractions differ and whether the degree of asymmetry varies over the business cycle or depends on the size of monetary policy changes. In order to identify possible industry effects, tests for the sign, state, and size effects of monetary policy emphasize cross-industry differences in structural characteristics related to the interest rate, credit, and exchange rate channel. Estimates are derived from dynamic panel models which employ information on the output growth performance of 24 industries in Germany, Italy, and Spain over the period 1995:1-2002:4. In order to control for cross-country heterogeneities, the models are separately estimated for each country.

Consistent with theoretical predictions, the empirical evidence points to asymmetries in the industry output growth effects of monetary expansions and contractions. Conclusions as to the direction and strength of the sign effects are sensitive to the choice of country. For each country, the asymmetric effects tend to be robust to the business cycle position of industries. That is, economic downturns do not amplify the effects of contractionary or expansionary monetary policy changes. Similarly, the evidence does not point to significant size effects of monetary policy in estimations for Germany, Spain, and Italy. We argued that this result is likely to be driven by the small number of cross sections which influences the structure of the empirical model and the definition of small and large monetary policy changes. In addition, there is at best weak evidence that the sign effects of monetary contractions and expansions are influenced by industry effects. Because the industry effects are primarily attributable to cross-industry differences in capital intensity, the evidence lends cautious support to the operation of an interest rate channel. The ambiguity of the results is attributed to data 
limitations.

Overall, this thesis points to the importance of industries as determinant of monetary policy effectiveness through an interest rate channel (chapter 4, 6). Similar to existing studies, there are cross-industry differences in the interest rate effects, which reflect differences in the degree of capital intensity of production. Endorsing theoretical predictions, the interest rate effects are more pronounced for capital-intensive sectors. This thesis also stresses the importance of industries as determinant of the credit channel effects of monetary policy. For the present set of country studies, the evidence in favor of credit channel effects is at best weak (chapter 4, 5, 6) and largely confined to bank lending rather than to balance sheet effects. In a study for Germany, the strength of the bank lending effects differs between industries (chapter 5). This, however, points to the importance of the industry composition of bank credit portfolios as determinant of monetary policy effectiveness.

\subsection{Caveats and Avenues for Future Research}

Although the evidence points to the role of industries as determinant of monetary policy effectiveness through interest rate and credit channel effects, the empirical results are subject to a number of caveats. Given the political relevance for the current but also prospective future EMU member countries, one major limitation certainly concerns the failure to qualify and quantify the industry effects of monetary policy transmission for a comprehensive set of European countries in general and European regions in particular. Investigations for Europe should employ industry data at the region rather than country level. As became evident from the analysis for Europe in annex 4B, country-specific industry data display too little variation between countries in order to allow for discernible country effects. This problem is not expected to prevail with regional data. Furthermore, regional data are deemed to be better suited to identify the possible effects of industry specialization on monetary policy effectiveness. This is because specialization patterns are likely to materialize faster in regions than in countries given that regions have a more condensed industry structure than countries.

A second caveat applies to the discussion of the 'investment' channel in chapter 3 and the simplifying assumption of perfect capital markets. Credit market imperfections certainly prevail, with important implications for the availability of external financial funds. The present study does not impose financial constraints since this would require a priori assumptions as to the relative riskiness of firms in either the market center or market periphery. Furthermore, the consequent analysis would implicitly assume that firms within each market segment do not differ in terms of risk. This would be as simplifying an assumption as the assumed absence of financial constraints for small and large firms. Future research on these issues might be able to offer appropriate solutions to these problems.

The analysis in chapter 4 is subject to two main limitations. As we discussed in the chapter, 
one limitation relates to the identification scheme of the monetary policy shocks. A second weakness concerns the interpretation of the results from the cross-section estimations. To illustrate, the cross-section models explain the cumulative impulse response estimates from vector autoregressive models with firm size and capital intensity. In order to determine the statistical significance of the firm size and capital intensity variable, heteroscedasticityadjusted standard errors are computed. The limitation of the study concerns the fact that the significance properties of the firm size and capital intensity variable are likely to be overstated given that the dependent cumulative impulse response estimates are also estimated. ${ }^{1}$ We acknowledge this caveat, but do not expect this limitation to affect the study's main conclusions. This is because the cross-section analysis predominantly compares the results from cross-section estimations whose structure only differs with respect to a single industry dummy. Nevertheless, the weaknesses of the time-series and cross-section analysis are such that future research is required to establish the robustness of the results to the use of alternative estimation methodologies. One avenue of research involves the use of a standard panel data approach along the lines suggested in chapter 6 . Because a panel data model is estimated in one step, it may solve some of the problems inherent to the two-step procedure of time-series and cross-section analysis.

Chapter 5 discusses the industry effects of bank lending in Germany. To this end, it is asked whether bank lending to single industries depends on industry-specific bank credit demand or on monetary policy. The analysis' main limitation is evident from the way the question is phrased. Inherent to the answer is the simplifying assumption that monetary policy does not immediately affect bank credit demand, but only bank credit supply. Of course, bank credit demand is likely to respond to monetary policy changes because of, for example, balance sheet effects. Unfortunately, we can only acknowledge, but not address this shortcoming. However, the assumption regarding the contemporaneous monetary policy insensitivity of bank credit demand appears plausible if potential debtors prefer internal finance to external bank- and non-bank finance. If potential debtors first deplete their internal sources of finance because they are less expensive compared with external finance, monetary policy may indeed only affect bank credit demand with a lag. In contrast, banks are expected to be swift in adjusting lending patterns in response to changes (i) in the creditworthiness of debtors and (ii) in the probability of non-performing loans. ${ }^{2}$

Another caveat of chapter 5 concerns the failure to explain cross-industry differences in the strength of bank lending effects. The discussion merely states that industry-specific bank lending differs in the response to monetary policy changes, but does not ask whether the cross-industry differences in the evidence on bank lending effects can be explained with, for example, industry characteristics. While information on industry characteristics is available,

\footnotetext{
${ }^{1}$ This caveat was suggested by a referee of the corresponding paper.

${ }^{2}$ The speed of adjustment concerns quantity as well as price adjustments, with the ultimate effect being determined by the degree of banking sector competition.
} 
the number of industry cross sections ${ }^{3}$ is far too low in order to establish a meaningful, let alone significant relationship between industry characteristics (e.g., capital intensity or firm size distribution) and the bank lending effects of industry bank credit demand.

Future research may deal with some of these caveats. Alternative avenues for research involve the following extensions of the present study. The theoretical analysis of the 'investment' channel in chapter 3 clearly asks for empirical assessments. If investment irreversibility indeed affects the monetary policy sensitivity of small- and large-sized firms, firm size distribution will determine monetary policy efficacy beyond what is suggested by credit market imperfections. Furthermore, market consolidation through mergers and acquisitions and the consequent potential increase in the average size of firms will have important repercussions for monetary policy effectiveness. While small monetary policy shocks may not significantly affect investment and hence real output, large monetary policy shocks may cause very pronounced adverse responses. Unfortunately, a corresponding analysis is likely to be complicated by the unavailability of (high-frequency) firm-level data on the capital stock and capital adjustment costs.

The analysis of the industry bank lending effects in chapter 5 is purely econometric. An interesting avenue for future research involves the development of a theoretical model that describes the bank lending effects of changes in industry-specific bank credit demand and monetary policy. The empirical results in chapter 5 suggest that such a model would have to define the credit supply decision of banks at the industry level conditional on (i) the bank financing needs of an industry, (ii) the importance of an industry in a bank's credit portfolio, (iii) the bank's perception as to the riskiness of an industry, and (iv) the market's perception as to the riskiness of a bank. Unfortunately, such a model is unlikely to have a tractable closed-form solution.

Furthermore, the studies in the previous chapters assume that the performance of industries depends on the level of the interest rate, but not on the degree of interest rate uncertainty. However, Ingersoll and Ross (1992), Dixit and Pindyck (1994), and Alvarez and Koskela (2006), among others, show that investment uncertainty influences the timing of investment by creating an option value of delaying investment. Given this relationship, interest rate uncertainty could depress aggregate investment spending and thus economic activity. The strength of this effect is likely to depend on the industry composition of regions and countries. Because capital-intensive production requires more (irreversible) investment, the real effects of interest rate uncertainty might be stronger for regions with a larger share of capital-intensive industries. These considerations suggest that an activist monetary policy is potentially more effective in countries with a larger share of capital-intensive industries. To this point, these relationships are hypothetical and empirical research is needed to investigate the impact of interest rate uncertainty on industry investment and therefore industry output. The consequent results may help to determine the optimal degree of monetary policy activism

\footnotetext{
${ }^{3}$ The number of cross sections is at most equal to 15 .
} 
for countries and regions with a given industry structure.

Another promising direction for future research may qualify and quantify the pricing behavior of industries as additional determinant of monetary policy effectiveness. The pricing behavior and hence the degree of price stickiness is likely to differ between industries, with the differences being accounted for by cross-industry asymmetries in the degree of capital intensity and market competition (i.e., firm size distribution). For example, capital-intensive industries and/or industries in competitive markets are likely to adjust prices faster than capital-extensive industries and/or industries in imperfectly competitive markets. An investigation of industry-specific pricing behavior is of interest since the results allow for more direct inferences as to the role of industry composition as factor which determines the time it takes for a monetary policy shock to fully work through the system.

Finally, in only emphasizing industry structure as monetary transmission mechanism, this thesis ignores that the real effects of monetary policy changes are determined by a "complex web of economic interactions" (European Central Bank, 2001, p. 44). This also involves households and their saving and spending decisions. A more detailed understanding of monetary policy transmission could certainly be gained from studies that characterize the behavioral spending and saving relationships of households and the interaction between households and industries. Corresponding future research seems worthwhile.

\subsection{Policy Implications}

Despite the different caveats, the findings in this thesis have policy implications. The introduction to this thesis states that the political and public support for the European economic and monetary union (EMU) depends on the ability of the European Central Bank to define a monetary policy stance that suits the economic needs of all regions and countries. In order to have a one-size-fits-all monetary policy stance, countries and regions should be characterized by similar industry structures or industries should display a homogenous response to monetary policy changes. Evidently, this thesis shows that none of these conditions is met: industries respond differently to monetary policy changes and cross-country differences in industry composition account for differences in the real effects of monetary policy. ${ }^{4}$

Is this bad news for the future economic and political stability of the European economic and monetary union? The answer to this question partly depends on future developments in regional industry structures. If Krugman $(1991,1993)$ is right and the manufacturing industry continues to specialize, cross-region asymmetries in the real effects of monetary policy will be amplified in the future: regions with a large share of capital-intensive industries respond more strongly to monetary policy shocks than regions with a comparatively large share of capital-extensive industries. The consequent increase in income disparities would

\footnotetext{
${ }^{4}$ These findings are particularly evident from the analyses in chapter 4 and 6 .
} 
erode political support for EMU. However, if the production of non-tradable service goods continues to expand relative to manufacturing goods, the effect of growing specialization on cross-region differences in income developments might be less pronounced. Furthermore, they could be compensated for by within-region transfer payments between sectors in order to smooth the differential income effects of monetary policy across industries.

Apart from fiscal redistribution schemes, alternative adjustment mechanisms need to be in place in order to mitigate the effect of cross-country differences in industry structure on the real effects of monetary policy. According to the optimum currency area theory (cf. Mundell, 1961), these relate to capital mobility and to labor market flexibility, including labor mobility and real wage flexibility. While capital moves freely between countries in Europe, labor mobility is low and real wages still tend to be downward rigid. ${ }^{5}$ These are structural problems and the stability and sustainability of the European economic and monetary union depends on the ability and willingness of national governments to reform the labor market.

The results for Germany in chapter 5 indicate another avenue to limit the industry effects of monetary policy and thus possible cross-region asymmetries in the real effects of a common monetary policy shock. The analysis demonstrates that conclusions as to the bank lending effects of monetary policy depend on the choice of industry and hence on the industry composition of bank credit portfolios. Because banks are only constrained in their maximum exposure to single debtors, but not to industries, the industry effects of bank lending might be easier to anticipate when banks are required to diversify not only across single debtors, but also across all industries, with an upper bound on the maximum exposure to a single sector.

Surely, this last argument disregards possible future changes in the structure of European financial markets and in the importance of banks as source of external finance to industries. Because financial structures develop and change, the relative strength of the credit channel is equally likely to be subject to continuous periodic changes. In fact, institutional and behavioral changes may cause the emergence of new monetary policy transmission channels. For example, one can argue that the evolution of deep, broad, and liquid non-bank sources of external finance affects the distribution of bank and non-bank financial institutions in a way that mitigates the credit channel effects of monetary policy on the one hand and the industry effects of bank lending on the other hand. This is because non-bank (non-depository) institutions are not subject to reserve requirements and hence do not have to reduce lending in response to a monetary tightening (Putkuri, 2003).

Closely related to the growing importance of non-bank financial institutions, De Bondt (2004) stresses the emergence of the Euro area corporate debt securities market as another source

\footnotetext{
${ }^{5}$ Surely, these adjustment mechanisms need to be in place even when European countries experience a convergence of industry structures. This is because convergence is slow.
} 
of external corporate finance. ${ }^{6}$ Because the corporate debt market facilitates the substitution between debt securities and other intermediated (e.g., bank) sources of corporate finance, it reduces the bank dependence of firms and therefore ameliorates financial constraints when banks cut lending in periods of tight money. In due course, the credit channel effects through bank lending may weaken. Monetary-policy-induced cross-industry differences in the response of bank and non-bank lending then only reflect cross-industry differences in bank credit demand.

Besides these developments, the wave of bank mergers and acquisitions and the consequent process of banking market consolidation may also attenuate the credit channel effects of monetary policy, at least in Europe. This scenario is intrinsic to the finding in Adams and Amel (2005) according to which the credit channel effects of monetary policy are less pronounced in concentrated banking sectors, where the number of small (large) banks is low (high). Again, if this is true, the industry effects of bank lending only reflect monetary-policy-induced changes in industry-specific bank credit demand and industries predominantly determine monetary policy effectiveness through effects associated with the interest rate channel. Future developments in financial structures may therefore enable the European Central Bank to assess the real effects of monetary policy by primarily stressing the industry effects through an interest rate channel.

\footnotetext{
${ }^{6}$ See Putkuri (2003) for a description of the securities markets in Europe.
} 


\section{Bibliography}

Abel, A.B. (1980). Empirical Investment Equations: An Integrative Framework. In: K. Brunner and A. Meltzer (eds.). On the State of Macroeconomics. Carnegie-Rochester Conference Series, Vol. 12 (6), pp. 39-91.

Abel, A.B. and O.J. Blanchard (1986). The Present Value of Profits and Cyclical Movements in Investment. Econometrica, Vol. 54 (2), pp. 249-273.

Abel, A.B. and J.C. Eberly (1994). A Unified Model of Investment under Uncertainty. The American Economic Review, Vol. 84 (5), pp. 1369-1384.

Abel, A.B. and J.C. Eberly (1996). Optimal Investment with Costly Reversibility. Review of Economic Studies, Vol. 63 (4), pp. 581-593.

Abel, A.B. and J.C. Eberly (1997). An Exact Solution for the Investment and Value of a Firm Facing Uncertainty, Adjustment Costs, and Irreversibility. Journal of Economic Dynamics and Control, Vol. 21 (4-5), pp. 831-852.

Adams, J.D. (1999). The Structure of Firm R\&D and the Factor Intensity of Production. The Review of Economics and Statistics, Vol. 81 (3), pp. 499-510.

Adams, R.M. and D.F. Amel (2005). The Effects of Local Banking Market Structure on the Bank Lending Channel of Monetary Policy. Division of Research and Statistics and Monetary Affairs, Federal Reserve Board Washington, DC: Finance and Economics Discussion Series WP No. 2005-16.

Akaike, H. (1974). A New Look on the Statistical Model Identification. IEEE Transactions on Automatic Control, AC-19, pp. 716-723.

Altunbaș, Y., O. Fazylov, and P. Molyneux (2002). Evidence on the Bank Lending Channel in Europe. Journal of Banking and Finance, Vol. 26 (11), pp. 2093-2110.

Alvarez, J. and M. Arellano (2003). The Time Series and Cross-Section Asymptotics of Dynamic Panel Data Estimators. Econometrica, Vol. 71 (4), pp. 1121-1159. 
Alvarez, L.H.R. and E. Koskela (2006). Irreversible Investment under Interest Rate Variability: Some Generalizations. Journal of Business, Vol. 79 (2), pp. 623-644.

Anderson, T.W. and C. Hsiao (1982). Formulation and Estimation of Dynamic Models Using Panel Data. Journal of Econometrics, Vol. 18 (1), pp. 47-82.

Andrews, D.W.K. and B. Lu (2001). Consistent Model and Moment Selection Criteria for GMM Estimation with Applications to Dynamic Panel Models. Journal of Econometrics, Vol. 101 (1), pp. 123-164.

Angeloni, I., A.K. Kashyap, and B. Mojon (2003). Monetary Policy Transmission in the Euro Area. Cambridge: Cambridge University Press.

Angeloni, I., A. Kashyap, B. Mojon, and D. Terlizzese (2003). Monetary Policy Transmission in the Euro Area: Where Do We Stand? In: I. Angeloni, A. Kashyap, and B. Mojon (eds.): Monetary Policy Transmission in the Euro Area. Cambridge: Cambridge University Press, pp. 383-412.

Arellano, M. (1987). Computing Robust Standard Errors for Within-Groups Estimators. Oxford Bulletin of Economics and Statistics, Vol. 49 (4), pp. 431-434.

Arellano, M. and S. Bond (1991). Some Tests of Specification for Panel Data: Monte Carlo Evidence and an Application to Employment Equations. The Review of Economic Studies, Vol. 58 (2), pp. 277-297.

Arellano, M. and M. Bover (1995). Another Look at the Instrumental Variable Estimation of Error-Components Models. Journal of Econometrics, Vol. 68 (1), pp. 29-51.

Arestis, P. and I. Biefang-Frisancho Mariscal (1995). The Endogenous Money Stock: Empirical Observations from the United Kingdom. Journal of Post-Keynesian Economics, Vol. 17 (4), pp. 545-559.

Arnold, I.J.M. (2000). The Industry Effects of Monetary Policy and their Welfare Implications. Banca Nazionale del Lavoro Quarterly Review, Vol. 53 (214), pp. 287-315.

Arnold, I.J.M. (2001). The Regional Effects of Monetary Policy Integration in Europe. Journal of Economic Integration, Vol. 16 (3), pp. 386-406.

Arnold, I.J.M. and C.G. De Vries (2000). Endogenous Financial Structure and the Transmission of ECB Policy. In: J. von Hagen and C. Waller (eds.). Regional Aspects of Monetary Policy in Europe. Dordrecht: Kluwer Academic Publishers, pp. 193-218.

Arnold, I.J.M. and E.B. Vrugt (2004). Firm Size, Industry Mix, and the Regional Transmission of Monetary Policy in Germany. German Economic Review, Vol. 5 (1), pp. 35-59.

Ashcraft, A.B. (2003). New Evidence on the Lending Channel. Federal Reserve Bank of New York: Manuscript. 
Ashcraft, A.B., M. Campello (2002). Borrowers' Financial Constraints and the Transmission of Monetary Policy: Evidence from Financial Conglomerates. Federal Reserve Bank of New York: Manuscript.

Atanasova, C. (2003). Credit Market Imperfections and Business Cycle Dynamics: A Nonlinear Approach. Studies in Nonlinear Dynamics and Econometrics, Vol. 7 (4), pp. 1-20.

Audretsch, D.B. and J.A. Elston (2002). Does Firm Size Matter? Evidence on the Impact of Liquidity Constraints on Firm Investment Behavior in Germany. International Journal of Industrial Organization, Vol. 20 (1), pp. 1-17.

Baas, T. and M. Schrooten (2005). Relationship Lending and SMEs: A Theoretical Analysis. DIW Berlin: Discussion Paper No. 469.

Balke, N. (2000). Credit and Economic Activity: Credit Regimes and Nonlinear Propagation of Shocks. Review of Economics and Statistics, Vol. 82 (2), pp. 344-349.

Ball, L. and G.N. Mankiw (1994). Asymmetric Price Adjustment and Economic Fluctuations. The Economic Journal, Vol. 104 (423), pp. 247-261.

Ball, L. and D. Romer (1990). Real Rigidities and the Non-Neutrality of Money. Review of Economic Studies, Vol. 57 (2), pp. 183-203.

Baltagi, B.H. (2005, 3rd ed.). Econometric Analysis of Panel Data. West Sussex: John Wiley \& Sons Ltd., Chapter 1.

Barnett, S.A. and P. Sakellaris (1998). Nonlinear Response of Firm Investment to Q: Testing a Model of Convex and Non-Convex Adjustment Costs. Journal of Monetary Economics, Vol. 42 (2), pp. 261-288.

Barran, F., V. Coudert, and B. Mojon (1997). The Transmission of Monetary Policy in the European Countries. In: S.C. Collignon (ed.): European Monetary Policy. London: Pinter, pp. 81-111.

Baumol, W., J. Panzar, and R. Willig (1982). Contestable Markets and the Theory of Industry Structure. San Diego: Harcourt Brace Jovanovich.

Bean, C., J. Larsen, and K. Nikolov (2003). Financial Frictions and the Monetary Transmission Mechanism: Theory, Evidence, and Policy Implications. In: I. Angeloni, A. Kashyap, and B. Mojon (eds.): Monetary Policy Transmission in the Euro Area. Cambridge: Cambridge University Press, pp. 107-130.

Berben, R.-P., A. Locarno, J. Morgan, and J. Valles (2004). Cross-Country Differences in Monetary Policy Transmission. European Central Bank: ECB Working Paper Series No. 400.

Berger, A.N. and G.F. Udell (1998). The Economics of Small Business Finance: The Roles of Private Equity and Debt Markets in the Financial Growth Cycle. Journal of Banking and 
Finance, Vol. 22 (6-8), pp. 613-673.

Berger, A.N. and G.F. Udell (2002). Small Business Credit Availability and Relationship Lending: The Importance of Bank Organizational Structure. The Economic Journal, Vol. 112 (477), pp. F32-F53.

Bernanke, B.S. (1993). How Important is the Credit Channel in the Transmission of Monetary Policy? A Comment. Carnegie-Rochester Conference Series on Public Policy, Vol. 39 (0), pp. 47-52.

Bernanke, B.S. and A.S. Blinder (1988). Credit, Money, and Aggregate Demand. American Economic Review, Vol. 78 (2), pp. 435-439.

Bernanke, B.S. and A.S. Blinder (1992). The Federal Funds Rate and the Channels of Monetary Transmission. American Economic Review, Vol. 82 (4), pp. 901-921.

Bernanke, B.S. and M. Gertler (1989). Agency Costs, Net Worth, and Business Fluctuations. American Economic Review, Vol. 79 (1), pp. 14-31.

Bernanke, B.S. and M. Gertler (1995). Inside the Black Box: The Credit Channel of Monetary Policy Transmission. Journal of Economic Perspectives, Vol. 9 (4), pp. 27-48.

Bernanke, B.S., M. Gertler, and S. Gilchrist (1996). The Financial Accelerator and the Flight to Quality. Review of Economics and Statistics, Vol. 78 (1), pp. 1-15.

Bernanke, B.S., M. Gertler, and S. Gilchrist (1999). The Financial Accelerator in a Quantitative Business Cycle Framework. In: J.B. Taylor and M. Woodford (eds.). Handbook of Macroeconomics, Vol. IC. Amsterdam, North Holland: Elsevier Science, pp. 1341-1393.

Bernanke, B.S., M. Gertler, and M. Watson (1997). Systematic Monetary Policy and the Effects of Oil Price Shocks. Brookings Papers on Economic Activity, Vol. 1, pp. 91-142.

Bernanke, B.S. and K.N. Kuttner (2005). What Explains the Stock Market's Reaction to Federal Reserve Policy? The Journal of Finance, Vol. 60 (3), pp. 1221-1257.

Bernanke, B.S. and I. Mihov (1998). Measuring Monetary Policy. Quarterly Journal of Economics, Vol. 113 (3), pp. 869-902.

Blanchard, O.J. and N. Kiyotaki (1987). Monopolistic Competition and the Effects of Aggregate Demand. The American Economic Review, Vol. 77 (4), pp. 647-666.

Bloom, N., S. Bond, and J. Van Reenen (2001). The Dynamics of Investment Under Uncertainty. London, The Institute for Fiscal Studies: Working Paper No. 01/05.

Blundell, R. and S. Bond (1998). Initial Conditions and Moment Restrictions in Dynamic Panel Data Models. Journal of Econometrics, Vol. 87 (1), pp. 115-143.

Blundell, R., S. Bond, and F. Windmeijer (2000). Estimation in Dynamic Panel Data Models: 
Improving on the Performance of the Standard GMM Estimators. London, The Institute for Fiscal Studies: Working Paper No. 00/12.

Böhm, H. and M. Funke (1999). The Uncertainty-Investment Relationship. Hamburg University: Quantitative Macroeconomics Working Paper Series No. 3/99.

Bond, S.R. and C. Meghir (1994). Dynamic Investment Models and the Firm's Financial Policy. Review of Economic Studies, Vol. 61 (2), pp. 197-222.

Bond, S.R. and J. Van Reenen (2003). Microeconometric Models of Investment and Employment. London, The Institute for Fiscal Studies: Manuscript.

Bondt, G.J. De (1998). Credit Channels in Europe: Bank-Level Panel Data Analyses. De Nederlandsche Bank: Research Memorandum WO\&E No. 543.

Bondt, G.J. De (1999). Credit Channels in Europe: Cross-Country Investigation. De Nederlandsche Bank: Research Memorandum WO\&E No. 569.

Bondt, G.J. De (2000). Financial Structure and Monetary Transmission in Europe: A CrossCountry Study. Northampton, Mass.: Edward Elgar.

Bondt, G.J. De (2004). The Balance Sheet Channel of Monetary Policy: First Empirical Evidence for the Euro Area Corporate Bond Market. International Journal of Finance and Economics, Vol. 9 (3), pp. 219-228.

Boone, C. and A. Van Witteloostuijn (1999). A Synthesis of Resource Partitioning and Sunk Cost Theories: Local Partitioning, Profile Differentiation, Scale Economies, and Organizational Performance in the Dutch Newspaper Industry in 1950-1994. Maastricht University: Research Memorandum.

Boone, C., Bröcheler, V., and G.R. Carroll (2000). Custom Service: Application and Tests of Resource-Partitioning Theory among Dutch Auditing Firms from 1896 to 1992. Organization Studies, Vol. 21 (2), pp. 355-382.

Boschen, J.F. and L.O. Mills (1991). The Effects of Countercyclical Policy on Money and Interest Rates: An Evaluation of Evidence from FOMC Documents. Federal Reserve Bank of Philadelphia: Working Paper No. 91-20.

Breitung, J., B. Chirinko, and U. von Kalckreuth (2003). A Vectorautoregressive Investment Model (VIM) and Monetary Policy Transmission: Panel Evidence from German Firms. Frankfurt/Main: Deutsche Bundesbank Discussion Paper No. 06/03.

Brissimis, S.N., N.C. Kamberoglou, and G.T. Simigiannis (2003). Is There a Bank Lending Channel of Monetary Policy in Greece? Evidence from Bank Level Data. In: I. Angeloni, A. Kashyap, and B. Mojon (eds.): Monetary Policy Transmission in the Euro Area. Cambridge: Cambridge University Press, pp. 309-322. 
Bruinshoofd, A. and B. Candelon (2005). Nonlinear Monetary Policy in Europe: Fact or Myth. Economic Letters, Vol. 86 (3), pp. 399-403.

Büschgen, H.E. (1998, 5th edition). Bankgeschäfte und Bankmanagement. Wiesbaden: Betriebswirtschaftlicher Verlag Dr. Th. Gabler GmbH, chapter 4B, pp. 796-806.

Butzen, P., C. Fuss, and P. Vermeulen (2003). The Interest Rate and Credit Channel in Belgium: An Investigation with Micro-Level Firm Data. In: I. Angeloni, A. Kashyap, and B. Mojon (eds.): Monetary Policy Transmission in the Euro Area. Cambridge: Cambridge University Press, pp. 162-172.

Caballero, R.J. and E.M.R.A. Engel (1993). Heterogeneity and Output Fluctuations in a Dynamic Menu-Cost Economy. Review of Economic Studies, Vol. 60 (202), pp. 95-119.

Caballero, R.J. and J.V. Leahy (1996). Fixed Costs: The Demise of Marginal q. Cambridge, Mass.: NBER Working Paper No. 5508.

Cabral, L. (1995). Sunk Costs, Firm Size, and Firm Growth. The Journal of Industrial Economics, Vol. 43 (2), pp. 161-172.

Caner, M. and L. Kilian (2000). Size Distortions of Tests of the Null Hypothesis of Stationarity: Evidence and Implications for the PPP Debate. CEPR Discussion Paper No. 2425.

Carlino, G.A. and R. DeFina (1998). The Differential Regional Effects of Monetary Policy. Review of Economics and Statistics, Vol. 80 (4), pp. 716-723.

Carlino, G.A. and R. DeFina (1999a). Do States Respond Differently to Changes in Monetary Policy? Federal Reserve Bank of Philadelphia: Business Review (July/ August), pp. 17-27.

Carlino, G.A. and R. DeFina (1999b). The Differential Regional Effects of Monetary Policy: Evidence from the US States. Journal of Regional Science, Vol. 39 (2), pp. 339-358.

Carlino, G.A. and R. DeFina (2000). Monetary Policy and the U.S. States and Regions: Some Implications for European Monetary Union. In: J. von Hagen and C. Waller (eds.). Regional Aspects of Monetary Policy in Europe. Dordrecht: Kluwer Academic Publishers, pp. $45-68$.

Carroll, G.R. (1985). Concentration and Specialization: Dynamics of Niche Width in Populations of Organizations. American Journal of Sociology, Vol. 90, pp. 1262-1283.

Carruth, A., A. Dickerson, and A. Henley (2000). What Do We Know about Investment Under Uncertainty? Journal of Economic Surveys, Vol. 14 (2), pp. 119-153.

Cecchetti, S. (1999). Legal Structure, Financial Structure, and the Monetary Policy Transmission Mechanism. Federal Reserve Bank of New York: Economic Policy Review, Vol.5 (2), pp. 9-28.

Chatelain, J.-B., A. Generale, I. Hernando, U. von Kalckreuth, and P. Vermeulen (2003). 
Firm Investment and Monetary Transmission in the Euro Area. In: I. Angeloni, A. Kashyap, and B. Mojon (eds.): Monetary Policy Transmission in the Euro Area. Cambridge: Cambridge University Press, pp. 133-161.

Chatelain, J.-B. and J.-C. Teurlai (2004). The Impact of the Cost of Capital and of the Decision to Invest or to Divest on Investment Behavior: An Empirical Investigation Using a Panel of French Services Firms. Paper presented at the Money and Finance (MMF) Research Group Conference 2003.

Chatelain, J.-B. and A. Tiomo (2003). Monetary Policy and Corporate Investment in France. In: I. Angeloni, A. Kashyap, and B. Mojon (eds.): Monetary Policy Transmission in the Euro Area. Cambridge: Cambridge University Press, pp. 187-197.

Christiano, L.J. and M. Eichenbaum (1992). Identification and the Liquidity Effect of a Monetary Policy Shock. In: A. Cukierman, Z. Hercowitz, and L. Leiderman (eds.). Political Economy, Growth, and Business Cycles. Cambridge, Mass.: MIT Press, pp. 335-370.

Christiano, L.J. and M. Eichenbaum (1995). Liquidity Effects, Monetary Policy, and the Business Cycle. Journal of Money, Credit, and Banking, Vol. 27 (4), pp. 1113-1136.

Christiano, L.J., M. Eichenbaum, and C. Evans (1996). The Effects of Monetary Policy Shocks: Evidence from the Flow of Funds. Review of Economics and Statistics, Vol. 78 (1), pp. 16-34.

Christiano, L.J., M. Eichenbaum, and C. Evans (1999). Monetary Policy Shocks: What Have We Learned and to What End? In: J. Taylor and M. Woodford (eds.). Handbook of Macroeconomics, Vol. 1A. Amsterdam, North Holland: Elsevier Science, pp. 65-148.

Chrystal, A. and P. Mizen (2002). Modelling Credit in the Transmission Mechanism of the United Kingdom. Journal of Banking and Finance, Vol. 26 (11), pp. 2131-2154.

Corney, D. (2002). Intelligent Analysis of Small Data Sets for Food Design. University College London: Dissertation.

Cover, J.P. (1992). Asymmetric Effects of Positive and Negative Money-Supply Shocks. The Quarterly Journal of Economics, Vol. 107 (4), pp. 1261-1282.

Dale, S. and A.G. Haldane (1995). Interest Rates and the Channels of Monetary Transmission: Some Sectoral Estimates. European Economic Review, Vol. 39 (9), pp. 1611-1626.

De Haan, L. (2003). The Impact of Monetary Policy on Bank Lending in the Netherlands. In: I. Angeloni, A. Kashyap, and B. Mojon (eds.): Monetary Policy Transmission in the Euro Area. Cambridge: Cambridge University Press, pp. 335-346.

De Haan, L. and E. Sterken (2000). Capital Structure, Corporate Governance, and Monetary Policy: Firm Level Evidence for the Euro Area. De Nederlandsche Bank: Research Memorandum WO\&E No. 637. 
Dedola, L. and F. Lippi (2005). The Monetary Transmission Mechanism: Evidence from the Industries of Five OECD Countries. European Economic Review, Vol. 49 (6), pp. 1543-1569.

DeJong, D.N. and C.H. Whiteman (1991). Reconsidering Trends and Random Walks in Macroeconomic Time Series. Journal of Monetary Economics, Vol. 28 (2), pp. 221-254.

Deutsche Bundesbank (1996). Kreditentwicklung nach Kreditnehmern und Bankengruppen. Deutsche Bundesbank: Monthly Report, Vol. 48 (10), pp. 49-63.

Deutsche Bundesbank (1998a). Trends in the Banking Sector and the Market Position of the Individual Categories of Banks Since the Beginning of the Nineties. Deutsche Bundesbank: Monthly Report, Vol. 50 (3), pp. 33-64.

Deutsche Bundesbank (1998b). Methodische Grundlagen der Unternehmensbilanzstatistik der Deutschen Bundesbank. Deutsche Bundesbank: Monthly Report, Vol. 50 (10), pp. 51-67.

Deutsche Bundesbank (2000). The Relationship between Bank Lending and the Bond Market in Germany. Deutsche Bundesbank: Monthly Report, Vol. 52 (1), pp. 33-47.

Deutsche Bundesbank (2001). Bank Balance Sheets, Bank Competition, and Monetary Policy Transmission. Deutsche Bundesbank: Monthly Report, Vol. 53 (9), pp. 51-70.

Deutsche Bundesbank (2002a). The Pass-Through from Market Interest Rates to Bank Lending Rates in Germany. Deutsche Bundesbank: Monthly Report, Vol. 54 (3), pp. 49-62.

Deutsche Bundesbank (2002b). Monetary Policy and Investment Behavior - An Empirical Study. Deutsche Bundesbank: Monthly Report, Vol. 54 (7), pp. 41-54.

Deutsche Bundesbank (2002c). The Development of Bank Lending to the Private Sector. Deutsche Bundesbank: Monthly Report, Vol. 54 (10), pp. 31-47.

Dicky, D.A. and Fuller, W.A. (1979). Distribution of the Estimators for Autoregressive Time Series with a Unit Root. Journal of the American Statistical Association, Vol. 74, pp. 427-431.

Diebold, F.X., G.D. Rudebusch, and S.B. Arouba (2003). The Macroeconomy and the Yield Curve: A Nonstructural Analysis. Penn Institute for Economic Research: Pier Working Paper No. 03-024.

Dixit, A.K. and R.S. Pindyck (1994). Investment under Uncertainty. Chichester: Princeton University Press.

Dolado, J.J. and R. María-Dolores (2001). An Empirical Study of the Cyclical Effects of Monetary Policy in Spain (1977-1997). Investigaciones Económicas, Vol. 25 (1), pp. 3-30.

Dornbusch, R., Favero C. A., and F. Giavazzi (1998). Immediate Challenges for the ECB: Issues in Formulating a Single Monetary Policy. Economic Policy, No. 26, pp. 15-64. 
Ehrmann, M. (2005). Firm Size and Monetary Policy Transmission: Evidence from German Business Survey Data. In: J.-E. Sturm and T. Wollmershäuser (eds.): Contributions to Economics. Heidelberg: Physica, pp. 145-172.

Ehrmann, M. and M. Fratzscher (2004). Taking Stock: Monetary Policy Transmission to Equity Markets. Journal of Money, Banking, and Credit, Vol. 36 (4), pp. 719-737.

Ehrmann, M., L. Gambacorta, J. Martínez-Pagés, P. Sevestre, and A. Worms (2003). Financial Systems and the Role of Banks in Monetary Policy Transmission in the Euro Area. In: I. Angeloni, A. Kashyap, and B. Mojon (eds.): Monetary Policy Transmission in the Euro Area. Cambridge: Cambridge University Press, pp. 235-269.

Ehrmann, M. and A. Worms (2004). Bank Networks and Monetary Policy Transmission. Journal of the European Economic Association, Vol. 2 (6), pp. 1148-1171.

Eichenbaum, M. (1994). Monetary Policy and Bank Lending: Comment. In: N.G. Mankiw (ed.): Monetary Policy, Studies in Business Cycles, Vol. 29. Chicago: University of Chicago Press, pp. 256-261.

Ellingsen, T. and U. Söderström (2001). Monetary Policy and Market Interest Rates. American Economic Review, Vol. 91 (5), pp. 1594-1607.

Ellingsen, T. and U. Söderström (2003). Monetary Policy and the Bond Market. Stockholm School of Economics: Manuscript.

Elsas, R. and J.P. Krahnen (2004). Universal Banks and Relationships with Firms. In: J.P. Krahnen and R.H. Schmidt (eds.). The German Financial System. Oxford: Oxford University Press, pp. 197-232.

Erickson, T. and T.M. Whited (2000). Measurement Error and the Relationship between Investment and q. Journal of Political Economy, Vol. 108 (5), pp. 1027-1057.

European Central Bank (2001). The Monetary Policy of the ECB. Frankfurt/Main.

European Commission (1990). One Market, One Money. European Economy, Vol. 44.

European Commission (2003). SMEs and Access to Finance. Observatory of European SMEs No. 2.

Evans, C.L. and D.A. Marshall (1998). Monetary Policy and the Term Structure of Nominal Interest Rates: Evidence and Theory. Carnegie-Rochester Conference Series on Public Policy, Vol. 49 (0), pp. 53-111.

Farinha, L. and C. Robalo Marques (2003). The Bank Lending Channel of Monetary Transmission: Identification and Estimation Using Portuguese Micro Bank Data. In: I. Angeloni, A. Kashyap, and B. Mojon (eds.): Monetary Policy Transmission in the Euro Area. Cambridge: Cambridge University Press, pp. 359-371. 
Fase, M.M.G. and G.J. de Bondt (2000). Institutional Environment and Monetary Transmission in the Euro Area. A Cross-Country View. REVUE de la Banque/ Bank- en Financiewezen, Vol. 2-3. pp. 149-155.

Favero, C.A., F. Giavazzi, and L. Flabbi (1999). The Transmission Mechanism of Monetary Policy in Europe: Evidence from Bank's Balance Sheets. Cambridge, Mass.: NBER WP 7231.

Fazzari, S., G. Hubbard, and B. Petersen (1988). Financing Constraints and Corporate Investment. Brooking Papers on Economic Activity, Vol. 1, pp. 141-206.

Florio, A. (2004). The Asymmetric Effects of Monetary Policy. Journal of Economic Surveys, Vol. 18 (3), pp. 409-426.

Friedman, M. (1968). The Role of Monetary Policy. American Economic Review, Vol. 58, pp. 1-17.

Gaiotti, E. and A. Generale (2003). Monetary Policy and Firm's Investment in Italy. In: I. Angeloni, A. Kashyap, and B. Mojon (eds.): Monetary Policy Transmission in the Euro Area. Cambridge: Cambridge University Press, pp. 198-211.

Gambacorta, L. (2003). The Italian Banking System and Monetary Policy Transmission: Evidence from Bank Level Data. In: I. Angeloni, A. Kashyap, and B. Mojon (eds.): Monetary Policy Transmission in the Euro Area. Cambridge: Cambridge University Press, pp. 323-334.

Gambacorta, L. (2005). How Do Banks Set Interest Rates? Banca D'Italia: Temi di Discussione No. 542.

Gambacorta, L. and S. Iannotti (2005). Are There Asymmetries in the Response of Bank Interest Rates to Monetary Shocks? Banca D'Italia: Temi di Discussione No. 566.

Gambacorta, L. and P.E. Mistrulli (2004). Does Bank Capital Affect Lending Behavior? Journal of Financial Intermediation, Vol. 13 (4), pp. 435-457.

Ganley, J. and C. Salmon (1997). The Industrial Impact of Monetary Policy Shocks: Some Stylized Facts. Bank of England Working Paper 68.

Garcia, R. and H. Schaller (2002). Are the Effects of Monetary Policy Asymmetric? Economic Inquiry, Vol. 40 (1), pp. 102-119.

Garretsen, H. and J. Swank (1998). The Transmission of Interest Rate Changes and the Role of Bank Balance Sheets: A VAR-Analysis for the Netherlands. Journal of Macroeconomics, Vol. 20 (2), pp. 325-339.

Gertler, M. and S. Gilchrist (1993a). The Cyclical Behavior of Short-Term Business Lending: Implications for Financial Propagation Mechanisms. European Economic Review, Vol. 37 (2-3), pp. 623-631. 
Gertler, M. and S. Gilchrist (1993b). The Role of Credit Market Imperfections in the Monetary Transmission Mechanism: Arguments and Evidence. The Scandinavian Journal of Economics, Vol. 95 (1), pp. 43-64.

Gertler, M. and S. Gilchrist (1994). Monetary Policy, Business Cycles, and the Behavior of Small Manufacturing Firms. Quarterly Journal of Economics, Vol. 109 (2), pp. 309-340.

Ghosal, V. and P. Loungani (2000). The Differential Impact of Uncertainty of Investment in Small and Large Businesses. The Review of Economics and Statistics, Vol. 82 (2), pp. 338-349.

Gibson, M.S. (1997). The Bank Lending Channel of Monetary Policy Transmission: Evidence from a Model of Bank Behavior that Incorporates Long-Term Customer Relationships. Board of Governors of the Federal Reserve System: International Financial Discussion Papers No. 584.

Gilchrist, S.G., J.-O. Hairault, and H. Kempf (2002). Monetary Policy and the Financial Accelerator in a Monetary Union. European Central Bank: ECB Working Paper No. 175.

Goodfriend, M. (1998). Using the Term Structure of Interest Rates for Monetary Policy. Federal Reserve Bank of Richmond: Economic Quarterly, Vol. 84 (3), pp. 13-30.

Gordon, D.B. and E.M. Leeper (1994). The Dynamic Impacts of Monetary Policy: An Exercise in Tentative Identification. The Journal of Political Economy, Vol. 102 (6), pp. 1228-1247.

Greene, W.H. (2003, 5th edition). Econometric Analysis. New Jersey: Prentice Hall.

Guender, A. and M. Moersch (1997). On the Existence of a Credit Channel of Monetary Policy in Germany. Kredit und Kapital, Vol. 30 (2), pp. 173-185.

Guiso, L., A.K. Kashyap, F. Panetta, D. Terlizzese (1999). Will a Common European Monetary Policy Have Asymmetric Effects? Federal Reserve Bank of Chicago: Economic Perspectives, Vol. 23 (4), pp. 56-75.

Hackethal, A. (2004). German Banks and Banking Structure. In: J.P. Krahnen and R.H. Schmidt (eds.). The German Financial System. Oxford: Oxford University Press, pp. 69-105. Hall, R.E. (2004). Measuring Factor Adjustment Costs. The Quarterly Journal of Economics, Vol. 119 (3), pp. 899-927.

Harhoff, D. and T. Körting (1998). Lending Relationships in Germany - Empirical Evidence from Survey Data. Journal of Banking and Finance, Vol. 22 (10-11), pp. 1317-1353.

Hausman, J.A. (1978). Specification Tests in Econometrics. Econometrica, Vol. 46 (6), pp. 1251-1271.

Hayashi, F. (1982). Tobin's Marginal q and Average q: A Neoclassical Interpretation. Econo- 
metrica, Vol. 50 (1), pp. 213-224.

Hayo, B. and B. Uhlenbrock (2000). Industry Effects of Monetary Policy in Germany. In: J. von Hagen and C. Waller (ed.). Regional Aspects of Monetary Policy in Europe. Dordrecht: Kluwer Academic Publishers, pp. 127-158.

Henrekson, M. and D. Johansson (1999). Institutional Effects on the Evolution of the Size Distribution of Firms. Small Business Economics, Vol. 12 (1), pp. 11-23.

Hernando, I. and J. Martínez-Pagés (2003). Is there a Bank Lending Channel of Monetary Policy in Spain? In: I. Angeloni, A. Kashyap, and B. Mojon (eds.): Monetary Policy Transmission in the Euro Area. Cambridge: Cambridge University Press, pp. 284-296.

Heuvel, Van den S.J. (2002a). Does Bank Capital Matter for Monetary Transmission? Federal Reserve Bank of New York: Economic Policy Review, Vol. 8 (1), pp. 259-265.

Heuvel, Van den S.J. (2002b). The Bank Capital Channel of Monetary Policy. University of Pennsylvania: unpublished paper.

Hicks, J. (1939, 2nd Edition). Value and Capital. London: Oxford University Press.

Holtemöller, O. (2003). Further VAR Evidence for the Effectiveness of a Credit Channel in Germany. Applied Economics Quarterly, Vol. 49 (4), pp. 359-381.

Holtz-Eakin, D., W. Newey, and H.S. Rosen (1988). Estimating Vector Autoregressions with Panel Data. Econometrica, Vol. 56 (6), pp. 1371-1395.

Hu, C. (1999). Leverage, Monetary Policy, and Firm Investment. Federal Reserve Bank of San Francisco: Economic Review, Vol. 2, pp. 32-39.

Hubbard, G.R. (1995). Is there a Credit Channel for Monetary Policy. Cambridge, Mass.: NBER Working Paper No. 4977.

Hülsewig,O., E. Mayer, and T. Wollmershäuser (2005). Bank Loan Supply and Monetary Poliy: Transmission in Germany. Munich: CESifo Working Paper No. 1380.

Hülsewig, O., P. Winker, and A. Worms (2004). Bank Lending in the Transmission of Monetary Policy: A VECM Analysis for Germany. Jahrbücher für Nationalökonomie und Statistik, Vol. 224 (5), pp. 511-529.

Ingersoll, J.E. and S.A. Ross (1992). Waiting to Invest: Investment and Uncertainty. The Journal of Business, Vol. 65 (1), pp. 1-29.

Jarque, C.M. and A.K. Bera (1980). Efficient Tests for Normality, Heteroscedasticity, and Serial Independence of Regression Residuals. Economic Letters, Vol. 6, pp. 255-259.

Jarque, C.M. and A.K. Bera (1987). A Test for Normality of Observations and Regression Residuals. International Statistical Review, Vol. 55, pp. 163-172. 
Jorgenson, D.W. (1963). Capital Theory and Investment Behavior. American Economic Review, Vol. 53 (2), pp. 247-259.

Jung, H. (2005). A Test for Autocorrelation in Dynamic Panel Data Models. Hitotsubashi University: Hi-Stat Discussion Paper Series No. 77.

Kakes, J. (1998). Monetary Policy and Business Cycle Asymmetry. University of Groningen, Research Institute SOM: Research Report No. 98C36.

Kakes, J. (2000a). Identifying the Mechanism: Is there a Bank Lending Channel of Monetary Transmission in the Netherlands. Applied Economic Letters, Vol. 7 (2), pp. 63-67.

Kakes, J. (2000b). Monetary Policy and Business Cycle Asymmetry in Germany. Kredit und Kapital, Vol. 33 (2), pp. 182-197.

Kakes, J. and J.-E. Sturm (2002). Monetary Policy and Bank Lending: Evidence from German Banking Groups. Journal of Banking and Finance, Vol. 26 (11), pp. 2077-2092.

Kakes, J., J.-E. Sturm, and P. Maier (2001). Monetary Transmission and Bank Lending in Germany. Kredit und Kapital, Vol. 34 (4), pp. 505-525.

Kalckreuth, U. von (2003). Monetary Transmission in Germany: New Perspectives on Financial Constraints and Investment Spending. In: I. Angeloni, A. Kashyap, and B. Mojon (eds.): Monetary Policy Transmission in the Euro Area. Cambridge: Cambridge University Press, pp. 173-186.

Kaplan, S.N. and L. Zingales (1997). Do Investment-Cash Flow Sensitivities Provide Useful Measures of Financing Constraints? Quarterly Journal of Economics, Vol. 112 (1), pp. 169-215.

Karras, G. (1996a). Are the Output Effects of Monetary Policy Asymmetric? Evidence from a Sample of European Countries. Oxford Bulletin of Economics and Statistics, Vol. 58 (2), pp. 267-278.

Karras, G. (1996b). Why Are the Effects of Money-Supply Shocks Asymmetric? Convex Aggregate Supply or 'Pushing on a String'? Journal of Macroeconomics, Vol. 18 (4), pp. 605-619.

Karras, G. (1999). Openness and the Effects of Monetary Policy. Journal of International Money and Finance, Vol. 18 (1), pp. 13-26.

Karras, G. and H.H. Stokes (1999). On the Asymmetric Effects of Money-Supply Shocks: International Evidence from a Panel of OECD Countries. Applied Economics, Vol. 31 (2), pp. 227-235.

Kashyap, A.K., O.A. Lamont, and J.C. Stein (1994). Credit Conditions and the Cyclical Behavior of Inventories. The Quarterly Journal of Economics, Vol. 109 (3), pp. 565-592. 
Kashyap, A.K. and J.C. Stein (1994). Monetary Policy and Bank Lending. In: N.G. Mankiw. Monetary Policy. National Bureau of Economic Research, University of Chicago Press: NBER Studies in Business Cycles, Vol. 29, chapter 7, pp. 221-256.

Kashyap, A.K. and J.C. Stein (1995). The Impact of Monetary Policy on Bank Balance Sheets. Carnegie-Rochester Conference Series on Public Policy, Vol. 42 (0), pp. 151-195.

Kashyap, A.K. and J.C. Stein (1997). The Role of Banks in Monetary Policy: A Survey with Implications for the European Monetary Union. Federal Reserve Bank of Chicago: Economic Perspectives, September/October, pp. 2-18.

Kashyap, A.K. and J.C. Stein (2000). What Do a Million Observations on Banks Say about the Transmission of Monetary Policy? American Economic Review, Vol. 90 (3), pp. 407-428.

Kashyap, A.K., J.C. Stein, and D.W. Wilcox (1993). Monetary Policy and Credit Conditions: Evidence from the Composition of External Finance. American Economic Review, Vol. 83 (1), pp. 78-98.

Kaufmann, S. (2003). The Cross-Sectional and the Time Dimension of the Bank-Lending Channel: The Austrian Case. In: I. Angeloni, A. Kashyap, and B. Mojon (eds.): Monetary Policy Transmission in the Euro Area. Cambridge: Cambridge University Press, pp. 347-358.

Keynes, J.M. (1936). The General Theory of Employment, Interest, and Money. London: Macmillan.

Kieler, M. and T. Saarenheimo (1998). Differences in Monetary Policy Transmission? A Case not Closed. European Commission, Directorate-General for Economic and Financial Affairs: Economic Papers No. 132.

Kishan, R.P. and T.P. Opiela (2000). Bank Size, Bank Capital, and the Bank Lending Channel. Journal of Money, Credit, and Banking, Vol. 32 (1), pp. 121-141.

Kiviet, J. (1995). On Bias, Inconsistency, and Efficiency of Some Estimators in Dynamic Panel Data Models. Journal of Econometrics, Vol. 68 (1), pp. 63-78.

Krugman, P. (1991). Geography and Trade. Cambridge, Mass.: MIT Press.

Krugman, P. (1993). Lessons of Massachusetts for EMU. In: F. Torres and F. Giavazzi (eds.): Adjustment and Growth in the European Monetary Union. Cambridge, Mass.: Cambridge University Press, pp. 241-261.

Kumar, K.B., R.G. Rajan, and L. Zingales (1999). What Determines Firm Size? Cambridge, Mass.: NBER Working Paper No. 7208.

Küppers, M. (2001). Curtailing the Black Box: German Banking Groups in the Transmission of Monetary Policy. European Economic Review, Vol. 45 (10), pp. 1907-1930.

Kuttner, K.N. (2001). Monetary Policy Surprises and Interest Rates: Evidence from the Fed 
Funds Futures Market. Journal of Monetary Economics, Vol. 47 (3), pp. 523-544.

Kuttner, K.N. and P.C. Mosser (2002). The Monetary Transmission Mechanism: Some Answers and Further Questions. Federal Reserve Bank of New York: Economic Policy Review, Vol. 8 (1), pp. $15-26$.

Kwiatkowski, D., P.C.B. Phillips, P. Schmidt, and Y. Shin (1992). Testing the Null Hypothesis of Stationarity against the Alternative of a Unit Root: How Sure Are We that Economic Time Series Have a Unit Root? Journal of Econometrics, Vol. 54 (1-3), pp. 159-178.

Kyotaki, N. and J. Moore (1997). Credit Cycles. Journal of Political Economy, Vol.105 (2), pp. 211-248.

Lensink, R. and E. Sterken (2002). Monetary Transmission and Bank Competition in the EMU. Journal of Banking and Finance, Vol. 26 (11), pp. 2065-2075.

Lensink, R., P. Van Steen, and E. Sterken (2000). Is Size Important for the InvestmentUncertainty Relationship? An Empirical Anlysis for Dutch Firms. University of Groningen, Research Institute SOM: Research Report No. 00E03.

Letterie, W.A. and G.A. Pfann (2003). On the Identification of High and Low Regimes in Equipment Investment Expenditures of Firms. Maastricht University: Manuscript.

Ljung, G.M. and G. Box (1978) . On a Measure of Lack of Fit in Time Series Models. Biometrika, Vol. 65 (2), pp. 297-303.

Lobo, B.J. (2000). Asymmetric Effects of Interest Rate Changes on Stock Prices. The Financial Review, Vol. 35 (3), pp. 125-144.

Lopez Iturriaga, F.L. (2000). More on the Credit Channel of Monetary Policy Transmission: An International Comparison. Applied Financial Economics, Vol. 10 (4), pp. 423-434.

Loupias, G., F. Savignac, and P. Sevestre (2003). Is There a Bank Lending Channel in France: Evidence from Bank Panel Data. In: I. Angeloni, A. Kashyap, and B. Mojon (eds.): Monetary Policy Transmission in the Euro Area. Cambridge: Cambridge University Press, pp. 297-308.

Loveman, G. and W. Sengenberger (1991). The Reemergence of Small-Scale Production: An International Comparison. Small Business Economics, Vol. 3 (1), pp. 1-37.

Lown, C.S. and D.P. Morgan (2002). Credit Effects in the Monetary Mechanism. Federal Reserve Bank of New York: Economic Policy Review, Vol. 8 (1), pp. 217-235.

Ludvigson, S. (1998). The Channel of Monetary Transmission to Demand: Evidence from the Market for Automobile Credit. Journal of Money, Banking, and Credit, Vol. 30 (3), pp. 365-383.

Lünnemann, P. and T. Mathä (2003). Monetary Transmission: Empirical Evidence from 
Luxembourg Firm Level Data. In: I. Angeloni, A. Kashyap, and B. Mojon (eds.): Monetary Policy Transmission in the Euro Area. Cambridge: Cambridge University Press, pp. 212-220.

Mallick, R. and A. Chakraborty (2002). Credit Gap in Small Businesses: Some New Evidence. Unpublished paper.

Mateut, S., S. Bougheas, and P. Mizen (2003). Trade Credit, Bank Lending, and Monetary Policy Transmission. European University Institute: Working Paper No. 2003/02.

McCallum, B.T. (1999). Analysis of the Monetary Transmission Mechanism: Methodological Issues. Cambridge, Mass.: NBER WP 7395.

McMillin, W.D. (2001). The Effects of Monetary Policy Shocks: Comparing Contemporaneous Versus Long-Run Identifying Restrictions. Southern Economic Journal, Vol. 67 (3), pp. 618-636.

Meltzer, A.H. (1995). Monetary, Credit, and (other) Transmission Processes: A Monetarist Perspective. Journal of Economic Perspectives, Vol. 9 (4), pp. 49-72.

Midelfart-Knarvik, K.H., H.G. Overman, S.J. Redding, and A.J. Venables (2000). The Location of European Industry. Report prepared for the Directorate General for Economic and Financial Affairs. Brussels: European Commission, Economic Papers No. 142.

Mises, L. von (1981). Theory of Money and Credit. Indianapolis: Liberty Fund. First published 1912. Translated from the German by H.E. Batson.

Mishkin, F.S. (1995). Symposium on the Monetary Transmission Mechanism. Journal of Economic Perspectives, Vol. (9), pp. 3-10.

Mishkin, F.S. (2001). The Transmission Mechanism and the Role of Asset Prices in Monetary Policy. Cambridge, Mass.: NBER WP 8617.

Modigliani, F. and M. Miller (1958). The Cost of Capital, Corporate Finance, and the Theory of Investment. American Economic Review, Vol. 48 (3), pp. 261-297.

Mojon, B. (2001). Financial Structure and the Interest Rate Channel of ECB Monetary Policy. Economie et Prevision, Vol. 147 (1), pp. 89-115.

Mojon, B., F. Smets, and P. Vermeulen (2002). Investment and Monetary Policy in the Euro Area. Journal of Banking and Finance, Vol. 26 (11), pp. 2111-2129.

Nelson, C.R. and C.I. Plosser (1982). Trends and Random Walks in Macroeconomic Time Series: Some Evidence and Implications. Journal of Monetary Economics, Vol. 10 (2), pp. 139-162.

Nickell, S. (1981). Biases in Dynamic Models with Fixed Effects. Econometrica, Vol. 49 (6), pp. 1417-1426. 
Nilsen, J.H. (2002). Trade Credit and the Bank Lending Channel. Journal of Money, Credit, and Banking, Vol. 34 (1), pp. 226-253.

Ninh, L.K., N. Hermes, G. Lanjouw (2004). Investment, Uncertainty, and Irreversibility. Economics of Transition, Vol. 12 (2), pp. 307-332.

Oguzoglu and Stengos (2005). Can Dynamic Panel Data Explain the Finance-Growth Link? An Empirical Likelihood Approach. University of Guelph: Working Paper No. 2005-2.

Oliner, S. and G. Rudebusch (1996). Is there a Broad Credit Channel for Monetary Policy? Federal Reserve Bank of San Francisco: Economic Review (1), pp. 3-13.

Pagan, A. (1986). Two Stage and Related Estimators and their Applications. Review of Economic Studies, Vol. 53 (4), pp. 517-538.

Peek, J. and E. Rosengren (1995). Bank Lending and the Transmission of Monetary Policy. In: J. Peek and E. Rosengren (eds.): Is Bank Lending Important for the Transmission of Monetary Policy? Federal Reserve Bank of Boston: Conference Series, Vol. 39, pp. 47-68.

Peersman, G. and F. Smets (2005). The Industry Effects of Monetary Policy in the Euro Area. Economic Journal, Vol. 115 (503), pp. 319-342.

Perez-Quiros, G. and A. Timmermann (2000). Firm Size and Cyclcial Variations in Stock Returns. Journal of Finance, Vol. 55 (3), pp. 1229-1262.

Phillips, P.C.B. and P. Perron (1988). Testing for a Unit Root in Time Series Regression. Biometrika, Vol. 75 (2), pp. 335-346.

Putkuri, H. (2003). Cross-Country Asymmetries in Euro Area Monetary Transmission: The Role of National Financial Systems. Bank of Finland: Discussion Paper No. 15/2003.

Ramaswamy, R. and T. Sloek (1997). The Real Effects of Monetary Policy in the European Union: What Are the Differences? Washington, D.C.: IMF Working Paper No. WP/97/160.

Ramey, V. (1993). How Important Is the Credit Channel of Monetary Transmission? Cambridge, Mass.: NBER Working Paper No. 4285.

Ramírez, M. and M.A. Espitia (2002). The Impact of Product Diversification Strategy on the Corporate Performance of Large Spanish Firms. Spanish Economic Review, Vol. 4 (2), pp. 119-137.

Rao, C.R. (1973). Linear Statistical Inferences and its Applications. New York: John Wiley and Sons.

Ravn, M.O. and M. Sola (1996). A Reconsideration of the Empirical Evidence on the Asymmetric Effects of Money Supply Shocks: Positive vs. Negative or Big vs. Small? University of Aarhus: unpublished manuscript. 
Ravn, M.O. and M. Sola (2004). Asymmetric Effects of Monetary Policy in the United States. Federal Reserve Bank of St. Louis Review, Vol. 86 (5), pp. 41-60.

Rhee, W. and R. W. Rich (1995). Inflation and the Asymmetric Effects of Money on Output Fluctuations. Journal of Macroeconomics, Vol. 17 (4), pp. 683-702.

Rochelle, M.E., T. Laubach, and J.C. Williams (2003). The Response of Wages and Prices to Technology Shocks. Federal Reserve Bank of San Francisco: Working Papers in Applied Economic Theory No. 21.

Romer, C.D. and D.H. Romer (1989). Does Monetary Policy Matter? A New Test in the Spirit of Friedman and Schwartz. In: O. Blanchard and S. Fischer (eds.). NBER Macroeconomics Annual. Cambridge, Mass.: MIT Press, pp. 82-131.

Romer, C.D. and D.H. Romer (1990). New Evidence on the Monetary Transmission Mechanism. Brookings Papers on Economic Activity, Vol. 1, pp. 149-198.

Schiantarelli, F. (1996). Financial Constraints and Investment. A Critical Review of Methodological Issues and International Evidence. Oxford Review of Economic Policy, Vol. 12 (2), pp. $70-89$.

Siegfried, N.A. (2000). Microeconometric Evidence for a German Credit Channel. Hamburg University: Quantitative Macroeconomics Working Paper Series No. 1/2000.

Sims, C.A., J.H. Stock, and M.W. Watson (1990). Inference in Linear Time-Series Models with Some Unit Roots. Econometrica, Vol. 58 (1), pp. 113-144.

Stein, J. (1998). An Adverse Selection Model of Bank Asset and Liability Management with Implications for the Transmission of Monetary Policy. Rand Journal of Economics, Vol. 29 (3), pp. 466-486.

Sutton, J. (1991). Sunk Costs and Market Structure: Price Competition, Advertising, and the Evolution of Concentration. Cambridge, Mass.: MIT Press.

Sutton, J. (1998). Technology and Market Structure: Theory and History. Cambridge, Mass.: MIT Press.

Taylor, J.B. (1995) The Monetary Transmission Mechanism: An Empirical Framework. Journal of Economic Perspectives, Vol. 9 (4), pp. 11-26.

Thorbecke, W. and L. Coppock (1996). Monetary Policy, Stock Returns, and the Role of Credit in the Transmission of Monetary Policy. Southern Economic Journal, Vol. 62 (4), pp. 989-1001.

Tirole, J. (1989). The Theory of Industrial Organization. Cambridge, Mass.: MIT Press.

Tobin, J. (1969). A General Equilibrium Approach to Monetary Policy. Journal of Money, Credit, and Banking, Vol. 1 (1), pp. 15-29. 
Topi, J. and J. Vilmunen (2003). Transmission of Monetary Policy Shocks in Finland: Evidence from Bank Level Data on Loans. In: I. Angeloni, A. Kashyap, and B. Mojon (eds.): Monetary Policy Transmission in the Euro Area. Cambridge: Cambridge University Press, pp. 372-382.

Trautwein, H.-M. (2000). The Credit View, Old and New. Journal of Economic Surveys, Vol. 14 (2), pp. 155-189.

Valderrama, M. (2003). The Role of Trade Credit and Bank Lending Relationships in the Transmission Mechanism in Austria. In: I. Angeloni, A. Kashyap, and B. Mojon (eds.): Monetary Policy Transmission in the Euro Area. Cambridge: Cambridge University Press, pp. 221-232.

Vermeulen, P. (2002). Business Fixed Investment: Evidence of a Financial Accelerator in Europe. Oxford Bulletin of Economics and Statistics, Vol. 64 (3), pp. 213-231.

Weise, C.L. (1999). The Asymmetric Effects of Monetary Policy: A Nonlinear Vector Autoregression Approach. Journal of Money, Credit, and Banking, Vol. 31 (1), pp. 85-108.

Wesche, K. (2000). Is there a Credit Channel in Austria? The Impact of Monetary Policy on Firms' Investment Decisions. Österreichische Nationalbank: Working Paper No. 41.

Westerlund, J. (2003). A Panel Data Test of the Bank Lending Channel in Sweden. Lund University: Manuscript.

White, H. (1980). A Heteroscedasticity-Consistent Covariance Matrix and a Direct Test for Heteroscedasticity. Econometrica, Vol. 48 (4), pp. 817-838.

Whited, T.M. (1992). Debt, Liquidity Constraints, and Corporate Investment: Evidence from Panel Data. Journal of Finance, Vol. 47 (4), pp. 1425-1460.

Worms, A. (2003). Interbank Relationships and the Credit Channel in Germany. Empirica, Vol. 30 (2), pp. 179-198. 



\section{Nederlandse Samenvatting}

In de economische literatuur is er een voortdurende discussie over de rol die de sectorale structuur van een economie speelt bij de transmissie van monetair beleid. De interesse voor sectorale effecten komt voort uit het idee dat de structurele eigenschappen van sectoren van nut kunnen zijn bij het identificeren van monetaire transmissiekanalen. Zodoende kunnen de macro-economische reële effecten van acties met betrekking tot monetair beleid beter uitgelegd en begrepen worden. Er is veel empirisch onderzoek gedaan naar de rol van sectorale effecten in de transmissie van monetair beleid. Niettemin geloven wij dat de bestaande studies niet diep genoeg zijn ingegaan op de rol van de sectorale compositie als belangrijke factor voor de effectiviteit van monetair beleid op nationaal en regionaal niveau. Dit proefschrift draagt bij aan het debat over de rol van sectoren door middel van het kwalificeren en kwantificeren van de sectorale effecten in relatie tot zowel het rente- als het kredietkanaal van monetaire transmissie. Voor dit doel worden twee vragen behandeld. Ten eerste, bestaan er verschillen tussen de economische reacties van verschillende sectoren op veranderingen in het monetaire beleid? En ten tweede, zijn deze gerelateerd aan een onderscheid in de relatieve sterkte van het rente- en het kredietkanaal en kunnen mogelijke discrepanties worden verklaard door verschillen in de structurele eigenschappen van sectoren?

Bevindingen met betrekking tot de rol van sectoren als belangrijke factor van rente- en kredietkanaaleffecten van monetair beleid zijn van vitaal belang voor de Europese Centrale Bank. Deze zouden namelijk van nut kunnen zijn om te bepalen wat de effecten van een gemeenteschappelijke monetair beleid op de inkomensverdeling in regio's van de Europese Economische en Monetaire Unie (EMU) zijn. Het is waarschijnlijk dat deze effecten worden veroorzaakt door regionale verschillen in economische structuur - tot uitdrukking komend in verschillen in sectorale compositie - in combinatie met verschillen in reactie op veranderingen in monetair beleid tussen sectoren.

In dit proefschrift wordt in zeven hoofdstukken het belang van sectoren als monetair transmissiekanaal geanalyseerd. Hoofdstuk 1 omvat de te beantwoorden vragen en geeft een algemeen overzicht van de rol van sectoren in de transmissie van monetair beleid via het rente- en het kredietkanaal. Hoofdstuk 2 presenteert de theorieën en bestaande empirische gegevens 
over het rente- en kredietkanaal vanuit een macro-economisch, micro-economisch en sectoraal perspectief. Zowel het rente- als het kredietkanaal hebben in de literatuur aanzienlijke theoretische en empirische aandacht gekregen. De primaire studies (i) wijzen naar verschillende factoren om de reële effecten van monetair beleid te verklaren en (ii) variëren in de mate van belang die zij hechten aan sectoren als mogelijke bepalende factor van de effectiviteit van monetair beleid. Terwijl studies naar het rentekanaal van monetaire transmissie de rol van de structuur van niet-financiële sectoren behandelen, benadrukken studies naar het kredietkanaal hoofdzakelijk financiële structuren en imperfecties van de financiële sector.

De bestaande empirische literatuur laat zien dat monetaire beleidsschokken reëlle effecten hebben via het rentekanaal: in reactie op een monetaire verkrapping wordt de productie kleiner, en bij een monetaire verruiming wordt de productie groter. De empirische uitkomsten illustreren ook dat verschillen in de sterkte van het rentekanaal tussen landen kunnen worden toegewezen aan heterogeniteit in economische structuren met betrekking tot de sectorale compositie. In tegenstelling tot studies naar het rentekanaal, geeft empirisch onderzoek naar de werking van een kredietkanaal dubbelzinnige resultaten. Studies die de effecten van monetair beleid via kredietkanalen theoretisch onderbouwen laten zien dat een verkrapping van het beleid gepaard gaat met strakkere externe financiële beperkingen, veroorzaakt door een verslechtering van informatieasymmetrieën. Verschillen in de sterkte van het kredietkanaal tussen landen kunnen worden toegewezen aan verschillen in financiële structuren met betrekking tot de verdeling van bank en niet-bankinstellingen (b.v. ondernemingen) en de verdeling van kredietverlening door banken aan soorten debiteuren. Met betrekking tot de verdeling van ondernemingen veronderstelt de 'credit view' theorie dat kleine ondernemingen vergeleken met grote ondernemingen gevoeliger zijn voor monetaire beleidsveranderingen, aangezien informatieasymmetrieën sterker zijn.

Het empirisch onderzoek van het 'credit view' theorie toont echter dat empirische bewijzen slechts dubbelzinnige onderbouwing geven voor de veronderstelling dat de reëlle effecten van monetair beleid kunnen afhangen van de ondernemingsgrootte in de Verenigde Staten en de Europese landen: de empirische gegevens voor de Verenigde Staten wijzen op een grotere reactie van kleine ondernemingen op monetair beleid, terwijl de gegevens voor Europese landen het bestaan van een dergelijke reactie slechts zwak of niet ondersteunen. Hoofdstuk 3 is gebaseerd op deze empirische ambiguïteit. In het hoofdstuk wordt een non-lineair investeringsmodel gepresenteerd, dat tot doel heeft vast te stellen onder welke omstandigheden kleine ondernemingen niet meer reageren op monetaire beleidsschokken dan grote ondernemingen. In tegenstelling tot bestaand onderzoek naar het kredietkanaal legt het investeringsmodel geen nadruk op imperfecties in de kredietmarkt om de gevoeligheid voor monetair beleid van kleine ondernemingen, vergeleken met grote ondernemingen, uit te leggen. In plaats daarvan legt het model de gevoeligheid van kleine en grote ondernemingen uit aan de hand van aan ondernemingsgrootte gerelateerde verschillen in de kosten van de aanpassing van de kapitaalgoederenvoorraad en de grootte van monetaire beleidsschokken. 
De aanpassingskosten per eenheid kapitaal zijn gedefinieerd als een combinatie van twee factoren: (i) aankoopkosten (verkoopkosten) per eenheid van kapitaal (des)investering en (ii) vaste aanpassingskosten per eenheid van geïnstalleerd kapitaal. Beide componenten beïnloeden investeringen door hun effect op de mate van de onomkeerbaarheid van investeringen. Het wordt aangenomen dat de aan bedrijfsgrootte gerelateerde verschillen in de aanpassingskosten van kapitaal zodanig zijn dat de mate van de onomkeerbaarheid van investeringen minder uitgesproken is voor kleine dan voor grote ondernemingen. Bovendien bepalen de kostencomponenten het bereik waarvoor nul (zero) en niet-nul (non-zero) investeringen optimaal zijn. Omdat aanpassingskosten hoger zijn voor grote dan voor kleine ondernemingen, is het bereik waarvoor ondernemingen de kapitaalgoederenvoorraad door investeringen niet aanpassen uitdrukkelijk positief gerelateerd aan ondernemingsgrootte. De aan grootte gerelateerde verschillen in investeringskosten en, dus ook, in het bereik waarvoor ondernemingen niet investeren suggereren dat kleine ondernemingen hun investeringsbeleid vaker veranderen dan grote. Aan de andere kant, als kleine en grote ondernemingen hun investeringsbeleid veranderen, dan zorgen aan grootte gerelateerde verschillen in de vaste kosten per bestaande kapitaaleenheid voor opvallendere veranderingen in investeringen van grote ondernemingen dan in die van kleine. Het model voorspelt daarom dat kleine ondernemingen geleidelijker investeren dan grote ondernemingen.

Door de verschillen in de mate van de onomkeerbaarheid van investeringen van kleine en grote ondernemingen zijn de reacties van investeringen op monetair beleid voornamelijk afhankelijk van de grootte van de monetaire beleidsschok. Voor kleine renteschokken zijn de voorspellingen van het model op één lijn met de voorspellingen van het kredietkanaal: investeringen van kleine ondernemingen reageren op veranderingen in monetair beleid, terwijl dit niet het geval is bij grote ondernemingen. Bij een grote monetaire beleidsschok veranderen investeringen van kleine en grote ondernemingen. In tegenstelling tot de 'credit view' op monetaire transmissie zorgen hogere vaste aanpassingskosten per eenheid van geïnstalleerd kapitaal voor een groter effect bij grote ondernemingen. Dit betekent dat conclusies over de gevoeligheid van kleine ondernemingen voor veranderingen in monetair beleid voornamelijk afhangen van de sterkte van de monetaire beleidsschok.

Het overzicht van de bestaande empirische studies in hoofdstuk 2 laat zien dat de bewijzen voor de effecten van monetair beleid via het rente- en kredietkanaal wellicht worden beïnvloed door problemen met de identificatie van individuele monetaire transmissiekanalen. Om het identificatieprobleem op te lossen, benadrukken sommige studies de rol van de sectorale compositie van landen/regio's als de bepalende factor in de sterkte van monetaire transmissiekanalen en monetair beleidseffectiviteit. De reële effecten van monetair beleid worden toegeschreven aan de economische prestaties van sectoren en aan de sectorspecifieke structurele eigenschappen met betrekking tot het rente- en kredietkanaal. Hoofdstuk 4 komt voort uit de observatie dat de meeste empirische studies niet voor de potentiële onderlinge afhankelijkheid tussen sector en indicator-variabelen van het rente- zowel als kredietkanaal controleren. Wij stellen de vraag of de veronderstelde onafhankelijkheid van ondernemingsgrootte 
en sector invloed heeft op de conclusies met betrekking tot de rente- en kredietkanaaleffecten van monetair beleid voor de Verenigde Staten.

In een eerste stap wordt in de analyse de gevoeligheid voor de rente van inkomsten van de Amerikaanse verwerkende industrie en overige sectoren over de periode 1958-2000/01 vastgesteld. De resultaten laten verschillen in de gevoeligheid van sectoren voor de rente zien en wijzen dus op het belang van sectoren als bepalende factor van monetaire beleidseffectiviteit. Regionale heterogeniteit in de effecten van monetair beleid komt voort uit de ongelijkheden tussen regio's in de mix van sectoren en, daardoor, uit verschillen in regionale economische structuren. Vanwege deze verschillen tussen sectoren, onderzoekt de studie vervolgens of de sectorale eigenschappen ondernemingsgrootte (een veel gebruikte indicator-variabele van het kredietkanaal) of kapitaalintensiteit (een indicator-variabele van het rentekanaal) de heterogeniteit van monetaire beleidseffecten tussen sectoren kan verklaren.

De empirische resultaten van cross-sectie schattingen laten zien dat conclusies erg afhangen van de veronderstelde onderlinge afhankelijkheid van ondernemingsgrootte of kapitaalintensiteit met sectoren. Cross-sectie schattingen, die niet voor de sectorale effecten controleren, wijzen op de werking van een kredietkanaal. In die modellen is kapitaalintensiteit niet significant. Er kunnen tegenstrijdige conclusies worden getrokken uit de cross-sectie specificaties, die wel rekening houden met het onderlinge verband tussen sector en ofwel ondernemingsgrootte ofwel kapitaalintensiteit. De bijbehorende empirische resultaten geven aan dat sectorale effecten de effecten van bedrijfsgrootte kleiner doen lijken, maar niet die effecten, die samenhangen met kapitaalintensiteit. In de mijnsector treft men bijzonder sterke sectorale effecten aan. Op basis van deze bevindingen concluderen we dat tests naar het bestaan van een rente- of kredietkanaal van monetaire transmissie rekening zouden moeten houden met de sectorale effecten. Vanwege de resultaten voor de Verenigde Staten is de studie herhaald voor landen in Europa. Helaas kunnen er door de slechte kwaliteit van de data geen overtuigende conclusies worden getrokken wat betreft de rol van sectoren in monetaire transmissie.

De analyse in hoofdstuk 5 komt voort uit de observatie dat bestaande 'credit view' studies over de invloed van een monetaire beleidswijziging op de bancaire kredietverlening geen rekening houden met verschillen tussen sectoren in de vraag naar bankkrediet. Bovendien wordt niet onderzocht hoe sterk de kredietverlening door banken reageert op veranderingen in de vraag naar bankkrediet door sectoren. De studie in hoofdstuk 5 controleert wel voor mogelijke sectorale effecten en onderzoekt of de groei van bancair krediet aan sectoren voornamelijk bepaald wordt door de vraag naar bancair krediet of door een monetaire beleidswijziging. Een onderzoek naar de sectorale effecten van kredietverlening door banken is van belang omdat het inzicht verschaft in de vraag of de effectiviteit van monetair beleid wordt bepaald door de sectorale structuur van bankkredietportefeuilles.

Het empirische bewijs in dit hoofdstuk komt van een unieke set van micro-economische data (i) over variabelen van de balanspositie van banken en (ii) over de bancaire kredietverlen- 
ing aan individuele sectoren in Duitsland. De analyse bevat de schatting van individuele bankkredietfuncties voor 17 sectoren over de periode 1992:1-2002:4. Het empirische onderzoek op basis van dynamisch panel data modellen toont aan dat de sectorspecifieke groei van bancair krediet vooral reageert op een verandering in de sectorspecifieke vraag naar bankkrediet en in mindere mate op een verandering in monetair beleid. Conclusies over de effecten van monetair beleid op bancaire kredietverlening hangen in feite sterk af van de betreffende sector. Dit wijst op het belang van de sectorale compositie van bankkredietportefeuilles als bepalende factor in de effectiviteit van monetair beleid.

De studies in hoofdstuk 4 en 5 veronderstellen dat monetaire verkrappingen en verruimingen symmetrische effecten hebben op de economische groei. Dat wil zeggen, een monetaire verkrapping en verruiming beïnvloeden de groei van sectorale productie in gelijke mate, maar met tegenovergestelde kenmerken. Hoofdstuk 6 onderzoekt de aanwezigheid van mogelijke asymmetrieën en analyseert of monetaire verkrappingen en verruimingen een verschillend effect hebben op de productietoename ('sign effect'). Bovendien wordt onderzocht of de mate van asymmetrie varieert over de conjunctuurcyclus ('state effect') of afhangt van de sterkte van veranderingen in monetair beleid ('size effect'). Om mogelijke sectorale effecten te identificeren, leggen de testen de nadruk op de structurele verschillen tussen sectoren met betrekking tot het rente-, krediet- en wisselkanaal. De schattingen komen van dynamische panel data modellen die informatie gebruiken over de productiegroei van 24 sectoren in Duitsland, Italië en Spanje over de periode 1995:1-2002:4. Vanwege de heterogeniteit tussen landen, zijn de modellen voor elk land apart geschat.

De empirische resultaten wijzen, in overeenstemming met de theoretische voorspellingen, op asymmetrieën in de effecten van monetaire verkrappingen en verruimingen op de productiegroei van sectoren. De conclusies wat betreft de richting en de sterkte van 'sign effecten' zijn afhankelijk van de keuze van het land: de empirische resultaten wijzen op 'sign effecten' in Duitsland en Italië maar niet in Spanje. Tegen de verwachtingen in, zijn de effecten van monetaire beleidsveranderingen niet gevoelig voor de conjunctuurcyclus in schattingen voor zowel Duitsland, Italië als ook Spanje. Dit betekent dat een economische recessie de effecten van een monetaire verkrapping of verruiming niet versterkt. De bewijzen voor elk land wijzen ook niet op substantiële verschillen in de effecten van kleine en grote monetaire beleidsschokken. Dit resultaat is mogelijk beïnvloed door het kleine aantal cross secties. Het aantal cross secties bepaalt de structuur van het empirische model en de definitie van kleine en grote monetaire beleidsveranderingen. Bovendien is er op zijn best slechts zwak bewijs dat de 'sign effecten' van een monetaire contractie en expansie worden beïnvloed door sectorale effecten. Aangezien de sectorale effecten voornamelijk zijn toe te schrijven aan verschillen in kapitaalintensiteit, leveren de resultaten voorzichtig bewijs voor de werking van een rentekanaal. De dubbelzinnigheid van de resultaten is waarschijnlijk te wijten aan de beperktheid van de data.

Hoofdstuk 7 bevat de conclusies van dit proefschrift. Het presenteert de twee belangrijkste inzichten die volgen uit de empirische analyses in hoofdstuk 4 tot en met 6 . Het eerste 
resultaat heeft te maken met de observatie dat er verschillen zijn tussen sectoren wat betreft hun reactie op monetaire beleidsschokken. Als gevolg hiervan worden de macro-economische effecten van monetair beleid bepaald door sectorale compositie. Verder dragen regionale verschillen in het relatieve belang van sectoren bij aan regionale verschillen in de reële effecten van monetaire beleidsveranderingen. Het tweede inzicht is dat sectoren de veranderingen in monetair beleid doorgeven via een rentekanaal. De effecten van kredietkanalen zijn relatief zwak. De sectorale asymmetrieën in de effecten van monetair beleid via het renteen kredietkanaal zijn toe te schrijven aan, respectievelijk, verschillen in de kapitaalintensiteit van sectoren en in de monetaire reactie van bancaire kredietverlening aan individuele sectoren. In hoofdstuk 7 worden, behalve deze resultaten, ook enkele beperkingen van dit onderzoek behandeld. Verder worden er suggesties voor toekomstig onderzoek gepresenteerd, die wellicht de zwakke punten van de empirische analyses kunnen oplossen. Bovendien worden de empirische resultaten geanalyseerd met betrekking tot hun implicaties voor de toekomstige economische en politieke stabiliteit van de Europese Economische en Monetaire Unie. 




\section{Curriculum Vitae}

Katharina Raabe was born on September 04, 1976 in Eberswalde-Finow, Germany. Following her secondary education at the Charles-Darwin-Gymnasium in Berlin from 1990 to 1996, she enrolled in the International Economic Studies program at Maastricht University, the Netherlands. During her studies, she spent one semester at the University of Western Ontario in London, Canada. In August 2000, Katharina graduated with distinction (cum laude) from Maastricht University. The master thesis 'The Choice of Exchange Rate System for Canada and the United States' - supervised by Professor Dr. Clemens Kool - was granted the Thesis Award of the Faculty of Economics and Business Administration of Maastricht University. From August 2000 to May 2001, she followed the advanced studies program in 'International Economic Policy Research' at the Institute for World Economics in Kiel. On completion of the program, she became research assistant at the Institute for Economic Research (Ifo) in Munich. In fall 2002, Katharina returned to Maastricht University to start her PhD research in the department of economics under the supervision of Professor Dr. Clemens Kool (Utrecht School of Economics) and Professor Dr. Ivo Arnold (Nyenrode Business University). Within the framework of the $\mathrm{PhD}$ project, she visited the Deutsche Bundesbank in Frankfurt/Main from June to November 2005. Chapter 5 of this thesis reports the results of the underlying research. Katharina's main research interests include macro-, monetary, and financial economics, with emphasis on empirical applications. 
